
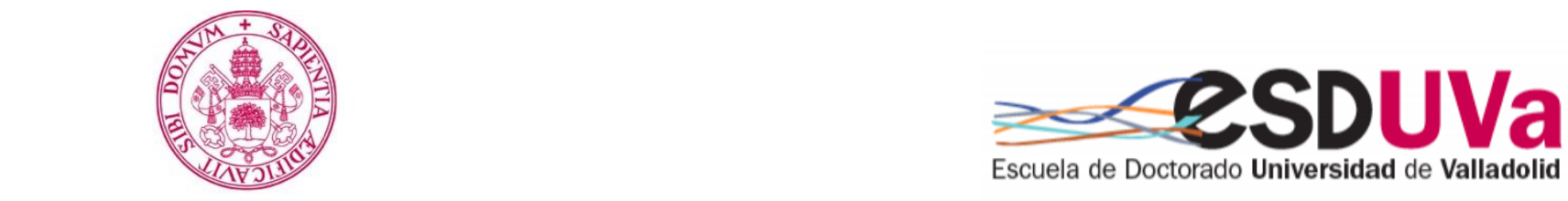

Universidad deValladolid

PROGRAMA DE DOCTORADO EN INVESTIGACIÓN

TRANSDISCIPLINAR EN EDUCACIÓN

TESIS DOCTORAL:

\title{
LA EDUCACIÓN PATRIMONIAL EN CASTILLA Y LEÓN: EVALUACIÓN DE PROGRAMAS Y EVALUACIÓN DE APRENDIZAJES EN SECUNDARIA Y BACHILLERATO
}

Presentada por Inmaculada Sánchez Macías para optar al grado de Doctora por la Universidad de Valladolid

Dirigida por:

Dra. Olaia Fontal Merillas

Dr. Cosme Jesús Gómez Carrasco 


\section{DECLARACIÓN PERSONAL DE NO PLAGIO}

Dña. Inmaculada Sánchez Macías con NIF 09194486 Y

estudiante del Programa de Doctorado en Investigación Transdisciplinar de la Universidad de Valladolid, como autor/a de este documento académico, titulado:

"La educación patrimonial en Castilla y León: Evaluación de programas y evaluación de aprendizajes en Secundaria y Bachillerato” presentado para la obtención del título correspondiente,

\section{DECLARO QUE}

es fruto de mi trabajo personal, que no copio, que no utilizo ideas, formulaciones, citas integrales e ilustraciones diversas, sacadas de cualquier obra, artículo, memoria, etc., (en versión impresa o electrónica), sin mencionar de forma clara y estricta su origen, tanto en el cuerpo del texto como en la bibliografía.

Así mismo, soy plenamente consciente de que el hecho de no respetar estos extremos es objeto de sanciones universitarias y/o de otro orden.

En Valladolid, a 10 de septiembre de 2019 Fdo: Inmaculada Sánchez Macías 


\section{ACKNOWLEDGEMENTS}

I dedicate this work to Teresa, Antonio, Chelo, Pedro, Tere and José $\mathrm{M}^{\mathrm{a}}$ : my best examples of life, which helped to understand my

heritage.

I want to thank Olaia for her work as a guide on the path to wisdom, teacher, companion and candlelight with her light in the painful moments of learning. I appreciate your opportunity to learn about academic work in this field as beautiful as heritage in the education of people and the education of people in heritage. Thanks, Olaia. To Cosme, for his patience, organization, kindness and determination for difficult times. Ivan, because from the beginning he has encouraged my desire to investigate and his mentor, Stake, of whom I share the question of quantification. Thank you.

To my colleagues and teammates of the OEPE team, with whom I have learned and continue to learn so much. Thank you, Pablo, Sofia, Carmen, Silvia, Marta, Jesus. To the colleagues of other teams, who welcomed me in their universities as if they were mine: Ramón, Álex, Miriam, Chema, Alice. Thanks to all who have participated in the realization of this work, colleagues, students, friends, colleagues in the Department, other departments and Administration and Services staff.

And thanks to you, Alejandro, for being the flame while writing this work and for teaching me so much about culture.

This work has been carried out thanks to the financing of the predoctoral hiring of research staff by the Government of Castilla y León, co-financed by the European Social Fund since 2015. 


\begin{abstract}
This thesis has as its thematic nuclei the Patrimonial Education and the evaluation. These two mentioned thematic nuclei share a controversial historical development, so their theoretical roots have been deepened, through diachronic analysis of both. The heritage education evolves in the thesis as a thriving area, to acquire importance in such a curriculum of classical subjects and in legislative structures and organizations with great inertia. This evolution of the area runs aside to the laying job to valuate, they have been doing numerous university scientific groups throughout the territory national, of those who wanted to state an interpretative review about the perspective theoreticalpractical that each one contributes. Evaluation is, by definition, a polysemic concept that in its multiple conceptions and praxis we will also see included in these pages. Specifically, later on, a selection of suitable programs is methodologically developed for heritage education in Castilla y León, secondly, a review of the evaluation of learning in secondary and high school students. Regarding the selection of heritage education programs through standards, we have made a translation of the theoretical contributions of national groups, looking for those standards that reflect the different perspectives that each group provides us. This research is done through a mixed method, the qualitative process predominates, inspiring us in excellence theorists like Stake and his constructivist and interpretive evaluation paradigm, through of a diversified series of bilateral and multilateral interviews, classroom observations and questionnaires, to validate our case study. The conclusions are included in a invitation to diversity in several ways: balance of learning together with teaching of learning, learning techniques, and multiform evaluation. Diversity of skills to be developed by the students amplifying what was said in the curriculum. Diversity and amplification of participation of all the agents involved in the educational area. Diversity in the sources of teacher motivation: intrinsic, institutional and informal. Diversity in contents of heritage education and deepening in cross-cutting but combining it with giving importance to the area as a subject with significant teaching hours
\end{abstract}

\title{
Keywords:
}

Assessment; Evaluation; Heritage Education; High School; Mixed Method 


\section{AGRADECIMIENTOS}

Dedico este trabajo a Teresa, Antonio, Pedro, Chelo, Tere y José $M^{a}$ : mis mejores ejemplos de vida, que ayudaron a entender mi

patrimonio.

Quiero agradecer a Olaia su labor de guía en el camino a la sabiduría, maestra, compañera y veladora con su luz en los momentos dolorosos de aprendizaje. Agradezco su oportunidad para conocer el trabajo académico en este ámbito tan bonito como es el patrimonio en la educación de las personas y la educación de las personas en el patrimonio. Gracias, Olaia. A Cosme, por su paciencia, organización, bondad y determinación para los tiempos difíciles. A Iván, porque desde el principio ha alentado mis ganas de investigar y a su mentor, Stake, del que comparto la duda de la cuantificación. Gracias.

A mis compañeras y compañeros del equipo OEPE, con quienes he aprendido y sigo aprendiendo tanto. Gracias Sofía, Carmen, Silvia, Marta, Jesús, Pablo. A los colegas de otros equipos, que me acogieron en sus universidades como si estuviera en la mía: Ramón, Álex, Chema, Alice. Gracias a todos los que han participado en la realización de este trabajo, compañeros, alumnos, amigos, colegas del Departamento, de otros departamentos y personal de Administración y Servicios.

Y gracias a ti, Alejandro, por ser la llama mientras escribía este trabajo y por enseñarme tanto de la cultura.

Este trabajo se ha realizado gracias a la financiación de la contratación predoctoral de personal investigador por la Junta de Castilla y León, cofinanciada por el Fondo Social Europeo desde el año 2015. 


\section{Resumen}

Esta tesis tiene como núcleos temáticos la Educación patrimonial y la evaluación. Estos dos núcleos temáticos mencionados comparten un desarrollo histórico controvertido, por lo cual se ha profundizado en las raíces teóricas, mediante análisis diacrónicos de ambos. La educación patrimonial evoluciona en la tesis como área pujante, para adquirir carta de naturaleza en un currículo de asignaturas clásicas y en unas estructuras legislativas y organizaciones con gran inercia. Esta evolución del área discurre paralela al trabajo de puesta en valor, que llevan haciendo numerosos grupos científicos universitarios en todo el territorio nacional, de los que se ha querido hacer una reseña interpretativa acerca de la perspectiva teórico-práctica que aporta cada uno. La evaluación es, por definición, un concepto polisémico que en sus múltiples concepciones y praxis veremos también reflejarse en estas páginas. Específicamente, más adelante, se elabora metodológicamente una selección de programas idónea de educación patrimonial en Castilla y León, en segundo lugar, se hace una revisión de la evaluación de aprendizajes en alumnos de Educación Secundaria y Bachillerato. Respecto de la selección de los programas de educación patrimonial a través de estándares, hemos hecho una traslación de las aportaciones teóricas de los grupos nacionales, buscando aquellos estándares que reflejen las distintas perspectivas que nos aporta cada grupo. Esta investigación se realiza a través del método mixto, predominando el proceso cualitativo, inspirándonos en eximios teóricos como Stake y su paradigma constructivista e interpretativo de la evaluación, a través de una serie diversificada de entrevistas bilaterales y multilaterales, observaciones en aula y cuestionarios, para validar nuestro estudio de caso. Las conclusiones se engloban en una invitación a la diversidad en varios sentidos: equilibrio de aprendizajes junto a didáctica de los mismos, sus técnicas, y evaluación multiforme. Diversidad de competencias a desarrollar por los alumnos amplificando lo dicho en el currículo. Diversidad y amplificación de la participación de todos los agentes implicados en el hecho educativo. Diversidad en las fuentes de motivación del profesorado: intrínsecas, institucionales e informales. Diversidad en los contenidos de educación patrimonial y profundización en la transversalidad, pero compaginándola con dar carta de naturaleza al área como asignatura con horas significativas de docencia.

\section{Palabras clave:}

Evaluación de Aprendizajes; Evaluación Educativa; Educación Patrimonial; Educación Secundaria; Bachillerato; Método Mixto 


\section{ÍNDICE}

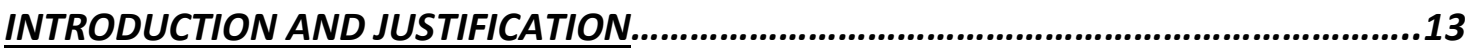

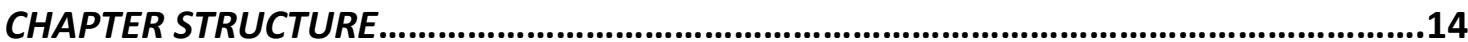

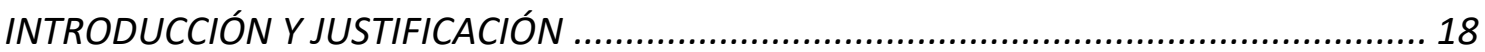

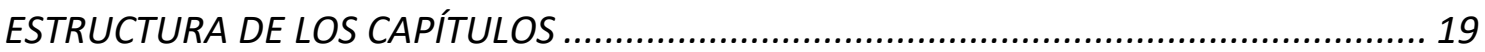

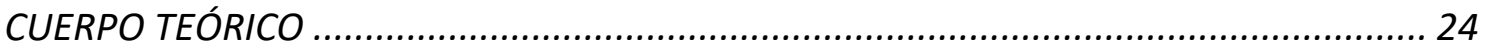

1. EDUCACIÓN PATRIMONIAL: PASADO, PRESENTE Y FUTURO …................................. 24

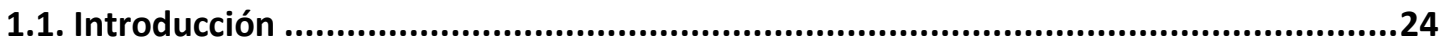

1.2. Clarificación conceptual de Educación patrimonial ....................................................25

1.3. Inclusión del patrimonio en la enseñanza mundial: nivel MACRO ..............................35

1.4. Inclusión del patrimonio en la enseñanza española: nivel MESO ........................39

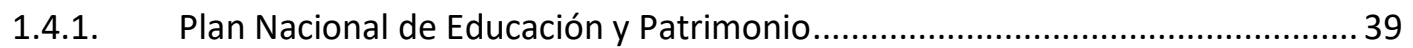

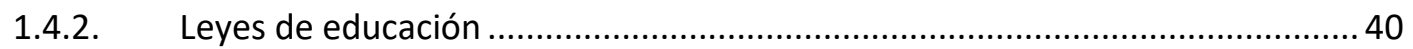

1.5. Inclusión del patrimonio en la enseñanza autonómica: nivel MICRO ....................46

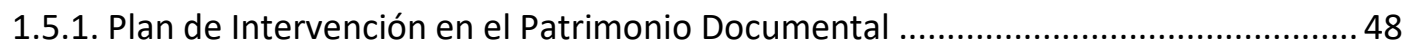

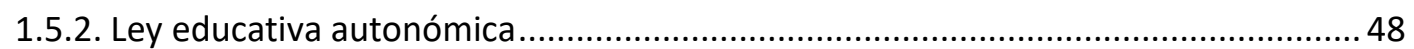

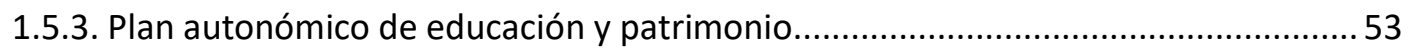

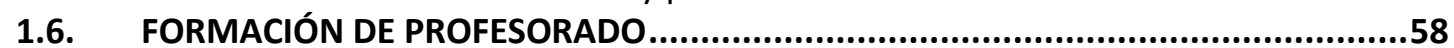

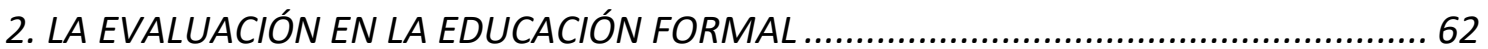

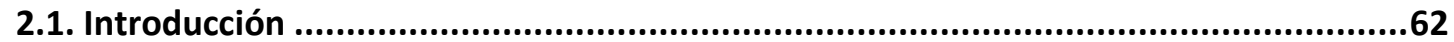

2.2. Clarificación conceptual de evaluación.......................................................................63

2.2.1. Evaluation y Assessment: historia de la evaluación ................................................67

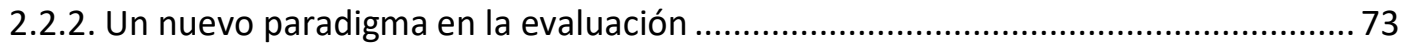

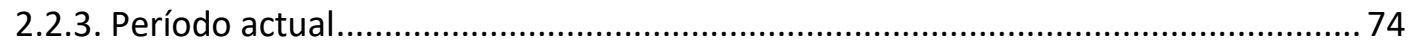

2.3. Evaluación en la actualidad: estado de la cuestión internacional .............................78

2.3.1. Tensiones y aspectos críticos del programa PISA .................................................. 79

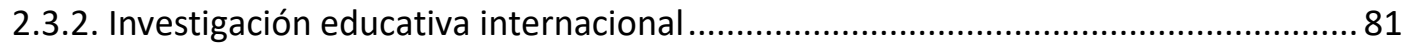

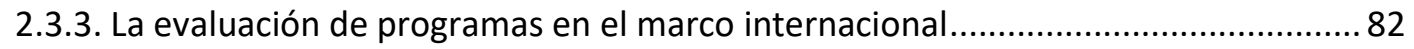

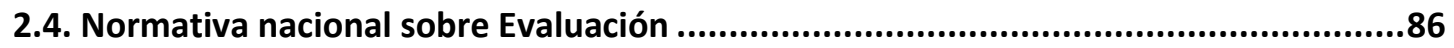

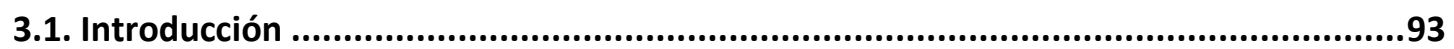

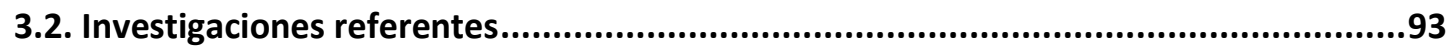

3.2.1. Grupos de investigación nacionales ......................................................................93 


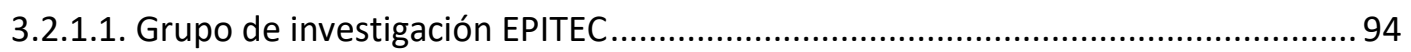

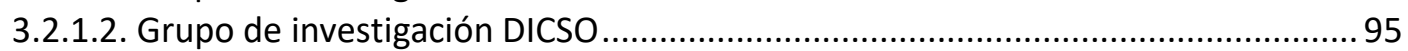

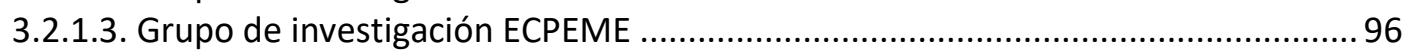

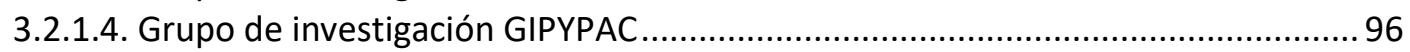

3.2.1.5. Grupo de investigación Educomunicación web 2.0 ............................................ 98

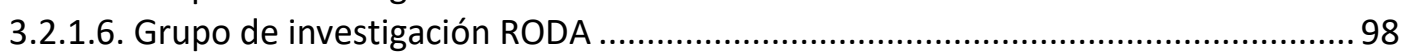

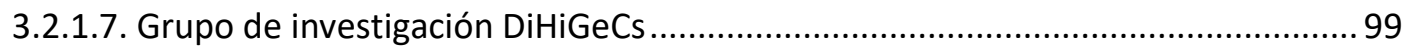

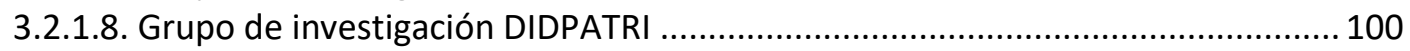

3.2.1.9. El observatorio de Educación Patrimonial en España (OEPE) ............................. 101

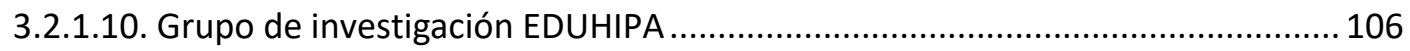

3.2.3. Investigaciones, publicaciones y tesis doctorales..................................................109

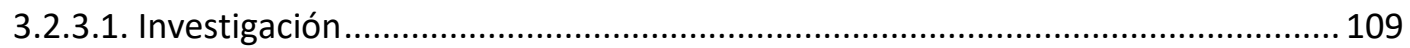

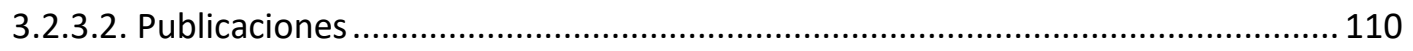

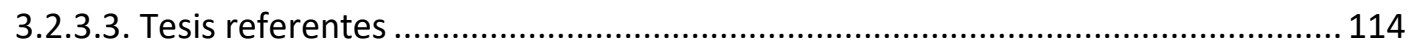

3.3. Análisis conjunto de referentes: conclusiones .......................................................144

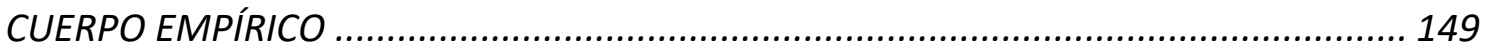

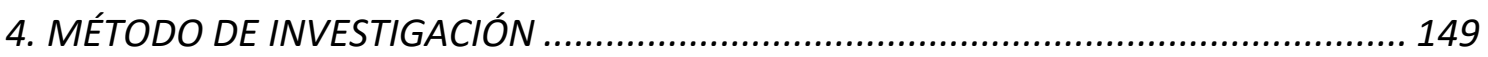

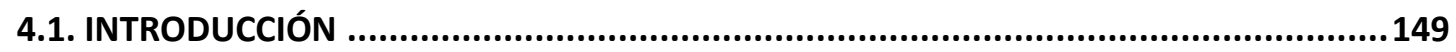

4.2. Justificación y finalidad de la investigación.........................................................150

4.3. Problema de investigación. Hipótesis y objetivos...............................................153

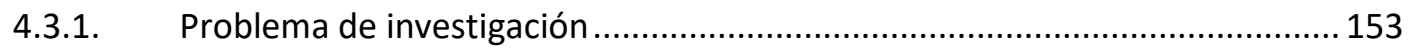

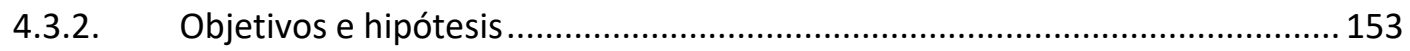

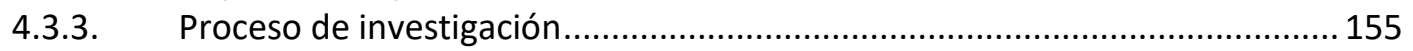

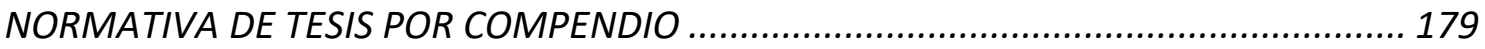

4.4. RESULTADOS: COMPENDIO DE ARTÍCULOS DE INVESTIGACIÓN ..............................181

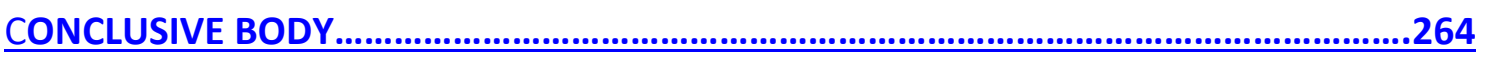

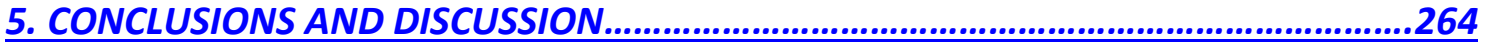

5.1. CONCLUSIONS OF ARTICLES AND DISCUSSION.............................................................................264

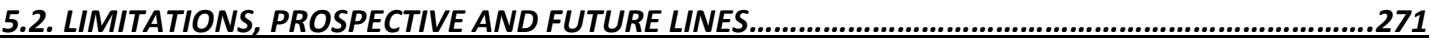

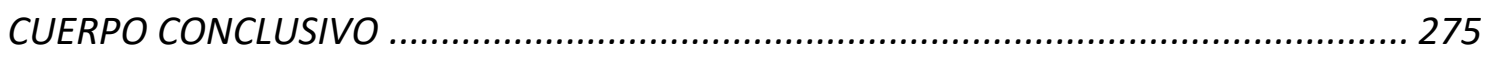

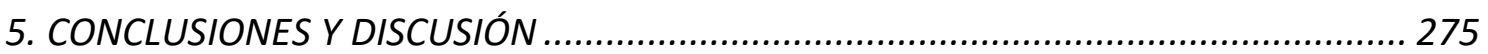

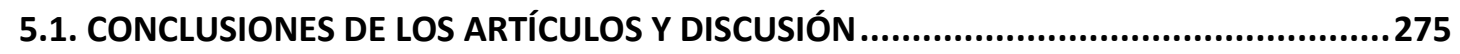

5.2. LIMITACIONES, PROSPECTIVA Y LÍNEAS FUTURAS..........................................283

REFERENCIAS BIBLIOGRÁFICAS Y BIBLIOGRAFÍA .............................................. 287 


\section{ÍNDICE DE FIGURAS}

Figura 1. 1a. Página de revista Arquitectura, no 19. 1b. Artículo sobre la carta de

Atenas.

Figura 2. Clasificación de patrimonio según UNESCO. 30

Figura 3. Evolución y timeline de las leyes educativas en España. 40

Figura 4. Generaciones en la historia de la Evaluación. 68

Figura 5. Evaluación de la docencia en la universidad. 76

Figura 6. Tipologías de Evaluación según seis dimensiones. 78

Figura 7. Resultados del aprendizaje en jerarquía. 80

Figura 8. Fases del Observatorio de educación patrimonial en España. 103

Figura 9. Esquema de componentes y funcionamiento del OEPE 105

Figura 10. Esquema de componentes y funcionamiento del GIR EUDHIPA. 108

Figura 11. Modelo Hopscotch para el diseño de investigación, Jorrín-Abellán (2014). 150

Figura 12. Proceso de investigación. Fuente: propia..... 156

Figura 13. Secciones de la ficha del inventario del OEPE. Fuente: www.oepe.es........ 157

Figura 14. Rúbrica de dimensiones y estándares básicos del OEPE. 158

Figura 15. Rúbrica de estándares específicos. 160

Figura 16. Estructura conceptual del caso. 164

Figura 17. Estructura conceptual del Caso 1 de la investigación. 166

Figura 18. Estructura conceptual del Caso 2 de la investigación. .167 


\section{ÍNDICE DE TABLAS}

Tabla 1. Estructura cruzada de la tesis doctoral. Elaboración propia.....

Tabla 2. Relación de documentos para la conservación del patrimonio

Tabla 3. Fundaciones que desarrollan Educación Patrimonial en Castilla y León 57

Tabla 4. Relación de Grados y universidades que incluyen "patrimonio" en su plan ... 59

Tabla 5. Tesis de Apolline Torregrosa. Fuente: TESEO.

Tabla 6. Tesis de Helena Pinto. Fuente: TESEO.

Tabla 7. Tesis de Luisa López. Fuente: TESEO

Tabla 8. Tesis de Apolline Torregrosa. Fuente: TESEO.

Tabla 9. Tesis de Helena Pinto. Fuente: TESEO.

Tabla 10. Tesis de Luisa López. Fuente: TESEO

Tabla 11. Tesis de Marion Spendlove. Fuente: TESEO.

Tabla 12. Tesis de José Ma Cuenca. Fuente: TESEO

Tabla 13. Tesis de Olaia Fontal. Fuente: TESEO

Tabla 14. Tesis de Álex Ibáñez. Fuente: TESEO 124

Tabla 15. Tesis de Laia Coma. Fuente: TESEO. 126

Tabla 16. Tesis de Naiara Vicent. Fuente: TESEO. 
Tabla 18. Tesis de Ana Sánchez. Fuente: TESEO

Tabla 19. Tesis de Sofía Marín. Fuente: TESEO

Tabla 20. Tesis de Pablo de Castro. Fuente: TESEO

138

Tabla 21. Tesis de Iratxe Gillate. Fuente: TESEO

Tabla 22. Tesis de Stella Maldonado. Fuente: TESEO. 140

Tabla 23. Tesis de Laura de Pablos. Fuente: TESEO

Tabla 24. Tesis de Silvia García Ceballos. Fuente: TESEO.

Tabla 25.Objetivos del estudio basados en Maxwell (2008). 153

$\underline{\text { Tabla 26. Comparativa del estudio de caso entre Merrian, Stake y Yin realizada por }}$

Yazan. Fuente: Yazan (2015)...... 
"Mientras haya un reino de la necesidad habrá suficiente penuria, también una cultura no afirmativa tendrá el lastre de la transitoriedad y de la necesidad: será un baile sobre un volcán, una risa en la tristeza, un juego con la muerte. En este caso también la reproducción de la vida será una reproducción de la cultura: organización de anhelos no realizados, purificación de instintos no satisfechos."

Herbert Marcuse, "Acerca del carácter afirmativo de la cultura", en Cultura y Sociedad, 1967. 


\section{INTRODUCTION AND JUSTIFICATION}

In the research framework of the Observatory of Heritage Education in Spain (OEPE), its catalogue of research programs in heritage education in the field of Castilla y León, which as an extensive work in the number of items and in time, is remarkable. So, it offers a tool, in principle, of a quantitative nature. In parallel, a huge qualitative work has been developed in the numerous doctoral theses, articles and different scientific publications, all based on the foundational theoretical sequence of Fontal (2003) on the concept of heritage: knowing, understanding, respecting, valuing, taking care, enjoying and transmitting the heritage. Not only the OEPE, but the rest of the research groups in Spain provides us, each one, a perspective with individual nuances, about why and how to approach and promote heritage education.

Coming back to the OEPE catalogue of projects, this thesis aims to elucidate which programs have the best quality standards in the community of Castilla y León, precisely by launching a selection from the different perspectives that so many researchers bring us all over the nation. That is, the main thread would be that such diversity and qualitative power of visions on the subject will have to provide an accurate and valuable scrutiny of a series of inventory projects.

Next, this selection must be quickly broadcasted to promote the same strategies, methodologies and approaches that have made them stand out for the chosen programs, providing feedback to all other programs, whether they are current or for future proposals.

In this sense, the categorization by standards (Fontal et al., 2019) that we have used also offers a quantitative aspect that we think to be interesting to mix with the qualitative look of the different research groups, in order to make a selection by standards of the best programs.

To list some of these theoretical perspectives and areas of interest, let us mention sociocriticism, territorialisation

, broad historical range or, on the contrary, temporal concretion, age diversity, functional diversity, ICT education, archaeology or museum research.

Focusing on our case study, we have started from a parallel vision to that described in the selection of programs that we have just explained: 
There is a huge potential at all levels to extract from the deep theoretical reflections that we have collected in interviews. The specific potential is given by our Heritage Education subject and its specific characteristics: the thinking of our informants corresponds, first of all, to a cross-sectional area and break through the rigidities of the established subjects, the legislative curricula, and the inertia of the institutions and some educational agents. Besides, also among sociological tendencies sometimes not eager to Art. In addition, the Art and its reflection also generates, by itself, tensions with a pedagogy or an evaluation, sometimes designed for other more Cartesian or positivist subjects.

From all this thought in conflict, carried out by so many teachers, sometimes alone, we have tried to draw proposals and conclusions that redefine or offer renewed light in the before mentioned areas: curricular, institutional, theoretical, organizational, editorial, social, in the educational agents, and above all, in the students themselves and their educators.

Thus, we see that the comprehensive and standards-based evaluation of Stake (2006) has been used as a theoretical framework that gives value to the experience and knowledge of the researcher, combining interpretative aspects based on quantifiable criteria.

Regarding the quantifiable criteria in this part of the thesis we wanted to question a series of competences of Primary students, but above all of Secondary and Baccalaureate and their statistical correlation. Let's say that, again, being a crosssectional area, that of Artistic Education, it is common for them to launch without justifying hypothetical assertions and relationships about student skills. Precisely because of this, we saw a scientific work on these skills necessary to clarify misconceptions, poorly founded or accepted as merely traditional.

\section{CHAPTER STRUCTURE}

From the conceptual point of view the first two chapters that deal with the two focuses of the thesis are: Chapter 1. Heritage Education; and Chapter 2. The Evaluation. However, we can also establish a cross-relationship between chapters 1 and 3, referring to the fact that the issue status of heritage education is addressed in both. And between chapters 2 and 4, since both focus on the evaluation more specifically. 
Going on defining this cross-relationship, we begin by focusing on chapters 1 and 3 (See Table 1).

Chapter 1, of course, begins with the conceptual clarification of Heritage Education. It is a particularly essential starting point because of the multiple approaches of the discipline that generate as many definitions and subtle dimensions in the theoretical field.

This chapter also focuses on both transnational and national and regional laws to give a critical analysis of such legislation and further on of the projection that society and politics have of Heritage Education reflected in the drafting and implementation of such regulations.

It is noteworthy that the approach to the subject does not remain in a status quaestionis but that the inner dynamics of our transversal area of education launch us to a critical analysis, not only of the successes, but of the sometimes structural lacks that laws include, both at European, national or autonomous community levels. Thus, chapter 1 has, on the one hand, a diatopic scope when referring to the different territorial laws that are increasingly interrelated in the contemporary world; and likewise, it reflects a diachronic analysis consistent with the successive and profuse enactment of laws. The legislation is doubly large, both because of the legislative volubility in Spanish education, at all levels, and because of the constant redefinition of an area considered historically diffuse as Patrimonial Education, which is reflected in its mainstreaming in the curriculum.

And chapter 1 is linked precisely to chapter 3, which deepens and insists in this diatopic vision. This chapter describes the abundant research groups in Patrimonial Education of the national territory, born in the last decades, while the subject becomes important in the different Spanish universities and autonomous communities. The theoretical depth of the topic is based on the fact that a remarkable coordination between all groups has been made compatible with a respect for the particularity of each approach given by each group on this discipline.

In parallel, all this diversity of theoretical angles is based, both on the specific scientific and intellectual formation of each research group, and on the establishment of the democratic territorial state in the last 40 years and its interrelation with the growing of the identity of the various communities, both autonomous, as local, as intellectuals. This aspect in which the heritage process carried out by the populations and promoted by the 
researchers of the subject, that is, of the groups mentioned in the chapter, has a remarkable importance.

The chapter tries to show that such a crossing of ordinates and abscissa which are, on the one hand, the scientific preferences of each working group, and of each individual researcher, and on the other hand, the approaches that on the heritage and the conformation of identity have crowded in Spain in the last 45 years.

Special mention is made in the thesis of the groups of the University of Valladolid, in section 3.2.2, since, with this group, the thesis not only shares the theoretical centres of interest that the group manages decades ago, but also it approaches the scientific methodology, coinciding with many of his works and publications.

And since we mentioned the methodology we can jump to the cross-relationship that we mentioned between chapter 2: Evaluation in formal education, and chapter 4. Research method.

Chapter 2 addresses a critical analysis of the evaluation. Let us remember what was said in Chapter 1 regarding Heritage Education: evaluation does also require a critical analysis as it is an ontologically voluble concept and a controversial practice approached from a multiplicity of theoretical, pragmatic and even sociological angles. In this regard, different sections are made on the PISA program, whose controversy alone would give hundreds of pages, or on the evaluation of programs in the international framework. The evaluation of programs is as complex as the complexity that the choice of programs has in society, due to the multiplicity of social, political and economic interests, and theoretical approaches that intersect in them.

A separate section deserves the evaluation / assessment dichotomy of point 2.2.1 that defines one of the key issues of the educational evaluation on the necessary balance between quantifiable tests and research and the complex, qualitative and meaningoriented evaluation.

In this key issue of the adequacy of this balance and how to carry it out, let's mention Stake (2006), an inspirational intellectual of the thesis methodology developed in Chapter 4.

In research on heritage education programs through standards we have sought this balance mainly to highlight certain programs in the end: a balance between the multiple approaches to discipline: pedagogical, territorial, identity, technical, media focussed, or macroscopic / microscopic, and for that, We have had diversified collaborators taking this aspect into account. 
In the research on learning, using the case study, we try to balance the quantitative and statistical tools with the qualitative techniques to draw conclusions that are both interpretive and consistent with the data.

Table 1

Cross structure of the doctoral thesis. Own elaboration

Focus: HERITAGE EDUCATION Focus: EVALUATION

\begin{tabular}{llll}
\hline Chapter 1. & $\underline{\text { Chapter 3. }}$ & $\underline{\text { Chapter 2. }}$ & Chapter 4. RESEARCH \\
$\underline{\text { HERITAGE }}$ & $\underline{\text { HERITAGE }}$ & $\underline{\text { EVALUATION IN }}$ & METHOD \\
$\underline{\text { EDUCATION: }}$ & $\underline{\text { ASSESSMENT: }}$ & $\underline{\text { FORMAL }}$ & \\
$\underline{\text { PAST, PRESENT }}$ & $\underline{\text { STATE OF THE }}$ & $\underline{\text { EDUCATION }}$ & \\
$\underline{\text { AND FUTURE }}$ & $\underline{\text { QUESTION. }}$ & \\
& $\underline{\text { REFERENCE }}$ & & \\
& $\underline{\text { ANALYSIS }}$ &
\end{tabular}

\begin{tabular}{llll}
\hline Diatopic & Diatopic & Evaluation issues: & Balance of issues:
\end{tabular}

Diachronic

a. Conceptuals:

a. Legislation

a. Research

assessment/evaluation

a. Programs: balance of

groupes

perspectives

b. Curricula: PISA...

b. Learning: Qualitative

/ Quantitative 


\section{INTRODUCCIÓN Y JUSTIFICACIÓN}

En el marco de investigación del Observatorio de Educación Patrimonial en España (OEPE), es destacable su catálogo de programas de investigación en educación patrimonial en el ámbito de Castilla y León, que como labor extensa en el número de ítems y en el tiempo, nos ofrece una herramienta, en principio, de carácter cuantitativo. Paralelamente se ha desarrollado un ingente trabajo cualitativo en las numerosas tesis doctorales, artículos y distintas publicaciones científicas, todo ello, basado en la secuencia teórica fundacional de Fontal (2003) sobre el concepto de patrimonio: conocer, comprender, respetar, valorar, cuidar, disfrutar y transmitir el patrimonio. No sólo el OEPE, sino el resto de los grupos de investigación de España nos aportan, cada uno, una perspectiva con matices individuales, acerca de por qué y cómo acercarnos e impulsar la educación patrimonial.

Volviendo al catálogo de proyectos del OEPE, esta tesis pretende elucidar qué programas presentan mejores estándares de calidad en la comunidad de Castilla y León, precisamente lanzando una selección desde las distintas perspectivas que nos aportan tantos investigadores a nivel nacional. Es decir, el hilo principal sería que tanta diversidad y potencia cualitativa de visiones sobre la materia tendrán que proporcionar un escrutinio preciso y valioso de una serie de proyectos de los inventariados. A renglón seguido, esta selección podría ser rápidamente difundida para promover las mismas estrategias, metodologías y enfoques que les han hecho destacar a los programas elegidos, proporcionando feedback a todos los demás programas, estén ya en vigor o sean futuras propuestas.

En este sentido, la categorización por estándares (Fontal et al., 2019) que hemos utilizado ofrece también un aspecto cuantitativo que vemos interesante cruzar con la mirada cualitativa de los diferentes grupos de investigación, a efecto de hacer una selección por estándares de los mejores programas.

Por enumerar algunas de esas perspectivas teóricas y áreas de intereses, citemos la sociocrítica, la territorialización, la amplitud histórica o, por el contrario, la concrección temporal, la diversidad en edades, diversidad funcional, la educación con TIC, la arqueología o la museística.

Centrándonos en nuestro estudio de caso, hemos partido de una visión paralela a la descrita en la selección de programas que acabamos de explicar: 
existe un ingente potencial a todos nos niveles que extraer de las profusas reflexiones teóricas que hemos recogido en entrevistas. El potencial específico lo da nuestra materia de Educación Patrimonial y sus características específicas: el pensamiento de nuestros informantes corresponde, en primer lugar, a un área transversal y ha de abrirse paso entre las rigideces de las asignaturas establecidas, los currícula legislativos, y la inercia de las instituciones y algunos agentes educativos. Por extensión, también entre las tendencias sociológicas a veces no proclives a lo artístico. Además, el hecho artístico y su reflexión también genera, por sí mismo, tensiones con una pedagogía o una evaluación, a veces pensada para otras materias más cartesianas o positivistas. De todo ese pensamiento en conflicto, realizado por tanta cantidad de docentes, a veces en solitario, hemos pretendido sacar propuestas y conclusiones que redefinan u ofrezcan luz renovada en los ámbitos ya señalados: curriculares, institucionales, teóricos, organizativos, editoriales, sociales, en los agentes educativos, y sobre todo, en el propio alumnado y sus educadores.

Así, vemos que se ha utilizado como marco teórico la evaluación comprensiva y basada en estándares de Stake (2006) que concede valor a la experiencia y al conocimiento del investigador, combinando aspectos interpretativos en base a criterios cuantificables. Respecto a los criterios cuantificables en esta parte de la tesis hemos querido cuestionarnos una serie de competencias de los alumnos de Primaria, pero sobre todo de Secundaria y Bachillerato y su correlación estadística. Digamos que, de nuevo, al tratarse de un área transversal, el de la Educación Artística, es habitual que se lancen sin justificar hipotéticos asertos y relaciones sobre competencias del alumnado. Precisamente por ello, veíamos necesario un trabajo científico sobre dichas competencias para clarificar concepciones erróneas, poco fundadas o aceptadas como meramente tradicionales.

\section{ESTRUCTURA DE LOS CAPÍTULOS}

Desde el punto de vista conceptual los dos primeros capítulos que versan sobre los dos focos de la tesis son: Capitulo 1. La Educación Patrimonial; y Capítulo 2. La Evaluación.

No obstante, también podemos establecer una relación cruzada entre los capítulos 1 y 3 referida a que en ambos se aborda el estado de la cuestión de la educación patrimonial. 
Y entre los capítulos 2 y 4, ya que ambos se enfocan en la evaluación más específicamente.

En la línea de seguir definiendo esta relación cruzada, empezamos centrándonos en los capítulos 1 y 3 (Ver Tabla 1).

El capítulo 1, como no puede ser menos, se inicia con la clarificación conceptual de la Educación Patrimonial. Es un inicio particularmente imprescindible por los múltiples enfoques de la disciplina que generar otras tantas definiciones y acotaciones sutiles en el ámbito teórico.

Este capítulo también se centra en las leyes tanto transnacionales como nacionales y autonómicas para hacer un análisis crítico de tal legislación y por extensión de la proyección que la sociedad y la política tiene de la Educación Patrimonial reflejada en la redacción y puesta en práctica de tal normativa.

Es de destacar que el abordaje del tema no se queda en un status quaestionis sino que la dinámica intrínseca de nuestra área transversal de educación, nos impele a un análisis crítico, no solo de los aciertos, sino de las carencias a veces estructurales que expresan las leyes, tanto en los ámbitos europeos, nacionales o de comunidad autónoma. Así, el capítulo 1 cuenta, por una parte, con una visión diatópica al referirse a las distintas legislaciones territoriales que se interrelacionan de modo creciente en el mundo contemporáneo; e igualmente, refleja un análisis diacrónico consonante con la sucesiva y profusa promulgación de leyes. La legislación es doblemente cuantiosa, tanto por la volatilidad legislativa en la educación española, en todos sus niveles, como por la redefinición constante de un área considerada históricamente difusa como la Educación Patrimonial, lo cual, se refleja en la transversalidad de ésta en los currícula. Y el capítulo 1 se vincula precisamente con el capítulo 3, que profundiza y abunda en esta visión diatópica. Este capítulo describe los múltiples grupos de investigación en Educación Patrimonial del territorio nacional, nacidos en las últimas décadas, a la par que la materia tomaba carta de naturaleza en las diferentes universidades españolas y comunidades autónomas. La profundidad teórica del tema se basa en que se han hecho compatibles una coordinación notable entre todos los grupos, con un respeto a la particularidad de cada enfoque dado por cada grupo sobre esta disciplina. Paralelamente, toda esta diversidad de ángulos teóricos se basa, tanto en la formación científica e intelectual específica de cada grupo de investigación, como en el establecimiento del estado territorial democrático en los últimos 40 años y su interrelación con la formación de la identidad de las diversas comunidades, tanto 
autonómicas, como locales, como intelectuales. Aspecto éste en el que sí que tiene una notable importancia el proceso de patrimonialización que hacen las poblaciones y promueven los investigadores de la materia, es decir, de los grupos citados en el capítulo.

El capítulo pretende mostrar ese cruce de ordenadas y abscisas que son, de una parte, las preferencias científicas de cada grupo de trabajo, y de cada investigador individual, y de otra parte, los enfoques que sobre el patrimonio y la conformación de la identidad se han agolpado en España en los últimos 45 años.

Mención especial tienen en la tesis los grupos de la Universidad de Valladolid, en el apartado 3.2.2, ya que, con dicho grupo, la tesis no solo comparte los centros de interés teóricos que maneja el grupo hace décadas, sino que además, se aborda la metodología científica, coincidente con muchos de sus trabajos y publicaciones.

Y ya que mencionamos la metodología podemos saltar a la relación cruzada que mencionábamos entre el capítulo 2: La evaluación en la educación formal, y el capítulo 4. Método de investigación.

El capítulo 2 aborda un análisis crítico de la evaluación. Recordemos lo dicho en el capítulo 1 respecto a la Educación Patrimonial: también la evaluación requiere un análisis crítico al ser ontológicamente un concepto volátil y una práctica controvertida y abordada desde una multiplicidad de ángulos teóricos, pragmáticos e incluso sociológicos. Al respecto se hacen secciones diferenciadas sobre el programa PISA, cuya controversia por sí solo daría para cientos de páginas, o sobre la evaluación de programas en el marco internacional. La evaluación de programas es tan compleja como la complejidad que la elección de programas tiene en la sociedad, debido a la multiplicidad de intereses sociales, políticos y económicos, y de enfoques teóricos que se entrecruzan en los mismos.

Sección aparte merece la dicotomía evaluation/assessment del punto 2.2.1 que define una de las tensiones claves de la evaluación educativa sobre el balance necesario entre las pruebas e investigaciones cuantificables y la evaluación compleja, cualitativa y orientada al sentido.

En este tema clave de la idoneidad de este balance y el cómo llevarlo a cabo mencionemos a Stake (2006), intelectual inspirador de la metodología de la tesis desarrollada en el capítulo 4.

En la investigación sobre programas de educación patrimonial mediante estándares hemos buscado este equilibrio principalmente para destacar al final ciertos programas: 
un balance entre los múltiples enfoques sobre la disciplina: pedagógicos, territoriales, identitarios, tecnicistas, mediáticos o macroscópicos/microscópicos, y para ello, hemos contado con colaboradores diversificados teniendo en cuenta este aspecto.

En la investigación sobre aprendizajes, utilizando el estudio de caso, pretendemos el balance de las herramientas cuantitativas y estadísticas con las técnicas cualitativas para armar unas conclusiones a la par interpretativas y coherentes con los datos.

Tabla 1

Estructura cruzada de la tesis doctoral. Elaboración propia

Foco: EDUCACIÓN PATRIMONIAL

\begin{tabular}{|c|c|c|c|}
\hline Capítulo 1. & Capítulo 3. & Capítulo 2. LA & Capítulo 4. MÉTODO \\
\hline EDUCACIÓN & EVALUACIÓN & EVALUACIÓN EN & DE INVESTIGACIÓN \\
\hline PATRIMONIAL: & PATRIMONIAL: & LA EDUCACIÓN & \\
\hline$\underline{\text { PASADO, }}$ & $\underline{\text { ESTADO DE LA }}$ & $\underline{\text { FORMAL }}$ & \\
\hline PRESENTE Y & CUESTIÓN. & & \\
\hline FUTURO & $\begin{array}{l}\text { ANÁLISIS DE } \\
\text { REFERENTES }\end{array}$ & & \\
\hline
\end{tabular}

Diatópico

Diacrónico

a. Legislación
Diatópico

a. Grupos de investigación
Foco: EVALUACIÓN

Capítulo 4. MÉTODO

Equilibrio de tensiones: evaluación:

a. Conceptuales: assessment/evaluation

a. Programas: balance de perspectivas b. Aprendizajes:

b. Curriculares: Cualitativo/cuantitativo PISA... 
"Si alguien ama a una flor de la que sólo existe un ejemplar entre millones y millones de estrellas, es suficiente mirar al cielo para ser feliz pues puede decir satisfecho: "Mi flor está allí, en alguna parte..."

El Principito (Antoine de Saint-Exupéry) 


\section{CUERPO TEÓRICO}

\section{EDUCACIÓN PATRIMONIAL: PASADO, PRESENTE Y FUTURO}

\subsection{Introducción}

En este capítulo se contrastan los diferentes conceptos que a lo largo de las últimas décadas se han formado acerca de la educación patrimonial.

Estas visiones van, desde algunas más explicitas acerca de los elementos físicos históricos, hasta las teorías más contextuales y societarias, que conciben la cultura como un hecho colectivo, dinámico y polifacético y, por ende, a lo patrimonial como un campo mucho más amplio e interpretativo, no solo de elementos físicos sino de estructuras relacionales y usos inmateriales.

Seguidamente, se aborda el patrimonio personal como elemento específico de investigación abordando el debate teórico que se establece al respecto. Paralelamente a lo ya dicho, hay enfoques más estáticos de este tema, y otros que conciben a la persona como un elemento dinámico, complejo y sociable, y que conforma un amplio elenco cultural de elementos patrimoniales en su interior y en su entorno. Se estudia, en este sentido, el patrimonio inmaterial del sujeto en su complejidad.

También se aborda qué es lo patrimonial en el ámbito específico de la educación. Se hace hincapié en la progresiva diversificación de los ámbitos de educación patrimonial, abarcando la formal, no formal e informal. Y las diferentes instituciones implicadas: escuela, museo, ayuntamientos, fundaciones, bibliotecas y otras.

Este primer capítulo también ofrece un estado de la cuestión de la situación de la educación patrimonial tanto desde el punto de vista diatópico, haciendo un descenso desde lo general del nivel internacional o europeo, hasta el nivel autonómico.

Dentro de cada apartado territorial hay un avance diacrónico o temporal, correspondiente a la sucesión de instituciones, leyes e iniciativas en cada uno de los ámbitos.

En el ámbito internacional, se habla de los antecedentes históricos y del núcleo de iniciativas que en torno a la creación de la UNESCO y otros organismos globales se concentró en las décadas de los 50 y 60 del siglo XX.

Se hace una recensión de Cartas y convenciones de estos organismos, que, por décadas, destacan en los 70, y en las dos ultima décadas del siglo XXI. 
En el ámbito nacional se estudian las numerosas leyes educativas y el sucesivo enfoque que han dado a la educación patrimonial, a la vez que la presencia del tema en los curricula de las últimas leyes nacionales.

Se describe el papel fundamental del Instituto de Patrimonio Cultural de España (IPCE) y los planes Plan Nacional de Educación y Patrimonio (PNEyP), como salto cualitativo que ha engarzado el auge teórico y estructural que está tomando el área en la universidad española con la necesaria prolongación a las diferentes áreas de la sociedad y el territorio nacional.

Por último, en la comunidad de Castilla y León se estudia el plan PAHIS como articulación necesaria, en una comunidad con una cantidad tan ingente de elementos patrimoniales. Este plan se profundiza en sus objetivos y decretos subsiguientes legislativos y se explica la articulación de elementos, organizaciones, instituciones, fundaciones etc. que se pretende con el mismo.

\subsection{Clarificación conceptual de Educación patrimonial}

En la actualidad, debido a los cambios producidos en la sociedad y en la educación, el concepto de educación patrimonial es complejo para definir. No se ubica ni se entiende como disciplina, confundiéndola en la mayoría de los casos con visiones historicistas, monumentalistas e incluso lúdico-turísticas.

Etimológicamente se podría hablar, por una parte, del término patrimonio, que tiene su origen en el latín, derivado de pater, padre, pai. La Real Academia Española (RAE) ofrece en su diccionario de lengua española, como primera y segunda acepción del término:

\section{1. hacienda que alguien ha heredado de sus ascendientes}

2. conjunto de los bienes y derechos propios adquiridos por cualquier título (RAE $\left.E^{l}, 2018\right)$. Pero relacionado con estos conceptos y su etimología se puede encontrar la palabra que recordó Tim Copeland del International Centre for Heritage Education (University of Gloucestershire, Reino Unido) en el primer Congreso de Educación Patrimonial (2012): herencia. Es una palabra nacida del latín, haerentia que proviene de haerere, cuyo significado es "estar adherido". Precisamente es de destacar la palabra Heritage, que es según el diccionario Collins de inglés, originario del francés antiguo. Para ellos

\footnotetext{
${ }^{1}$ Consultado en: $\underline{\text { https://dle.rae.es/?id=SBOxisN }}$
} 
la palabra era heriter, que proviene del latín antiguo hereditare, hereditas, y que se traduce también como herencia.

Con ambas palabras (pater y haerere/hereditare) se podría formar el concepto de patrimonio en su originalidad, como "estar adherido al padre". En el fondo, es así como se entiende el término en el ámbito de la educación, estar unido, tener un vínculo con el objeto patrimonial, que sería el "padre", el creador, el origen de todo lo que conforma nuestra identidad personal y social.

A nivel histórico el término educación en el mundo de lo patrimonial podría decirse que comienza a utilizarse en la Francia post-revolucionaria, para el fin de proteger sus bienes históricos. Posteriormente, al configurarse los estados nacionales de Europa, se le da fuerza a las tradiciones e historia de cada pueblo como factor básico en la formación de la identidad propia como nación.

Pero es, sobre todo, tras la I Guerra Mundial cuando se afina y arraiga más esta idea de la identidad de los pueblos, tras la devastación sufrida en muchos países. Para ello se realizaron varias acciones: por un lado, en la Primera Conferencia Internacional de Arquitectos y Técnicos de Monumentos Históricos (Atenas, 1931) y dirigida a los países miembros de la Unión de Estados, se redactó la llamada “carta del Restauro", la carta de Atenas. Dicha carta tuvo un carácter técnico sobre la restauración de los edificios históricos, como mediadores para el entendimiento de la historia de esa cultura. Además, propone un punto relacionado con la educación, en el que se aconseja que los educadores de niños y jóvenes mantengan un papel primordial en esa conservación y transmisión de valores. Años más tarde, y gracias a la primera carta, se realizaron otras acciones, como el impulso de instituciones:

A. La Organización de las Naciones Unidas para la Educación, la Ciencia y la Cultura (UNESCO) se dedica, desde su nacimiento en 1958, a establecer la paz con la cooperación entre los países en educación, en ciencia y en cultura. Nacida en el seno de una guerra mundial, es una organización que rechaza la intolerancia, los ataques a la diversidad cultural, amenazas a la libertad de expresión y los derechos humanos. La sede está en París.

B. El Centro Internacional de Estudios para la Conservación y la Restauración de los Bienes Culturales, ICCROM, es una organización entre gobiernos de distintos países, que desde que se inició en Nueva Delhi en 1956, se dedica a preservar el patrimonio cultural a través de distintos programas de información, formación, sensibilización, cooperación e investigación. La sede está en Roma. 
C. El Consejo Internacional de Monumentos y Sitios, ICOMOS, se consolida en 1964, y ha ido marcando una doctrina y filosofía sobre el patrimonio a nivel internacional, organización no gubernamental (ONG), unida a UNESCO y con 151 países miembros.

La siguiente carta fue la de Roma (1932), y la siguiente propuesta en el II Congreso de Arquitectos Técnicos, la Carta Internacional para la Conservación y Restauración de Monumentos y Sitios, fue la carta de Venecia (1964). Esta carta es un documento con carácter histórico que se realizó por profesionales del mundo de la cultura, de poca extensión, pero comprimiendo más de un siglo de reflexión sobre la conservación y transmisión del patrimonio, siempre referido a un patrimonio tangible (Gazzola y Pane, 1974; Aceves, 2004; DiBiase, 2014; López-Morales, 2016)

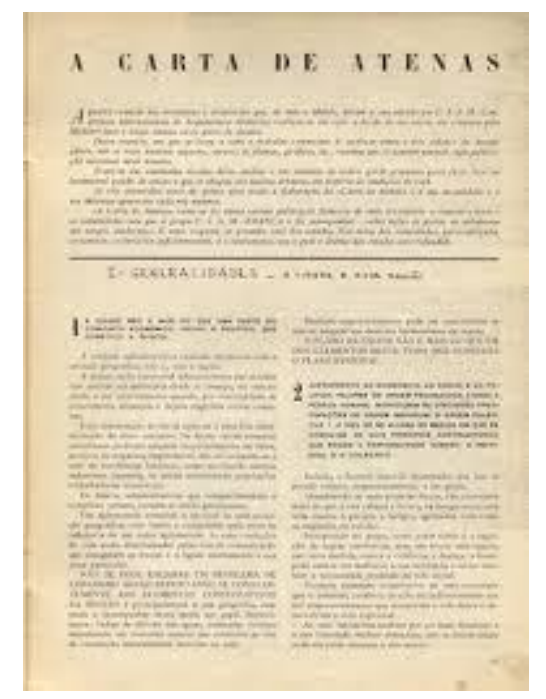

(1a)

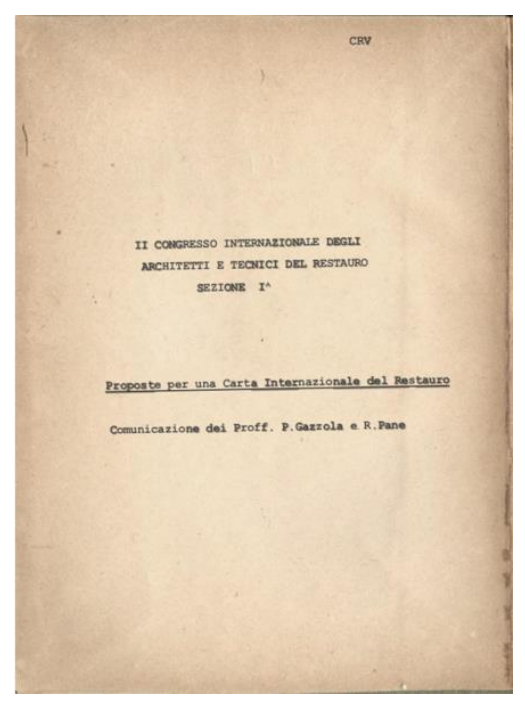

(1b)

Figura 1. 1a. Página de revista Arquitectura, n 19. Artículo sobre la carta de Atenas. Fuente: Biblioteca Joao Archer. 1b. Carta de Venecia (ICOMOS, 1964). Fuente: Archivo personal.

El resto de documentos se han ido sucediendo a lo largo de los años hasta el siglo XX: París (1972), Roma (1972), Copenhague (1984) o Cracovia (2001), etc. Se sintetizan en la Tabla 2.

Tabla 2

Relación de documentos para la conservación del patrimonio 


\begin{tabular}{|c|c|c|}
\hline CARTA & AÑNO & LUGAR \\
\hline Carta de Atenas & 1931 & Atenas \\
\hline Convención de La Haya & 1954 & La Haya \\
\hline Carta de Venecia & 1964 & Venecia \\
\hline Convención del patrimonio Mundial, Cultural y Natural & 1972 & París \\
\hline Confrontación de Bolonia & 1974 & Bolonia \\
\hline Resolución de Santo Domingo & 1974 & Santo Domingo \\
\hline Resolución de Brujas & 1975 & Brujas \\
\hline Recomendación de Nairobi & 1976 & Nairobi \\
\hline Carta de Turismo cultural & 1976 & Bruselas \\
\hline Coloquio de Quito & 1977 & Quito \\
\hline Carta de Florencia & 1981 & Florencia \\
\hline Carta de Burra & 1988 & Burra \\
\hline Documento de Nara sobre Autenticidad & 1994 & Japón \\
\hline Carta de Cracovia & 2000 & Cracovia \\
\hline Nueva Carta de Atenas & 2003 & Atenas \\
\hline Declaración de Xián & 2005 & Xián \\
\hline Memorándum de Viena & 2005 & Viena \\
\hline Carta de Ename & 2005 & Ename \\
\hline Carta sobre Itinerarios Culturales & 2008 & Quebec \\
\hline Principios de La Valeta & 2011 & La Valeta \\
\hline
\end{tabular}

Cada una de las instituciones citadas desarrollan a lo largo de los años sus propios documentos en los ámbitos que dominan. Así, UNESCO desarrolla convenciones, destacando:

- Convención sobre la Protección y la Promoción de la Diversidad de las Expresiones Culturales (2005).

- Convención para la Salvaguardia del Patrimonio Cultural Inmaterial (2003). 
- Declaración Universal sobre la Diversidad Cultural (2001).

- Convención de la UNESCO sobre la Protección del Patrimonio Cultural Subacuático (2001).

- Convención para la Protección del Patrimonio Mundial Cultural y Natural (1972).

- Convención sobre la Protección de los Derechos de Autor y Derechos Conexos (1952, 1971).

- Convención sobre las medidas que deben adoptarse para prohibir e impedir la importación, exportación y la transferencia de propiedad ilícitas de bienes culturales (1970).

- Convención de la Haya para la Protección de Bienes Culturales en caso de Conflicto Armado (1954).

Estos documentos dan cuenta de la concepción de patrimonio y educación patrimonial que evolucionan según las sociedades en la historia. Es decir, se pueden considerar distintas clases de patrimonio, según la óptica desde la que se mire.

Así, para DeCarli (2006) el patrimonio es un conjunto de bienes culturales y naturales, tangibles e intangibles, generados localmente, y que una generación hereda/transmite a la siguiente con el propósito de preservar, continuar y acrecentar dicha herencia. Las tipologías de patrimonio ayudan a la definición del mismo. UNESCO ${ }^{2}$ propone una clasificación funcional para su estudio e investigación (ver Figura 2).

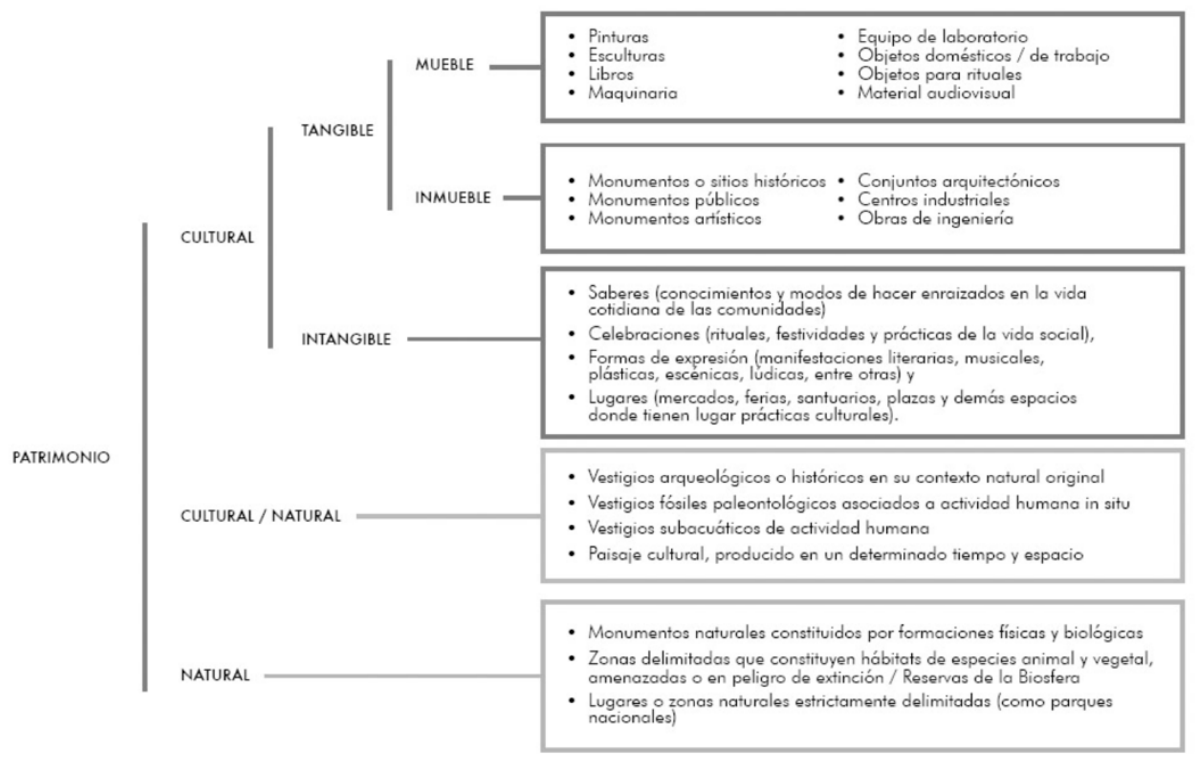

2 Actualmente, la Lista de Patrimonio Mundial cuenta con 1073 sitios inscritos, de los cuales 832 son bienes culturales, 206 bienes naturales y 35 bienes mixtos, situados en 167 Estados Partes. Desde noviembre de 2016, 192 Estados Partes han ratificado la Convención del Patrimonio Mundial. 
Figura 2. Clasificación de patrimonio según UNESCO. Fuente: https://es.unesco.org/

Sin embargo, a continuación, se propone una clasificación alternativa, en la que se irá perfilando el concepto de patrimonio.

1. Patrimonio cultural: El ser humano construye, a través de sistemas simbólicos, un ambiente artificial en el cual vive y que transforma continuamente. Ese sistema es el que forma la cultura. La cultura es propiamente el movimiento de creación, transmisión y reformulación de ese ambiente artificial (Ribeiro, 1998, p. 132). El patrimonio es, justamente, una construcción cultural que ayuda a construir vínculos entre el pasado y el presente (Mcdonald, 1997, p.162) y además es construido por un conjunto de personas que forman parte de un mismo grupo.

En este caso, el patrimonio se conjuga en plural, porque hace referencia siempre a un nosotros heredado, en consecuencia, lo nuestro, lo que nos pertenece. De acuerdo con esto, se hace imprescindible resaltar una definición de patrimonio cultural siguiendo a Muriel (2015) como "la articulación explícita de lo que es nuestro, lo que nos pertenece como individuo, ciudadano, comunidad, grupo, pueblo, nación o colectividad” (Muriel, 2015, p.264). En esa definición está contenida la idea clave del patrimonio desde un planteamiento experto y de historiadores: una propiedad que poseemos, del que nos apropiamos de forma simbólica y que nos define.

2. Patrimonio personal: esta definición anterior es extensible al sujeto como ser individual. Nos define como personas. Esto es lo que quiere decir "sin personas no hay patrimonio" (Fontal, 2013, p.18); en sí mismo el patrimonio no tiene un valor intrínseco a menos que sea apropiado y existan sujetos que le den un valor determinado. Muchos de los que trabajan con el patrimonio lo conceptualizan en términos de una relación de propiedad: que los sujetos sientan como propios y se apropien de una serie de objetos simbólicomateriales que son los distintos patrimonios. Es la relación sujeto-objeto patrimonial, es decir, el vínculo que los une a ese sujeto y a ese objeto. Precisamente es Fontal (2003) quien define de esa manera el patrimonio en su tesis. Esta autora habla del proceso que realiza un objeto para llegar a ser patrimonio, para que se adhiera a una persona: conocer, comprender, valorar, sensibilizar, cuidar, disfrutar, transmitir, socializar e identizar. También se puede señalar un patrimonio individualizado que nos ofrece nuestra idiosincrasia como personas únicas. Cada cual tendrá su punto de vista sobre el patrimonio individual de los demás y cuando los bienes son personas, el patrimonio es 
la relación entre personas y personas, la relación más inmaterial y espiritual que existe (Fontal 2012).

Los procesos de patrimonialización suponen la selección de unos elementos y por tanto excluyen a otros, (Tunbridge y Ashworth, 1996) y obligan a darle de nuevo significados a esos bienes y a una reducción de su polisemia. Estos autores, describen un modelo disonante del patrimonio que refuerza las instancias de poder que lo crean y potencialmente deshereda o no incluye a todo el mundo. El patrimonio es disonante porque no produce uniones o intercambios, resonancias (Deleuze, 1994, 98) con otras personas, no se ubica en la frecuencia de voz en la que las personas ordinarias hablan o sienten (Muñoz, 2006, 677), no afecta a personas que no han creado el patrimonio por y para ellas, o alejadas de instancias de poder. Tunbridge y Ashworth (1996) identifican tres enfoques principales hacia la resolución del concepto de patrimonio: un enfoque inclusivo que busca la incorporación de distintas perspectivas en una especie de colcha de mosaico del patrimonio (p. 219); un enfoque minimalista que busca "evitar la disonancia al desarrollar solo los temas de patrimonio que son comunes a todos los habitantes, evitando así la posible objeción de uno u otro grupo a parches particulares en la colcha inclusiva" (p. 220); y un enfoque de localización que promueve o proporciona una "aceptación tácita de diferentes mensajes de herencia que emanan de diferentes ubicaciones y diferentes escalas en la jerarquía espacial” (p. 221). Los procesos de patrimonialización son procesos en los que las alianzas, las negociaciones y los conflictos son frecuentes (Sánchez-Carretero y Jiménez-Esquinas, 2016) y donde la heterogeneidad de intereses y de poder se muestran, y esto se aplica tanto a nivel individual, como a nivel social o de comunidades.

3. Patrimonio en comunidad: Siguiendo a Noyes (2012) se pueden distinguir entre un concepto fundacional de comunidad (es un colectivo esencialmente definido, por su vinculación con la tierra y la historia), un concepto relacional (un colectivo que se define por oposición a otros, que son diferentes y antagónicos) y un concepto performativo (un colectivo que se performa, se define y reconstituye en el "hacer patrimonio", en la misma transformación social que "hace" el patrimonio). Los dos primeros conceptos son los que aparecen implícitos en la Convención de 2003; están ligados a comunidades (o grupos) étnica e históricamente definidos y tienen cierto sesgo esencialista; el tercero se opone a estos dos, se concibe como red y no existiría independientemente del patrimonio (Hertz, 2015), es decir, se conforma a través de la patrimonialización. Esta última es lo que en la Convención de Faro de 2005 se ha 
denominado "comunidad patrimonial" (Faro, 2005) y lo que proponen los académicos en el Expert Report on Community Involvement de UNESCO (Organización de las Naciones Unidas para la Educación, la Ciencia y la Cultura) de 2006.

El patrimonio así conceptualizado es un patrimonio vivo, compartido y, por otra parte, al protagonismo que se otorga a las "comunidades, grupos y en algunos casos individuos", las personas en comunidad, en el "nuevo paradigma participativo" del patrimonio (Adell et al., 2015). La creación de nuevos referentes de identificación que articulan un sentido de pertenencia ligado a un lugar, grupo o causa distintiva (Anico, 2009, p.67). Las acciones patrimonializantes se presentan de este modo como generadoras de colectividad, de participación ciudadana, de fortalecimiento o creación del tejido social: el patrimonio ayuda a construir sociedad (Hernández Ramírez y Ruiz Ballesteros, 2008, p.139).

Depositar la legitimidad de la patrimonialización en las comunidades y grupos locales supone una transformación profunda: es lo que ciertos autores denominan como el nuevo "paradigma participativo del patrimonio" (Adell et al., 2015; Sánchez-Carretero y Jiménez-Esquinas, 2016; Cortés et al., 2017) inscrito en los actuales modelos de comunidades.

Nos pueden parecer patrimonios opresivos respecto a algunos colectivos (Crooke, 2007), patrimonios disonantes (Tunbridge, Ashworth, 1996; Graham, 2002; Ashworth et al., 2007; Poria et al., 2009), patrimonios indeseables (Mclean, 2006) o patrimonios incómodos (Prats, 1997; Mesa-Bains, 2004), pero, al fin y al cabo, son nuestro patrimonio.

Son los valores que poseemos, los que están en la base de una mirada selectiva que enfoca y hace que algunos elementos de la realidad "se vuelvan significativos para nosotros, y solo esos" (Weber, 1973, p.23). Los valores se colocan sobre objetos o actividades por las propias personas que, cuando asimilan el patrimonio, lo hacen a través de toda una serie de lentes, los más obvios de los cuales son: la nacionalidad, la religión, la etnia, la clase, la riqueza, el género o la historia personal; y esa lente extraña se conoce como interioridad (Graham \& Howard, 2008, 2).

Por ello, se puede hablar de los valores del patrimonio como conformantes del concepto; el patrimonio por sí mismo no tiene valor ni deja de tenerlo; es justamente el ser humano quien se lo confiere y, por ello, los valores son múltiples, cambiantes y educables. Ahí es donde cobra su verdadero valor la acción educativa (Fontal, 2013, 1012). 
4. Patrimonio en educación: Por otra parte, y para entender el concepto, tal y como se entiende en la actualidad, como parte de la educación, hay que señalar que hay autores que datan su origen en la década de los 70 (s. XX) con la confluencia de una serie de acontecimientos y concretamente bajo la influencia de la pedagogía de Freire, a efectos conceptuales y prácticos (Horta 1999).

Se mantienen ideas en la época como la de concebir la educación permanente como pilar importante para las personas, con tres sectores complementarios y no excluyentes: la educación formal (dentro de un centro de formación sistematizado y organizado, es intencional para el alumnado, acabando en una certificación), la no formal (fuera de centro pero también es sistematizado e intencional para el alumnado, no concluye en certificación) y la informal (aprendizaje que se obtiene en las actividades de la vida cotidiana relacionadas con el trabajo, la familia o el ocio que no está estructurado y normalmente no conduce a una certificación, puede ser intencional, pero en la mayoría de los casos, es aleatorio). Además, es el tiempo en que los museos comienzan a hablar dentro de su entorno de educación, la educación en el ámbito no formal.

En los distintos países a nivel mundial, es difícil diferenciar qué sistema educativo introduce la educación patrimonial o no. Sin embargo, se pueden encontrar estudios que desvelan algunas ideas importantes para poder realizar un boceto del panorama mundial en cuanto a la educación patrimonial.

En este sentido, se recomienda desde la UNESCO, en su convención de 1972, en la que se incluía un capítulo con dos artículos dedicados explícitamente a la educación, la Convención sobre la protección del patrimonio mundial, cultural y natural, de la siguiente forma:

Artículo 27

Los Estados Partes en la presente Convención, por todos los medios apropiados, y sobre todo mediante programas de educación y de información, harán todo lo posible por estimular en sus pueblos el respeto y el aprecio del patrimonio cultural y natural definido en los artículos 1 y 2 de la presente Convención.

Artículo 28

Los Estados Partes en la presente Convención, que reciban en virtud de ella, una asistencia internacional tomarán las medidas necesarias para hacer que se conozca la importancia de los bienes que hayan sido objeto de asistencia y el papel que ésta haya desempeñado (UNESCO, 1972). 
También la UNESCO, en un informe de seguimiento de la educación en el mundo (2016) desvela cómo han evolucionado los países en su educación para llegar a la consecución de los objetivos de desarrollo sostenible. En este estudio se tiene en cuenta el patrimonio como eje transversal en la educación de las personas, pero dejando clara la evidencia de que, en pocos países a nivel mundial, incluyen una educación patrimonial en sus sistemas educativos. Sin embargo, en una revisión sobre este tema, se pueden encontrar los países que abogan por una educación en la que el patrimonio forme parte de su sistema de enseñanza.

La educación patrimonial es un ámbito que se empieza a desarrollar dentro de la educación con un fin fundamentado en los objetivos de la UNESCO en el conocimiento, la valoración, la conservación y la difusión del patrimonio cultural y su rol como el que proporciona identidad y pertenencia social. El referente dentro del campo educativo es la pedagogía del patrimonio que se define en la Resolución n ${ }^{\circ} 5$ del Consejo de Europa (1998), como la educación que aúna distintos métodos pedagógicos activos y ayuda a relacionar cultura en su sentido más extenso y educación.

Las teorías desarrolladas más recientemente en este campo de la educación, dan riqueza y revalorizan la perspectiva que se diseñó en 1998 en la Resolución nº5 del Consejo de Europa, reemplazando el interés tradicional en la identificación, conservación y transmisión del patrimonio cultural, por el interés por el contexto histórico, social, económico, identitario y cultural donde se dan las experiencias de apropiación del patrimonio y se produce el acto consciente del mismo y en el que intevienen las emociones (Fontal, 2003).

Este importante cambio se llevó a cabo al insertar como tópico de la educación patrimonial la reflexión sobre el rol del patrimonio cultural en las personas que se articula como expresión de diversidad, como derecho humano, hilo social, como aporte identitario de las personas y de su comunidad e incluso como lugar de tensión y complicidades sociales. Estos análisis se nutren de trabajos críticos sobre la cultura y la función del patrimonio cultural en las relaciones sociales, inter y transculturales (Ventosa, 1993; González-Varas, 2000; Miralles, 2004; Llull, 2005; Essomba, 2008).

En el diseño de proyectos educativos en materia interpretación, valoración y apropiación del patrimonio cultural desde una contextualización social, histórica y cultural del patrimonio, es imprescindible tener en cuenta corrientes teóricas como la 
pedagogía de la complejidad (Morin, 1999) y las postvigoskianas que ayuden a reinterpretar la educación patrimonial en nuevas categorías y nuevos conceptos, como el de comunidad patrimonial (Convenio de Faro, 2005).

Así, podemos encontrar proyectos educativos de este tipo, que reinterpretan el patrimonio y su enseñanza, como los que describimos a continuación, de los niveles más globales, macro, a los más locales o micro, pasando por los niveles intermedios o meso, siguiendo las líneas abierta de Mateos-Rusillo $(2009,26)$ que distingue entre tres grandes tipos de entes gestores: las instituciones públicas supra-estatales -como la UNESCO, el ICCROM, el ICOMOS, el ICOM, el Consejo de Europa y la Unión Europea-, las instituciones públicas estatales -que aparte del Estado español y las Comunidades Autónomas incluye también a las diputaciones y los ayuntamientos- y las organizaciones privadas.

\subsection{Inclusión del patrimonio en la enseñanza mundial: nivel MACRO}

Se pueden encontrar diversos proyectos educativos de interés a escala mundial, en los que intervienen países que se relacionan a través de la educación patrimonial. Estas relaciones llevan a una característica del patrimonio que lo define, dedicada a enseñar las diferencias y diversidades de culturas.

A modo de ejemplo, se destacan a continuación varios de estos proyectos a escala mundial, que sobresalen por los valores asociados a la acción patrimonial.

\section{RED DE ESCUELAS ASOCIADAS DE IA UNESCO}

Es una red de 11.500 escuelas asociadas por todo el mundo de 182 países, que desarrollan proyectos de educación con la finalidad de dar especial importancia a las relaciones interculturales y el desarrollo sostenible. En el período que dura hasta 2021 se ha innovado en dos ámbitos: educación para la ciudadanía mundial (ECM) y educación para el desarrollo sostenible (EDS). Ambas facetas se desarrollan con distintos proyectos y aludiendo a unos objetivos comunes. Por ejemplo, en la educación para la ciudadanía mundial, se desarrollan tres tipos de objetivos: a) cognitivo: conocer, comprender, desarrollar un pensamiento crítico con el mundo que les rodea a nivel local, regional, nacional e internaciones b) socioemocional: desarrollar el sentido de pertenencia a la humanidad común, compartiendo valores de respeto a la diversidad, solidaridad, etc, y c) conductual: actuar con responsabilidad en los distintos niveles 
(local, regional, nacional e internacional), para mantener la paz y la sostenibilidad. En los distintos objetivos puede descubrirse un concepto actual sobre patrimonio.

\section{HERITAGE HUBS}

Se hace imprescindible señalar el proyecto Herirage Hubs de la Asociación Cultural de Finlandia, un proyecto transnacional y financiado por la ayuda de Europa Creativa, en el que intervienen, además de Finlandia, Serbia, Italia y España. En este trabajo participan jóvenes de 11 a 15 años de distintos centros educativos para intercambiar sus identidades culturales a través de medios digitales y en persona, eligiendo el patrimonio que quieren mostrar al resto de participantes. Existen ejemplos de intercambios dentro de este programa en Castilla y León.

\section{AÑO EUROPEO DEL PATRIMONIO CULTURAL}

La Comisión Europea desarrolla, con los socios clave, el año europeo del patrimonio cultural en 2018, con el lema "Nuestro patrimonio: donde el pasado se encuentra con el futuro". Para darle continuidad a las actividades propuestas, se desarrollan una serie de iniciativas a largo plazo, con el fin de que se proteja y disfrute el patrimonio a nivel europeo, nacional, regional y local. Atendiendo a cuatro objetivos, se desarrollarán estos proyectos:

1) Compromiso: A) Patrimonio compartido, el patrimonio cultural nos pertenece a todos. B) Patrimonio en la escuela: para que los niños descubran los más preciados tesoros y tradiciones de Europa. C) Juventud para el patrimonio: revitalizar el patrimonio a través de los jóvenes.

2) Sostenibilidad: D) Patrimonio en movimiento: imaginar de nuevo los lugares y paisajes industriales, religioso y militares. E) Turismo y patrimonio: turismo responsable y sostenible en torno al patrimonio cultural.

3) Protección: F) Valoración del patrimonio: desarrollar normas de calidad para las intervenciones en el patrimonio cultural. G) Patrimonio en peligro: lucha contra el comercio ilícito de bienes culturales y para gestionar el riesgo para el patrimonio cultural.

4) Innovación: H) Competencias relativas al patrimonio: una mejor educación y formación para los profesionales tradicionales y nuevos del sector. I) Todo por el patrimonio: fomentar la innovación social y la participación de la gente y las comunidades. J) 
Ciencia para el patrimonio: investigación, innovación, ciencia y tecnología en beneficio del patrimonio.

\section{HUMAN FUTURES, Shared Memories and Visions}

Es un proyecto que se lleva a cabo de forma interdisciplinaria, dirigido a todos los ciudadanos, con el fin de una construcción de comunidad a través de las nuevas tecnologías. Se tiene en cuenta el rol del artista como mediador en el diálogo translocal, participando cuatro artistas europeos y cuatro canadienses que acuden a las ciudades que colaboran con el proyecto y enseñan nuevos espacios con el poder del intercambio cultural para sus identidades patrimoniales. Se lleva a cabo por varios países, como Canadá, Inglaterra, Alemania, Austria y Dinamarca, en distintos contextos de las ciudades y llevados a cabo por distintas instituciones, en los cuales, lo primordial es tanto el intercambio de las realidades vitales y significativas, como el imaginario colectivo, para mantener estos lugares formando parte de los ciudadanos.

Estos son algunos ejemplos de proyectos a nivel europeo alrededor del concepto de educación patrimonial. En la web de Europa Creativa se pueden encontrar propuestas educativas de distintos países que animan a participar en los proyectos, unos 3000 ejemplos aproximadamente de las buenas prácticas en la enseñanza del patrimonio, entre los años 2014 y 2019.

Desde que se entró en el siglo XXI, el concepto de patrimonio cultural y su enseñanza ha sufrido una gran variación a nivel mundial. Concretamente se ha pasado de un enfoque estrecho de miras a otro en el que se involucran valores y a todos los agentes que intervienen. Para llegar a nuevos actores del patrimonio es necesario tener en cuenta no solo la educación o la capacitación, sino también el desarrollo de competencias. La finalidad es dar al patrimonio un lugar importante en la vida comunitaria, aplicado a nivel global, nacional, regional y local.

No se puede dejar a un lado el grupo de países de Iberoamérica que poseen un especial interés en todo lo relacionado con la educación y el patrimonio. La Organización de Estados Iberoamericanos para la Educación, la Ciencia y la Cultura (OEI) es un organismo internacional de carácter gubernamental para la cooperación entre los países iberoamericanos en el campo de la educación, la ciencia, la tecnología y la cultura en el contexto del desarrollo integral, la democracia y la integración regional. Los Estados 
Miembros de pleno derecho y observadores son todos los países iberoamericanos que conforman la comunidad de naciones.

En 2019 la OEI, apoyada en sus 18 oficinas, plantea identificar, analizar, sistematizar y documentar experiencias significativas del proyecto Educación, Arte y Cultura, en los sistemas educativos de los países Iberoamericanos. La estrategia apunta a entender las apuestas y condiciones que han favorecido el desarrollo de esos casos, para construir evidencias sustentadas en experiencias propias y, desde allí, fomentar su réplica y escalabilidad en la región.

Concretamente, Brasil, Chile, Argentina o Colombia, por mencionar algunos, son países con un bagaje extenso en cuanto a patrimonio. Brasil es el referente principal por el volumen de programas educativos sobre patrimonio. Allí fue creado el Instituto do Patrimonio Histórico e Artístico Nacional/ IPHAN (1930-1945).

Este hincapié en la disciplina se debe principalmente a las políticas que ayudan a que se desarrollen y a la disposición de los agentes para llevarlos a cabo, tanto en los espacios formales, no formales, como en los informales, por ejemplo, los medios de comunicación que, en líneas generales, los expertos aseguran que dichos medios deberían llevar a cabo una labor de difusión formativa para concienciar al gran público de la necesidad de salvaguardar su patrimonio (Lavín Berdonces et al., 1996, 103; Sánchez Castillo, 2005, 387), a la vez que educarlo en la sensibilidad, en percepción, valoración y aprecio del mismo (Gómez Ferrer y Phares, 1998, 75).

Un ejemplo de buenas prácticas en Brasil es el Proyecto de Extensión Patrimônio Cultural: aprendendo a conhecer. Proposta para uma ação de Educação Patrimonial, que concurrió a un presupuesto propio junto al Ministerio de la Educación, a finales del año de 2005. Está registrado en la Pro-Rectoría de Extensión/UENF desde el año 2004. El proyecto cuenta con la participación de alumnado de los cursos de Ciencia de la Educación y Ciencias Sociales.

Desde el Instituto de Patrimonio Histórico y Artístico Nacional de Brasil, se han señalado casos puntuales como: Kit educativo Nuestro patrimonio cultural (Perú) y Educación en Valores Patrimoniales para los Habitantes de la Poligonal de Xochimilco, (México). Así como, el desarrollo de áreas como Museo y Territorio (Museo de Antioquia, Colombia) que trabaja procesos de apropiación social del 
patrimonio en comunidades. Por otra parte, la creación de páginas web interactivas como: Nuestro Patrimonio (DIBAM ${ }^{3}$, Chile), Pasos (Municipalidad Viña del Mar, Chile), entre otras, o la incorporación en eventos científicos de Patrimonio Cultural como el V Congreso de Educación, Cultura y Patrimonio (Chile).

\subsection{Inclusión del patrimonio en la enseñanza española: nivel MESO}

En España la educación patrimonial ha tenido un recorrido parecido a otras disciplinas, con una salvedad: el carácter joven y dinámico de ésta. El concepto de patrimonio, según Jiménez de Madariaga (2002), tiene que ver con el hecho de formarse las autonomías, para reafirmar las singularidades e identidades culturales de cada lugar, conformando una memoria histórica. Y, a partir de esta formación de Comunidades Autónomas, todo lo que conlleva las leyes que se desarrollan en cada una de ellas. De cualquier manera, se tiene en la actualidad una concepción que proviene principalmente de dos áreas disciplinares como son la Didáctica de las Ciencias Sociales y desde la Didáctica de las Artes.

\subsubsection{Plan Nacional de Educación y Patrimonio}

La normativa en cuestión de patrimonio pasa por revisar no sólo las leyes de educación sino también los Planes Nacionales, como el de educación y patrimonio, que desarrollan una serie de pautas para llevar a cabo en los proyectos educativos que se utilizan en las aulas (Mayordomo, 2013; Ávila y Castri, 2015; Fontal, 2016; Puche, 2016; Fontal, Ibáñez-Etxeberría, Martínez y Rivero, 2017) y fuera de ellas (Fontal y Juanola, 2015; Puche y Pinto, 2015).

Los Planes Nacionales de Patrimonio Cultural nacen en los años 80 del siglo XX con el fin de ser una herramienta de difusión, custodia, conservación, investigación y documentación de todos los bienes muebles, inmuebles, materiales, inmateriales que se poseen en España con la coordinación de políticas de protección. Sin embargo, no fue hasta el año 2010 en que el Instituto de Patrimonio Cultural de España (IPCE) realiza una serie de revisiones de los citados planes junto a las Comunidades Autónomas debido al cambio de paradigma en la concepción de patrimonio, más transversal. Por ello, se diseñó el Plan Nacional de Educación y Patrimonio, para facilitar acciones de investigación e innovación, en las que se integren los distintos agentes culturales y

\footnotetext{
${ }^{3}$ Servicio nacional del Patrimonio cultural
} 
educativos y para que se asegure el derecho fundamental del acceso a la cultura y el respeto a la diversidad cultural.

En su documento, el citado Plan hace alusión a la educación formal de la forma siguiente:

el Plan velará por la implementación de la normativa educativa para un progresivo incremento cualitativo y cuantitativo de los contenidos patrimoniales en los currículos, así como por la mejora de la capacitación del profesorado y de los recursos destinados a la transmisión del Patrimonio Cultural (p.5).

El Plan Nacional de Educación y Patrimonio se desarrolla dentro del conjunto de estrategias educativas de los ámbitos formal, no formal e informal. Estas estrategias se dirigen a la apropiación por parte de la ciudadanía de los valores del Patrimonio Cultural. Dentro del ámbito formal el Plan se propone unos retos muy concretos a largo plazo:

1) Implementar los contenidos que se relacionan con el Patrimonio Cultural dentro de los cuarrícula educativos

2) Mejorar el material didáctico sobre Patrimonio

3) Fomentar la formación del profesorado en valor social, cultural, económico e identitario de los bienes culturales. (p.8).

\subsubsection{Leyes de educación}

En España, las leyes educativas han ido cambiando, dependiendo de las ideologías políticas imperantes en los distintos momentos (ver Figura 3).

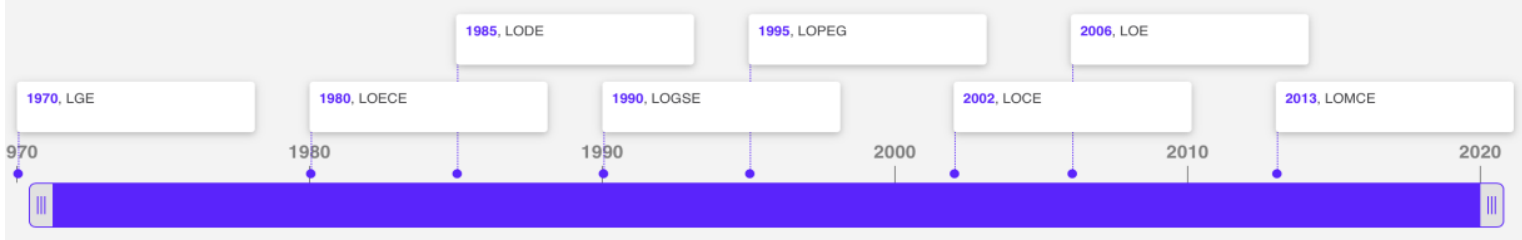

Figura 3. Evolución y timeline de las leyes educativas en España. Fuente: elaboración propia

Es decir, se han desarrollado leyes de educación del partido que gobierna, pero no son leyes de Estado, de consenso de partidos: Ley General de Educación (LGE,1970), Ley Orgánica de Estatutos de Centros Escolares (LOECE, 1980), Ley Orgánica Reguladora del Derecho a la Educación (LODE, 1985), Ley Orgánica de Ordenación General del Sistema Educativo (LOGSE, 1990), Ley Orgánica de la Participación, la Evaluación y 
el Gobierno de los Centros Docentes (LOPEG, 1995), Ley de Calidad de la Educación (LOCE, 2002), Ley Orgánica de Educación (LOE, 2006) y Ley Orgánica de Mejora de la Calidad Educativa (LOMCE, 2013).

Además, las leyes han tenido como principio mejorar la educación, pero lo han hecho como leyes escolares (medir el sistema escolar) y no como leyes educativas, que intervienen en la comunidad (Torres, 2000). Y, por último, se ha delegado en exceso en las administraciones, sin tener en cuenta los agentes y profesionales educativos, ni las condiciones para los cambios.

En concreto, en la Ley General de Educación de 1970, se prolongó la enseñanza obligatoria, Enseñanza General Básica (EGB) a ocho cursos y la Secundaria se formaba por el Bachillerato Unificado y Polivalente (BUP), con tres cursos y que se complementaban con otro que era el Curso de Orientación Universitaria (COU). Esto dio problemas estructurales y funcionales a lo largo de los años y por ello, se dividió la Enseñanza Media en dos ciclos, siendo el primero obligatorio y suprimiendo el COU, al dividir el Bachillerato o segundo ciclo. Estos cambios se recogen en la LOE (Fernández-Enguita, 1983). La LOGSE (1990) extiende la obligatoriedad hasta los 16 años y diseña una etapa de cuatro años y dos ciclos como es la Enseñanza Secundaria Obligatoria (ESO). Tras esta etapa, se agregan dos cursos de Bachillerato. Pero de nuevo, problemas de diversa índole cultural, de desigualdad social y de necesidades educativas especiales provocaron un cuestionamiento de la ESO, y el nuevo gobierno propuso itinerarios diversificados, dando al currículo un carácter más cerrado en la LOCE (2002). Esta ley quería volver a la centralización curricular y afectando a la acreditación en varias vías: repetición de curso, sistema numérico de calificar, calificación por asignatura, recuperación de materias suspensas. Y en la última etapa de estas reformas y contrarreformas se sitúa la Ley Orgánica de la Mejora de la Calidad Educativa, LOMCE, aún en vigor desde 2013. Está publicada en Real Decreto 1105/2014, de 26 de diciembre, por el que se establece el currículo básico de la Educación Secundaria Obligatoria y del Bachillerato. En esta ley, hay menciones al patrimonio en los siguientes apartados: 
GENERAL

Artículo 11. Objetivos de la Educación Secundaria Obligatoria: j) Conocer, valorar y respetar los aspectos

básicos de la cultura y la historia propias y de los demás, así como el patrimonio artístico y cultural.

\section{$1^{\circ}, 2^{\circ} \mathrm{Y} 3^{\circ} \mathrm{ESO}$}

Lengua Castellana y Literatura. 1er ciclo de ESO. Bloque 3. Conocimiento de la lengua. Contenidos: Conocimiento de los orígenes históricos de la realidad plurilingüe de España y valoración como fuente de enriquecimiento personal y como muestra de la riqueza de nuestro patrimonio histórico y cultural.

Lengua Castellana y Literatura. 1er ciclo de ESO. Bloque 3. Conocimiento de la lengua. Criterios de evaluación:

7. Conocer el origen y evolución de las distintas lenguas de España y sus principales variedades dialectales, reconociendo y explicando sus rasgos característicos en manifestaciones orales y escritas y valorando la diversidad lingüística como parte del patrimonio cultural de nuestro país.

Lengua Castellana y Literatura. 1er ciclo de ESO. Bloque 3. Conocimiento de la lengua. Estándares de aprendizajes evaluables: 7.1. Explica, a partir de un texto, el origen y evolución de las lenguas de España, así como sus principales variedades dialectales y valora la diversidad lingüística como parte de nuestro patrimonio cultural.

Educación Plástica, Visual y Audiovisual. 1er ciclo ESO. Bloque 2. Comunicación audiovisual. Criterios de evaluación: 13. Identificar y reconocer los diferentes lenguajes visuales apreciando los distintos estilos y tendencias, valorando, respetando y disfrutando del patrimonio histórico y cultural.

Música, 1er ciclo de ESO. Introducción: "Contextos musicales y culturales" relaciona la música con la cultura y la historia, da a conocer el valor del patrimonio musical español y enseña a identificar el estilo y las características distintivas de la música que delimitan cada uno de los periodos históricos básicos.

Música, 1er ciclo de ESO. Bloque 1. Interpretación y Creación. Estándares de aprendizajes evaluables: 8.2. Practica, interpreta y memoriza piezas vocales, instrumentales y danzas del patrimonio español. Bloque 3.

Contextos musicales y culturales. 5. Apreciar la importancia del patrimonio cultural español y comprender el valor de conservarlo y transmitirlo.

Música, 1er ciclo de ESO. Bloque 3. Contextos musicales y culturales. Criterios de evaluación: 5. Apreciar la importancia del patrimonio cultural español y comprender el valor de conservarlo y transmitirlo.

Música, 1er ciclo de ESO. Bloque 3. Contextos musicales y culturales. Estándares de aprendizajes evaluables: 5.1. Valora la importancia del patrimonio español. 5.1. Valora la importancia del patrimonio español. 5.2. Practica, interpreta y memoriza piezas vocales, instrumentales y danzas del patrimonio español.

Cultura clásica, 1er ciclo de ESO. Introducción: Especial atención merecen también las distintas manifestaciones artísticas que nos han legado las civilizaciones griega y romana y que constituyen en gran medida los modelos y precedentes de muchas de las producciones actuales; entre estas destacan las relativas a las artes plásticas, y más concretamente a la escultura y la arquitectura, cuyos vestigios perviven aún como parte de nuestro patrimonio histórico

Cultura clásica, 1er ciclo de ESO. Bloque 4. Arte. Criterios de evaluación: 2. Conocer algunos de los monumentos clásicos más importantes del patrimonio español.

Cultura clásica, 1er ciclo de ESO. Bloque 4. Arte. Estándares de aprendizaje evaluables: 2.1. Localiza en un mapa los principales monumentos clásicos del patrimonio español y europeo, identificando a partir de elementos 
concretos su estilo y cronología aproximada.

\section{$4^{\circ} \mathrm{ESO}$}

Latín $4^{\circ}$ ESO. Bloque 7. Léxico. Contenidos: Nociones básicas de evolución fonética, morfológica y semántica del latín a las lenguas romances. Palabras patrimoniales y cultismos.

Latín $4^{\circ}$ ESO. Bloque 7. Léxico. Estándares de aprendizajes evaluables: 2.2. Identifica y diferencia cultismos y términos patrimoniales relacionándolos con el término de origen.

Artes escénicas y Danza, $4^{\circ}$ ESO. Bloque 1. Común. Criterios de evaluación: 2. Apreciar la importancia del patrimonio español en artes escénicas y comprender el valor de conservar y transmitir su legado.

Artes escénicas y Danza, $4^{\circ}$ ESO. Bloque 1. Común. Estándares de aprendizajes evaluables: 2.1. Valora el legado del patrimonio artístico español, comprendiendo la importancia de su preservación y transmisión.

Cultura clásica $4^{\circ}$ ESO. Bloque 4. Arte. Criterios de evaluación: 2. Conocer y saber localizar los principales monumentos clásicos del patrimonio español y europeo.

Cultura clásica $4^{\circ}$ ESO. Bloque 4. Arte. Estándares de aprendizajes evaluables: 2.1. Localiza en un mapa los principales monumentos clásicos del patrimonio español y europeo, identificando a partir de elementos concretos su estilo y cronología aproximada.

Cultura clásica $4^{\circ}$ ESO. Bloque 6. Lengua/léxico. Estándares de aprendizajes evaluables: 6.3. Identifica y diferencia con seguridad cultismos y términos patrimoniales relacionándolos con el término de origen sin necesidad de consultar diccionarios u otras fuentes de información.

Educación Plástica, Visual y Audiovisual. 4o ESO. Bloque 1. Expresión plástica. Criterios de evaluación: 5. Reconocer en obras de arte la utilización de distintos elementos y técnicas de expresión, apreciar los distintos estilos artísticos, valorar el patrimonio artístico y cultural como un medio de comunicación y disfrute individual y colectivo, y contribuir a su conservación a través del respeto y divulgación de las obras de arte.

\section{$1^{\circ} \mathrm{BCH}$}

En Griego I de $1^{\circ}$ de Bachillerato: Bloque 7. Léxico: Contenidos: Pervivencia de helenismos: términos patrimoniales, cultismos y neologismos.

Latín I, $1^{\circ}$ Bachillerato. Bloque 1. El latín, origen de las lenguas romances. Contenidos: Pervivencia de elementos lingüísticos latinos: términos patrimoniales y cultismos.

Latín I, $1^{\circ}$ Bachillerato. Bloque 1. El latín, origen de las lenguas romances. Criterios de evaluación: 4. Conocer y distinguir términos patrimoniales y cultismos.

Latín I, $1^{\circ}$ Bachillerato. Bloque 1. El latín, origen de las lenguas romances. Estándares de aprendizajes evaluables: 4.1. Explica e ilustra con ejemplos la diferencia entre palabra patrimonial y cultismo. 4.2. Conoce ejemplos de términos latinos que han dado origen tanto a una palabra patrimonial como a un cultismo y señala las diferencias de uso y significado que existen entre ambos. 
Latín I, $1^{\circ}$ Bachillerato. Bloque 5. Roma: historia, cultura, arte y civilización. Criterios de evaluación: 7. Identificar los rasgos más destacados de las edificaciones públicas y el urbanismo romano y señalar su presencia dentro del patrimonio histórico de nuestro país.

Latín I, $1^{\circ}$ Bachillerato. Bloque 5. Roma: historia, cultura, arte y civilización. Estándares de aprendizajes evaluables: 7.2. Localiza en un mapa los principales ejemplos de edificaciones públicas romanas que forman parte del patrimonio español, identificando a partir de elementos concretos su estilo y cronología aproximada.

Latín I, $1^{\circ}$ Bachillerato. Bloque 7. Léxico. Contenidos: Nociones básicas de evolución fonética, morfológica y semántica del latín a las lenguas romances. Palabras patrimoniales y cultismos.

\section{$2^{\circ} \mathrm{BCH}$}

En Economía de la Empresa de $2^{\circ}$ de Bachillerato: Bloque 6. La información de la empresa. Contenidos: La composición del patrimonio y su valoración.

En Economía de la Empresa de $2^{\circ}$ de Bachillerato: Bloque 6. La información de la empresa. Estándares evaluables:

1.1. Reconoce los diferentes elementos patrimoniales y la función que tienen asignada.

1.2. Identifica y maneja correctamente los bienes, derechos y obligaciones de la empresa en masas patrimoniales.

1.4. Detecta, mediante la utilización de ratios, posibles desajustes en el equilibrio patrimonial, solvencia y apalancamiento de la empresa

1.7. Reconoce la conveniencia de un patrimonio equilibrado.

En Geografía de $2^{\circ}$ de Bachillerato: Bloque 5. Los paisajes naturales y las interrelaciones naturaleza-sociedad. Contenidos: Políticas favorecedoras del patrimonio natural.

En Geología de $2^{\circ}$ de Bachillerato: Bloque 10. Geología del campo. Contenidos: Elementos singulares del patrimonio geológico del lugar donde se realiza la práctica.

En Criterios de evaluación: 7. Entender las singularidades del patrimonio geológico.

En estándares de aprendizaje evaluables: 7.1. Comprende la necesidad de apreciar, valorar, respetar y proteger los elementos del patrimonio geológico

En Griego II de $2^{\circ}$ de Bachillerato en Bloque 6. Léxico. Estándares de aprendizajes evaluables: 3.2. Reconoce y distingue a partir del étimo griego cultismos, términos patrimoniales y neologismos explicando las diferentes evoluciones que se producen en uno y otro caso.

Historia de España, $2^{\circ}$ Bachillerato. Introducción: A través del estudio de la Historia de España, los estudiantes deberán adquirir determinados valores y hábitos de comportamiento, como la actitud crítica hacia las fuentes, el reconocimiento de la diversidad de España, o la valoración del patrimonio cultural e histórico recibido; así mismo, tal estudio deberá contribuir a fomentar una especial sensibilidad hacia la sociedad del presente y su problemática, que anime a adoptar una actitud responsable y solidaria con la defensa de la libertad, los derechos humanos y los valores democráticos.

Historia de España, $2^{\circ}$ Bachillerato. Bloque 2. La Edad Media: Tres culturas y un mapa político en constante cambio. Criterios de evaluación: 2. Explicar la evolución y configuración política de los reinos cristianos, relacionándola con el proceso de reconquista y el concepto patrimonial de la monarquía.

Historia del Arte, $2^{\circ}$ Bachillerato. Introducción: Por último, el conocimiento de la Historia del Arte consolida en los alumnos y alumnas ciertos valores y actitudes fundamentales, como la capacidad de disfrute ante la 
contemplación del arte, el respeto por la creación artística, aunque no exento de espíritu crítico, y de forma muy especial la valoración del patrimonio artístico y la responsabilidad de su conservación, pues se trata de un legado que ha de transmitirse a las generaciones futuras.

Historia del Arte, $2^{\circ}$ Bachillerato. Bloque 1. Raíces del arte europeo: el legado del arte clásico. Criterios de evaluación: 5. Respetar las creaciones artísticas de la Antigüedad grecorromana, valorando su calidad en relación con su época y su importancia como patrimonio escaso e insustituible que hay que conservar.

Historia del Arte, $2^{\circ}$ Bachillerato. Bloque 2. Nacimiento de la tradición artística occidental: el arte medieval. Criterios de evaluación: 5. Respetar las creaciones del arte medieval, valorando su calidad en relación con su época y su importancia como patrimonio que hay que conservar.

Historia del Arte, $2^{\circ}$ Bachillerato. Bloque 3. Desarrollo y evolución del arte europeo en el mundo moderno. Criterios de evaluación: 5. Respetar las creaciones del arte de la Edad Moderna, valorando su calidad en relación con su época y su importancia como patrimonio que hay que conservar.

Historia del Arte, $2^{\circ}$ Bachillerato. Bloque 4. El siglo XIX: el arte de un mundo en transformación. Criterios de evaluación: 6. Respetar las creaciones del arte del siglo XIX, valorando su calidad en relación con su época y su importancia como patrimonio que hay que conservar.

Historia del Arte, $2^{\circ}$ Bachillerato. Bloque 6. La universalización del arte desde la segunda mitad del siglo XX. Contenidos: El patrimonio artístico como riqueza cultural. La preocupación por su conservación.

Historia del Arte, $2^{\circ}$ Bachillerato. Bloque 6. La universalización del arte desde la segunda mitad del siglo XX. Criterios de evaluación: 5. Explicar qué es el Patrimonio Mundial de la UNESCO, describiendo su origen y finalidad

Historia del Arte, $2^{\circ}$ Bachillerato. Bloque 6. La universalización del arte desde la segunda mitad del siglo XX. Criterios de evaluación: 7. Respetar las manifestaciones del arte de todos los tiempos, valorándolo como patrimonio cultural heredado que se debe conservar y transmitir a las generaciones futuras.

Historia del Arte, $2^{\circ}$ Bachillerato. Bloque 6. La universalización del arte desde la segunda mitad del siglo XX. Estándares de aprendizajes evaluables: 5.1. Explica el origen del Patrimonio Mundial de la UNESCO y los objetivos que persigue. 7.1. Realiza un trabajo de investigación relacionado con los bienes artísticos de España inscritos en el catálogo del Patrimonio Mundial de la UNESCO.

Latín II, $2^{\circ}$ Bachillerato. Bloque 1. El latín, origen de las lenguas romances. Contenidos: Pervivencia de elementos lingüísticos latinos en las lenguas modernas: términos patrimoniales, cultismos y neologismos.

Latín II, $2^{\circ}$ Bachillerato. Bloque 1. El latín, origen de las lenguas romances. Criterios de evaluación: 1. Conocer y distinguir términos patrimoniales y cultismos.

Latín II, $2^{\circ}$ Bachillerato. Bloque 1. El latín, origen de las lenguas romances. Estándares de aprendizajes evaluables: 1.1. Reconoce y distingue a partir del étimo latino términos patrimoniales y cultismos explicando las diferentes evoluciones que se producen en uno y otro caso.

Latín II, $2^{\circ}$ Bachillerato. Bloque 6. Léxico. Contenidos: Evolución fonética, morfológica y semántica del latín a las lenguas romances. Palabras patrimoniales y cultismos.

Literatura Universal. $2^{\circ}$ Bachillerato. Introducción: La lectura de textos procedentes de la Literatura Universal interviene en el proceso de maduración afectiva, intelectual y estética de los jóvenes, pues el conocimiento de esta parte fundamental del patrimonio cultural de la humanidad, en la que se han ido depositando la imaginación, sentimientos y pensamientos de las distintas culturas a lo largo de la historia, conduce a los estudiantes a profundizar en la comprensión de la propia identidad, tanto individual como colectiva, así como a valorar de forma crítica la realidad del mundo contemporáneo. La lectura de fragmentos u obras completas representativas del 
patrimonio literario universal permite al alumnado conocer otras realidades sociales y culturales, enriquecer su personalidad, ampliando su visión del mundo, y afianzar sus hábitos lectores, desarrollando su sentido estético.

Fundamentos de Administración y Gestión. $2^{\circ}$ Bachillerato. Bloque 7. Gestión de la contabilidad de la empresa. Estándares de aprendizajes evaluables: 1.1. Maneja los elementos patrimoniales de la empresa, valora la metodología contable y explica el papel de los libros contables.

No se puede olvidar la competencia clave (García y Criado, 1999; Casal, 2003; Alcina, 2003) denominada Competencia en conciencia y expresiones culturales, que relaciona directamente la educación con patrimonio en toda su extensión, para conocerlo, comprenderlo, cuidarlo, transmitirlo y socializarlo.

\subsection{Inclusión del patrimonio en la enseñanza autonómica: nivel MICRO}

Castilla León es una Comunidad autónoma con 2156 bienes de interés cultural, aspecto relevante para la mejora de la economía y la educación de un pueblo, ya que los bienes de patrimonio son demandados cada vez con mayor intensidad por un número creciente de turistas (Velasco, 2009).

Según el Anuario de Estadísticas Culturales 2013 del Ministerio de Educación, Cultura y Deportes, Castilla y León es la quinta Comunidad en Bienes de Interés Cultural en España (la cuarta Comunidad de España en número de Bienes inmuebles de Interés Cultural y la octava en Bienes muebles). Canto y Moral (2004) aseguran que un grupo social es la colección de dos o más personas que, al poseer la misma identidad social, se identifican a sí mismos del mismo modo y poseen la misma definición de quiénes son, de cuáles son sus atributos y cómo se relacionan y se diferencian de los exogrupos. Este es el caso de Castilla y León, diferenciando a sus ciudadanos del resto de comunidades autónomas.

Teniendo en cuenta lo anterior, para valorizar el patrimonio cultural de Castilla y León, se realiza desde el área científica de Educación Patrimonial. Esta área se rige bajo dos ejes fundamentales en cuestión de normativa: el Plan Nacional de Educación y Patrimonio y la ley educativa adaptada a dicha comunidad.

El debate estratégico en la Junta de Castilla y León se centra en la aplicación o no del Reglamento del Uno por ciento cultural sobre la creación de la Red de Espacios 
Culturales y el Instituto de Patrimonio Cultural, así como la elaboración de un análisis del estado de los bienes culturales.

Los planes de la Junta sobre el Patrimonio se denominan Plan de intervención en el Patrimonio (PAHIS) y son cuatrienales, un Plan PAHIS acabó en 2012 y otro entró en vigor en 2015 hasta 2019.

En 2020 entra en vigor el Plan PAHIS 2020. El Plan se estructura en cinco ejes estratégicos, contiene 28 objetivos promocionados a través de 26 programas, que contendrán 139 acciones, todos estos proyectos y actividades, serán promovidos y ejecutados directamente por la Consejería de Cultura y Turismo o en otro caso, concertados y coordinados con otras instituciones, titulares y gestores, intentando integrar todas estas iniciativas en el marco general del Plan.

El Plan PAHIS 2020 se articula en torno a cinco principios fundamentales:

- Sociedad, fomentando el empleo en sectores afines al patrimonio y aumentando la calidad de vida.

- Conocimiento, fomentando la investigación y la trasferencia de conocimiento hacia la sociedad mediante proyectos, divulgación etc.

- Sistema, partiendo de la vinculación de los actores se buscará la mayor coordinación de todas las acciones.

- Territorio, se pretende conjugar el desarrollo socioeconómico con la promoción del patrimonio.

- Cooperación entre todos los actores públicos y privados para la protección, investigación y promoción del patrimonio.

El Plan PAHIS 2020 se complementa con otros planes sectoriales paralelos como el Plan Jacobeo 2021, el Plan de investigación, conservación y difusión en materia de Arqueología (2018-2024), o el Plan de inspección de los Bienes culturales de CastillaLeón (2017-2020).

La Junta de Castilla y León cuenta con un Centro de Conservación y Restauración de Bienes culturales con especial dedicación a los bienes muebles patrimoniales.

Debido a una serie compleja de factores Castilla y León suma ya 216 bienes culturales en peligro incluidos en la Lista Roja, por 77 de Andalucía, 65 de Castilla-La Mancha y 63 de Aragón. 
Por tales factores complejos según los datos de Hispania Nostra en 2014, se especifica que en cuatro años se ha pasado de 136 monumentos en 2010 en dicha situación a haberse disparado en 2014 a 216.

La Lista Roja aumentó un 53 \% desde junio de 2011 -son ya 216 monumentos en peligro- el resto de los puntos críticos de debate estratégico son los presupuestos destinados a inversión, la inyección de recursos que puede dar el 1\% cultural, el expolio de los yacimientos arqueológicos y la estadística del empleo cultural.

\subsubsection{Plan de Intervención en el Patrimonio Documental}

Respecto al patrimonio documental y archivístico destacamos el siguiente decreto de 2010:

- ACUERDO 18/2010, de 18 de febrero, de la Junta de Castilla y León, por el que se aprueba el III Plan de Intervención en el Patrimonio Documental de Castilla y León 2010- 2015.

Se diseñarán y se pondrán en marcha campañas dirigidas a los estudiantes de educación secundaria y bachillerato, que tendrán por objetivo el que los jóvenes conozcan, de un modo práctico, diferentes aspectos de la Administración autonómica y de la archivística a través de sus documentos.

\subsubsection{Ley educativa autonómica}

Se deben resaltar aspectos como la estrategia de educación patrimonial, incluida en el currículo de bachillerato de 2008, con especificaciones referentes a los diversos tipos de patrimonio a desarrollar en cada asignatura.

Así mismo, hay que destacar ampliaciones contemporáneas del concepto de patrimonio hacia ámbitos como el medio ambiente, recogido en la enseñanza de la Biología, o es ámbito de la Economía, enlazando patrimonio con recursos productivos en Castilla León.

Por el contrario, se echa de menos la suficiente mención de ciertos tipos de patrimonio como el lingüístico, de la Lengua castellana, el inmaterial, el de bienes muebles en general o el archivístico y documental, aunque este último sí aparece en el acuerdo de 2010 que hemos citado anteriormente.

- DECRETO 42/2008, de 5 de junio, por el que se establece el currículo de bachillerato en la Comunidad de Castilla y León.

Entre los objetivos generales recoge: 
"Conocer, valorar y respetar la historia, la aportación cultural y el patrimonio de España y de cada una de las Comunidades Autónomas."

Entre los objetivos de Educación Física recoge:

“Juegos y deportes propios de Castilla y León: profundización en el conocimiento y dominio de sus aspectos técnicos y reglamentarios. Valoración como patrimonio cultural y como medio para el recreo y el ocio."

Entre los objetivos de Artes Escénicas recoge:

“Asistir, siempre que sea posible, a espectáculos escénicos. Valorar y disfrutar de las artes escénicas como una manifestación artística que forma parte del patrimonio cultural común de los pueblos y participar activamente en su mantenimiento, desarrollo y proyección."

Y entre los criterios de evaluación de Artes Escénicas:

"Valorar y disfrutar de las artes escénicas de Castilla y León como una manifestación artística que forma parte de su patrimonio cultural"

En la introducción a Historia del Arte recoge:

"La materia contribuye, además, a la valoración y disfrute del patrimonio artístico, que en sí mismo, como legado de una memoria colectiva o desde la consideración del potencial de recursos que encierra, exige desarrollar actitudes de respeto y conservación para transmitirlo a las generaciones del futuro."

Entre los objetivos de Historia del Arte recoge:

"Conocer, disfrutar y valorar el patrimonio artístico internacional, de España y de Castilla y León, incluidos los museos, contribuyendo de forma activa a su conservación como fuente de riqueza y legado que debe transmitirse a las generaciones futuras rechazando aquellos comportamientos que lo deterioran."

Como contenidos:

"Arte y cultura visual de masas: el arte como bien de consumo. La preocupación por el patrimonio artístico y su conservación."

Entre los objetivos de Historia de la Música recoge:

"Conocer y valorar el patrimonio artístico de la música y de la danza como parte integrante del patrimonio histórico y cultural, reconociendo las aportaciones significativas realizadas desde España."

Entre los objetivos de Enseñanza de la Biología recoge:

"Integrar la dimensión social y tecnológica de la biología y la geología, comprendiendo las ventajas y problemas que su desarrollo plantea al medio natural, al 
ser humano y a la sociedad, para contribuir a la conservación y protección del patrimonio natural."

\section{Como contenidos:}

"La biosfera como patrimonio y como recurso frágil y limitado. Impactos sobre la biosfera: deforestación y pérdida de biodiversidad. La biodiversidad en Castilla y León."

Entre los objetivos de Enseñanza de la Economía recoge:

"El medio ambiente, la cultura y el patrimonio histórico como elementos determinantes de una estrategia de desarrollo sostenible de la Comunidad Autónoma de Castilla y León."

\section{En la Introducción al Griego:}

"Asimismo, es imprescindible contar, como apoyo y complemento, con los medios audiovisuales e informáticos para identificar y valorar los factores culturales heredados de los griegos que se han convertido en patrimonio universal (...)” En los objetivos:

"Valorar los factores culturales heredados de los griegos que se han convertido en patrimonio universal (...)”

Respecto al currículo de Educación Secundaria se encuentran las referencias al patrimonio recogidas en el mismo, diferenciándolas por asignaturas.

Este currículo nos muestra interesantes aportaciones más allá de una visión obsoleta del patrimonio, ceñida a una sucesión de monumentos arquetípicos y sus características. Por el contrario, entiende el patrimonio inserto en las dinámicas sociales y de organización fluida de las sociedades. En este sentido explicita el disfrute del Arte o el respeto general a lo patrimonial como reflexiones pedagógicas de fondo.

El currículo atiende a las cuestiones contemporáneas de la diversidad lingüística y cultural de todo el territorio nacional y el europeo. En general, es reflejo en todas las materias del enfoque autonomista de los contenidos que viene dándose a la educación desde la llegada de la democracia.

Igualmente se recogen aspectos trasversales, como, por ejemplo, la integración del patrimonio natural (en Educación física).

La educación artística contempla la diversidad de estilos en el espacio y en el tiempo. Las tensiones teóricas respecto a este currículo son por una parte el equilibrio (o desequilibrio) entre la ambición de objetivos en relación con la dotación de horas 
lectivas y medios materiales y humanos para conseguirlos. Se puede notar al respecto, la profusión de objetivos y competencias de las tendencias contemporáneas que hemos enumerado y que coexisten con los contenidos de conocimiento de la cultura clásica y el conocimiento clásico del patrimonio.

- ORDEN EDU/362/2015, de 4 de mayo, por la que se establece el currículo y se regula la implantación, evaluación y desarrollo de la educación secundaria obligatoria en la Comunidad de Castilla y León.

En la introducción a Geografía e Historia:

"La aproximación particular a las manifestaciones artísticas será necesaria para significar el esfuerzo creativo del ser humano a través del tiempo y, consiguientemente, para valorar en su riqueza y variedad el patrimonio cultural"

\section{Contenidos de $2^{\circ}$ :}

"El patrimonio artístico medieval."

En la introducción al Latín:

“...va a permitir acceder a los grandes legados de la cultura occidental al poner en contacto con el rico patrimonio literario, cultural y jurídico de la antigua Roma..."

\section{En los contenidos de $\mathbf{2}^{\mathbf{}}$ de Lengua Castellana y Literatura}

“Conocimiento de los orígenes históricos de la realidad plurilingüe de España y valoración como fuente de enriquecimiento personal y como muestra de la riqueza de nuestro patrimonio histórico y cultural."

Y en los criterios de evaluación de $\mathbf{2}^{\mathbf{0}}$ :

"Valorar como patrimonio de todos los españoles la riqueza lingüística y cultural de España y considerar las diferentes situaciones que originan las lenguas en contacto."

\section{En la introducción a Cultura Clásica:}

"este léxico hoy es patrimonio de la humanidad e instrumento de comunicación en el universo entero."

“Ambas culturas son modelos y precedentes de muchas de las producciones actuales y sus vestigios perviven aún como parte de nuestro patrimonio histórico."

\section{En criterios de evaluación de $\mathbf{2}^{\circ}$ :}

“Conocer algunos de los monumentos clásicos más importantes del patrimonio español." 


\section{En criterios de evaluación de $4^{\mathbf{0}}$ :}

“Conocer y saber localizar los principales monumentos clásicos del patrimonio español y europeo"

En los contenidos de $3^{\circ}$ y $\mathbf{4}^{\circ}$ de Educación Física:

"Valoración de las danzas folclóricas como parte del patrimonio cultural y como elemento de relación con los demás."

"Valoración del patrimonio natural como fuente de recursos para la práctica de actividades físicas y recreativas"

\section{En Educación Plástica, Visual y Audiovisual}

En los contenidos de $3^{\circ}$ y $4^{\circ}$ cursos:

"Diferenciación de los distintos estilos y tendencias de las artes visuales y

audiovisuales valorando, respetando y disfrutando del patrimonio histórico y cultural" En los criterios de evaluación:

"Identificar y reconocer los diferentes lenguajes visuales apreciando los distintos estilos y tendencias, valorando, respetando y disfrutando del patrimonio histórico y cultural”.

"valorar el patrimonio artístico y cultural como un medio de comunicación y disfrute individual y colectivo, y contribuir a su conservación a través del respeto y divulgación de las obras de arte."

\section{En la introducción a Música:}

“” Contextos musicales y culturales" relaciona la música con la cultura y la historia, da a conocer el valor del patrimonio musical español y enseña a identificar el estilo y las características distintivas de la música que delimitan cada uno de los periodos históricos básicos.”

En los criterios de evaluación de $\mathbf{2}^{\mathbf{0}}$ :

"Apreciar la importancia del patrimonio cultural español, en particular el de Castilla y León, y comprender el valor de conservarlo y transmitirlo."

En los contenidos de $4^{\circ}$ :

"El patrimonio musical español: características más importantes de la Música española."

\section{En la introducción a Lengua y Cultura Gallega}

"que el alumnado valore el patrimonio cultural y lingüístico que le rodea y contribuya a conservarlo, entendiendo éste como una fuente de riqueza personal, social y cultural. 
Bajo esta consideración, el aprendizaje de esta materia ayudará a que el alumnado muestre interés y respeto por la realidad plurilingüe del Estado español."

Entre las competencias a evaluar en los informes finales dentro del epígrafe:

"Conciencia y expresiones culturales", se recoge la competencia:

"Muestra interés por participar en las actividades culturales y por contribuir a la conservación del patrimonio artístico y cultura"

\subsubsection{Plan autonómico de educación y patrimonio}

En 2012 se redacta a nivel nacional el Plan Nacional de Educación y Patrimonio (PNEyP en adelante). A nivel autonómico de Castilla León no se ha redactado posteriormente un Plan regional paralelo. Por lo cual los programas, líneas de actuación y actuaciones han de partir en su fundamentación estratégica en su caso del citado PNEyP.

El componente autonómico del PNEyP vendría dado en todo caso por la importancia que en el mismo tienen órganos y personas concretos de Castilla León, destacando el Observatorio de Educación patrimonial en España (OEPE).

Podemos entonces ir seguidamente encuadrando en las estrategias del PNEyP los proyectos autonómicos que se están llevando a cabo, alertando de que la necesaria coordinación e implementación de medios pudiera partir de elaboración de un Plan regional.

El área institucional de la Junta de Castilla y León de conocimiento y difusión de Patrimonio cuenta con las siguientes acciones:

\section{CONOCIMIENTO Y DIFUSIÓN DEL PATRIMONIO}

El PNEyP aborda las TIC fomentando la diversidad de formatos a utilizar y la diversidad de los públicos objetivo de educandos. Podemos enumerar varias iniciativas TIC en Castilla León como las siguientes, observando que se debería profundizar en el futuro tanto en la diversidad de formatos y públicos:

- Visitas virtuales a través de la web de la Junta de Castilla y León.

- Documentales: Edición, producción y difusión de documentales en Jornadas y a través de la web de Junta de Castilla y León.

- Programas interactivos multimedia a través de la web de la Junta de Castilla y León.

- Exposiciones virtuales.

El PNEyP aboga por una exposición contextualizada de los bienes patrimoniales. De hecho, la idea teórica de la educación patrimonial la entiende como comprensión de las 
sociedades y la historia en toda su complejidad. En este sentido los proyectos de Itinerarios culturales y el resto que enumeramos engloban en conjuntos significativos los diferentes bienes culturales. Así se establecen rutas como "Caminos de la lengua castellana", "Los caminos de Santiago de Compostela", "Lugares cluniacenses en Europa".

- Exposiciones de patrimonio cultural, In situ, bienes inmuebles, muebles, arqueológicos, conceptuales.

- Itinerarios culturales.

- Enclaves patrimoniales.

El programa siguiente, en la misma línea de la interpretación holística del patrimonio, incluye además la interpretación geográfica del territorio como integrada con la comprensión cultural global de los bienes inmuebles o arqueológicos de varios lugares.

- Aulas al aire libre.

El PNEyP insiste en la pluralidad de públicos objetivo de la educación patrimonial concretando la diversidad tanto en las edades, como en el nivel socioeducativo. Hace una especial mención a la educación inclusiva respecto a la discapacidad, lo que se concreta en Castilla y León en el proyecto siguiente, que cuenta con una carta teórica "Monumentos para todos" y una red de monumentos accesibles. Monumentos para todos: Cuenta con monumentos accesibles incluidos en un catálogo, para los diversos tipos de discapacidad y con las correspondientes adaptaciones físicas y de recursos educativos.

\section{DIDÁCTICA Y FORMACIÓN}

- Cursos o jornadas técnicas: El PNEyP aborda de forma profunda la formación en educación patrimonial tanto en Educación formal como no formal e informal. La traslación a Junta de Castilla y León se hace mediante Cursos o jornadas técnicas. Podemos observar que la mayoría se hacen sobre bienes o territorios muy concretos, aunque puedan tener un enfoque científico diferente, primando por ejemplo lo arqueológico, lo estratégico-turístico, etc. Lo mismo se puede decir de las conferencias o presentaciones. Respecto a las jornadas más genéricas destacamos el evento ARPA, bienal Iberia de Patrimonio cultural o las jornadas de Gestión de emergencias en el Patrimonio cultural de Castilla León.

- Elaboración y difusión de unidades didácticas. La web de la Junta de Castilla y León patrimoniocultural.jcyl.es ofrece algunas unidades didácticas de acceso libre. 
- Concurso piedras preciosas de la Fundación Santa Ma La Real de Patrimonio Histórico para $5^{\circ}$ y $6^{\circ}$ de Primaria sobre documentales o videos sobre patrimonio cultural. El PNEyP insta a la utilización de muchos formatos de TIC y a la iniciativa de los propios alumnos en la vinculación hacia el patrimonio cultural y la posterior edición de productos, como se desarrolla en este proyecto.

\section{PATRIMONIO NATURAL}

En este apartado se desarrolla también el enfoque sistémico y holístico que se encuentra en el PNEyP referido esta vez a un sector del patrimonio como es el Patrimonio Natural. Está recogido como objetivo explícito y como diseño de actividades: la integración de todos los agentes socioeconómicos que participan en el contexto educativo.

Así, del Patrimonio Histórico se ha pasado al Patrimonio Cultural, mostrando una perspectiva sistémica, integradora y compleja, donde los referentes patrimoniales se articulan como un único hecho sociocultural, constituido de manera holística por manifestaciones de carácter diverso -histórico, artístico, etnológico, científico tecnológico y natural-, que en conjunción permiten el conocimiento de las diferentes sociedades tanto del pasado como del presente. (PNEyP. Ministerio de Educación y Formación Profesional, 2012)

Por Acuerdo de 5 de septiembre de 2002, la Junta de Castilla y León aprobó el "Programa Parques Naturales de Castilla y León”, que pretende como objetivo principal convertirse en la referencia básica del desarrollo sostenible para los Espacios Naturales de esta Comunidad, donde se pretende coordinar a los actores y sectores afines a esta área.

Se persigue integrar las acciones de Naturaleza, ocio y tiempo libre, y tiene en la actualidad grandes posibilidades del sector servicios en el medio natural. Esta oportunidad de desarrollo depende de la correcta conservación de un patrimonio natural, planificando y gestionando estas actividades según criterios de sostenibilidad. Para todo ello, el Programa Parques Naturales de Castilla y León es el resultado de la coordinación entre tres ideas fundamentales: la potencialidad de uso público del patrimonio natural, a la que se suma la potenciación específica del patrimonio cultural y etnográfico de Castilla y León, así como la aplicación al mundo rural de las modernas tecnologías de las telecomunicaciones.

Los objetivos que pretende cumplir el Programa se resumen en: 
- Poner en valor los recursos naturales de la Comunidad de forma coordinada con su conservación y la evolución de su entorno.

- Crear las dinámicas necesarias para el desarrollo de las actividades de uso público y socioeconómicas compatibles con la conservación de la Red de Espacios Naturales (REN).

- Promover la divulgación, el conocimiento y el disfrute de los valores que ofrece la REN de Castilla y León, en sintonía con difusión de los valores histórico-culturales y de las actividades rurales y tradicionales.

- Integrar activamente a la población local del entorno de los espacios de la REN en la "Sociedad de la Información", mediante el fomento significativo de las tecnologías de la información y de las comunicaciones.

- Fomentar la participación social en el desarrollo sostenible de los Espacios Naturales Protegidos.

- Promover la calidad de vida de los habitantes de los espacios mediante el desarrollo de infraestructuras y servicios locales y necesarios.

- Ayudar en la creación de empleo y fijar la población local de las zonas correspondientes socioeconómicas de los espacios de la REN.

La REN se estructura en "Casas del Parque" de cada especio natural. Cada una cuenta con guías y unidades didácticas y una estructura de visitas dentro del programa VEEN (Visitas escolares a los Espacios Naturales):

- Recepción - bienvenida.

- Visita guiada a la exposición.

- El "rincón de la memoria".

- Temática: geografía, y flora y fauna.

- El arte (por ejemplo: románico y la arquitectura medieval).

- Los cuadernillos didácticos adaptados a 3 niveles educativos diferentes, que complementan la visita.

- Audiovisual este vídeo nos enseña las características generales del espacio natural y de sus habitantes.

- Talleres.

- Juegos adaptados a los niveles educativos.

- Itinerarios didácticos.

- Itinerario guiado, flora y fauna. 
- Actividades de Educación Ambiental.

- Aparte del programa ofrecido, podrá planificar junto al equipo educativo actividades "a medida "según niveles educativos e intereses del profesorado.

\section{FUNDACIONES}

El PNEyP contempla explícitamente la participación de Fundaciones en la financiación de programas, estrategia que ha sido empleada en Castilla León a través de varias Fundaciones. Algunas de las más destacadas relativas al Patrimonio y la Educación patrimonial se encuentran en la Tabla 3.

También organismos de la Administración Local, fundaciones, asociaciones u otras instituciones podrán llevar a cabo acciones en el ámbito de la educación patrimonial que puedan ser incluidas en el Plan Nacional (PNEyP. Ministerio de Educación y Formación Profesional 2012)

Tabla 3

Fundaciones que desarrollan Educación Patrimonial en Castilla y León

\begin{tabular}{ll}
\hline FUNDACIÖN & LOCALIDAD \\
\hline F. Santa María la Real PH & Valladolid \\
\hline F. Villalar & Valladolid \\
\hline F. Prada a tope & León \\
\hline F. Las Médulas & León \\
\hline $\begin{array}{l}\text { F. General de la Universidad de } \\
\text { Salamanca }\end{array}$ & Salamanca \\
\hline $\begin{array}{l}\text { F. General de la Universidad de } \\
\text { Valladolid }\end{array}$ & Valladolid \\
\hline F. Inea & Valladolid \\
\hline $\begin{array}{l}\text { F. del Patrimonio Natural de Castilla y } \\
\text { León }\end{array}$ & Valladolid \\
\hline F. Museo Judío David Melul & Salamanca \\
\hline $\begin{array}{l}\text { F. Museo Ángel Mateos de Escultura } \\
\text { en Hormigón }\end{array}$ & Salamanca \\
\hline F. Biblioteca de Ciencia y Artillería & Segovia \\
\hline F. Caja Segovia & Segovia \\
\hline F. Re-habitar Tierra de Campos & Valladolid \\
\hline F. Laciana Reserva de la biosfera & León \\
\hline $\begin{array}{l}\text { F. VIII Centenario de la Catedral. } \\
\text { Burgos 2021 }\end{array}$ & Burgos \\
\hline $\begin{array}{l}\text { F. para el estudio de los Dinosaurios } \\
\text { en Castilla y León }\end{array}$ & Burgos \\
\hline F. Las Edades del Hombre & Valladolid \\
\hline
\end{tabular}




\subsection{FORMACIÓN DE PROFESORADO}

Un tópico importante en cualquier investigación sobre educación ha de ser sin duda la formación del profesorado, ya que el profesorado es un agente importante en el proceso de enseñanza-aprendizaje.

Para conseguir que el alumno se apropie simbólicamente del Patrimonio, el educador necesita ampliar sus conocimientos en otros ámbitos relacionados con la naturaleza dinámica y cambiante de los elementos que lo integran, con su gestión y con la metodología docente específica que requiere su enseñanza. (PN, 2015, p.6)

A nivel nacional no existe un Grado universitario que desarrolle todas las competencias en el ámbito de la educación patrimonial, aunque sí existen universidades con el grado en Maestro de educación primaria que se encargan de ciertos contenidos de este ámbito, sobre todo en los departamentos relacionados con las ciencias sociales y las artes (Fontal et al., 2017), como es el caso de ese grado en la Universidad de Granada (ver tabla $\mathrm{xxx}$ ). Y en ese mismo estudio, la mayoría de las veces, el concepto de patrimonio se tenía en cuenta en las asignaturas mayoritariamente optativas, no en las obligatorias, suponiendo una carencia en el tema para aquel alumnado que no elige estas asignaturas, siendo su formación en este tema escasa o nula.

En otro estudio longitudinal realizado por Domínguez y Facal (2017) en estudiantes de grado en Maestro de educación primaria, se demuestran las competencias adquiridas por siete maestros en formación que diseñaron un proyecto didáctico de forma colaborativa y en la asignatura de Prácticum. En este trabajo que se realizó entre 2013-2015 en dos fases se ha llegado a "comprobar cómo el alumnado, a medida que adquiere una valoración social de los paisajes de su entorno, se apropia de ellos" (Domínguez y López-Facal, 2017, p.58). Y de este estudio se puede extraer la idea de que aquellos maestros que forman parte de este tipo de proyectos es posible que sean portadores futuros de ideas que desarrollen la educación patrimonial en el aula.

En cuanto a secundaria, el profesorado dedicado a esta etapa educativa puede recibir formación de un abanico de carreras de nueva creación en las que se encuentra la palabra patrimonio dentro de su plan de estudios basado en el Plan Bolonia como, puede apreciarse en la Tabla 4:

Tabla 4 
Relación de Grados y universidades que incluyen "patrimonio" en su plan

\begin{tabular}{|c|c|}
\hline GRADO & LUGAR \\
\hline Humanidades & $\begin{array}{l}\text { Universidad Oberta de Catalunya } \\
\text { Universidad Abierta de Barcelona } \\
\text { Universidad Pablo de Olavide } \\
\text { Universidad Pompeu Fabra } \\
\text { Universidad de Alicante }\end{array}$ \\
\hline Historia & $\begin{array}{l}\text { Universidad a Distancia de Madrid } \\
\text { Universidad de Córdoba } \\
\text { Universidad de Oviedo } \\
\text { Universidad de Alicante } \\
\text { Universitat Rovira i Virgili } \\
\end{array}$ \\
\hline Musicología & Universidad Internacional de Valencia \\
\hline Humanidades y Patrimonio & Universidad de Castilla-La Mancha \\
\hline Humanidades: estudios interculturales & Universidad Jaume I \\
\hline Humanidades y estudios culturales & Universidad Internacional de Catalunya \\
\hline Humanidades y Antropología Social & Universidad Católica de Sana Antonio \\
\hline Humanidades: Historia Cultural & Universidad de Castilla-La Mancha \\
\hline Historia del Arte & $\begin{array}{l}\text { Universidad de Oviedo } \\
\text { Universidad de Córdoba } \\
\text { Universidad de Murcia } \\
\text { Universidad Islas Baleares } \\
\text { Universidad Autónoma de Barcelona } \\
\text { Universitat Rovira i Virgili } \\
\text { UNED Garrotxa } \\
\text { UNED }\end{array}$ \\
\hline Geografía e Historia & $\begin{array}{l}\text { Universidad Pablo de Olavide } \\
\text { Universidad Isabel I on-line }\end{array}$ \\
\hline Humanidades y estudios sociales & Universidad de Castilla-La Mancha \\
\hline Turismo & $\begin{array}{l}\text { Universidad de Huelva } \\
\text { Universidad de La Rioja } \\
\text { Universidad de Oviedo }\end{array}$ \\
\hline $\begin{array}{l}\text { Educación Infantil, Primaria y Humanidades y estudios } \\
\text { culturales }\end{array}$ & $\begin{array}{l}\text { Universidad internacional de Catalunya } \\
\text { Universidad de Valladolid }\end{array}$ \\
\hline Historia y Ciencias de la Música & Universidad de Granada \\
\hline Antropología Social y Cultural & Universidad de Barcelona \\
\hline Lengua y literatura catalanas & Universitat Rovira i Virgili \\
\hline Maestro en Educación Primaria & Universidad de Granada \\
\hline Español, lengua y literatura & Universidad de Valladolid \\
\hline Conservación y restauración de bienes culturales & Universidad de Barcelona \\
\hline Estudios árabes e islámicos & $\begin{array}{l}\text { Universidad de Alicante } \\
\text { Universidad de Granada }\end{array}$ \\
\hline Información y Documentación & Universidad de León \\
\hline Geografía y gestión del territorio & Universidad de Granada \\
\hline Lengua y Literatura Hispánicas & Universitat Rovira i Virgili \\
\hline Lenguas modernas y sus literaturas & Universidad de Granada \\
\hline
\end{tabular}


Muchos de los grados que se imparten en distintas universidades no recogen asignaturas relacionadas con el patrimonio. Sin embargo, existe la opción de cursar un Máster.

También con la Declaración de Bolonia, acuerdo que en 1999 firmaron los ministros de Educación de diversos países de Europa (tanto de la Unión Europea como de otros países como Rusia o Turquía), en la ciudad italiana de Bolonia, han proliferado los cursos de Máster y se encuentran por todo el territorio nacional aquellos que se relacionan con el patrimonio, como el Máster en evaluación y gestión del patrimonio cultural de la Universidad de Salamanca, o el Máster universitario en Patrimonio Histórico y Cultural de la Universidad de Huelva, como ejemplos.

Con estos datos se traza un mapa de los medios para la formación del profesorado en educación patrimonial en España. Normalmente es profesorado interesado por las ciencias sociales, humanidades o artes en general y que hacen una inmersión en el ámbito por interés particular. Este aspecto es importante en cuanto a la probabilidad de que en el futuro haya alumnado susceptible de conocer conscientemente el patrimonio personal y cultural de su entorno y de otras culturas, gracias a un profesorado que tenga en cuenta el patrimonio como eje transversal en el currículo. 
Yo creo que hay entre nosotros una especie de mito de la aprobación, de mito de la reprobación. Yo encuentro que no hay práctica que no deba ser evaluada. Toda práctica exige de un lado, su programación, del otro, su evaluación. La práctica tiene que ser pensada constantemente. La planificación de la práctica tiene que ser permanentemente rehecha y es rehecha en la medida en que permanentemente es evaluada.

\section{P. Freire}




\section{LA EVALUACIÓN EN LA EDUCACIÓN FORMAL}

\subsection{Introducción}

El capítulo 2 aborda el núcleo temático de la Evaluación, concepto clave de esta tesis.

En él se hace un análisis, tanto conceptual, como paralelamente histórico del concepto. La polisemia de la evaluación que se ve claramente en lengua inglesa nos demuestra la complejidad y proliferación de teorías y terminología que ha reunido la palabra.

El análisis histórico abarca desde finales del S XIX a la actualidad. Los dos términos clave conceptualmente serán evaluation y assessment. Ambos corresponden sucesivamente a enfoques más interpretativos el primero, y cuantitativos el segundo. Las etapas históricas harán inclinar la balanza a uno u otro lado; y la época contemporánea se caracterizará por la multiplicación de términos polisémicos respecto a evaluación debido a la diversidad de corrientes de pensamiento y praxis educativa. Se estudiarán los hitos históricos del período tyleriano, de mediados del siglo XX; la Guerra Fría, y su correspondiente apremio de rendición de cuentas económicas, estratégicas y administrativas, lo que generó un auge del assessment desde diversas corrientes evaluativas.

Posteriormente se estudiará la cuarta generación sensible (década 70-90), y actualmente la época de la profesionalización.

Mención especial, por la influencia en nuestra tesis, merece la evaluación sensible y constructivista, que se apoya en la metodología constructivista y la evaluación responsable de Stake.

En el siglo XXI el cambio epistemológico que se produce realmente es entre el evaluador y la realidad, con la afloración de las corrientes relativistas, las cuales consideran relevante el fomento del intercambio de opiniones, valores y experiencias de los agentes implicados en la evaluación, mediante métodos participativos, lo cual generará una interacción cada vez más fructífera entre métodos de evaluación y de assessment; todos estos aspectos definen el panorama contemporáneo del tema. Posteriormente, se hace un análisis de los informes PISA como elemento pragmático donde confluyen todas estas cuestiones históricas y teóricas que se han planteado en la primera parte del capítulo.

La importancia social (y sociológica) de los resultados de PISA, hace que se cuestionen por parte de todos los actores implicados, tanto las pruebas utilizadas, como las poblaciones y correlaciones, donde se especifica que se utilizan sesgos correspondientes 
a distintos intereses o prevalencias por territorios, e igualmente sesgos de teorización educativa; y todos son debatidos y rebatidos.

Por último, la evaluación de programas corre paralela al desarrollo histórico que hemos visto en la conceptualización, evidenciando las etapas tylerianas mencionadas y de necesidad de resultados en los años 60, o de multifuncionalidad y diversidad en el mundo contemporáneo.

\subsection{Clarificación conceptual de evaluación}

El origen de la palabra evaluación se encuentra en el vocablo del latín valore, que significa tasar, valorar o atribuir valor a una cosa. En la lengua española se muestra, por tanto, una clara descendencia etimológica al considerar sinónimos los términos valorar y evaluación. Aunque pese a tal sinonimia, existen matices y diferencias en su aplicación, puesto que, incluso atendiendo a cuestiones de valoración social, se estima más el término valorar. En otras lenguas, como la inglesa, se realizan distinciones entre términos, como evaluation o assessment, si se evalúan objetos o personas. (Expósito, 2002).

La evaluación es un término más amplio que la medición. Es más integral que lo meramente inclusivo del término medición. Se adelanta a la medición, que simplemente indica el valor numérico. Da el juicio de valor al valor numérico. Incluye cualidades tangibles e intangibles.

Encontramos diferentes definiciones desde el ámbito educativo:

James M. Bradfield (1957):

La evaluación es la asignación de símbolos a un fenómeno, para caracterizar el valor o valor de un fenómeno, generalmente con referencia a algunos estándares culturales o científicos.

Thorndike y Hegan (1977):

El término evaluación está estrechamente relacionado con la medición. Es, en cierto sentido, inclusivo, incluido el juicio informal e intuitivo del progreso del alumno. La evaluación es describir algo en términos de ciertos atributos seleccionados y juzgar el grado de aceptabilidad o idoneidad de lo que se ha descrito.

Norman E. Gronlund y Robert L. Linn (1965):

La evaluación es un proceso sistemático de recopilación, análisis e interpretación de información para determinar en qué medida los alumnos son objetivos del logro educativo.

Good, C.V. (1936): 
El proceso de determinar o juzgar el valor o la cantidad de algo mediante el uso de un estándar o una evaluación estándar incluye el juicio en términos de comprobación interna y criterios externos.

De las definiciones anteriores se puede decir que la evaluación es un término mucho más completo e inclusivo que la medición y la prueba. Una prueba es un conjunto de preguntas que consiste en asignar números a los resultados de la prueba de acuerdo con algunas reglas específicas, por otro lado, la evaluación agrega juicio de valor. Por ejemplo, cuando decimos que alguien puntuó 45 en aritmética, simplemente indica cuánto ha respondido esa persona con éxito. No incluye ninguna descripción cualitativa, es decir, "qué tan bueno" es en Aritmética. La evaluación, por otro lado, incluye tanto la descripción cuantitativa (medición) como la descripción cualitativa (no medición) junto con juicios de valor.

En la revisión sobre la polisemia de la palabra evaluación se encuentran trabajos como el de Stronge (2013), en el que podemos dilucidar algunas diferencias entre evaluation y assessment, definidas sobre todo en el ámbito de la educación con enfoque sociológico. Se puede utilizar assessment para referirse a aquellos procedimientos deliberados y planificados de medición y los usos para los cuales la información generada se utiliza, mientras que evaluation se refiere a las interpretaciones posteriores de tales mediciones, aunque contradigan normas particulares de rendimiento y, por lo tanto, a los procesos más generales de juicio y retroalimentación (Broadfoot, 1996).

Como ambos conceptos son vistos como procesos destinados a legitimar las prácticas escolares para grupos ajenos a lo educativo, a veces, la distinción se vuelve borrosa. En nuestro análisis generalmente aplicamos el término assessment y únicamente evaluation cuando nos referimos a la evaluación en relación con la normativ y la política. Por lo tanto, nuestros intereses se refieren a los roles sociales de assessment y los efectos de las políticas de evaluation y planteamos preguntas sobre la relación entre percepciones políticas e interpretaciones y prácticas entre docentes y alumnos.

Otra distinción relacionada con los conceptos anteriores es en qué medida el assessment apunta hacia un mayor control externo o hacia la mejora de la creatividad en enseñanza y educación. Los procesos formativos buscan mejorar o desarrollar la creatividad educativa, mientras que los procesos sumativos buscan estimar o certificar productos finales (Nevo, 1986). Mientras que el aspecto formativo forma parte del proceso de enseñanza y aprendizaje, los procedimientos de assessment más formalizados, denominados sumativos, generalmente se separan de la situación del aula (Ottobre 
1978, p.12) y tienen lugar en la etapa final de una actividad escolar particular. La Evaluación sumativa puede entenderse como información externa sobre el proceso de educación en la que aquellos que no están involucrados personalmente reciben información sobre el aprendizaje que ha tenido lugar (Harlen et al. 1992; Broadfoot 1996).

Se considera que las sociedades posindustriales con una oferta educativa masiva se caracterizan por una concentración de la fuerza laboral en los sectores secundario y terciario y un impulso constante para expandir la productividad, lo que conduce a una tasa rápida de Innovación tecnológica (Aron, 1980). En tales sociedades posindustriales, los instrumentos de assessment desempeñan un papel social significativo con respecto a: a) atestiguar la competencia; b) regular de la competencia; definir el contenido de la educación; c) y proporcionar control del sistema (Broadfoot, 1996: 11). Dentro de estos cuatro roles de assessment, examinamos en qué medida un paradigma de aprendizaje o un paradigma de medición es dominante.

Habría que especificar a qué clase de evaluación se hace referencia, porque en el idioma anglosajón la palabra designada en español como "evaluación” cuenta con muchas distintas que hemos encontrado:

- Accountability: evaluación por auditoría, responsabilización social, fijar la responsabilidad por las propias acciones y los resultados de dichas acciones (McMeekin, 2006). La interpretación más conocida de la accountability educativa es que las escuelas deben responsabilizarse por los resultados que producen. Según McMeekin, (2006) hay otros conceptos que están estrechamente relacionados con accountability: evaluation, estándares, inspección, acreditación, certificación, elección de escuela para ejercer presión para lograr buenos desempeños y sistemas de recompensas.

- Appraisal: evaluación del desarrollo profesional, también designa valoración, proviene de la teoría de la Valoración, que es la teoría de la psicología que mantiene que las emociones son extraídos de nuestras evaluaciones (tasaciones o estimaciones) de eventos que causan reacciones específicas en diferentes personas. En esencia, nuestra apreciación de una situación causa una reacción emocional o afectiva, la respuesta que va a estar basada en que la evaluación. El razonamiento y la comprensión de la reacción emocional de uno se convierte en importante para las evaluaciones futuras. El aspecto importante de la teoría de la valoración es que representa las variaciones individuales de las reacciones emocionales al mismo evento. Las teorías de la valoración de la emoción 
son las teorías que afirman que las emociones son el resultado de interpretaciones y explicaciones de sus circunstancias, incluso en ausencia de excitación fisiológica (Aronson, 2005) de las personas. Hay dos enfoques básicos: el modelo de enfoque y el proceso estructural. Estos modelos ambos proporcionan una explicación para la valoración de las emociones y explicar de diferentes maneras cómo las emociones se pueden desarrollar. En ausencia de excitación fisiológica que decidamos cómo sentirse acerca de una situación después de que hemos interpretado y explicado los fenómenos. Así, la secuencia de eventos es la siguiente: evento, el pensamiento y eventos simultáneos de la excitación y la emoción. Los psicólogos sociales han utilizado esta teoría para explicar y predecir los mecanismos y patrones de la emotividad de la gente frente a fenómenos como el afrontamiento. Por el contrario, por ejemplo, la psicología de la personalidad estudio las emociones en función de la personalidad de una persona, y por lo tanto no tiene en cuenta la valoración de la persona, o la respuesta cognitiva, a una situación. La principal controversia que rodea a estas teorías sostiene que las emociones no pueden suceder sin la activación fisiológica.

- Arousal: Stanley Schachter y George Mandler fueron los primeros en proponer una teoría fisiológica-cognitiva de la emoción. Para Schachter (1964) un estado emocional es el resultado de la interacción entre la activación fisiológica y la evaluación cognitiva de la situación. La activación fisiológica se conceptualiza como un arousal (impulso) generalizado y difuso que determinaba la intensidad, pero no la cualidad de la emoción. El tipo de emoción vivida por la persona está determinado por la evaluación cognitiva de la situación. La emoción podía ser generada de dos formas. La emoción se daba después de evaluar un estímulo generador de emoción. La percepción del estímulo emocional producía una "cognición emocional” y una activación fisiológica. Juntos, la cognición emocional y la activación fisiológica se unían para definir el estado emocional. Las cogniciones emocionales determinan el tipo de emoción que se tiene mientras que la activación emocional determina la intensidad de esa emoción. Las personas tienen activación inexplicada. Ante la activación inexplicada las personas realizan una búsqueda cognitiva. Howie Becker (1963) enseñó la manera de cómo las personas aprenden a drogarse, o entrar en el trance que produce fumar marihuana. La primera experiencia con una droga (el efecto fisiológico que esta produce) puede ser interpretada como agradable o no. Existen límites en cuanto a la interpretación que se puede hacer del arousal fisiológico en base a las señales ambientales. El arousal 
inexplicado no produce la emoción, lo que si hace es provocar la búsqueda de una interpretación, podríamos decir que evalúa.

- Assessment: medición de resultados de los alumnos a través de pruebas estandarizadas con el fin de elaborar rankings a nivel de aula, de centro, locales, regionales, estatales e internacionales.

- Evaluation: evaluación educativa, sobre programas educativos, o formas de educación en distintos contextos, como centros educativos acogidos a normas estatales, $u$ otros centros no formales.

- Self evaluation: autoevaluación, evaluarse a sí mismo en cualquier ámbito.

En la revisión de literatura, este trabajo se centra en la búsqueda de dos acepciones de la palabra evaluación: evaluation y assessment.

El acto de evaluar está intrínsecamente unido a la condición humana. Constantemente valoramos, evaluamos, en el espacio más cotidiano, la conducta y los resultados de las demás personas, desde situaciones sociales, como en lo económico o político, a lo más abstracto, como a nivel cultural o emocional (Bordas y Cabreras, 2001).

Recíprocamente somos también evaluados por los demás. La evaluación se extiende también al ámbito profesional o laboral con unos juicios más elaborados y técnicos en cualquier disciplina que se desarrolle (Levy Leboyer, 1994).

En la mayoría de artículos de revisión de la literatura sobre evaluación, como en publicaciones sobre los temas de evaluación de programas, se discuten principalmente los diferentes enfoques para realizar la evaluación. Estos enfoques incluyen evaluación orientada a objetivos (Provus 1971; Tyler 1942), evaluación orientada a la gestión (Stufflebean y Shinkfield, 1985), evaluación orientada al consumidor (Scriven, 1993), evaluación orientada a la experiencia (Eisner, 1991), evaluación orientada a los participantes, y algunos otros enfoques alternativos. Las teorías de evaluación de programas generalmente se discuten dentro de estos contextos.

\subsubsection{Evaluation y Assessment: historia de la evaluación}

Históricamente los primeros vestigios de evaluación se sitúan en China en el siglo II a.C. (Sacristán 2002) como sistema de selección de los funcionarios. Posteriormente, se encuentran en Grecia en el siglo IV a.C. las pruebas orales en el entorno de Sócrates (Lemus, 2012) y otros maestros de la época. Pero epistemológicamente, los sistemas de evaluación educativa (dogmáticos) se sitúan entre el siglo V y XV. Se puede comprobar una evolución en la figura 4: 


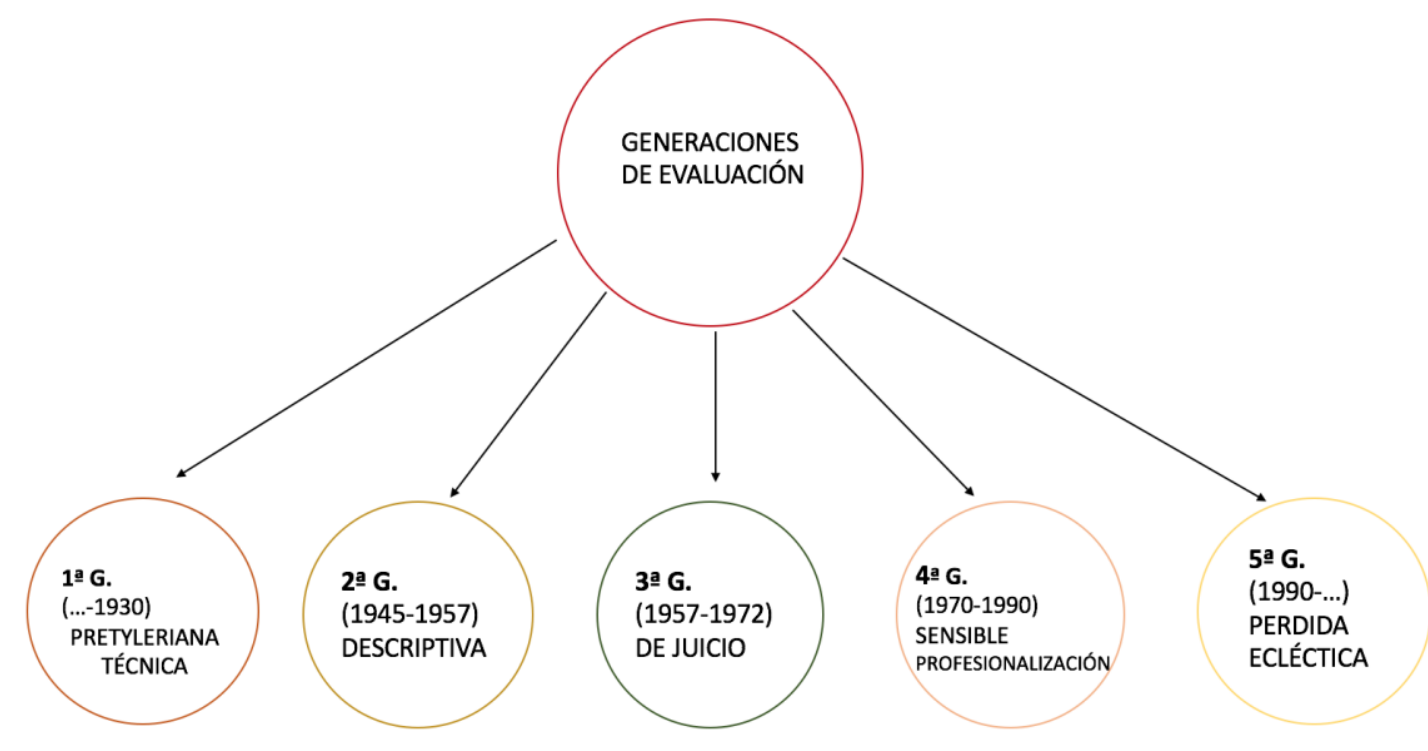

Figura 4. Generaciones en la historia de la Evaluación. Fuente: Alcaraz, 2015. Elaboración propia.

Ya en el siglo XIX se constatan evaluaciones del rendimiento de los estudiantes en EEUU y en Gran Bretaña se conocen en ese siglo las primeras comisiones para evaluar los servicios públicos. En este mismo país, en una evaluación de la educación de Irlanda (Hernández y Guzmán, 1991) y como consecuencia de los bajos resultados, se propuso la medida de pagar por resultados a los docentes a través de una parte de su salario. La evaluación de programas se inicia en 1845 en Boston, y entre 1887 y 1898 el pedagogo Joseph Rice mide la eficacia de los programas mediante grupos de comparación, y resultados en ortografía. Ésta se considera la primera evaluación formal sobre un programa educativo realizado en América, según Stufflebeam y Shinkfield (citado en Vélez, 2007, p. 146).

Hasta ahora se ha descrito lo que correspondería a la primera generación de evaluación, también conocida como época pretyleriana o técnica. Comprendería entre el año 2000 a.C. hasta el año 1930.

En la década de 1920 la evaluación de programas se realiza eminentemente mediante la aplicación técnica de herramientas específicas test, encuestas, acreditaciones y comparaciones experimentales. Los test preferidos son los test de rendimiento y test de inteligencia (Reyes, 2001). El criterio metodológico es la medición científica, en el cual importan las ciencias humanas desde las ciencias físico-naturales. 
Desde la Sociología, esta época se caracteriza por el éxito de la revolución industrial y la importancia predominante de las máquinas. Paralelamente se potencian los mecanismos de acreditación y selección de estudiantes, en función de sus conocimientos, lo que se conoce por assessment. La correcta selección de estudiantes desde los niveles más bajos del sistema educativo es una característica de las sociedades contemporáneas hasta nuestros días. Los test estandarizados son muy utilizados en la década de los años 20, para medir la inteligencia y grandes colectivos de estudiantes. El punto más alto del testing se sitúa en la década entre 1920 y 1930, donde los tests estandarizados ocupan un espacio privilegiado en el ámbito de la educación. Esta época pretyleriana o primera generación, denominada así por Guba y Lincoln (1989), los test son fuentes informantes sobre algunos aspectos del alumnado, pero tenían poca relación con los programas escolares. Terminológicamente se usaban indisolublemente evaluación y medida sin reconocer la profunda diferencia que tienen ambos enfoques de enjuiciar la educación.

Existen aún muchos autores, que como Gronlund (1985), afirman que esta primera generación permanece todavía viva, ya que aún existen textos y publicaciones que utilizan de manera indisoluble evaluación y medida.

\section{Período tyleriano}

El padre de la evaluación educativa (Evaluation), Ralph Tyler (1969), fue quien acuñó el término y es un período que abarca desde 1930 a 1945, por ello Stufflebeam y Shinkfield (2005) lo llaman tyleriano. Con él la evaluación pasó a un primer término y la medición al segundo. Es decir, en esta época es cuando se empieza a diferenciar entre evaluar y calificar. Es una etapa que supera la mera evaluación psicológica y sistematiza la educación en el ámbito educativo. Esta propuesta basada en la formulación de objetivos curriculares y en la medición de la consecución o no de los mismos, se extiende por EEUU, para más tarde pasar al resto del mundo.

El núcleo del sistema educativo es determinar los cambios producidos en los alumnos, pero no sólo como un elemento de feedback para los alumnos, padres y profesores, sino que, además, proporcionará reportes y reformas sobre la eficacia del programa educacional. Se abandona la evaluación basada en la norma, y surge lo que se conoce como evaluación criterial. Según Stenhouse (1984), la primera nos informa del 
rendimiento del individuo en comparación con un grupo, mientras que la segunda, indica rendimiento de un individuo en relación con un estándar

Abarcando también hasta 1957 se extiende la segunda generación de la evaluación, la descriptiva, incluyendo dos períodos, el tyleriano ya descrito y la época de la inocencia o de la irresponsabilidad social (1945-1957), llamándose así porque los estudios descriptivos no generaban después recomendaciones para la mejora de los programas, existiendo una carencia de planes coherentes de acción (Stufflebeam y Shinkfield, 2005).

El período que se extiende entre 1957 y 1972 es la tercera generación de la evaluación, Guba y Lincoln $(1982,1989)$, la del juicio, o la del realismo Stufflebeam y Shinkfield (2005). El ambiente convulso entre EEUU y URSS, con la Guerra Fría, produce el adelanto tecnológico de la URSS en los años 50, resultando como consecuencia a la vez, en un desencanto de los resultados de la escuela pública de EEUU, que produce la era de la rendición de cuentas (accountability) (Escudero, 2003; MacDonald, 1976; Popham, 1980,1983; Stenhouse, 1984).

Se reconoce la responsabilidad del docente en el logro de los objetivos educativos. Los programas educativos en EEUU, costeados con dinero federal, se someten anualmente a escrutinio de resultados para justificar o no las subvenciones. A nivel económico y social, es una época en la que confluye además la crisis sobre todo en los años 70, lo que acrecienta la idea de rendir cuentas económicas y optimizar el gasto. (Escudero, 2003).

Conceptualmente entran en juego en la evaluación todos los demás elementos que confluyen en el proceso educativo (programa, profesorado, medios, contenidos, organización, experiencias de aprendizajes etc.) (Stobart, 2010). Este mismo autor, destacó en este contexto, el programa de pago por resultados de Lowe, (1862) sobre el plan de enseñanza de las tres R (reading, writing, arithmetic), cuyos resultados se dirigían por el gobierno y generaban ayudas económicas proporcionales a los resultados en las escuelas elementales (Stobart, 2010).

Pero esta rendición de cuentas continúa hasta nuestros días con las pruebas externas, con los estudios de Programme for International Student Assessment, o programa internacional para la evaluación de estudiantes (PISA) o Progress in International 
Reading Literacy Study o Estudio Internacional de Progreso en Comprensión Lectora (PIRLS).

En esta generación del juicio y valoración se ve la necesidad de redefinición de la evaluación (Escudero, 2003). Hay un período de proliferación de reflexión y ensayos teóricos y una expansión de la evaluación de programas donde se insiste en la multidimensionalidad de la evaluación.

Los autores fundamentales de la generación del juicio son Cronbach (1963) y Scriven (1967) que influyeron en la comunidad de evaluadores, incidiendo en la evaluación orientada al sujeto, entendiendo la evaluación como assessment. Esta generación se caracteriza por incluir la valoración y el juicio del docente, más allá de la mera descripción y análisis de la realidad.

Cronbach (1963) y Scriven (1967) son los padres de la evaluación curricular moderna (Hernández y Guzmán,1991). Así, Crombach (1963) no cree en la simplicidad de una evaluación de programas, sino en los factores complejos que implica dicha evaluación. La evaluación de programas no es una mera carrera cuantitativa entre los diversos programas, no es la simple aplicación de instrumentos de medición. Ambos autores asocian, siendo pioneros, la evaluación a la toma de decisiones. Crombach (1963) añade nuevos instrumentos más allá de los test, como son las entrevistas, observación sistemática y no sistemática. Scriven (1967), por su parte, crea los términos evaluación formativa y evaluación sumativa, evaluación intrínseca y evaluación extrínseca.

Las dos décadas desde 1970 a 1990 se caracterizan porque se desarrolla la llamada cuarta generación sensible (Guba y Lincoln 1982, 1989). y época de la profesionalización (Stufflebeam y Shinkfield, 2005). La característica principal es la proliferación de los modelos de evaluación, existiendo simultáneamente una gran diversidad conceptual y metodológica.

En la primera mitad de los 70 todavía hay predominio de los modelos tylerianos y en la segunda mitad de los modelos alternativos de evaluación como los de evaluación responsable de Stake $(1975,1976)$ o los de evaluación democrática de Mac Donald (1976) la evaluación iluminativa de Parlett y Hamilton (1977), con su concepto ambiente entorno de aprendizaje es destacable el entorno escolar particular que genera la interdependencia entre enseñanza y aprendizaje y Eisner (1985), es decir, la evaluación como crítica artística, en el que la enseñanza sería más bien un proceso más 
artístico que tecnológico. A nivel teórico, la evaluación democrática de Mac Donald trasladada a la autoevaluación de Elliot (1993) y del profesor como investigador de Stenhouse (1984); la teoría de House (1994) referida a la importancia social de la evaluación, y de los conceptos moral, ética, justicia y poder; Kushner (2002) ve la evaluación como una forma de acción política, con su preocupación por la justicia social. Todos estos enfoques coinciden en la perspectiva naturalista en la cual los procesos se analizan respecto a su naturaleza social, política y ética.

Entre la proliferación de estos modelos de evaluación, hay dos corrientes muy claras: los cuantitativos y los cualitativos.

A la vez, se destaca el distanciamiento respecto a generaciones anteriores, por ejemplo, frente al tradicional modelo positivista se opone el modelo naturalista. Dentro de la evaluación de aprendizajes se concibe el proceso de Enseñanza-Aprendizaje como constructivista. Surge la generación sensible y constructivista. Anteriormente los parámetros se construían a priori. Ahora los parámetros los construyen los actores del proceso educativo que cobran así especial relevancia. En esta generación se parte de las preocupaciones, cuestiones y opiniones de los intervinientes, con pluralidad de valores e intereses. Los parámetros para la emisión de juicios de valor se buscarán a través del diálogo con todos los implicados en el programa o política. Se da relevancia a los contextos que se interrelacionan con los procesos educativos, lo que fomenta el enfoque participativo y sociocrítico. Hay aspectos importantes como la negociación en los contextos, la atención a las demandas de los evaluados (empoderamiento) y la contribución de esto al proceso evaluativo y de toma de decisiones y optando por una evaluación coherente con todo esto. Según Rodríguez (2003) teóricamente la evaluación sensible y constructivista se apoya en la metodología constructivista y la evaluación responsable de Stake $(1975,1976)$. El constructivismo respecto a la psicología evolutiva se basa en las teorías de Vigotsky (1985), Piaget (1968, 1973) y Ausubel (1983) que postulan la adquisición gradual del conocimiento y la autoconstrucción cognitiva del alumno. Sus estudios en psicología afirman que no sólo conocemos registrando memorísticamente en nuestro cerebro, sino construyendo nuestra propia estructura cognitiva. La crítica al constructivismo por autores como Enkvist $(2006,2010)$ propone que minimiza el papel del esfuerzo y la importancia de la memoria. El constructivismo también promueve el Multiculturalismo generando una tensión con los contenidos culturales autóctonos. 


\subsubsection{Un nuevo paradigma en la evaluación}

En los finales de los años 80 se produce un cambio conceptual sobre la evaluación, llamado el nuevo paradigma, denominado así por Guba y Lincoln (1989), y no es meramente un sistema reactivo al positivismo, Carr y Kemmis (1998, p. 77) admiten el término positivismo para designar "un estilo de pensamiento informado por determinados supuestos acerca de la naturaleza del conocimiento", sino un modelo asentado en diferentes asunciones ontológicas y epistemológicas. Paralelamente generará metodologías distintas a las anteriores. El sistema tradicional defendía que hay una realidad única definida por las leyes predeterminadas de causa-efecto. El paradigma naturalista dice que hay múltiples realidades dependiendo de los enfoques que se hacen de la misma. El relativismo supone relaciones sociales múltiples, complejas y a veces en conflicto construidas por el intelecto humano pero que pueden modificarse mediante la formación de los sujetos.

El cambio epistemológico que se produce realmente es entre el evaluador y la realidad.

En cambio, el positivismo se basaba en el fenomenalismo, en el cual el conocimiento se aplica sobre la realidad entendida como lo que aprehenden nuestros sentidos.

Consecuentemente los juicios de valor al no ser conocimiento empírico no podrían generar un conocimiento válido. En el positivismo las interferencias entre el evaluador y la realidad deben ser mínimas. El juicio del evaluador no será introducido hasta la tercera generación de la evaluación. En conclusión, el paradigma naturalista utiliza el enfoque cualitativo, es decir, que entiende de manera inductiva y holística la conducta humana en un contexto específico; el positivista, por su parte, usa enfoques cuantitativos y experimentales mediante el método hipotético-deductivo (Patton citado por Vélez, 2007, p. 52).

El nuevo modelo de la cuarta generación (Guba y Lincoln, 2002) considera relevante el fomento del intercambio de opiniones, valores y experiencias de los agentes implicados en la evaluación mediante métodos participativos (Vélez, 2007). El nexo común de esta generación con la anterior, sería la adopción de fundamentos epistemológicos y metodológicos naturalistas para conocer y analizar los procesos según su naturaleza social, política y ética. El modelo se aleja de la intención medidora o sancionadora que a menudo se asocia a los procesos de evaluación, unida al concepto calificar, y se aproxima a la comprensión del proceso educativo dinámico de las aulas (Wrigley, 2013). 
Respecto a las funciones que se asignan a la evaluación son muchas y de naturaleza diversa: administrativas, autoritarias, orientadoras, de retroalimentación, etc. y hay que señalar que son muchas veces contradictorias entre sí (Álvarez Méndez, 2001). Scriven (1967) ya intentó la clarificación con los términos "evaluación formativa" y "evaluación sumativa". Igualmente, Stake (2006) insiste en diferenciar ambas funciones. La formativa genera un proceso de cambio en el evaluando; la sumativa centra sus esfuerzos en medir los efectos del evaluando. La formativa se asociaría al término evaluación y la sumativa al término calificación.

Las estadísticas del informe Talis sobre la Organización para la Cooperación y el Desarrollo Económicos (OCDE) publicado por el MECD (2014) presenta la paradoja siguiente: las prácticas docentes constructivistas de enseñanza-aprendizaje son globalmente del 74\% y del $87 \%$ en España, pero simultáneamente los porcentajes de los exámenes estandarizados son del 66\% para la OCDE y el 76\% para España. Así pues, hay una atmósfera del nuevo paradigma, pero aún existe el predominio de las prácticas evaluadoras de la función sumativa.

Los conceptos se sofistican, pero se mantienen las prácticas, es decir, se sigue teorizando en torno a la evaluación, pero existe poca práctica sobre el tema. Se podría hablar de un "enmascaramiento de prácticas calificadoras tradicionales", apellidando la evaluación con ciertos calificativos. Esta coexistencia ambigua podría definirse como la quinta generación de la evaluación, o sea, la generación perdida o ecléctica.

En esta etapa, se produce una mezcla de funciones, primero las funciones de evaluación enfocadas a la comprensión y la mejora, segundo las funciones de calificación centradas en la selección y la acreditación.

\subsubsection{Período actual}

En estas últimas décadas en la que la multiplicidad de funciones coincide en la evaluación, toma relevancia la Docimología, rama de la Pedagogía que estudia los sistemas de evaluación tratando de encontrar parámetros objetivos y elaborando herramientas específicas a tal efecto, como pruebas estructuradas junto a otras. La Docimología incorpora los diferentes objetivos de la educación: transmitir conocimiento, proactividad, actitudes, certificación, selección y en paralelo, trata de no dejar atrás los aspectos de validez y fiabilidad de las herramientas evaluativas, atendiendo igualmente a la evaluación diacrónica y proponiendo: evaluación inicial, 
formativa o intermedia, final o sumativa y predictiva. La Docimología estudia qué parámetros se miden en cada tipo de prueba atendiendo a la gran diversidad en este ámbito: por ejemplo, en los exámenes, si son de opción múltiple, orales, la evaluación por proyecto, la evaluación contínua, etc.

Gulikers, Bastiaens y Kirschner (2004) resumen su idea de forma contundente:

Aprendizaje y evaluación son dos caras de la misma moneda, e influyen fuertemente el uno en la otra. Para cambiar el aprendizaje del alumno en la dirección del desarrollo de competencias auténticas es necesaria una enseñanza basada en competencias auténticas, alienada con una evaluación basada también en competencias auténticas (p. 68).

Wiggins (1990), investigador y especialista en reformas escolares distingue entre evaluación educativa o de aprendizajes, siendo el primero muy utilizado en los últimos tiempos y de carácter genérico, sistemático, para comprender la realidad educativa, que permite obtener información para tomar decisiones sobre aquellos a los que se evalúan, bien el alumnado, el currículo, el profesorado o el propio centro, generador de juicios de valor para tomar decisiones y la mejora del sistema.

Merece atención especial la evaluación llamada assessment, en terminología de Stake (2006). Este autor expone y desarrolla su modelo que, debe sostenerse tanto en estándares como en la evaluación comprensiva. El estudio panorámico de visiones, que no serán necesariamente complementarias, genera mayor sutileza y profundidad en el análisis de la evaluación de la calidad. Su modelo, The countenance model, sigue la línea de Tyler, pero es más completo al considerar las discrepancias entre lo observado y lo esperado.

La Figura 5 demuestra, a modo de ejemplo, la idea central de atención a la complejidad que fundamenta los postulados de Stake (2008): 


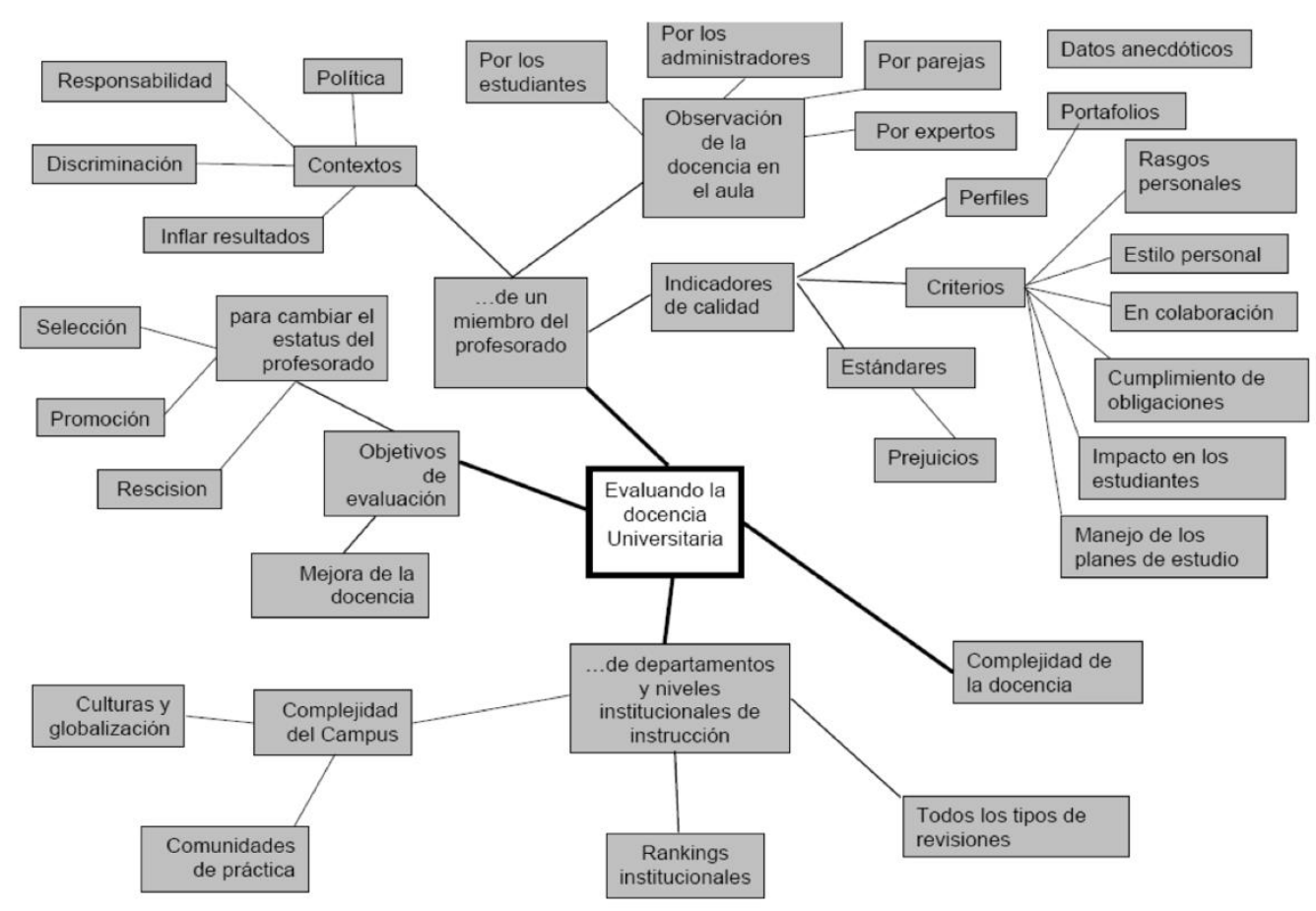

Figura 5. Evaluación de la docencia en la universidad. Fuente: Stake, 2008.

La llamada por muchos autores evaluación auténtica suele emplearse de manera genérica para describir una amplia variedad de nuevos enfoques e instrumentos de evaluación que se contraponen a los utilizados reiteradamente en la evaluación tradicional, la denominada testing culture, la cultura del examen (Álvarez, 2005; Angelo y Cross, 1993; Monereo, 2003). Entre estos enfoques suelen citarse la evaluación no formal o alternativa (alternative assessment), la evaluación del proceso de realización (performance assessment), la evaluación basada en problemas (problem-based assessment), la evaluación dinámica, la evaluación formadora o la evaluación formativa (Campbell, 1994; Custer, 1998; Darling-Hammond, 1995; Darling-Hammond y Snyder, 2000; Nunziati, 1990; Sternberg y Grigorenko, 2003; Weber, 1999; Weinstein y Meyer, 1998).

Es importante concluir con una serie de puntos que aclaren los conceptos vistos anteriormente:

1. Guba y Lincoln $(1982,1989)$ establecieron la clasificación de las "cuatro generaciones de la evaluación"

2. Hasta 1930 predominaba el término medición. Con la llegada de Tyler (1969) cobra protagonismo la evaluación, Tyler es reconocido como el padre de la evaluación educativa; la evaluación es antepuesta a la medición. 
3. A partir de 1957 la evaluación se asocia a la toma de decisiones, para mejorar los programas educativos, pero no directamente a los individuos sujetos de aprendizaje.

4. Después de 1973 la evaluación empieza a entenderse como herramienta de empoderamiento de los sujetos. Se introduce el concepto de evaluación educativa; el constructivismo impregna la evaluación de aprendizajes. Una se nutre de la otra.

5. Actualmente vivimos en la quinta generación o generación ecléctica donde la evaluación educativa se tiñe de muchos calificativos dependiendo de las funciones que intenta enfocar.

6. La evaluación no ha conseguido diferenciar claramente los terrenos de la medición, la calificación y la evaluación. Ocurre que muchas de las prácticas que se llaman evaluación contienen a su vez prácticas de calificación o medición.

Se puede realizar una clasificación de la evaluación (Scriven, 2007), en su término más amplio, según sus seis dimensiones que se resumen en la figura 6 . Se puede observar que se distinguen las dimensiones: objeto, modelo, evaluador, finalidad, momento e instrumento; dependiendo de cada una de ellas la evaluación es de un tipo u otro. Y es un esquema aplicable, tanto a la Evaluation como al Assessment.

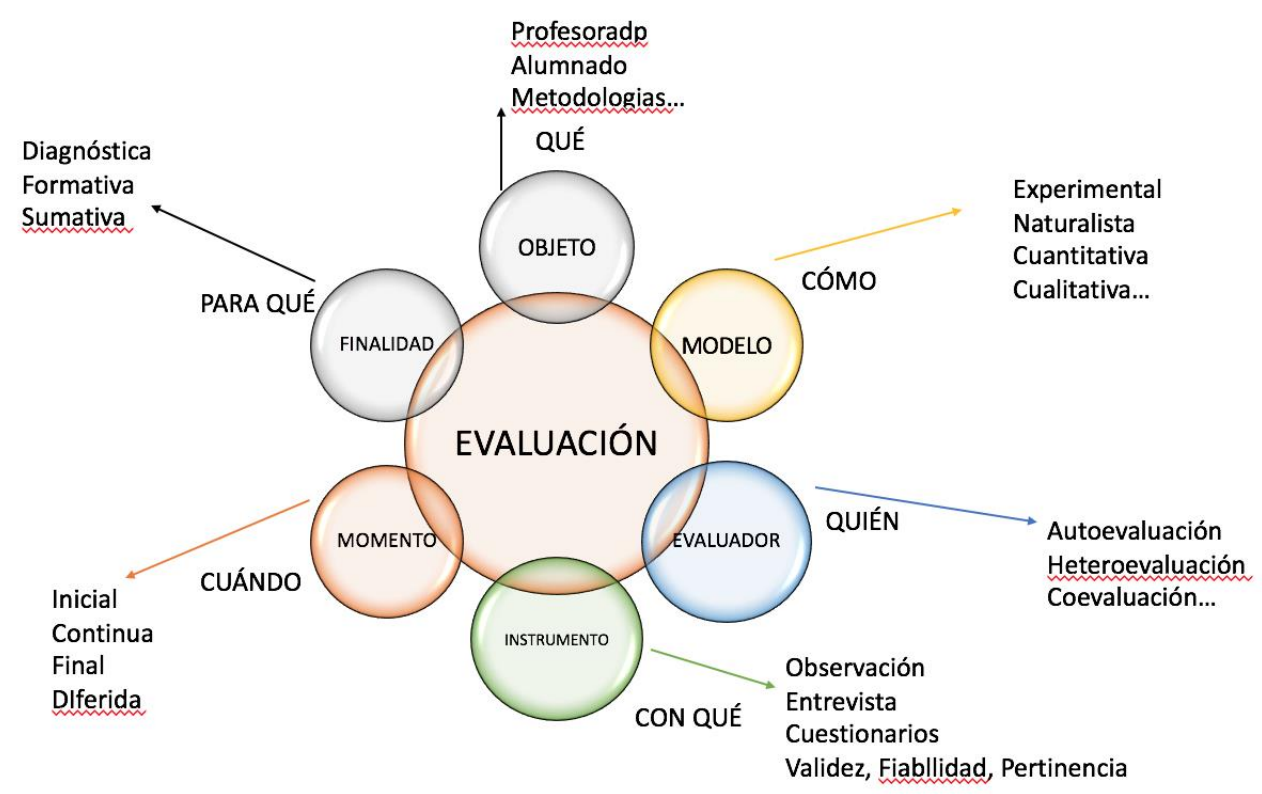


Figura 6. Tipologías de Evaluación según seis dimensiones. Fuente: basado en Scriven (2007). Elaboración propia.

\subsection{Evaluación en la actualidad: estado de la cuestión internacional}

Las evaluaciones internacionales se podrían clasificar en informes que nos remite el Ministerio de Educación Ciencia y Deporte (2013d):

-Los informes basados en competencias: Informes del Programa para la evaluación internacional de alumnos (PISA, Programme for International Student Assessment) y del Programa para la Evaluación Internacional de Competencias en Adultos (PIACC). El primero realiza estudios sobre la competencia en lectura, matemáticas y ciencias de alumnos de 15 años de edad (MECD, 2003) y relaciones entre las estrategias docentes y el rendimiento de los alumnos (Méndez, 2015; Le Donné et al., 2016), así como el cómo afecta el contexto escolar a las prácticas docentes implementadas por los profesores (Austin et al., 2015). En PISA 2105, por primera vez, se incluye un cuestionario dirigido a los profesores, en el que estos proporcionan información sobre las actividades desarrolladas en el aula; y el segundo, PIACC, realizado por la Organización para la Cooperación y el Desarrollo Económicos (OCDE), tiene como fines:

- proporcionar a los encargados de formular políticas en cada país participante un perfil de referencia de adultos en su país en términos del conocimiento, las habilidades y las competencias que se consideran subyacentes tanto al éxito personal como social;

- evaluar el impacto de estas competencias en una variedad de resultados sociales y económicos a nivel individual y agregado;

- medir el desempeño de los sistemas de educación y capacitación en la generación de las competencias requeridas;

- y ayudar a aclarar algunas de las palancas de políticas que podrían contribuir a mejorar las competencias (Kirsch, 2013).

-Los informes basados en el contexto: La misma OCDE (2008) lanza por primera vez el Estudio Internacional sobre la Enseñanza y el Aprendizaje (Teaching and Learning International Survey, TALIS). Este estudio examina recoge más información sobre los profesores, el entorno escolar, la enseñanza, y el impacto que estos tienen sobre el aprendizaje de los alumnos de Educación Secundaria de los países participantes, (24 en 2008 y 34 en 2013). Hace hincapié en la importancia del liderazgo del director de los 
centros, aunque según Marzano, Waters y McNulty (2014) es un papel muy poco definido y hay pocos estudios al respecto.

-Los informes basados en el currículo: Se encuentran dos, desde la Asociación Internacional para la Evaluación del Rendimiento Educativo (International Association for the Evaluation of Educational Achievement, IEA), el Estudio Internacional de Tendencias en Matemáticas y Ciencias (International Association for the Evaluation of Educational Achievement, TIMSS), centra en contenidos de matemáticas y ciencias; y el Estudio Internacional del progreso de la Comprensión Lectora, (Progress in International Reading Literacy Study, PIRLS), en la comprensión lectora de alumnos de Educación Primaria entre 9 y 10 años de edad (INEE, 2006), en el que hay estudios en los que se determina que la lectura es una de las claves para mejorar el rendimiento en todas las competencias, no sólo en la comprensión lectora (Machin y McNally, 2008).

\subsubsection{Tensiones y aspectos críticos del programa PISA}

Las pruebas que se han llevado a cabo durante las últimas décadas, entre los que destacan lo de la IEA, (2011), se han centrado en los rendimientos asociados a los currícula y en las materias comunes a los distintos países participantes. No se han tomado en consideración a la hora de realizar las evaluaciones la diversidad curricular de los países a nivel individual (OCDE, 2006). Así, PISA hace posible la comparación entre países evaluando:

- La comprensión de conceptos de cada materia.

- El dominio de los procedimientos.

- La capacidad de actuar en distintas situaciones y ámbitos de la vida adulta.

Sin embargo, Yus (2011) concluye acerca de PISA que su evaluación dista de la definición de competencias que se propuso desde la OCDE mediante el proyecto Definición y selección de competencias clave (DeSeCo, donde la noción de competencia (McClelland, 1973) aúna los aspectos cognitivos con los de motivación, éticos, sociales y conductuales, se definen las competencias clave como aquellas que proporcionen un beneficio mensurable tanto económicos como sociales para todos los individuos; además esos beneficios deben darse no en un solo contexto sino en un amplio abanico de contextos (Weinert, 2004); y por último, se deben dar menos valor a las competencias más específicas y más a aquellas competencias transversales que todos deberíamos aspirar a desarrollar y mantener. Pero el aprendizaje se produce de forma jerárquica como se indica en la Figura 7: 


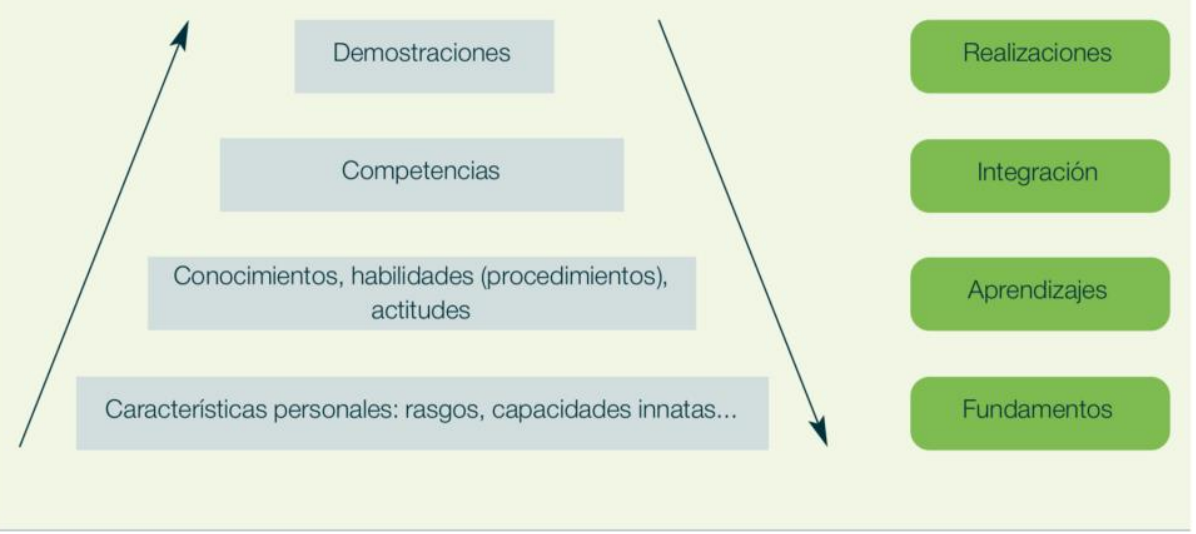

Figura 7. Resultados del aprendizaje en jerarquía. Fuente: $\mathrm{NCES}^{4}, 2002$.

Cuando se elaboraron las pruebas PISA, se asoció la competencia a las materias curriculares. En PISA 2000, la puntuación establecida para estas pruebas era el sumatorio de conocimientos, procesos y situaciones o contextos. Una vez finalizado el proyecto DeSeCo en 2002, al entrar en vigor PISA 2006, se añadió la actitud de los alumnos hacia las pruebas y el conocimiento científico. En el año 2015 la principal fueron las Ciencias como en el 2006. Además, en cada edición de PISA se plantea el análisis de alguna otra competencia, como la resolución colaborativa de problemas en 2015, o la competencia global, en el PISA 2018 (Álvarez Morán et al., 2018).

Pero no se alcanzaba la definición de competencia por el proyecto DeSeCo, ya que PISA evalúa las tres capacidades en las que se descompone la actitud de forma independiente, y no lo hace de forma combinada o global. En cuanto al contexto, la adquisición de una competencia en el contexto académico no asegura que se domine o aplique en un contexto no académico (Yus, 2011, 18). También ha sido cuestionado el modo en el que ha sido incluida en PISA 2006 la evaluación de las actitudes.

Finalmente, respecto al contenido de PISA, diversos autores (Murphy, 2010; Grisay y Monseur, 2007) ponen en duda los siguientes puntos:

- Las áreas de conocimiento que se piensa que requieren los jóvenes de 15 años para participar "plenamente en sociedad": se ha cuestionado si estas evaluaciones han sido diseñadas para personas entre 16 y 65 años, al encontrar semejanzas entre algunas preguntas de PISA y las preguntas elaboradas en la Encuesta Internacional de

\footnotetext{
${ }^{4}$ NCES: El Centro Nacional de Estadísticas de la Educación (NCES, por sus siglas en inglés) es la principal entidad federal para recopilar, analizar e informar datos relacionados con la educación en los Estados Unidos y otras naciones.
} 
Alfabetización de Adultos (International Adult Literacy Survey (IALS), Educational Testing Service (ETS), 2001).

- Las formas en que el lenguaje representa ese conocimiento. En la traducción de las pruebas PISA, se han sustituido algunas palabras o frases por expresiones locales, como por ejemplo la moneda, nombres de personas, la sintaxis, la ortografía. Las adaptaciones de la prueba en algunas lenguas provocan que se varíe la dificultad de los ítems entre unos países y otros. El índice de equivalencia entre unos y otros es menor de lo deseable, ya que muchas preguntas de selección múltiple no funcionan de manera equivalentes en sus versiones para países asiáticos que en países occidentales.

- La manera en que ciertos aspectos de las culturas son escogidos o no para ser representados como la base de las preguntas de la prueba PISA. Antes de realizar las pruebas se consulta a los países si consideran los ítems adecuados para su distribución. No siempre los criterios estaban apoyados por todos los países, pero la organización tomó la decisión de mantenerlos sin fundamentar estos hechos.

\subsubsection{Investigación educativa internacional}

En Estados Unidos la investigación pedagógica ha alcanzado un alto nivel de desarrollo, siendo precisamente allí dónde, en 1882, apareció el primer seminario con el propósito de crear una pedagogía de carácter científico.

Bartolomé (1984) realiza una síntesis de los logros generales de la investigación educativa norteamericana, introduciendo instrumentos de medida y evaluación, desde los test de rendimiento a los más recientes de carácter ecológico, desde la incorporación del método experimental a los estudios pedagógicos (Campbell y Stanley, 1982), la introducción de nuevos diseños mejor adaptados a las singulares condiciones de los contextos educativos, cuasi-experimentales de Cook y Campbell (1979) y de caso único de Kratochwill (1978). Y también, desde una perspectiva más funcional, la mejora del tratamiento de datos mediante la incorporación de métodos multivariados apoyados por los soportes informáticos, o la potenciación de la difusión de la información a través de diversos soportes como la realizada por la American Educational Research Association (A.E.R.A. $)^{5}$, que sintetiza, recopila y publica las principales aportaciones empíricas en el ámbito educativo. Todo ello en un fuerte ámbito de apoyo económico y político.

\footnotetext{
${ }^{5}$ A.E.R.A.: American Educational Research Association. Análisis cientimétrico, conceptual y metodológico de la investigación española sobre evaluación de programas educativos (1975/2000).
} 
En Europa, sin embargo, la investigación educativa se ha realizado, en general, de una forma mucho más aislada y dispar, con escaso reconocimiento e insuficiente colaboración de las instituciones oficiales. La tradición investigadora sobre educación se remonta, en Gran Bretaña, a la creación del Instituto de Pedagogía de la Universidad de Londres, en 1931. Se destaca entre sus contribuciones más relevantes, por medio de la creación de centros de prestigio y la relevancia de ciertas figuras, o la publicación de revistas de prestigio mundial como: British Journal of Educational Tecnology, Research into Higher Education, Educational Research o British Journal of Educational Psychology, la construcción de test, la exploración de la inteligencia y delimitación de diferencias individuales, el diagnóstico de aptitudes escolares o la predicción del rendimiento, tomando como factor las implicaciones sociales (Expósito, 2002).

En Alemania, la investigación educativa tiene sus orígenes en los institutos psicológicos que han tratado aspectos diferenciales y psicológicos del desarrollo, siendo de gran importancia las aportaciones metodológicas cualitativas y la filosofía humanista, bajo el liderazgo de la escuela de Franckfurt y autores como Habermas y Dilthey.

El mismo autor, Expósito (2002) nos recuerda, en el ámbito francófono, el prolífico pasado en las primeras dos décadas del siglo veinte, de las instituciones educativas belgas, como la Universidad de Bruselas. Y de las francesas, a partir de los años cuarenta.

Desde la revolución bolchevique de 1923, en Rusia, se hace patente la preocupación por la Pedagogía, que lleva a fundar en 1943 la Academia de las Ciencias Pedagógicas. Enmarcándose todos los estudios que se realizan en planes quinquenales con planes de evaluación, centrados en el estudio de los contenidos curriculares, de métodos de enseñanza y formación del profesorado.

\subsubsection{La evaluación de programas en el marco internacional}

El empleo de programas como estrategia de intervención educativa tiene una historia relativamente reciente, en la que es posible constatar la evolución de la propia concepción de lo que es un programa y cómo debe ser su evaluación, como los avatares de su coexistencia con el resto de la investigación educativa. Como en muchos otros campos de la investigación educativa, la evaluación de programas encuentra a sus pioneros en Estados Unidos, donde desde finales del siglo XIX el sentido de la 
evaluación era entendido como sinónimo de aplicación de test para marcar diferencias individuales dentro de un grupo normativo, con poca relación con la evaluación de programas (Guba y Lincoln, 1985). En los años 30 del siglo XX, se comienzan a promover modelos centrados en la experimentación para comprobar la relación entre objetivos y resultados. Focalizando en la evaluación que centra su atención en la detección de diferencias individuales, mediante puntuaciones específicas se quiere comprobar el nivel de cumplimiento de parámetros previamente establecidos. Se consolida esta etapa entorno a los años 50, en los trabajos de Tyler, que hacen referencia a los objetivos del programa y a la descripción de la medida. Para algunos autores es aquí dónde comienza y se consolida la Evaluación de Programas, tal y como hoy se entiende, en el entorno de las actividades de evaluación de objetivos desarrolladas por Tyler. Modelo que ha tenido una gran influencia posterior debido a su lógica básica, y a que era científicamente aceptable y fácil de aplicar. La sustitución de estos modelos basados en las concepciones taylerianas se produce precisamente por su reduccionismo, ya que la consideración exclusiva de la consecución de objetivos no parece un factor para medir el éxito global de un programa.

En los años 60 con la promulgación de la Ley Every Student Succeeds Act - ESSA o $E S S E A$, en la que se concede gran importancia a los mecanismos evaluativos dentro del propio proceso educativo, se comienza a hablar de programas, sobre todo en el ámbito de la orientación psicoeducativa, en su doble faceta profesional de guidance y counseling. Siendo en esta segunda mitad del s. XX, cuando se produce un gran auge de la disciplina, evolucionando de la etapa de inocencia al realismo. Las nuevas pretensiones no alcanzan tan sólo a aspectos como la medida, sino que además se pretende describir e interpretar; aunque todavía bajo el predominio de la evaluación como investigación positivista, mediante el empleo de procedimientos estandarizados para la recogida y el análisis de datos orientados a la toma de decisiones.

Durante los años 70, la evaluación centra su objeto y atención en los programas formativos, existiendo una gran demanda y voluntad de rendir cuentas sobre el mérito y efectividad de los programas educativos (accountability), y realizándose un gran esfuerzo por garantizar la exactitud de las medidas que se toman, mediante el establecimiento de unas claras pautas metodológicas, que como las ofrecidas por Campbell y Stanley (1982), siguen orientando en cierto sentido, la investigación evaluativa actual. Incluso durante este periodo, se produce una profesionalización de la 
evaluación, y se elaboran normas para la evaluación de programas y materiales (Joint Committee on Standars for Educational Evaluation, 1981/1998).

Este desarrollo culmina en Estados Unidos, Canadá y algunos países europeos durante los años ochenta, cuando comienza a producirse un asentamiento científico y la aceptación social de la evaluación de programas educativos. Y aunque se cuestiona la viabilidad de los estudios experimentales en el ámbito de las Ciencias Sociales, se abren nuevas perspectivas que suponen la incorporación de nuevos modelos evaluativos y de nuevas estrategias metodológicas, tanto cuantitativas (diseños correlacionales, series, técnicas de clasificación, etc.) como cualitativas. Algunas de estas múltiples concepciones, propuestas desde una pluralidad de perspectivas, han sido en ocasiones consideradas exageradamente como modelos, sin tener el rigor y validez propio de estos, siendo esta concepción uno de los principales handicaps en el desarrollo de la disciplina como campo científico.

Hoy en día, nadie duda de lo complejo del objeto de estudio de las Ciencias Sociales, de las diversidades metodológicas de su investigación y los problemas que plantea su evaluación. Y tampoco, que esta situación encuentra algunas dificultades al no existir una concepción paradigmática lo suficientemente fuerte y unitaria que oriente la teoría y sustente la práctica investigativa y evaluativa de forma diferencial a otras. Las posibilidades de la evaluación de la investigación como proceso de mejora, se ven empañadas por una escasa mentalidad y concienciación evaluativas. A escala internacional, la situación actual se define por la utilización de múltiples modelos que se aplican a distintos contenidos (necesidades, diagnóstico, productos o impacto), la multidisciplinaridad (análisis etnográfico y estadístico), el análisis cientimétrico, conceptual y metodológico de la investigación española sobre evaluación de programas educativos y la multidimensionalidad en objetivos, en perspectivas y niveles de valoración (validez, credibilidad, costes, rentabilidad, aplicabilidad).

En síntesis, se usan múltiples metodologías, múltiples impactos, múltiples formatos de información. Una consecuencia de este panorama es sin duda la dificultad de conceptualizar la evaluación de programa como campo, encontrándose múltiples definiciones en la que cada autor destaca lo que más le interesa. Sin embargo, prueba de la importancia que se le comienza a ofrecer a esta tarea evaluativa es que en algunos países la evaluación de programas está institucionalizada, no sólo como ajuste de las 
intervenciones públicas a unos estándares o criterios y a un gasto público, sino como proceso de mejora y perfeccionamiento.

Algunos de estos problemas de la evaluación educativa en general y de la evaluación de programas en concreto, serían:

- Los modelos de evaluación fracasan como modelos científicos. Para Cook y Reichardt (1979) la relación entre paradigmas y métodos es instrumental, siendo la metodología una simple colección de técnicas y procedimientos, no siendo axiomáticos ni deductivos y con limitaciones en su generalización.

- Es necesario imprimir una dinámica evaluativa como proceso constructivo formativo/sumativo, utilizando metodologías complementarias, diversidad de instrumentos y técnicas, que permitan una evaluación válida y eficaz con alto grado de responsabilidad social. Su valor reside en ayudarnos a pensar, ser fuente de nuevas ideas o técnicas y servir de esquema mental de cuestiones a considerar o que no debemos olvidar.

- Se hacen necesarias fuentes de triangulación en diversos aspectos del proceso: datos, investigador, teoría y metodología. Existen dos tendencias actuales: una, hacia la complementariedad metodológica, pero primando las metodologías cualitativas; y otra, el carácter amateur al considerar que cualquier docente puede investigar, aún sin preparación específica.

Y desde la perspectiva de la práctica evaluativa, los problemas que habrá que cuidar en la evaluación de programas se refieren sobre todo a la tendencia del programa o centro a cambiar mientras se está siendo evaluado, las relaciones entre evaluadores/evaluados y el hecho de que el sistema socio político en el que se inserta el programa determine éste incluso en cuestiones que no debería. Por tanto, en general, la investigación evaluativa sigue adoleciendo de las limitaciones de las disciplinas incipientes o en ciernes de reestructuración. Sólo una enorme seriedad en las fundamentaciones teóricas, mayor rigor en los procesos metodológicos, aumento de los canales y estilos en la comunicación harán generar la suficiente consistencia científica como para ofrecer mayor credibilidad y mejorar las posibilidades de difusión. 


\subsection{Normativa nacional sobre Evaluación}

En el sistema educativo español la evaluación se ha desarrollado a la par que las distintas reformas de leyes educativas, como se vio en el apartado 1.4.2. (Figura 3). Y éstas a su vez han ido cambiando según ha ido variando el objeto de evaluación. Las leyes educativas en España han pasado, desde la Constitución por varias etapas, como se indicó en la figura 3.

Las distintas leyes que han sido llevadas a cabo por el sistema educativo español han tenido cambios dependiendo del clima político en ese momento. Pero el hito en la educación patrimonial ha sido la Ley de Ordenación General del Sistema Educativo (LOGSE, 1990), ya que es la ley que da más poder educativo a las comunidades autónomas, permitiendo que redactaran parte importante de los contenidos educativos, se adapta a un modelo más tecnológico en la educación, y amplía la escolaridad obligatoria a los 16 años, además de introducir la Educación Secundaria Obligatoria. Además, es la ley que introduce un tipo de evaluación que intenta la igualdad y la equidad entre el alumnado, siendo un modelo de democratización de la educación. No se da una evaluación diagnóstica, que se introduce posteriormente con la Ley Orgánica de Calidad de la Educación (LOCE), una ley que no aborda la evaluación de forma global, pero sí continua. Y, por último, la Ley Orgánica de Educación (LOE) aborda todos los tipos de evaluación: continua, global y diagnóstica.

En la Ley Orgánica de Mejora de la Calidad Educativa (LOMCE) se producen tres cambios importantes que afectan a todas las etapas educativas:

a) Por un lado, se definen términos como currículo, como: "la regulación de los elementos que determinan los procesos de enseñanza y aprendizaje para cada una de las enseñanzas" (p. 12) y aparece también un nuevo elemento en el currículo como los estándares de aprendizaje, importantes para las pruebas externas, otro nuevo elemento de la ley. Las competencias también cambian, dejan de ser ocho para ser siete y se denominan de forma distinta "competencias clave". La Recomendación 2006/962/EC, del Parlamento Europeo en 2006, sobre las competencias clave para el aprendizaje permanente, insta a los Estados miembros a "desarrollar la oferta de competencias clave”. De esta manera se delimita la definición de competencia, entendida como una combinación de conocimientos, capacidades, o destrezas, y actitudes adecuadas al contexto. Se encuentran distintas definiciones de competencia en la revisión de la literatura sobre el tema, como: 
La capacidad de actuar de manera eficaz en un tiempo definido de situación, una capacidad que se sustenta en conocimientos, pero que no queda reducida a estos (Perrenoud, 1999).

Un saber hacer complejo, resultado de la integración, la movilización y la adecuación de capacidades (conocimientos, actitudes y habilidades) utilizados eficazmente en situaciones que tengan un carácter común (Lasnier, 2000).

Un complejo que implica y comprende, en cada caso, al menos cuatro componentes: información, conocimiento (apropiación, procesamiento y aplicación de la información), habilidad y actitud o valor (Schmelckes, citada por Barrón, 2000).

La capacidad de movilizar y aplicar correctamente en un entorno laboral determinados recursos propios (habilidades, conocimientos y actitudes) y recursos del entorno para producir un resultado definido (Le Boterf, 2001).

Es la habilidad aprendida para llevar a cabo una tarea, un deber o un rol adecuadamente. Un alto nivel de competencia es un pre-requisito de buena ejecución. Tiene dos elementos distintivos: está relacionada con el trabajo específico en un contexto particular, e integra diferentes tipos de conocimientos, habilidades y actitudes. Hay que distinguir las competencias de los rasgos de personalidad, que son características más estables del individuo. Se adquieren mediante el learning-by-doing y, a diferencia de los conocimientos, las habilidades y las actitudes, no se pueden evaluar independientemente (Roe, 2002).

Las competencias son los conocimientos, las habilidades y las motivaciones generales y específicas que conforman los pre-requisitos para la acción eficaz en una gran variedad de contextos con los que se enfrentan los titulados superiores, formuladas de tal manera que sean equivalentes a los significados en todos estos contextos (Allen et al., 2003).

En el proyecto Tuning (2003), se define competencia como una combinación dinámica de atributos, con relación a conocimientos, habilidades, actitudes y responsabilidades, que describen los resultados del aprendizaje de un programa educativo o lo que los alumnos son capaces de demostrar al final de un proceso educativo (Tuning, 2003).

AQU, en su Marc general per a la integració europea, define la competencia como la combinación de saberes técnicos, metodológicos y participativos que se actualizan en una situación y un momento particular (AQU, 2004). 
ANECA define el término competencia como el conjunto de conocimientos, habilidades y destrezas relacionados con el programa formativo que capacita al alumno para llevar a cabo las tareas profesionales recogidas en el perfil de graduado del programa (ANECA, 2004).

La competencia es la capacidad de responder con éxito a las exigencias personales y sociales que nos plantea una actividad o una tarea cualquiera en el contexto del ejercicio profesional. Comporta dimensiones tanto de tipo cognitivo como no cognitivo. Una competencia es una especie de conocimiento complejo que siempre se ejerce en un contexto de una manera eficiente. Las tres grandes dimensiones que configuran una competencia cualquiera son: saber (conocimientos), saber hacer (habilidades) y ser (actitudes) (Rué, 2005).

El conjunto de capacidades instrumentales y actitudinales, habilidades, aptitudes y disposiciones que se adquieren, se desarrollan y evolucionan para dirigir un proceso con el fin de solucionar problemas en cualquier aspecto de la vida (Sánchez-Macías, 2014, p.6).

Se considera que "las competencias clave son aquellas que todas las personas precisan para su realización y desarrollo personal, así como para la ciudadanía activa, la inclusión social y el empleo" (Orden ECD/65/2015, p.6986).

Es decir, el aprendizaje no solo ha de ser de unos conceptos, sino que también han de adquirir habilidades y actitudes. Las competencias clave son de dos tipos: dos básicas (lingüística y matemáticas, ciencia y tecnología) y cinco transversales (digital, aprender a aprender, sociales y cívicas, iniciativa y emprendimiento, conciencia y expresión cultural).

b) Por otro lado, las asignaturas pasan a ser troncales, específicas y de libre configuración autonómica, dependiendo de las competencias que les asignen las autonomías.

c) Y, por último, las evaluaciones externas que se realizan en todas las etapas, pero solo en la Secundaria y el Bachillerato; en este último tendrán efectos académicos.

En la ley vigente hoy día, la LOMCE, se han producido varios cambios a nivel de la Educación Secundaria Obligatoria: se organizó en dos ciclos $\left(1^{\circ}, 2^{\circ}\right.$ y $3^{\circ}$, como primer ciclo y $4^{\circ}$, segundo). El $4^{\circ}$ de ESO tiene carácter propedéutico con enseñanzas académicas y aplicadas, dependiendo si opta por Bachillerato o Formación Profesional. 
En $3^{\circ}$ y $4^{\circ}$ se suprimen los programas de Diversificación Curricular y se introducen Programas de Mejora del Aprendizaje y el Rendimiento (PMAR). Desaparece la asignatura Educación para la Ciudadanía de $2^{\circ}$ y la Religión es sustituida por Valores Éticos, con contenidos curriculares.

En cuanto a la evaluación de Aprendizajes, es continua, formativa e integradora. La promoción se decide a nivel de claustro. El alumnado promociona cuando supere todas las asignaturas del curso o tengan dos suspensos (que no sean Matemáticas y Lengua a la vez). Con tres suspensos o más, repiten curso. Se exceptúan los casos en que tengan dos o tres suspensos que no sean Lengua y Matemáticas simultáneamente, que el equipo de docentes valore que no se impide seguir con éxito el siguiente curso y que apliquen las medidas de atención propuestas por el equipo de orientación. Se puede repetir curso dos veces en la misma etapa y cada curso una sola vez. El alumnado puede repetir una segunda vez el $4^{\circ}$, si no repitió en los cursos anteriores.

La evaluación externa-titular consiste en que una vez que finalizan $4^{\circ}$ necesitan superar la prueba para la opción que prefieran: Prueba de Enseñanzas Académicas para Bachillerato.

Para obtener el título de Graduado en Educación Secundaria Obligatoria se necesita superar la evaluación final y obtener una calificación superior a 5 sobre 10, ponderando con un $70 \%$, la media de las calificaciones de las materias cursadas en la ESO y con un $30 \%$ la nota de la evaluación final de la ESO. Pero esta evaluación es muestral, sin efectos académicos.

En cuanto al Bachillerato, la ley actual mantiene las tres modalidades de la LOE, como son: Ciencias, Humanidades y Ciencias Sociales, y Artes. Se realiza una evaluación del aprendizaje continua y diferenciada según las materias y acorde con los distintos aspectos del currículo. Quien decide si el alumnado logra los objetivos y adquiere las competencias correspondientes es el profesorado de cada asignatura. Todo el equipo docente valora la evolución de cada alumno o alumna en el conjunto de materias y su madurez académica con respecto a los objetivos del Bachillerato. Las Administraciones regulan las condiciones para que los centros organicen las pruebas extraordinarias e individualizadas para aquellos que deban recuperan materias con evaluación negativa. El Bachillerato consta de dos cursos y al finalizar el primero, el profesorado decide sobre la promoción al segundo curso. Para obtener el título de bachiller se necesita superar la evaluación final de Bachillerato que se pondera con un $60 \%$ la media de las 
calificaciones de las materias del Bachillerato y con un $40 \%$ la nota obtenida en la evaluación final del Bachillerato.

Según el artículo 28 (para ESO) y 36 (para bachillerato) de la LOMCE

(...) la evaluación del aprendizaje del alumnado será continua y diferenciada según las distintas materias. El profesorado de cada materia decidirá, al término del curso, si el alumno o alumna ha logrado los objetivos y ha alcanzado el adecuado grado de adquisición de las competencias correspondientes. (p.40)

En su artículo 20 (para la ESO, el 30 es parecido en la etapa de Bachillerato, aunque con pequeñas diferencias) el RD 1105/2014 establece tres ideas clave en cuanto a las evaluaciones:

1) Los referentes para saber si las competencias se están adquiriendo y si estamos consiguiendo los objetivos, son los criterios de evaluación y estándares de aprendizaje evaluables que figuran en los anexos I y II del RD 1105/2014.

2) La evaluación tiene que cumplir tres características: debe ser continua, formadora e integradora.

3) Hay que hacer una evaluación del alumnado, pero también de la práctica docente. De estas tres ideas que propone la ley nacional se pueden desprender varios aspectos de estas etapas educativas a tener en cuenta. Por un lado, hay que tener claras las competencias que el alumnado debe adquirir y desarrollar, y los objetivos que se pretenden en cada una de las asignaturas. Por otro, hay que tener claras las diferencias entre criterios de evaluación y estándares de aprendizajes. Para esto, la ley también ayuda con sus definiciones:

Criterios de evaluación:

(...) el referente específico para evaluar el aprendizaje del alumnado. Describen aquello que se quiere valorar y que el alumnado debe lograr, tanto en conocimientos como en competencias; responden a lo que se pretende conseguir en cada asignatura.

Estándares de aprendizaje evaluables:

(...) especificaciones de los criterios de evaluación que permiten definir los resultados de aprendizaje, y que concretan lo que el estudiante debe saber, comprender y saber hacer en cada asignatura; deben ser observables, medibles y evaluables y permitir graduar el rendimiento o logro alcanzado. Su diseño debe contribuir y facilitar el diseño de pruebas estandarizadas y comparables (artículo 2 del RD $1105 / 2014)$ 
A niveles prácticos, se puede entender que los criterios son más generales y los estándares más específicos y esto ayuda a que se puede graduar con más soltura el rendimiento. La evaluación de los objetivos y las competencias parten de estos útiles de la evaluación que después se traducirán en la calificación.

Es un proceso en cadena, en el que hay que definir los objetivos y las competencias, en una primera instancia, para después evaluarlos. Para evaluarlos, también la norma propone: "2. Han de establecerse las relaciones de los estándares de aprendizaje evaluables con las competencias a las que contribuyen, para lograr la evaluación de los niveles de desempeño competenciales alcanzados por el alumnado" (artículo 7 de la Orden ECD 65/2015)

Es decir, se relacionan las competencias y objetivos con sus estándares de aprendizaje. Otro aspecto importante son los niveles de desempeño competenciales, que se traducen en una escala Likert que el propio profesorado debe diseñar a su gusto para tal evaluación.

Aunque en la misma Orden se dice que:

6. El profesorado debe utilizar procedimientos de evaluación variados para facilitar la evaluación del alumnado como parte integral del proceso de enseñanza y aprendizaje, y como una herramienta esencial para mejorar la calidad de la educación

En todo caso, los distintos procedimientos de evaluación utilizables, como la observación sistemática del trabajo de los alumnos, las pruebas orales y escritas, el portfolio, los protocolos de registro, o los trabajos de clase, permitirán la integración de todas las competencias en un marco de evaluación coherente.

Se pueden utilizar los medios que se tienen a disposición para evaluar, siempre y cuando se establezcan los niveles de desempeño de las competencias que se pretenden adquirir y desarrollar en las materias.

En Castilla y León, como en el resto de comunidades, la ley está basada en la norma nacional, por ello, la adaptación que se realiza es contextualizada a cada comunidad. La Orden establece en su capítulo IV todo lo relacionado con la evaluación: evaluación, promoción y titulación; objetividad en la evaluación y los documentos oficiales para la evaluación, tanto en Secundaria como en Bachillerato. 
"Eres como ese anillo: una joya, valiosa y única. Y como tal, solo puede evaluarte un verdadero experto"

Jorge Bucay 


\section{EVALUACIÓN PATRIMONIAL: ESTADO DE LA CUESTIÓN. ANÁLISIS DE REFERENTES}

\subsection{Introducción}

Evaluación Patrimonial es un término que se ha venido utilizando desde el ámbito socioeconómico para valorar los bienes materiales de las personas, sus bienes patrimoniales. Sin embargo, se utiliza en este epígrafe para detallar la evaluación de programas y la evaluación de aprendizajes en el ámbito del patrimonio entendido desde una visión educativa, como el vínculo que une a las personas con sus objetos patrimoniales.

\footnotetext{
Se debe impulsar el desarrollo de propuestas con un enfoque didáctico, basado en contextos y modos de aprendizaje, en el que primen los diseños adecuados de estrategias de enseñanzaaprendizaje y las actitudes, junto con cuestiones conceptuales. Igualmente, la evaluación del proceso de enseñanza-aprendizaje ha de convertirse en un elemento fundamental; de tal forma sería interesante que el espacio web contase con herramientas, técnicas e instrumentos básicos para que la evaluación pudiera ejecutarse en todo momento. Los esfuerzos dedicados a la evaluación de los aprendizajes, de la eficacia de los procedimientos, de la efectividad de las estrategias didácticas o de los propios contextos educativos, son una garantía de mejora (PN, 2015, p.7).
}

Se detallan a continuación los distintos grupos de investigación, tanto nacionales como internacionales, publicaciones y otras transferencias de conocimiento que aportan base a la presente investigación, en relación a la evaluación patrimonial.

\subsection{Investigaciones referentes}

\subsubsection{Grupos de investigación nacionales}

Las investigaciones que se llevan a cabo a nivel nacional en este campo de las ciencias sociales se ciñen principalmente a transferencias generadas por distintos grupos de investigación. Estos han nacido en el seno de las universidades españolas, gracias a la colaboración entre distintos agentes e instituciones, como el Ministerio de Educación Cultura y Deporte o las ayudas económicas de los Fondos Europeos de Desarrollo Regional (FEDER), instrumento financiero de la Comisión Europea cuya finalidad es la ayuda para el desarrollo económico de las regiones deprimidas de la Unión Europea. En este contexto, pueden desarrollarse investigaciones transferidas a publicaciones en revistas especializadas, libros específicos del área o tesis doctorales. Se presentan en ese 
orden cada uno de ellos, haciendo hincapié en la importancia dada a la Educación Patrimonial.

\subsubsection{Grupo de investigación EPITEC}

\section{Educación Patrimonial para la inteligencia territorial y emocional de la ciudadanía, Universidad de Huelva}

El grupo está liderado por el Dr. Cuenca. Son cogestores de un Máster en Educación Patrimonial con la Universidad de Extremadura y la Universidad Internacional de Andalucía.

Su investigación se desarrolla en el Área de las Ciencias Sociales y Ciencias Experimentales. Su enfoque teórico y metodológico puede definirse como sociocrítico y participativo. Como es habitual en el marco de las Ciencias Sociales, se establece una correlación y una sinergia entre las investigaciones y dinámicas de educación para la ciudadanía y la Educación patrimonial. Paralelamente a lo anterior se estudia la formación de la identidad personal y social. Su foco de población estudiada congrega estudios específicos sobre su área territorial local, y otros también sobre el contexto europeo.

Como área transversal se estudia la Educación Patrimonial en museos. Además, se realizan comparaciones entre los recursos específicos de esta área, en educación formal y no formal (en especial Primaria y Secundaria).

Son de destacar sus análisis y diseño de materiales y recursos educativos (libro de texto) destinados a la Educación Patrimonial. Como línea paralela a ésta se estudian las dificultades de los docentes de Educación Primaria y Secundaria en relación a sus recursos para la Educación Patrimonial.

Entre los artículos más destacados se encuentra el de Estepa (2008), que refleja una homogeneidad en concepciones pedagógicas entre docentes de distintas áreas, a diferencia de su heterogeneidad de contenidos. En el ámbito de la publicación y crítica de libros de texto, en un artículo (Estepa, 2011) se da importancia a la dicotomía encontrada en los grupos de investigación entre definiciones de Patrimonio y actuaciones prácticas, y también a las divergencias en los elementos de recogida de datos.

Otro de los trabajos importantes de este grupo, (Cuenca 2010) en el que se estudiaron los factores correlacionales respecto a la conceptualización de la educación patrimonial, entre administradores y docentes. 
En revista nacional destacamos la investigación (Cuenca, 2014) en la que, tanto el profesor Cuenca, como la profesora Martín-Cáceres analizan 24 libros de texto de las tres principales editoriales nacionales en E.S.O., detectando el perfil histórico, artístico y monumental- arquitectónico que todas dan a la Educación Patrimonial.

En el trabajo de Cuenca y Martín-Cáceres (2017), se propone una visión interdisciplinar de la educación patrimonial entre las ciencias sociales, naturales y experimentales. Y se defiende el enfoque sociocrítico de la misma, mediante análisis cualitativos y cuantitativos.

Desde una perspectiva global el grupo de investigación de Huelva nos aporta tanto en la evaluación de proyectos como en la de aprendizajes una apuesta por el enfoque sociocrítico. Al tener un enfoque territorial en Andalucía claramente asentado, nos invita a la profundización en la importancia de los estudios locales en paralelo al tema de la identidad. Tanto Andalucía como Castilla y León son regiones con importantes crisis económicas y problemas estructurales que, siguiendo el enfoque utilizado en la Universidad de Huelva, nos influye en nuestro análisis categorial de programas educativos y patrimoniales.

\subsubsection{Grupo de investigación DICSO}

\section{Didáctica de las Ciencias Sociales, Universidad de Murcia}

Este grupo es liderado por Pedro Miralles Martínez. Su ámbito genérico de actuación son las Ciencias Sociales. De forma particular realizan estudios sobre la identidad regional a través de los currícula de Educación Primaria, Educación Secundaria y Bachillerato, igualmente sobre el concepto de familia. En conexión con esta tesis se valora sus trabajos sobre la percepción de profesorado y alumnado sobre los currícula y los sistemas de evaluación en Geografía e Historia, actualmente vigentes en el sistema educativo.

Todo este bagaje teórico se plasma en sus análisis y diseño de materiales y recursos educativos destinados a la Educación en Ciencias Sociales: materiales de evaluación y unidades didácticas.

Destacamos los artículos de Gómez y Miralles (2016) respecto a la evaluación de competencias históricas en los manuales escolares de España y Francia.

Y en las revistas anglosajonas, igualmente de Gómez y Miralles (2016) donde se desarrollan enfoques relativos al assessment. 
Paralelamente en revistas españolas encontramos el trabajo de Gómez, Miralles y Molina (2015) que profundiza en cómo adaptar la evaluación al nuevo marco legislativo de competencias del alumno y hacerla coherente con la epistemología específica de la enseñanza de la Historia.

El particular, este enfoque hacia las competencias históricas del grupo de Murcia nos ayuda en la variable territorial estratégica de Castilla y León, en la puesta en valor del extenso patrimonio histórico regional, y de cómo consolidar la conciencia regional a través de programas y aprendizajes.

\subsubsection{Grupo de investigación ECPEME}

\section{Evaluación Cualitativa de Programas Educativos en Museos españoles, Universidad de Oviedo}

El grupo está liderado por Roser Calaf Masachs.

Su área de investigación preferente ha sido los Museos. Respecto a nuestra evaluación de programas hemos estudiado sus análisis y diseño de los programas de Educación patrimonial en los Museos. El grupo ha elaborado una metodología del estudio de programas educativos en museos extrapolable a nivel nacional e internacional.

E igual que en nuestra tesis ha habido una elaboración sistematizada de estándares de calidad en la educación en los Museos.

Más allá del ámbito museístico, también han promovido un análisis de la correlación entre la Educación patrimonial en los Museos y en el Sistema educativo.

Así, destacamos sobre evaluación cualitativa de la acción museística el artículo de Suárez, Gutiérrez, Calaf y San Fabián (2013) donde se bosqueja un modelo de evaluación de programas en museos a través de la elaboración, discusión y aplicación de indicadores y descriptores. Dicho modelo pretende ser extensible a los distintos contextos de museo.

Del grupo de Oviedo nos ha interesado la pretensión modelizadora de su diseño de evaluación de programas museísticos para hacer traslación a nuestros programas de carácter generalista en el patrimonio castellano leonés.

\subsubsection{Grupo de investigación GIPYPAC}

\section{Investigación en patrimonio y paisajes culturales, Universidad del País Vasco}

El grupo es liderado por Alex Ibáñez Etxeberría. Como enfoque teórico podemos destacar su utilización de los enfoques participativos y sociocríticos. 
Respecto a sus ámbitos de investigación vemos los contextos de aprendizaje estudiados en estudios específicos sobre ciertos Museos del País Vasco. Así se ha estudiado la educación patrimonial en museos estableciéndose una comparación de recursos educativos específicos de esta área en educación no formal y formal.

En la última década nos han aportado un profundo análisis del uso de las TIC en Educación patrimonial y además del uso de las TIC en los programas educativos de los Museos.

También el ámbito arqueológico ha sido un foco de interés del grupo, aportándonos el uso de las TIC en yacimientos arqueológicos en colaboración con el Grupo de trabajo GIPYPAC de la UPV/EHU.

Como recientes estudios destacamos las posibilidades educativas de los nuevos dispositivos y APPS móviles GPS PDA.

De este modo, sobre investigaciones aplicadas al territorio concreto, destacamos el artículo de Vicent, Asensio, Ibáñez (2012), donde se evalúan los resultados sobre aprendizaje de contenidos y Tecnologías de Información y Comunicación (TIC), con sus factores positivos y otros sin determinar.

Ya en el trabajo de Kortabitarte et al. (2017) hay una posterior evaluación de aprendizajes en relación a las Aplicaciones (APP), en el que se proponen cinco dimensiones de análisis del tema a partir de la creación, recreación y delimitación de indicadores.

Destacamos el profundo asentamiento y análisis territorializado de las investigaciones de este grupo. El territorio y la comunidad y su tratamiento por los programas es el legado que hemos adoptado en nuestro análisis estructurado de programas de educación patrimonial.

Igualmente es prioritario como conjugar el territorio y los elementos con mayor valor identitario del mismo, con las tendencias más contemporáneas de la sociedad, como las TIC, que unitariamente han sido desarrollados por este grupo de investigación. El grupo ha trasladado así la dicotomía tradición/modernidad del País Vasco, que es una dicotomía con unas diferencias particulares, que habría que abordar en todas las comunidades españolas. 


\subsubsection{Grupo de investigación Educomunicación web 2.0}

\section{Educomunicación web 2.0 del patrimonio, Universidad de Zaragoza}

El grupo está liderado por Pilar Rivero García. Se desarrollan las investigaciones especialmente en el ares de: Área de Ciencias Sociales e Historia. Especialmente han realizado trabajos sobre ciencias sociales e Historia aplicados a la región aragonesa y en especial al período Romano.

El área museística es también de su interés, en concreto la educación patrimonial en museos aportando estudios monográficos sobre museos aragoneses

Como traslación a los recursos educativos han desarrollado un análisis y diseño de materiales y recursos educativos (materiales multimedia) destinados a la Educación Patrimonial

Respecto a las nuevas tecnologías nos han inspirado en el uso de las TIC en la enseñanza de las Ciencias Sociales. Especialmente también en el uso de las TIC en los programas educativos de los Museos.

Como líneas específicas de interés vemos el aprendizaje Multimedia de la Historia. El mundo Romano, las culturas precolombinas etc., paralelamente la atención a nuevas corrientes artísticas y su versión educativa: Manga, cómic, etc.

El artículo de Fontal et al. (2017) relaciona la presencia de los contenidos patrimoniales en los currícula de Educación Primaria y la escasez de materias específicas sobre Patrimonio en el Grado de Educación Primaria, generando así la reflexión necesaria sobre la formación del profesorado y del alumnado de Primaria.

Respecto a la Educación Patrimonial en relación con las TIC, punto fuerte del grupo de Zaragoza, destacamos el artículo que aporta un estado de la cuestión de Ibáñez, Fontal, Rivero (2018), en el que destaca la mención a programas referentes, mediante una selección de casos que aporta una prospección de futuro sobre el tema. La conjunción que destacamos del grupo de Zaragoza es la visión panorámica y exhaustiva de numerosas etapas históricas de la historia aragonesa, y de la nacional y mundial, unida al uso e investigación sobre las nuevas tecnologías.

\subsubsection{Grupo de investigación RODA}

\section{Universidad de Santiago de Compostela}

El grupo es liderado por Ramón López Facal.

Destacan entre sus líneas de investigación la investigación interdisciplinar en el área de ciencias sociales y experimentales, además de otros ámbitos relacionados con la 
educación patrimonial, ya que está integrado por 35 personas de las didácticas aplicadas de las áreas de Didáctica de las Ciencias Experimentales, de las Ciencias Sociales, de las Lenguas y Literaturas y de las Matemáticas.

Respecto a la evaluación de programas han profundizado en trabajos sobre la metodología científica y su adaptación a los currícula. Respecto a la recepción que se hace de los programas interesan sus líneas específicas sobre la percepción de profesores y alumnos de los currícula y los sistemas de evaluación de Geografía e Historia actualmente vigentes en el sistema educativo.

Como línea transversal interesan sus estudios sobre la identidad regional a través de los currícula de Educación Primaria, Secundaria, Bachillerato y los estudios de la identidad y su contexto histórico, geográfico y patrimonial.

Dentro del marco teórico de la identidad, clave de este grupo, destacamos el artículo de Castro y López-Facal (2019) enfocado a las necesidades descritas por los docentes vinculados al área de la educación patrimonial. En el artículo y respecto a cómo deben elaborarse programas de esta materia afloran las carencias en formación específica, en generación de materiales y en adaptación al contexto territorial.

Respecto a la evaluación de aprendizajes desarrollan también una línea trasversal de estudios sobre la identidad lingüística en el contexto específico de una Comunidad autónoma bilingüe como Galicia, Competencias de argumentación y razonamiento e Identidad y estudios literarios.

Por tanto, de este grupo de Santiago hemos adoptado la observación precisa del enfoque territorializado, tanto en programas como en aprendizajes. Al tratarse de una región, Galicia con ciertas similitudes en los problemas estructurales y socioeconómicos con Castilla y León, nos ha servido en nuestro estudio categorial de los programas de la comunidad castellana.

\subsubsection{Grupo de investigación DiHiGeCs}

\section{Didáctica de la Historia, Geografía y ciencias sociales, Univesidad de Barcelona}

El grupo es liderado por Joan Santacana i Mestrer.

Destacan entre sus áreas de investigación sus estudios sobre la museografía con amplia experiencia en Barcelona y Cataluña y en proyectos en el resto del Estado, y a nivel europeo. También como línea especializada su traslación científica y metodológica de los modelos europeos de enseñanza de la Historia y Arqueología y paralelamente los 
Estudios sobre yacimientos arqueológicos y su interacción con programas educativos tanto en Enseñanza formal como no formal.

En el ámbito museístico destacamos la colaboración con museos locales diseñados a nivel educativo e institucional por miembros del grupo. Y en el editorial la colaboración en editoriales y revistas promovidas por miembros del grupo e igualmente el análisis y diseño de materiales y recursos educativos destinados a la Educación en Historia: materiales de evaluación, unidades didácticas, libros de texto.

Acerca de la evaluación de programas y aprendizajes nos han inspirado sus estudios sobre la percepción de profesores y alumnos de los currículos y los sistemas de evaluación de Geografía e Historia actualmente vigentes en el Sistema educativo. Para la evaluación de aprendizajes interesa el artículo de Santacana et al. (2016), que aporta el enfoque cualitativo de las opiniones de los grupos de edades objetivo de la tesis, en este caso, opiniones sobre la Educación Patrimonial centrada en los Museos, institución en que se enfoca buena parte de las investigaciones de este grupo.

\subsubsection{Grupo de investigación DIDPATRI}

\section{Didàctica del Patrimoni, Museografia comprensiva i noves ì tecnologies, Universidad de Barcelona}

El grupo está liderado por Xavier Hernández Cardona, adjudicatario de varios proyectos nacionales de I+D. Este proyecto desarrolla actividades de investigación e innovación con la vocación de establecer corrientes de transferencia del conocimiento entre empresas emergentes del ámbito de las industrias culturales y de la administración. La didáctica del patrimonio y la museografía didáctica son los objetos prioritarios de investigación del grupo desde su inicio, aunque la investigación sobre didáctica de las ciencias sociales en el marco de la enseñanza formal y no formal también han formado parte de la esfera de intereses, así como las nuevas tecnologías y métodos aplicados a la investigación en historia.

Respecto al marco teórico contemporáneo y la contextualización del tejido cultural de nuestra evaluación de proyectos, nos hemos apoyado en dos artículos panorámicos como Rivero, Hernández (2015) y Hernández $(2002,2016)$ acerca de los diversos actores de la programación y gestión cultural y sus interacciones tanto en el ámbito estatal como en el catalán. 
Las investigaciones se gestan dentro de los grupos de investigación, aunque no siempre ha sido así. En España el impulso económico creciente, aunque lento de los proyectos de I+D+i (Investigación+Desarrollo+Innovación) ha provocado la aparición de proyectos de investigación de gran alcance y transferencia a la sociedad.

\subsubsection{El observatorio de Educación Patrimonial en España (OEPE)}

\section{Grupo de la Universidad de Valladolid}

En el caso del observatorio de educación patrimonial en España (OEPE), es un proyecto liderado por Olaia Fontal Merillas, que se ha gestado y desarrollado desde 2010 hasta la actualidad. Consta de tres proyectos sucesivos: el primero de ellos, denominado “Observatorio de Educación Patrimonial en España. Análisis Integral del estado de la Educación Patrimonial en España” (Ref. EDU2009-09679), se llevó a cabo entre 2010 y 2012, con subvención del Ministerio de Ciencia e Innovación. Dentro de esta primera etapa se llevaron a cabo acciones como la de localización, evaluación e inventario de programas de educación patrimonial, en España y distintos países.

El segundo proyecto, llamado "La educación en España: consolidación, evaluación de programas e internacionalización del OEPE" (Ref. EDU2012-37212), fue otro proyecto de $\mathrm{I}+\mathrm{d}+\mathrm{i}$, entre 2013 y 2015, que se centra principalmente en seleccionar programas de educación patrimonial y realizar una evaluación en base a estándares.

El tercer proyecto, que se ha llevado a cabo entre 2016 a 2018, se ha denominado "Evaluación de los aprendizajes en programas de Educación Patrimonial centrados en los procesos de sensibilización, valorización y socialización del patrimonio cultural" (Ref. EDU 2015/65716-C2-1-R); es un proyecto que ha hecho hincapié en las tipologías de los aprendizajes, cómo se adquieren, los procesos que se llevan a cabo y en qué ámbitos se desarrollan los aprendizajes en educación patrimonial, en aquellos programas referentes que hayan superado los estándares básicos y específicos. Los tres proyectos han recibido subvenciones del Ministerio de Economía y Competitividad y fondos europeos (Fondos Feder, Europa). Además, el OEPE ha sido financiado en el marco de la convocatoria de ayudas para el fomento de la cultura científica, tecnológica y de la innovación 2014 (FCT-14-9015).

El observatorio se desarrolla en unas fases concretas:

En el primer proyecto, fue conocer, analizar y diagnosticar el estado de la educación patrimonial en el territorio nacional. Para lograrlo, el proyecto se estructuraba en tres fases: 
- Conocimiento, análisis y diagnóstico (CAD),

- Sistematización y estandarización (SE) y

- Divulgación Científica y generación de redes de trabajo (DCR).

A continuación, se desarrolló el segundo proyecto en el que se desglosaron y añadieron tres nuevas fases:

- Consolidación (CON),

- Evaluación de Programas (EP) e

- Internacionalización (IN).

Para ello, se realizó, además, una evaluación basada en estándares de una selección de programas, atendiendo al enfoque teórico, las metas, la calidad del diseño y planificación de las actuaciones, el grado de cumplimiento y adecuación de la planificación (implementación) y, por último, la calidad y la utilidad de los resultados e impactos generados.

Y en el último proyecto, se desarrollaron las siguientes fases:

- Conceptualización y teorización de modelos de Educación Patrimonial (CTM-EP),

- Estudio de caso de programas de Educación Patrimonial (EC-EP),

- Definición de criterios de accesibilidad universal para el aprendizaje de contenidos patrimoniales (EP-Universal),

- Diseño de nuevos instrumentos de recogida de datos para la evaluación de aprendizajes (DIE-EP),

- Extensión del OEPE para potenciar los procesos de sensibilización, valorización y socialización del patrimonio (OEPE 3.0),

- Difusión e internacionalización de la investigación en la Educación Patrimonial (DIIEP). 


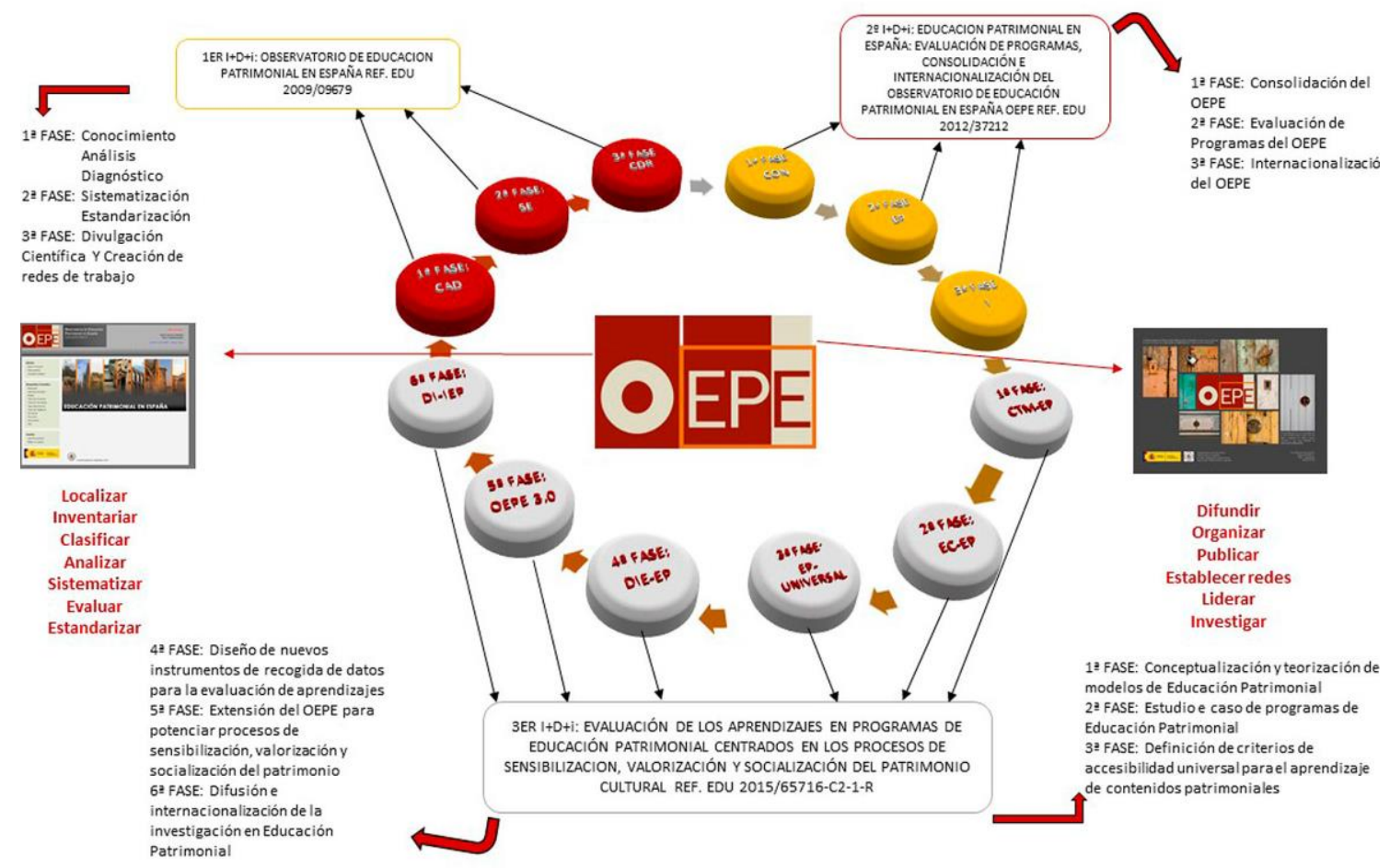

Figura 8. Fases del Observatorio de educación patrimonial en España. Fuente: www.oepe.es. Elaboración propia.

Existen tres componentes principales de transferencia del OEPE que se describen en la figura 9, que son:

1. Acciones de investigación

Estas acciones se refieren principalmente a las transferencias del conocimiento a través de:

- Congresos propios: Congreso Internacional de Educación Patrimonial CIEP I (2012):

Mirando a Europa: estado de la cuestión y perspectivas de futuro; el Congreso Internacional de Educación Patrimonial CIEP II (2014): Reflexionar desde las experiencias. Una visión complementaria entre España, Francia y Brasil; el Congreso Internacional de Educación Patrimonial CIEP III (2016): análisis, acción, innovación y reflexión en la educación patrimonial; el Congreso Internacional de Educación Patrimonial CIEP IV (2018): sobre proyectos internacionales y las comunidades patrimoniales. Cada uno de ellos con sus publicaciones de las Actas. 
- En los años intermedios en los que no se ha desarrollado congreso, se han diseñado las Jornadas Preparatorias del siguiente congreso, (PREP-1, PREP-2, PREP-3) con sus respectivas publicaciones.

- Cursos del proyecto de innovación docente Nuevas Estrategias para salvar el Patrimonio Cultural: personas, patrimonios y vínculos (NEP), como el curso Massive Online Open Courses (MOOC) de reciente lanzamiento sobre Nuevas estrategias educativas para el patrimonio industrial, arquitectónico y cultural.

- La página web Personas y patrimonios, un espacio para compartir patrimonios, interactiva abierta a todos los públicos, en la que cualquier persona puede intervenir con un texto y fotografía que describan su patrimonio particular.

- Contratos predoctorales para la realización de tesis doctorales en el marco del proyecto, dos del MINECO, dos de la Junta de Castilla y León y uno de la Universidad de Valladolid.

- Dos Artículos 83.

- Tesis doctorales.

- Publicaciones en libros de texto y revistas en papel y on-line.

2. Miembros investigadores

Los miembros del Observatorio pueden consultarse en la propia página. El OEPE está formado por un numeroso equipo investigador nacional e internacional con una reconocida trayectoria en el campo de la educación y el patrimonio, procedente de siete universidades españolas y una francesa. El equipo de investigación abarca nueve áreas de conocimiento: Didáctica de la Expresión Plástica, Didáctica de las Ciencias Sociales, Psicología, Didáctica y Organización Educativa, Didáctica de la Expresión Corporal, Didáctica de la Lengua y la Literatura, Música, Sociología y Expresión gráfica arquitectónica.

A su vez se ha ido configurando una red de investigación partiendo del Plan Nacional de Educación y Patrimonio, que unifica varios espacios: artistas, laboratorios, asociaciones, escuelas, diversidad funcional, museos y centros de patrimonio, localidades y barrios, redes 3.0, personas y grupos e investigadores. 


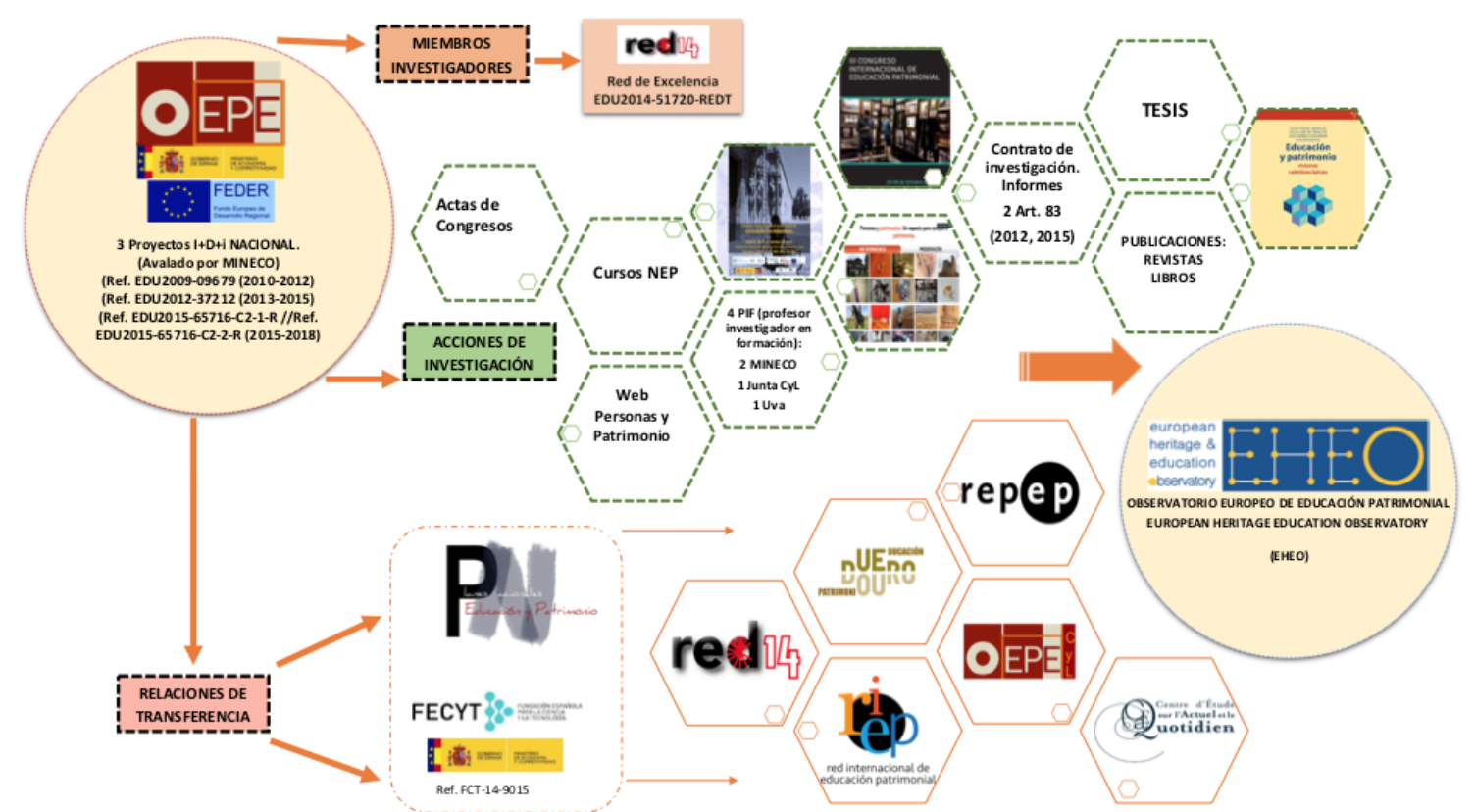

Figura 9. Esquema de componentes y funcionamiento del OEPE. Fuente: www.oepe.es. Elaboración propia.

\section{Relaciones de transferencia}

Las relaciones con otros grupos de investigación que se han desarrollado a lo largo de estos años desde el OEPE, han sido fructíferas y han ramificado el conocimiento a lo largo del territorio español, incluso fuera de él, formándose el EHEO: European

Heritage Education Observatoriy. Un observatorio para la transferencia de conocimiento desde España a Europa y viceversa.

Así, se ha relacionado con la RED14, una red de excelencia en la enseñanza de las ciencias sociales, constituido por diez grupos de investigación de 14 universidades, que se creó en 2014 con la finalidad de incentivar la colaboración e intercambio de proyectos, en campos como la educación patrimonial, la educación histórica, la construcción de identidades y el desarrollo de competencias sociales, entre otros. Por otro lado, sus relaciones también han sido más cercanas y transfronterizas, como en el caso de la relación con el cluster Aeice y su proyecto Duero Douro. En este proyecto se promociona la riqueza del patrimonio cultural y natural de todo el curso del río Duero, desde su nacimiento soriano hasta su desembocadura en Oporto. Integrar ese patrimonio y su valor en un espacio de impulso socio-económico y con la aportación de OEPE en su plan de educación, es el principal objetivo de dicho proyecto. 
Otro grupo con el que se relaciona el OEPE es la REPEP: Rede Paulista de Educação Patrimonial, es un principio de observatorio establecido en la provincia de São Paulo, Brasil, que trabaja junto con el Instituto de Patrimonio Histórico Artístico y Nacional (IPHAN, Brasilia), en el proyecto Plataforma paranapiacaba. memória y experimentación, que se configura como un Observatório Experimental del Patrimonio Cultural.

Y otra de las relaciones importantes que mantiene el OEPE es con el CEAQ (Centre d'Études sur l'Actuel et le Quotidien), un centro que nace en 1982 de la mano de dos profesores de la Sorbona, Michel Maffesoli y Georges Balandier y con el fin de desarrollar tres temas importantes: a) el imaginario, aquella parte que la imaginación aporta a las vivencias y a la construcción de las realidades particulares, b) las nuevas formas de socialización en la actualidad y c) la proximidad y el localismo, como medio para reapropiarse de la existencia social, el otro como ancla física y simbólica, contribuyen a enriquecer las investigaciones basadas en los dos temas anteriores y a evaluar la resistencia o las tendencias sociales, desde de estos enfoques.

Respecto a las publiciones de este grupo, encontramos artículos específicos sobre la evaluación de programas, (Fontal y Martínez, 2017; Fontal y Gómez, 2015).

Y para el estudio de la conjunción e imbricación de programas educativos con una evaluación de aprendizajes, muy amplia en el tiempo, mencionamos el artículo de Maldonado (2015) sobre la tesis del Dr. De Castro (2015).

En el ámbito de la evaluación de aprendizajes nos valemos de tres artículos que específicamente aportan diseños de actuación en Primaria y Secundaria, como son Fontal (2016), Fontal et al., (2017) y Fontal, (2007).

\subsubsection{Grupo de investigación EDUHIPA}

\section{Educación Histórica y Patrimonial, Universidad de Valladolid}

El grupo de investigación de Educación Histórica y Patrimonial (EDUHIPA) de la Uva (Universidad de Valladolid) es un grupo de investigación transdisciplinar que tiene como finalidad desarrollar investigaciones de alto nivel encaminadas a conocer determinados elementos de la realidad social (ciencia, conocimiento, cultura, historia, educación, población, patrimonio material e inmaterial, entre otros) que intervienen en el desarrollo del patrimonio cultural.

En la actualidad, este equipo está acreditado como Grupo de Investigación Reconocido (GIR) de la Universidad de Valladolid. El Grupo de Investigación es conocido en el 
ámbito académico nacional e internacional a través del estudio de las ciencias sociales y jurídicas, con una especificidad orientada hacia la Historia y el patrimonio cultural y donde los resultados más reconocidos se han dado en los análisis de valoración educativa de bienes culturales, la estimación del impacto educativo de eventos culturales y el análisis de eficiencia de instituciones educativas y culturales. Nace con unos objetivos muy concretos que se pueden resumir en:

a) Investigar sobre los procesos de enseñanza y aprendizaje de los contenidos históricos, patrimoniales y de formación ciudadana.

b) Realizar estudios de diagnóstico en materia educativa relacionados con las diferentes líneas de investigación.

c) Elaborar, aplicar y evaluar programas y recursos educativos para el aprendizaje histórico y patrimonial.

d) Generar conocimiento científico educativo, avanzando en la investigación científica de la historia y el patrimonio, mediante el impulso de acciones que den a conocer la actividad investigadora de los centros de investigación españoles en estos ámbitos.

e) Analizar y evaluar sistemas de formación inicial y permanente del profesorado.

f) Participar en redes de equipos de investigación nacionales e internacionales.

g) Fomentar la investigación educativa a través de la tutela y dirección de tesis doctorales en el ámbito del patrimonio y la historia. 


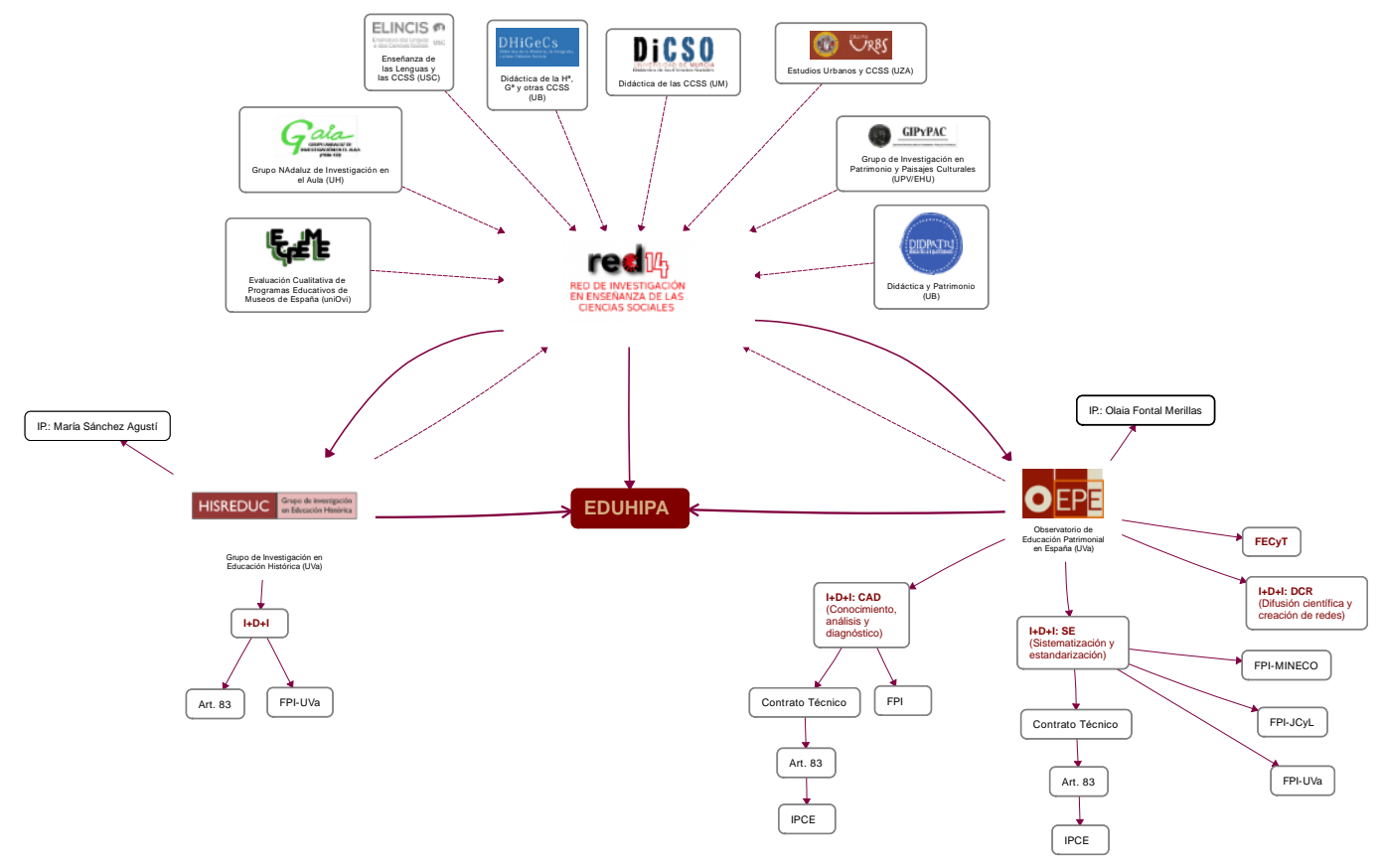

Figura 10. Esquema de componentes y funcionamiento del GIR EUDHIPA.

Elaboración propia.

Las líneas de investigación desarrolladas por este grupo provienen de ámbitos de la Educación, Historia y Patrimonio y son las que a continuación se detallan:

Investigación en Educación para la ciudadanía a través de la historia y el patrimonio: desde ambos grupos existe un interés común para la Educación en valores a través de sus ámbitos de conocimiento, bien Historia, bien el patrimonio material e inmaterial. Formación del profesorado: los dos grupos de investigación apuestan por la formación de su profesorado, tanto en la docencia como en la investigación, creando foros, simposio, congresos, jornadas formativas e incluso cursos de formación específicos.

$>$ Investigación en Educación Histórica: desde el grupo HISREDUC, junto al OEPE que relaciona patrimonio con Historia.

Investigación en Educación Patrimonial: desde el grupo OEPE, junto al HISREDUC que relaciona Historia y patrimonio.

Además, ambos grupos realizan evaluación de programas, evaluación educativa y de libros de textos. Es un GIR que investiga dentro de los campos de la Educación Patrimonial y de la evaluación en distintas vertientes. 


\subsubsection{Investigaciones, publicaciones y tesis doctorales}

\subsubsection{Investigación}

En este apartado se realiza un recorrido por los proyectos de investigación importantes que se llevan a cabo en las universidades españolas y que priorizan la educación patrimonial y algún tipo de evaluación, bien de programas, bien de aprendizajes. Se puede reseñar los últimos proyectos del ámbito de la educación patrimonial de los planes nacionales del Programa Estatal de Generación de Conocimiento y Fortalecimiento Científico y Tecnológico del Sistema de I+D+i y del Programa Estatal de I+D+i Orientada a los Retos de la Sociedad. Se obvian los proyectos sobre la dimensión arquitectónica o de mejoramiento físico de elementos, aunque se hace constar que esa línea patrimonial está siendo crecientemente, subvencionada por las instituciones. Las entidades financiadas señalan algunos de los grupos territoriales principales donde se está produciendo el auge científico de la investigación sobre educación patrimonial en el territorio nacional.

Los proyectos concedidos por el Ministerio competente en los últimos siete años, se constata el enfoque territorial y el área de conocimiento de Historia, Arqueología y Ciencias Sociales en el área de Cataluña en: EDU2012- 35299 Desarrollo de estrategias y técnicas didácticas a partir del patrimonio y la arqueología del conflicto para la enseñanzalaprendizaje de las ciencias sociales y la historia de la Universidad de Barcelona, Facultad de Formación del profesorado.

También cabe destacar el desarrollo de dos proyectos en regiones determinadas que fomentan respectivamente la recuperación del patrimonio cultural en zona industrial (Murcia) y en la autonomía completa (Galicia): HAR2014- 58151-R Análisis del impacto de estrategias de regeneración urbana sobre la conservación del patrimonio cultural de zonas industriales históricas de la Universidad de Murcia, Facultad de Letras y HAR2014- 53893-R Memoria, textos e imágenes. la recuperación del patrimonio perdido para la sociedad de Galicia, en la Universidad de Santiago de Compostela, Facultad de Geografía e Historia.

Se completa el año 2014 con el proyecto sobre el fomento de la participación social: HAR2014-54869-R Patrimonio y participación social: propuesta metodológica y revisión crítica agencia estatal, del Consejo Superior de Investigaciones Científicas (CSIC), Instituto de Ciencias del Patrimonio. 
La facultad de Barcelona aúna en el siguiente proyecto el factor diferencial de la crisis económica y mantiene el foco en el territorio: CSO2015- 68611-R El patrimonio cultural y natural en tiempos de crisis. retos, adaptaciones y estrategias en contextos locales, de la Universidad de Barcelona, Facultad de Geografía e Historia. Por último, el más conectado con esta tesis, explícito sobre la evaluación de aprendizajes, del grupo de Valladolid, siendo uno de los tres consecutivos que ha obtenido el grupo OEPE: EDU2015-65716-C2-1-R Evaluación de los aprendizajes en programas de educación patrimonial centrados en los procesos de sensibilización, valorización y socialización del patrimonio cultural, de la Universidad de Valladolid Facultad de Educación y Trabajo Social.

\subsubsection{Publicaciones}

En la bibliografía estudiada se pueden destacar dos ámbitos temáticos básicos: de una parte, los libros de teorización sobre Educación patrimonial (Fontal y Calaf, 2006), en el que se incluyen como subtemas los Museos (Suárez, 2014) y la Educación Artística (Fontal, Marín-Cepeda y García-Ceballos, 2015); y de otra, la Educación Patrimonial en las áreas de Ciencias Sociales e Historia (Cuenca, 2003), incluyendo los numerosos proyectos con óptica territorial (Estepa, Friera y Piñeiro, 2001). Cada uno de los grupos contendría los programas, metodologías y aprendizajes desarrollados en sendas áreas. Aunque a nivel nacional haya grupos de trabajo más decantados hacia el primer ámbito como el de Valladolid, o hacia el segundo como el de Huelva, no podemos negar la presencia de ambas áreas de interés en todos los grupos de España; así la teorización ha sido publicada por los grupos de Santiago (Domínguez y López-Facal, 2017), Huelva (Estepa, 2013), País Vasco (Fontal e Ibáñez-Etxeberría, 2017), Barcelona (Hernández Cardona y Santacana, 1984), etc; los Museos por los grupos de Oviedo (Gómez Redondo, Calaf y Fontal, 2016) o Zaragoza (Rivero y Trepat, 2010) y la territorialidad en diferente porcentaje por todos los grupos del país (Ibáñez-Etxeberria, 2003; Hernández Cardona, 2001; Ortega González et al. 1999).

Este resumen sobre bibliografía no puede olvidar las áreas, también trasversales, de análisis de legislación general (Fontal, 2016) y específica (Ibáñez-Etxeberría, Fontal y Rivero, 2018) sobre Educación Patrimonial, incluyendo los libros específicos sobre formación del profesorado (Estepa et al. ,1994), o el área de las nuevas tecnologías (Vicent, Ibáñez-Etxeberría y Asensio, 2015) en su desarrollo exponencial de la última década. 
Esta sección artículos de revistas científicas de impacto se divide en varias subsecciones:

1. La primera, los artículos en inglés, donde destacan bastantes recensiones del estado de la cuestión de la Educación Patrimonial en España (Fontal e IbañezEtxeberría, 2015) con temas particulares como por ejemplo la estructura y el funcionamiento del Observatorio de la Educación patrimonial en España (OEPE). Como material de fondo hay artículos sobre epistemología de la Educación Patrimonial (Falcón, Fontal y Torregrosa, 2015.)

Mención aparte merecen los artículos sobre el concepto de vínculo como piedra angular de la teorización sobre Educación Patrimonial (Fontal, Sánchez-Macías y Cepeda, 2017; Fontal y Marín-Cepeda, 2018).

Igualmente, se encuentra material sobre los diferentes modelos de Educación Patrimonial, así como sobre la consecución de la autonomía como área científica de la disciplina, y su importancia estratégica respecto las demás áreas del estudio del Patrimonio.

Respecto a la investigación en Red y las nuevas tecnologías, en auge en las últimas décadas, hallamos artículos específicos sobre las cartografías en red y el proceso de identidad, además de estudios sobre programas educativos de base tecnológica (Vicent, Ibáñez-Etxeberría y Asensio, 2015).

2. Otro tipo de artículos son: artículos sobre el marco teórico y conceptual Generalmente abordan el concepto de Educación Patrimonial refiriéndose a teorías diversas o generando modelos conceptuales innovadores, en las últimas décadas. Hay un primer abordaje de la conceptualización más abstracta de la Educación Patrimonial (Fontal, 2010). Se desarrolla la tensión entre Educación y Patrimonio con la progresiva toma de importancia de la Educación Patrimonial, para irse constituyendo en disciplina autónoma. Se estudian las autopercepciones de invisibilidad del profesor de Arte provenientes de los currícula más tradicionales (Fontal, 2010).

También se analiza la dinámica entre la práctica y la reflexión en que se encuentran los educadores en los sistemas más dinámicos de pedagogía y se aborda el avance desde modelos como la evaluación o la autoevaluación.

Ya en una descripción territorializada o especializada encontramos material publicado sobre los programas de Castilla-León, en varias entidades, una de ellas, el Observatorio de Educación Patrimonial en España (Fontal y Marín-Cepeda, 2011). Por otra parte, hay aportaciones desde el área de las Ciencias Sociales como las del grupo de Huelva o el 
de Zaragoza acerca de la socialización patrimonial (Cuenca y López, 2014) o los conceptos de ciudadanía crítica y participativa (Lucas y De Alba-Fernández, 2017) Otros trabajos se centran en el análisis del marco legislativo o en los programas concretos que abordan la idea de patrimonialización (Fontal y Marín-Cepeda, 2018). Y con orientación hacia la metodología hay estudios sobre el estado de la cuestión de la Educación Patrimonial desde los indicadores de alto impacto de las revistas y libros científicos (Fontal e Ibáñez-Etxeberría, 2017).

Como artículos referidos al mundo editorial, se destacan los dedicados a las cuestiones suscitadas en la elaboración de los libros de texto (Abril y Cuenca, 2016), tanto para la educación reglada, como la elaboración de materiales para la enseñanza en museos (Cuenca, Wamba y Aguaded, 2006), o demás espacios de patrimonio, o en educación no formal.

También inspira el material específico publicado sobre nuevas tecnologías y construcciones de identidad, como las cartografías identitarias en la red (GómezRedondo y Fontal, 2017), o las numerosas publicaciones en esta área de grupos significativos como el de la Universidad del País Vasco.

Hay artículos prospectivos de las próximas décadas que desde una visión panorámica de las bases sentadas en los últimos años permite lanzar unos futuribles sobre la Educación Patrimonial, desglosando sus estrategias e instrumentos presentes y futuros (Fontal, Ibáñez-Etxeberria, 2015).

3. Artículos del área de las Ciencias Sociales y/o de Historia / Arqueología. Estas áreas del sistema educativo han reunido gran parte de la investigación y acción sobre la Educación Patrimonial en España, necesitando una subsección específica para sus publicaciones. El área ha investigado en múltiples Universidades y territorios del Estado español.

3.1.Se puede hacer un análisis territorializado de las publicaciones empezando por el grupo de Huelva, con un foco básico en las Ciencias Sociales.

Se estudia el análisis de las sociedades, tanto actuales como históricas, que hace el alumnado, insistiendo sobre la pedagogía innovadora y sobre los paradigmas de ciudadanía participativa y crítica (Estepa, Domínguez Domínguez y Cuenca, 1998). Este enfoque cuenta históricamente con obstáculos que se desglosan (López Cruz y Cuenca, 2014). Se enumeran las competencias emocionales (Gómez y Cuenca, 2017) y territoriales como elementos específicos a reivindicar desde la Pedagogía Crítica. 
Siguiendo la elaboración de publicaciones que desarrolla el grupo hay artículos específicos sobre los libros de texto (Abril y Cuenca López, 2016) de Ciencias Sociales, Geografía e Historia para $\mathrm{ESO}^{6}$ y otros niveles de enseñanza. También se desglosan estrategias y actividades de enseñanza en Ciencias Sociales (Cuenca, 2010). Respecto al marco legislativo también hay una obra importante acerca de la reforma del currículo oficial de Ciencias Sociales en la ESO y demás niveles, haciendo una crítica sobre los contenidos y funcionalidad de estos (Estepa et al, 2011).

3.2.El grupo de la Universidad del País Vasco hace aportaciones significativas en el área de la Educación arqueológica patrimonial (Vicent, Rivero y Torruella, 2015). Relaciona el Aprendizaje de Prehistoria y Arqueología con las competencias, percepción de aprendizaje y satisfacción (Ibáñez Etxeberría et al., 2017), aplicando programas concretos a la práctica en varios niveles de enseñanza y publicando sus resultados. También hay artículos sobre el método de caso en las ciencias sociales (Gil Molina e Ibáñez-Etxeberría, 2013).

3.3.El grupo de Murcia estudia la educación histórica relacionada con las competencias (Gómez-Carrasco, (coord.), 2017) y describiendo acerca de métodos, recursos y enfoques de enseñanza. Paralelamente realizan una elaboración teórica de los temas más generales de identidad y ciudadanía (Gómez-Carrasco, Cózar y Miralles, 2014).

En esta área el grupo de Valladolid ha estudiado los contenidos actitudinales en la enseñanza de la historia del arte (Fontal, 2006) y los procedimientos de valorización del patrimonio cultural.

4. Artículos misceláneos Incluimos aquí el resto de las publicaciones en revistas, difíciles de categorizar en el resto de subapartados. Se incluyen artículos específicos acerca de la metodología utilizada en la investigación en Educación Patrimonial.

Hay publicaciones que desarrollan el grado de utilidad y satisfacción de ciertas metodologías en el alumnado y el profesorado/tutores de las escuelas de formación de profesorado: estudios de caso, valoraciones del Prácticum a través de cuestionarios, etc. Otras tratan el modelo reflexivo en la formación de maestros y el pensamiento narrativo.

\footnotetext{
${ }^{6}$ Educación Secundaria Obligatoria
} 
El grupo de Huelva continua sus análisis del paisaje cultural, su concepto y contenidos, además del concepto de ciudadanía y memoria (Cuenca, Estepa y Martín Cáceres, 2017), en el aprendizaje de la Historia.

El grupo de la Universidad del País Vasco nos aporta su conocimiento de los contextos informales (Vicent, Asensio e Ibáñez-Etxeberría, 2012) de Educación Patrimonial con elementos trasversales como la motivación o el autoconcepto, así como análisis estructurales de la educación con TIC en España, sobre normativa y programas (IbáñezEtxeberría, Fontal y Rivero, 2018).

\subsubsection{Tesis referentes}

Se reseña la secuencia procedimental educativa integral de la tesis de la Dra. Fontal, que se analiza en el apartado de tesis nacionales: conocer-comprender-respetar-valorarpatrimonializar-identizar (nivel individual)- compartir-consensuar-identizar (nivel colectivo).

Las sucesivas tesis nacionales e internacionales que se están teniendo en cuenta este marco de referentes han ido haciendo una labor de microscopio sobre cada uno de los conceptos de dicha secuencia.

La Dra. Torregrosa focaliza los tres últimos conceptos de la secuencia "compartirconsensuar-identizar (nivel colectivo)". Pone en valor las múltiples relaciones sociales del profesor y el educando como generadoras de sentido respecto a la Educación Patrimonial. Dichas relaciones son, por definición, dinámicas y fluctuantes. Utiliza consecuentemente metodología cualitativa con instrumentos como historias de vida. Su enfoque, desde la socialización, no olvida la interacción permanente con lo individual (en la secuencia “identizar (nivel individual)”) haciendo referencia explícita a elementos psicológicos en este sentido, como "epifanías de maestros en el espacio educativo". 
Tabla 4

Tesis de Apolline Torregrosa. Fuente: TESEO

\begin{tabular}{|c|c|}
\hline Autor/a: & Torregrosa Laborie, Apolline. \\
\hline Universidad: & Universidad de París Descartes \\
\hline Año: & 2011 \\
\hline Director/a: & Maffesoli, Michel \\
\hline Resumen: & $\begin{array}{l}\text { Esta investigación propone que las relaciones profesor y el } \\
\text { estudiante se redefinen en un contexto regido por sus relaciones } \\
\text { sociales. Esta relación se presenta como el punto nodal de la } \\
\text { formación que articula este espacio y el sentido de formación. Se } \\
\text { trata de captar esta dimensión socializadora colectiva de la } \\
\text { educación. Enfatiza la vida cotidiana y la educación emocional, } \\
\text { un lugar de encuentro y comunicación donde perpetuar la } \\
\text { dinámica de la vida colectiva. Así, este estudio propone como } \\
\text { investigación narrativa historias de vida de maestros en } \\
\text { educación secundaria para resaltar la vida cotidiana, situaciones, } \\
\text { epifanías de maestros en el espacio educativo y capturar sus } \\
\text { matices. }\end{array}$ \\
\hline
\end{tabular}

La siguiente tesis es de Portugal, país con el que diferentes grupos de investigación españoles como los de Valladolid, Santiago de Compostela y Huelva mantienen relaciones permanentes. Es una tesis que se apoya conceptualmente en la Grounded theory, y materialmente en paisajes arquitectónicos de la Edad Media. El estudio se desarrolla enfocando lugares concretos arqueológicos, pero preguntándose por los enfoques interpretativos que dan tanto profesores como educandos a los mismos.

En nuestro estudio de investigación de Castilla-León, por la ingente cantidad de patrimonio histórico artístico (numeroso de la época medieval) resulta muy interesante esta tesis con sus aportaciones acerca de cómo leer objetos, edificios y lugares históricos, en términos de educación formal e incluso informal. Especialmente es importante el papel que da a la evidencia como elemento central de interpretación poniéndola en tensión con las concepciones previas sobre el lugar y el tiempo histórico que llevaran previamente los participantes. 


\section{Tabla 5}

Tesis de Helena Pinto. Fuente: TESEO

\begin{tabular}{l|l}
$\begin{array}{l}\text { Educação histórica e patrimonial: conceções de alunos e professores sobre o passado em espaços do presente } \\
\text { Autor/a: }\end{array}$ & Pinto, Maria Helena Mendes Nabais Faria \\
Universidad: & Universidade do Minho (Portugal) \\
Año: & 2012 \\
Director/a: & Barca, Isabel \\
Resumen: & En el cruce de las diversas teorías de este marco conceptual, se \\
& definió el problema inicial de este estudio: ¿Cómo alumnos y \\
& profesores de Historia interpretan la evidencia de un sitio \\
& histórico? El estudio, que asumió un enfoque metodológico \\
& esencialmente cualitativo, basado en la Grounded Theory, intentó \\
profundizar, en una perspectiva transversal en términos de años \\
de escolaridad, la comprensión de los sentidos atribuidos por \\
alumnos y profesores de Historia a fuentes patrimoniales. En \\
relación con la observación directa y de interpretación de un \\
conjunto de fuentes patrimoniales (objetos, edificios, sitios \\
históricos) relacionadas con la Edad Media, pero teniendo en \\
cuenta su historicidad.
\end{tabular}

El modelo conceptual de alumnos surgió en torno a dos construcciones: "Uso de la evidencia", organizado en cuatro niveles conceptuales (idea alternativa, inferencia sobre detalles concretos, inferencia a partir del contexto, problematización), y "Conciencia histórica", organizado en cinco (conciencia ahistórica, conciencia de un pasado fijo, conciencia de un pasado simbólico, conciencia histórica emergente, conciencia histórica explícita). En cuanto a las concepciones de profesores, también surgió un modelo conceptual en torno a dos constructos: "Uso de fuentes patrimoniales" (con los patrones conceptuales: uso tácito, del contexto para la fuente, cruce de fuentes en contexto, de las fuentes para el contexto) y "Finalidades de enseñanza y divulgación del patrimonio", a su vez organizado en tres dimensiones (Aprendizaje, Conciencia Histórica y Conciencia Patrimonial), cada una de ellas involucrando también patrones conceptuales específicos.

La explotación educativa del patrimonio, de forma sistemática y fundamentada como la que se ha intentado en este estudio, podrá permitir el desarrollo de múltiples competencias por los niños y jóvenes, especialmente en el ámbito de la comprensión histórica, estimulando la capacidad de leer objetos, 
edificios y lugares históricos, en términos de educación formal e incluso informal. Este estudio pretende llamar la atención sobre las implicaciones de esas actividades, sobre todo la importancia de que los alumnos efectúen inferencias con mayor complejidad. Para ello es esencial que los profesores tomen conciencia de la importancia del uso de la evidencia de acuerdo con criterios metodológicos de la historia, en articulación con los currículos de historia, en particular en términos de historia local, con tareas que desafíen las concepciones previas de los alumnos y estimulen la enseñanza interpretación histórica. Esto puede también suscitar la comprensión de los vínculos entre la interpretación del patrimonio y la conciencia de las relaciones entre el pasado, el presente y el futuro.

La siguiente tesis, presentada en París, cuyas Universidades tienen interés indudable en Educación Patrimonial, abre camino hacia instituciones mundiales como la UNESCO, planteando la tensión de cómo las instituciones generan una idea de Patrimonio plasmada en un determinado proyecto. Las tesis de Francia son interesantes también desde la sociopolítica, en el sentido de la relación del Patrimonio con un Estado centralista y con el desarrollo de la francofonía como estrategia cultural nacional en su desarrollo diacrónico.

Por extensión, en nuestra área de conocimiento, es importante seguir las tendencias desarrolladas por las instituciones de países cercanos paralelas al Instituto Cervantes, como son la Alliance Francaise, el British Council, el Instituto Camoens, el Goethe Institut y la Societa Dante Alighieri.

Así, partiendo de los «Foros Juveniles del Patrimonio Mundial» que se desarrollaron en España entre 2009 y 2012, se estudia la Mediación cultural y el resultado conceptual que resulta en los destinatarios del proyecto. Se recoge explícitamente la idea de que la investigación puede extenderse a otros proyectos y localizaciones. También se estudia el protagonismo, en la actualidad, que se le debe dar a los jóvenes en el mismo momento que están captando y asimilando la Educación Patrimonial y transmitiendo sincrónicamente sus conocimientos, enfoques y conceptos. 


\section{Tabla 6}

Tesis de Luisa López. Fuente: TESEO

\section{La construcción, la apropiación, la materialización y la transmisión de la noción de «Patrimonio» en los jóvenes, una propuesta metodológica: los Foros Juveniles del Patrimonio Mundial celebrados en España} (2009-2012)

\begin{tabular}{|c|c|}
\hline Autor/a: & López Campos, Luisa Irazu \\
\hline Universidad: & Sorbonne Paris Cité \\
\hline Año: & 2013 \\
\hline Director/a: & Bertho-Lavenir, Catherine \\
\hline Resumen: & $\begin{array}{l}\text { Esta tesis de Doctorado está enfocada en el proceso a través del } \\
\text { cual los jóvenes construyen una noción de Patrimonio, la manera } \\
\text { en la que se apropian de ella y la materializan, mediante acciones } \\
\text { concretas, para transmitirla a los demás. También, intenta reflejar } \\
\text { la manera en la que el discurso institucional de la UNESCO } \\
\text { influye en su percepción de Patrimonio. La teoría del actor-red y } \\
\text { la Mediología vistas a partir de la Historia Cultural, la } \\
\text { Comunicación y la Mediación Cultural son las bases teórico- } \\
\text { metodológicas con las que está construido este análisis. ¿Cómo, a } \\
\text { través de técnicas pedagógicas, un dispositivo organizacional / } \\
\text { burocrático, ha producido una cierta ideología patrimonial, a } \\
\text { partir del trabajo con jóvenes? Trabajar directamente con la } \\
\text { población en proyectos patrimoniales nos permite tener un } \\
\text { acercamiento para estudiar cuestiones como, por ejemplo, ¿cómo } \\
\text { me comunico con mi Patrimonio y cómo mi Patrimonio se } \\
\text { comunica conmigo? } \\
\text { El análisis fue realizado a partir de un estudio de caso particular, } \\
\text { que consistió en revisar una mediación cultural puesta en marcha } \\
\text { en España por el Ministerio de Cultura y la UNESCO, en el } \\
\text { marco de los «Foros Juveniles del Patrimonio Mundial», } \\
\text { intervenciones creadas por la UNESCO en } 1995 \text {. Se estudiaron } \\
\text { cuatro ediciones de estos Foros, que se desarrollaron en España } \\
\text { entre } 2009 \text { y } 2012 \text {, en las que el conocimiento fue generado en } \\
\text { torno a temas patrimoniales, a partir de la conformación de una } \\
\text { comunidad de aprendizaje de jóvenes de entre } 12 \text { y } 15 \text { años, que } \\
\text { trabajaron con un método participativo, constructivista y } \\
\text { colectivo. Estos Foros trabajaron con la idea de que los jóvenes } \\
\text { son válidos en el presente, y no sólo en el futuro como futuros } \\
\text { adultos. Ellos son ciudadanos jóvenes, y en tanto que jóvenes, } \\
\text { cueden convertirse en elementos de transformación en sus } \\
\text { lomides. }\end{array}$ \\
\hline
\end{tabular}


presenta algunas aportaciones novedosas: una estrategia metodológica para implementar una intervención que favorece la construcción, la apropiación, la materialización y la transmisión de la noción de Patrimonio en los jóvenes; una metodología para analizar los resultados obtenidos de esta intervención; y la utilización de tres conceptos que resultaron de gran utilidad en este trabajo, el de «comunicación patrimonial», el de « mediación patrimonial » y el de « Patrimonio emocional o afectivo ».

La tesis de la Dra. Spendlove, de 2003, investiga en tres proyectos arqueológicos en las Midlands británicas y aporta conocimiento sobre la evaluación de programas. Su tensión se localiza entre un programa institucional desarrollado por profesionales, la intervención e importancia como colectivo de las asociaciones no profesionales involucradas y, en tercer lugar, los voluntarios individuales. Se basa en la definición de discurso de Foucault y en las teorías del capital humano de Bourdieu y su concepto de hábito y distinción.

Se destacan en este estudio las sinergias que resultan fructíferas entre esos tres grupos de la tensión indicada, subrayando la importancia del agente patrimonial, motor de los profesionales (en este caso arqueólogos), correctamente involucrados y preparados para la Educación Patrimonial y la dinamización sociocomunitaria.

Tabla 7

Tesis de Marion Spendlove. Fuente: TESEO

\begin{tabular}{|c|c|}
\hline Autor/a: & Spendlove, Marion \\
\hline Universidad: & University of Warwick \\
\hline Año: & 2003 \\
\hline Director/a: & Hill, Stephen; McKie, Jane \\
\hline Resumen: & $\begin{array}{l}\text { La tesis investiga si la política y la práctica contemporáneas } \\
\text { apoyan el aprendizaje formal e informal en el campo de la } \\
\text { arqueología. Además, se cuestiona el supuesto de que las } \\
\text { asociaciones multidisciplinares amplían la participación de la } \\
\text { comunidad en las actividades relacionadas con el patrimonio. } \\
\text { Mediante el modelo de investigación comparativa de varios } \\
\text { métodos se aplicaron métodos empíricos y cualitativos a tres } \\
\text { estudios de caso en las Midlands de Gran Bretaña. Cada uno de } \\
\text { estos proyectos obtuvo fondos para la exhibición de los restos } \\
\text { arqueológicos al público durante el curso de la investigación. Las }\end{array}$ \\
\hline
\end{tabular}


políticas y prácticas de los individuos- clave en las asociaciones se investigaron a través de entrevistas grabadas, y los datos se analizaron mediante mapeo cognitivo (Tolman, Buzan). Los datos sobre los visitantes se recopilaron a través de encuestas, grabaciones orales grabadas y estudios observacionales. Se compararon los intereses, preocupaciones y agenda de las principales partes interesadas.

Los resultados indicaron que el papel de los voluntarios fue esencial para el éxito y la sostenibilidad de los proyectos. Sin embargo, algunos voluntarios sintieron que eran agentes menos valiosos, y esto estaba vinculado a una distinción entre aficionados y profesionales. Se analiza el poder de las autoridades locales en las asociaciones de patrimonio y sus roles en tensión como promotores y guardianes del patrimonio arqueológico. Se sugieren formas de promover asociaciones más participativas.

La investigación se basa en la definición de discurso de Foucault y en las teorías del capital humano de Bourdieu y su concepto de hábito y distinción. Los vínculos entre el aprendizaje informal y el formal, rara vez se investigan y teorizan, pero este estudio identifica cómo los arqueólogos, actuando como "intermediarios culturales" (Bourdieu,), pueden crear y mantener oportunidades de aprendizaje para adultos, refutando algunas de las jerarquías intelectuales tradicionales acerca de:

"Entretenimiento popular", "conocimiento de la comunidad" y “conocimiento intelectual". La tesis sitúa el aprendizaje en arqueología dentro de la teoría de una taxonomía estructurada del aprendizaje (Biggs y Collis, 1982).

El análisis del estudio de la enseñanza formal se inicia en la Universidad de Huelva, una de las universidades que lidera el estudio de la Educación patrimonial tanto en Andalucía como a nivel nacional, que se remonta al año 2002 con la tesis del Dr. Cuenca titulada: El patrimonio en la didáctica de las ciencias sociales: análisis de concepciones, dificultades y obstáculos para su integración en la enseñanza obligatoria. La investigación desarrollada en esta tesis contextualiza esta premisa previa de nuestro trabajo sobre aprendizajes: los aprendizajes se fundamentan en lo estudiado por el Dr. Cuenca, es decir el conocimiento profesional del profesorado. 
Tabla 8

Tesis de José $M^{a}$ Cuenca. Fuente: TESEO

\begin{tabular}{|c|c|}
\hline \multicolumn{2}{|c|}{$\begin{array}{l}\text { El patrimonio en la didáctica de las ciencias sociales: análisis de concepciones, dificultades y obstáculos para } \\
\text { su integración en la enseñanza obligatoria }\end{array}$} \\
\hline Autor/a: & José María Cuenca López \\
\hline Universidad: & Universidad de Huelva \\
\hline Año: & 2002 \\
\hline Director/a: & Jesús Estepa Giménez, Consuelo Domínguez \\
\hline Resumen: & $\begin{array}{l}\text { Esta tesis Doctoral se trata de un estudio en el que se analiza qué } \\
\text { tratamiento didáctico recibe el patrimonio en los manuales de } \\
\text { Ciencias Sociales de la ESO más usados en España. Partimos de } \\
\text { un marco teórico que se sustenta en tres pilares fundamentales: el } \\
\text { concepto de Patrimonio, la Educación Patrimonial y los libros de } \\
\text { texto como recurso en la enseñanza de las Ciencias Sociales. } \\
\text { Entendemos los elementos patrimoniales como símbolos de las } \\
\text { diferentes culturas, posibles generadores de identidad y } \\
\text { elementos de conexión intercultural. Consideramos importante el } \\
\text { estudio del tratamiento patrimonial en los manuales puesto que el } \\
\text { libro de texto sigue siendo el material predominante en la } \\
\text { educación formal. Gracias a los resultados de análisis hemos } \\
\text { podido establecer unas dificultades en torno al tratamiento } \\
\text { didáctico del patrimonio en los manuales, así como proponer } \\
\text { unos parámetros que puedan guiar la elaboración de materiales en } \\
\text { relación con la Educación Patrimonial. }\end{array}$ \\
\hline
\end{tabular}

Por otro lado, la fundamentación teórica del presente estudio comienza a nutrirse de su revisión epistemológica del concepto de patrimonio, concretamente del conocimiento didáctico del patrimonio, que tendería en su nivel deseable, a una visión holística de carácter simbólico-identitario, centrada en una perspectiva integradora, innovadora y sociocrítica.

También se refleja el hecho de que nuestra investigación, como aquélla, esté planteada desde la integración de los métodos cualitativos y cuantitativos. En el enfoque cuantitativo destacamos la novedad que supuso en su día, abordar el patrimonio en términos numéricos.

Respecto a los ámbitos específicos de estudio, también hay una pretensión de coincidir en estudiar las concepciones que sobre el patrimonio y su enseñanza transmiten los diseños curriculares oficiales para Educación Primaria y Secundaria Obligatoria.

Destaca su amplio análisis legislativo estatal y autonómico. 
Igualmente se coincide con un segundo campo de estudio, que trabaja esas mismas concepciones, transmitidas por los materiales curriculares de uso, más común en el contexto que abordamos. El Dr. Cuenca analiza programas del ámbito local, criterio que también sigue nuestro trabajo a la hora de acotar la investigación.

Finalmente, ambas analizan las concepciones declaradas por el profesorado en formación inicial.

Seguidamente, de la Universidad de Valladolid, citamos la tesis de la Dra. Fontal titulada La educación patrimonial: Definición de un modelo integral y diseño de sensibilización.

Dicho trabajo definió un modelo integral de Educación Patrimonial a nivel nacional que ha sido muy seguido en las últimas dos décadas. La Dra. Fontal pretendió otorgar peso específico a la disciplina para transformarla en disciplina autónoma. En nuestra fundamentación teórica nos inspira el profuso análisis de los diferentes enfoques epistemológicos que existían previamente, y su voluntad integradora de todos ellos. Ambas tesis analizan proyectos de Educación Patrimonial y concretamente el trabajo en estos últimos años alrededor del Observatorio de la Educación Patrimonial en España (OEPE), gestado en base a los tres sucesivos proyectos de $\mathrm{I}+\mathrm{D}+\mathrm{i}$ subvencionados por los Ministerios sucesivos del área competente del Gobierno de España, cuya IP precisamente es la Dra. Fontal.

Tabla 9

Tesis de Olaia Fontal. Fuente: TESEO

La educación patrimonial: Definición de un modelo integral y diseño de sensibilización
$\begin{array}{ll}\text { Autor/a: } & \text { Olaia Fontal Merillas } \\ \text { Universidad: } & \text { Universidad de Oviedo } \\ \text { Departamento: } & \text { Ciencias de la Educación } \\ \text { Año: } & 2003 \\ \text { Director/a: } & \text { Roser Calaf Masachs } \\ \text { Resumen: } & \text { La Tesis Doctoral se ocupa de la educación patrimonial entendida } \\ & \text { como un cuerpo disciplinar autónomo. Los nueve capítulos de } \\ & \text { que consta se estructuran en cuatro grandes bloques. En primer } \\ & \text { lugar, la introducción, en la que se explican los antecedentes, el } \\ & \text { sentido y la orientación de la Tesis Doctoral. En segundo lugar, } \\ & \text { un cuerpo teórico, que parte de un análisis desde la óptica } \\ & \text { educativa, de los referentes conceptuales de la educación } \\ & \text { patrimonial (cultura y patrimonio cultural), para llegar a definir el } \\ & \text { estado de la cuestión de la educación patrimonial, que se concreta }\end{array}$




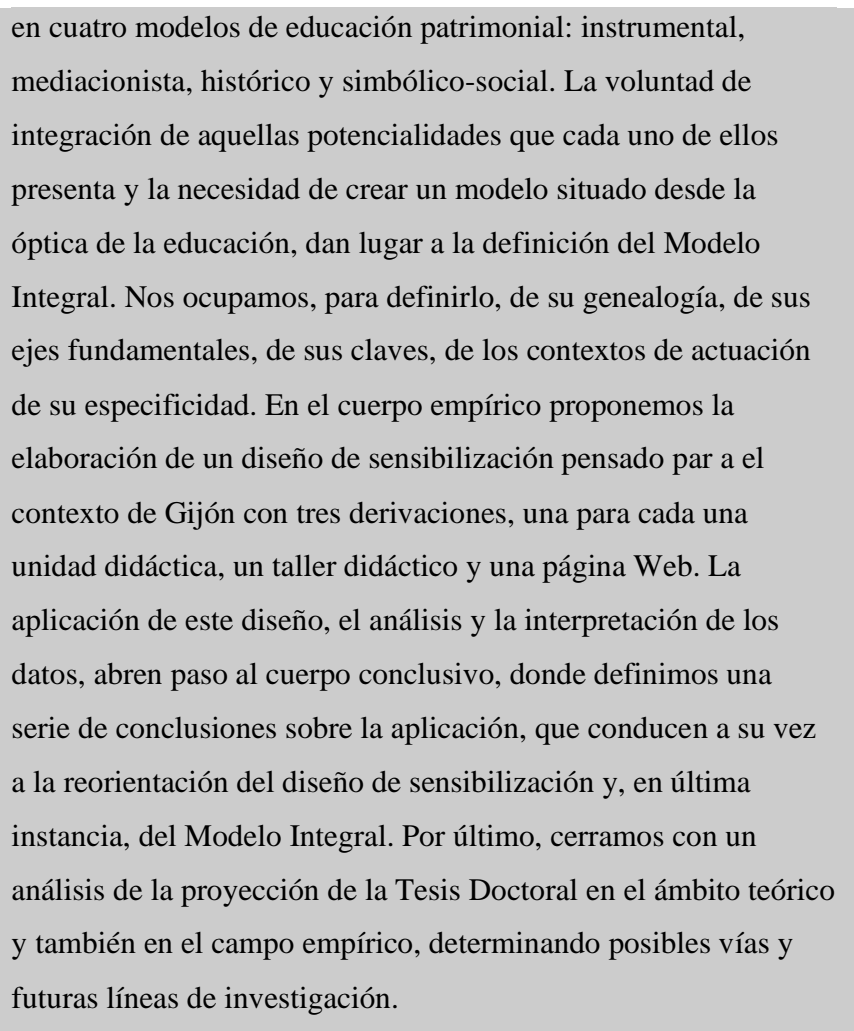

En cuanto a la metodología experimental, se destaca el carácter multifactorial de la investigación de la Dra. Fontal, que se desglosó en variados recursos: unidad didáctica, taller didáctico, página Web.

Igualmente, nuestro análisis de programas y aprendizajes también está poniendo el foco en múltiples variables el primero, y a diferenciadas estrategias el segundo.

La Dra. Fontal aborda las conclusiones incluyendo plenamente el feedback mediante la reorientación del diseño de sensibilización y, en última instancia, del Modelo Integral. Para este estudio es otro inspirador y pleno acierto el no dejar unos resultados planos, sino plantear un continuum hacia la autoreflexión, la sensibilización y la teorización.

En 2006 se leyó la tesis del Dr. Ibáñez, en la Universidad del País Vasco - Euskal Herriko Unibertsitatea: Educación y patrimonio el caso de los campos de trabajo en la comunidad autónoma del País Vasco.

En ella se estudian los campos de trabajo (CdT) que son una actividad juvenil de ocio y tiempo libre con una larga tradición en la sociedad occidental, concretamente centrándose en los del País Vasco. 
La tesis conceptualiza los mismos como una actividad educativa realizada sobre patrimonio generando personalmente a partir de varios enfoques teórico-pedagógicos un modelo de Educación Patrimonial centrada en los mismos.

Tabla 10

Tesis de Álex Ibáñez. Fuente: TESEO

Educación y patrimonio el caso de los campos de trabajo en la comunidad autónoma del País Vasco

\begin{tabular}{|c|c|}
\hline Autor/a: & Alejandro Ibáñez Etxeberria \\
\hline Universidad: & Universidad del País Vasco - Euskal Herriko Unibertsitatea \\
\hline Año: & 2006 \\
\hline Director/a: & José Miguel Correa Gorospe \\
\hline Resumen: & $\begin{array}{l}\text { Los campos de trabajo (CdT) son una actividad juvenil de ocio y } \\
\text { tiempo libre con una larga tradición en la sociedad occidental. } \\
\text { Con origen en los movimientos solidarios juveniles surgidos de la } \\
\text { resulta a los horrores de la I Guerra Mundial, pronto cumplirán } \\
\text { un siglo de existencia bajo la coordinación del Servicio civil } \\
\text { Internacional (SCI). Esta tesis aborda la organización de los CdT } \\
\text { y en especial, el aspecto educativo de los que están dedicados al } \\
\text { tratamiento del patrimonio. Para ello, el autor nos introduce en un } \\
\text { marco teórico que se sustenta sobre tres conceptos que son el } \\
\text { propio CdT, el Patrimonio y la Educación patrimonial, que son } \\
\text { ampliamente tratados, al igual que los tres principios educativos } \\
\text { sobre los que soporta esta acción, que serían el cuadrante } \\
\text { constructivista de los continuos educativos de Hein (1998), el } \\
\text { modelo de aprendizaje contextual de Falk y Dierking (2002) y el } \\
\text { aprendizaje informal basado en la percepción que del mismo nos } \\
\text { aporta Asensio (2001). En base a todo ello, estructura un soporte } \\
\text { teórico en el cual el CdT es entendido como una actividad } \\
\text { educativa realizada sobre patrimonio, y por ello, integrada en una } \\
\text { acción de educación patrimonial, que se sustenta, según la visión } \\
\text { del autor, sobre las ideas del constructivismo de Hein, el modelo } \\
\text { de aprendizaje contextual y la idea de aprendizaje informal, que } \\
\text { se vuelcan en el surgimiento de un "modelo de educación } \\
\text { patrimonial aplicable a los CdT". Bajo este paraguas teórico, se } \\
\text { realiza una investigación cuantitativa y cualitativa, en base a } \\
\text { cuestionarios y entrevistas en profundidad, en torno a los CdT, } \\
\text { cuyo objetivo general es describir, analizar e interpretar la } \\
\text { estructura de los campos de trabajo como contexto de aprendizaje } \\
\text { de libre elección, considerando para ello las principales variables } \\
\text { organizativas y educativas, así como su estructura administrativa } \\
\text { y marco legal. Para el desarrollo de esta investigación se han } \\
\text { estudiado los CdT dedicados a la investigación. }\end{array}$ \\
\hline
\end{tabular}


En relación con el presente trabajo interesa unificar una investigación cuantitativa y cualitativa, y el enfoque diversificado que se hizo de las variables organizativas y educativas, así como su estructura administrativa y del marco legal, para conseguir un resultado holístico de lo estudiado.

El Dr. Ibáñez mediante los resultados prácticos que va obteniendo a partir de la metodología aplicada describe el modelo teórico como Modelo de Educación Patrimonial, utilizando el método inductivo y la idea de retroalimentación, ambos valorados en esta tesis.

Se destacan los enfoques teóricos aportados, que genéricamente se podrían llamar constructivistas y de aprendizaje informal, como inspiradores del presente marco teórico y trabajo práctico.

El ámbito territorial de Cataluña es prolífico en los programas y estudios de Educación Patrimonial, hecho ligado al asunto de su territorialidad y cambio sociopolítico del Estado Español en las últimas décadas.

En 2011 la Dra. Coma presentó un estudio sinóptico de más de 350 de actividades educativas en el ámbito de los municipios españoles; se defendió en la Universitat de Barcelona bajo el título: Actividades educativas y didáctica del patrimonio en las ciudades españolas. Análisis, estado de la cuestión y valoración para una propuesta de modelización.

En primer lugar, la investigación analiza y expone un estado de la cuestión en torno a las actividades educativas patrimoniales, ofrecidas desde los Servicios Educativos o Áreas de Educación de los Ayuntamientos españoles. Se muestra cuál es nuestra oferta educativa patrimonial, así como qué se hace y cómo se utiliza el patrimonio en el ámbito educativo español. En segundo lugar, para saber la opinión personal y la valoración que hacen los usuarios (escolares de primaria y secundaria; profesorado, público general) de las actividades educativas patrimoniales, se hace un análisis de las actividades educativas estudiadas desde el punto de vista del usuario. En este caso se realiza una evaluación externa de las actividades patrimoniales desarrolladas en las ciudades españolas mediante un instrumento de evaluación. Finalmente, y, en tercer lugar, se procede a observar en cada lugar cada una de las actividades educativas patrimoniales objeto de estudio. Todo ello, para conocer a fondo la realidad y hacer una propuesta de 15 modelos educativos patrimoniales dentro del concepto de Ciudades Educadoras. 


\section{Tabla 11}

Tesis de Laia Coma. Fuente: TESEO

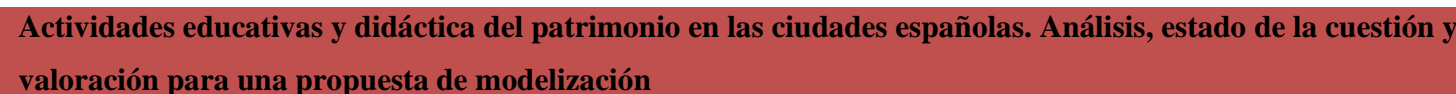

$\begin{array}{ll}\text { Autor/a: } & \text { Coma Quintana, Laia } \\ \text { Universidad: } & \text { Universitat de Barcelona }\end{array}$

Año:

Director/a:

Resumen:

\section{1}

Santacana, Joan

La investigación sobre Actividades educativas y didáctica del patrimonio en las ciudades españolas se articula en torno a tres objetivos fundamentales, y consecuentemente en tres estudios, que estructuran el cuerpo teórico de la misma. En primer lugar, la investigación ha analizado y realizado un estado de la cuestión en torno a las actividades educativas patrimoniales, ofertadas desde los Servicios Educativos o Áreas de Educación de los Ayuntamientos, en el marco geográfico español. Se ha tratado de conocer cuál es la oferta de los ayuntamientos en esta materia, así como conocer qué se hace y cómo se utiliza el patrimonio en el ámbito educativo español dentro del marco de las Ciudades Educadoras. Para ello, la investigación se ha basado en un análisis descriptivo del objeto de estudio, más de 350 actividades con la finalidad de establecer una clasificación tipológica de actividades y de los tipos de patrimonio más utilizados como recurso educativo en las ciudades españolas (Estudio I). En segundo lugar, con el objetivo de conocer la opinión personal y la valoración que hacen los usuarios (escolares de primaria y secundaria; profesorado de primaria y secundaria, público general) de las actividades educativas patrimoniales, se ha hecho un análisis de las actividades educativas estudiadas en el Estudio I, pero desde el punto de vista del usuario. Es evidente que pretender valorar la calidad de una actividad o acción educativa es una cuestión susceptible a la subjetividad de aquél o aquella que la organiza, participa o evalúa. En este caso (Estudio II), se ha optado en esta investigación por realizar una evaluación externa de las actividades patrimoniales desarrolladas en las ciudades españolas mediante un instrumento de evaluación creado ad hoc. Los resultados obtenidos del procesamiento de más de tres mil cuestionarios de satisfacción han permitido establecer un diagnóstico bastante completo de las actividades 
educativas patrimoniales españolas mediante la valoración personal de sus usuarios. Finalmente, y, en tercer lugar, se ha procedido a observar in situ cada una de las actividades educativas patrimoniales objeto de estudio para contrastar así la información obtenida en los dos estudios anteriores. Ello ha permitido una aportación más en la investigación; se trata de la propuesta de quince modelos educativos patrimoniales que pretenden ser un instrumento docente eficaz y que comulga con los principios de las Ciudades Educadoras. La estructura de la investigación se presenta bajo un esquema de diez capítulos. La primera parte (capítulos 1, 2 y 3) plantea la base a partir de la cual se ha desarrollado la investigación, así como el estado de la cuestión del tema objeto de estudio. En estos capítulos se hace especial hincapié en el marco real en el que se ha desarrollado la investigación, así como la situación o punto de partida. En el capítulo 4 se presenta el marco teórico, que, por su casi inexistencia hasta el momento en esta materia, se ha tenido que crear casi de forma expresa y un tanto extensa. Muy poco había escrito sobre el tema que en esta investigación se ha estudiado, y es por ello que ha sido necesario redactar y crear casi ex-novo el contenido que en esta investigación se presenta como marco teórico. El capítulo 5 plantea los objetivos de la investigación y la hipótesis de trabajo. Por un lado, los objetivos, tanto generales como específicos, aportan en esta investigación el máximo de información posible y necesaria para la validación final de la hipótesis formulada; por otro lado, la hipótesis de trabajo apunta hacia una posible modelización de las actividades educativas patrimoniales. A continuación, en el capítulo 6, se exponen los fundamentos metodológicos que han definido los distintos pasos necesarios para desarrollar la investigación, así como las distintas líneas a las que esta investigación se inscribe. A éste le sigue el capítulo 7 que ocupa una parte importante de la investigación presentando los tres estudios que se han realizado durante el llamado trabajo de campo. De igual manera que en el marco teórico, en este capítulo ha sido necesario elaborar un extenso trabajo de campo que ha permitido obtener un buen análisis, diagnóstico y evaluación sobre el tema objeto de estudio: las actividades educativas patrimoniales en el panorama español. Los capítulos 8 y 9 concluyen este trabajo de campo aportando los resultados, las conclusiones y las consideraciones pertinentes de cada estudio. Remarcar que es en el capítulo 9 en el que se presentan los modelos educativos patrimoniales creados, los cuales conforman una parte relevante de esta investigación. Finalmente, en el capítulo 10 se exponen las conclusiones finales de toda la investigación, con el fin de validar la hipótesis general 
y los objetivos formulados, así como algunas reflexiones finales sobre la problemática que se derivan de las mismas.

La investigación se focaliza en el estudio de la oferta municipal española de actividades educativas patrimoniales, encuadradas en la Red Estatal de Ciudades Educadoras. la ciudad, como espacio urbano en el que vivimos, y el patrimonio que esta posee (ya sea material o inmaterial) deben comprenderse en clave educativa para convertirse así en auténticos agentes educativos activos para la formación de la ciudadanía; esto es lo que se teoriza y analiza en esta investigación. Así pues, compartimos esa presentación panorámica de cientos de proyectos con carácter de inventario en un primer momento, para ofrecer un estado de la cuestión del ámbito territorial elegido. El objetivo primero es presentar cuál es nuestra oferta educativa patrimonial, así como qué se hace y cómo se utiliza el patrimonio en el ámbito educativo español en su caso, y de Castilla-León en el nuestro.

Fue inspiradora la creación exprofeso que realizó la Dra. Coma de una metodología de categorización y análisis de tantos proyectos.

Metodológicamente se hizo un análisis de las actividades educativas estudiadas desde el punto de vista del usuario. En este caso se realizó una evaluación externa de las actividades patrimoniales desarrolladas en las ciudades españolas mediante un instrumento de evaluación. Esto es un aspecto que corresponde con nuestro afrontamiento metodológico, a través de evaluación de estándares y métodos estadísticos.

Finalmente, y, en tercer lugar, se procedió a observar en cada lugar cada una de las actividades educativas patrimoniales objeto de estudio.

La evaluación de aprendizajes ha de contar en la actualidad con el impacto de las nuevas tecnologías aplicadas a la Educación, en esta línea es destacable la tesis de 2013 de la Dra. Vicent de la Universidad Autónoma de Madrid, titulada: Evaluación de un programa de educación patrimonial basado en tecnología móvil.

El trabajo de investigación se enmarca en el área de la Didáctica de las Ciencias Sociales, área paralela en Educación Patrimonial, al de Didáctica de la Expresión Plástica, en sus líneas referidas a la didáctica del patrimonio y el uso de tecnología en los procesos de enseñanza-aprendizaje. Se encuadra dentro del aprendizaje informal, en el ámbito del diseño de actividades educativas de los museos en torno al patrimonio. 


\section{Tabla 12}

Tesis de Naiara Vicent. Fuente: TESEO

Evaluación de un programa de educación patrimonial basado en tecnología móvil

\begin{tabular}{|c|c|}
\hline Autor/a: & Naiara Vicent \\
\hline Universidad: & Universidad Autónoma de Madrid (España) \\
\hline Año: & 2013 \\
\hline Director/a: & Mikel Asensio, Alex Ibáñez Etxeberria \\
\hline Resumen: & $\begin{array}{l}\text { El siguiente trabajo de investigación se enmarca en el área de la } \\
\text { didáctica de las ciencias sociales, en sus líneas referidas a la } \\
\text { didáctica del patrimonio y el uso de tecnología en los procesos de } \\
\text { enseñanza-aprendizaje. En concreto, se encuadra dentro del } \\
\text { aprendizaje informal, en el ámbito del diseño de actividades } \\
\text { educativas de los museos en torno al patrimonio, siendo Zarautz } \\
\text { en tus manos el programa que se evalúa. Este se desarrolla en el } \\
\text { Museo de Arte e Historia de Zarautz, con alumnos de secundaria, } \\
\text { utilizando la metodología mobile learning y dando lugar a un } \\
\text { aprendizaje basado en problemas. El programa Zarautz en tus } \\
\text { manos está destinado a trabajar la evolución del municipio a lo } \\
\text { largo de la historia de manera contextualizada con el patrimonio } \\
\text { local, visitando cada elemento en su emplazamiento original. La } \\
\text { tecnología móvil ayuda al alumno a desplazarse fácilmente por la } \\
\text { ciudad, así como a recopilar información en torno a este } \\
\text { patrimonio para poder ser trabajada posteriormente. El origen de } \\
\text { Zarautz en tus manos se sitúa en el proyecto I+D Innovación } \\
\text { educativa con m-learning. Aprendizaje y patrimonio y } \\
\text { arqueología en Territorio Menosca. (m-ONDARE) (UE03/A18), } \\
\text { a partir del cual se implementaron en el Museo de Arte e Historia } \\
\text { de Zarautz una serie de programas educativos de los que derivará } \\
\text { el que nos ocupa. Dentro del marco de aquel proyecto, se } \\
\text { desarrollaron varios estudios que dieron lugar a nuevas } \\
\text { cuestiones que se siguen trabajando a partir de una evaluación } \\
\text { sistematizada, para la cual se ha llevado a cabo el diseño de una } \\
\text { investigación compleja y aplicada que cuenta con una serie de } \\
\text { estudios cuyos resultados determinan el siguiente paso a dar. El } \\
\text { marco metodológico empleado para el diseño de la investigación } \\
\text { parte de una propuesta propia denominada Evaluación de } \\
\text { recorrido: la Evaluación de programas educativos y la Evaluación }\end{array}$ \\
\hline
\end{tabular}




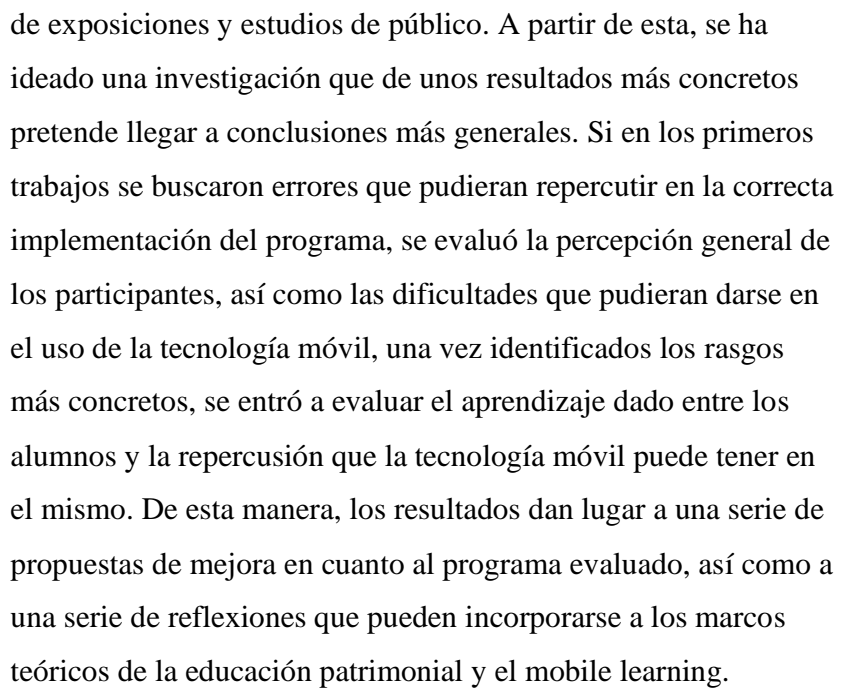

Los dos focos de atención diferenciales que aporta la tesis es la investigación focalizada en un territorio local y el uso proactivo de las nuevas tecnologías.

Conceptualmente, aporta el estudio diacrónico de la Historia local a partir de unos elementos arquitectónicos sincrónicos, que son los que el educando observa en la realidad actual, y además de un recurso en alza y de actualidad, como las TIC.

El origen de Zarautz en tus manos se sitúa en el proyecto I+D Innovación educativa, con m-learning, al igual que el OEPE de la Uva se sitúa en el marco de los proyectos de $\mathrm{I}+\mathrm{D}+\mathrm{i}$ “Retos Investigación” de los Ministerios pertinentes.

El marco metodológico empleado para el diseño de la investigación, parte de una propuesta propia denominada Evaluación de programas de educación patrimonial, que surge de la consideración de dos campos de conocimiento con largo recorrido: la Evaluación de programas educativos y la Evaluación de exposiciones y estudios de público, así pues, en nuestra tesis compartimos el punto de partida en la Evaluación de Programas como fundamento de ambas tesis y también compartimos la posterior evaluación de aprendizajes, que la Dra. Vicent recogió de los alumnos involucrados, así como las subsiguientes mejoras del programa, como de los marcos teóricos en que se encuadran las investigaciones.

Dentro del marco teórico y el Método Integral de Educación Patrimonial que planteó la Dra. Fontal en su tesis de 2003, se enmarca la tesis de la Dra. Gómez, presentada en la 
Universidad de Valladolid en 2013 y titulada Procesos de patrimonialización en el arte contemporáneo: diseño de un artefacto educativo para la identización.

Está relacionada directamente con la secuencia procedimental educativa integral de la Dra. Fontal: conocer-comprender-respetar-valorar-patrimonializar-identizar (nivel individual)- compartir-consensuar-identizar (nivel colectivo).

La Dra. Gómez pertenece al grupo de Valladolid que en torno al OEPE investiga en el ámbito de la Educación Patrimonial.

En esta tesis se pretende profundizar en el carácter constructivo de la identidad, desde una perspectiva patrimonial, incidiendo tanto a nivel individual, como colectivo, desde la acción educativa. Así pues, la tesis de la Dra. Gómez focaliza y desarrolla en profundidad los elementos clave del vínculo e identidad (individual y cultural) en la evaluación de aprendizajes que se recogen también en el presente estudio.

\section{Tabla 13}

Tesis de Carmen Gómez. Fuente: TESEO

\begin{tabular}{|c|c|}
\hline \multicolumn{2}{|c|}{$\begin{array}{l}\text { PROCESOS DE PATRIMONIALIZACIÓN EN EL ARTE CONTEMPORÁNEO: DISEÑO DE UN } \\
\text { ARTEFACTO EDUCATIVO PARA LA IDENTIZACIÓN }\end{array}$} \\
\hline Autor/a: & GÓMEZ REDONDO, MARÍA DEL CARMEN \\
\hline Universidad: & Universidad de Valladolid \\
\hline Año: & 2013 \\
\hline Director/a: & FONTAL MERILLAS, OLAIA \\
\hline Resumen: & $\begin{array}{l}\text { La siguiente tesis doctoral pretende, a través del análisis de los } \\
\text { referentes teóricos, proponer nuevos entornos metodológicos para } \\
\text { la acción educativa, en el ámbito patrimonial. Cada vez que se } \\
\text { plantea un texto sobre patrimonio y educación patrimonial se } \\
\text { hace necesario hablar de identidad, sin embargo, hasta este } \\
\text { trabajo no se ha afrontado dicha relación desde el punto de vista } \\
\text { educativo. Así pues, en esta tesis se pretende profundizar en el } \\
\text { carácter constructivo de la identidad desde una perspectiva } \\
\text { patrimonial, incidiendo tanto a nivel individual como colectivo } \\
\text { desde la acción educativa. El desarrollo de la tesis se estructura } \\
\text { de manera rizomática, a través de los tres ejes: arte } \\
\text { contemporáneo, patrimonio e identidad, mediante los cuales se } \\
\text { genera un sistema de relaciones configurándose como sustrato } \\
\text { para la acción educativa. Así pues, para llegar a esta acción } \\
\text { educativa se hace necesario reflexionar sobre el valor patrimonial } \\
\text { del arte contemporáneo, entenderlo como metonimia de la } \\
\text { cultura, en un momento histórico capaz de generar productos } \\
\text { significativos para el hoy y para el mañana. Otra de las }\end{array}$ \\
\hline
\end{tabular}


reflexiones necesarias para esta acción educativa pasa por comprender el patrimonio como un vínculo en sujeto y objeto y no como una cualidad intrínseca de los objetos. Alejar el protagonismo del objeto hacia el vínculo, supone una toma de agencia por parte del sujeto que decide conceder significados patrimoniales a los objetos. El patrimonio deja de ser un acervo de objetos, para pasar a ser un proceso cultural que afecta a las identidades culturales, tanto a nivel individual como colectivo y, por tanto, susceptible de ser afrontado desde la educación. El tercer eje de reflexión se centra en la identidad cultural, entendida ésta como una faceta de la identidad individual y como hecho que sucede en el interior del individuo tras la apropiación y no fuera, por la repetición de roles aprendidos. Esta identidad cultural, subjetivada y asimilada, se define por su carácter dinámico y mutante, además de por su dialéctica con el entorno. Esto la hace también definirse como multimatérica, dando cabida en la individualidad a las diferentes identidades colectivas. Finalmente se establece una acción educativa que parte de una secuencia procedimental significativa para los procesos de patrimonialización e identización y que queda descrita a través de los procedimientos: conocer-comprender-respetar-valorarpatrimonializar-identizar (nivel individual)- compartirconsensuar-identizar (nivel colectivo). Dicha acción educativa es llevada a cabo en el entorno museístico y en el entorno virtual, vinculando de manera significativa las esferas identitarias estimuladas mediante la acción educativa con la cotidianeidad de los participantes. A través de diversas estrategias, vinculadas directamente con la secuencia citada, se pone en marcha un cambio identitario a nivel individual que pasa por la patrimonialización de la obra de arte hasta la identización, es decir a la autodefinición a través de la obra. De manera sincrónica se trabaja la construcción de una identidad colectiva de grupo que tenga como seña definitoria la obra de arte, generando sinergias afectivas entre el grupo y las obras. Posteriormente a la acción sincrónica en el taller, aparece una estrategia anacrónica que pretende una vinculación de lo sucedido en el interior del taller con la cotidianeidad de los participantes, aportando así significatividad a la acción educativa y a los procesos allí estimulados. El método de investigación empleado para el desarrollo del estudio es el etnográfico, que en este caso permite observar qué fenómenos identitarios y patrimoniales ocurren dentro de la acción educativa. La observación como técnica empleada, se divide en tres perspectivas: una interna, una externa y una perspectiva neutra, de tal manera que los instrumentos de recogida aportan datos desde estas tres perspectivas, formando un 

cuerpo de resultados triangulado desde el origen. Finalmente se
hace posible confirmar la incidencia de la acción educativa en los
niveles identitarios descritos. A través de ésta se han generado
nuevas identidades colectivas entre cuyas señas identitarias
aparecen las obras de arte con las que se ha trabajado; además
estas señas aparecen como definitorias a nivel individual. Así
pues, se reconoce la acción educativa como mediadora en este
proceso y el museo como entorno propicio para su desarrollo. La
acción educativa es además concebida por los participantes como
una experiencia identitaria, vinculada también a las señas
definitorias de la identidad del grupo. Es en esta
acción/experiencia donde aparecen dos inercias grupales, una de
tipo afectivo, basada en una necesidad de formar grupo pero que
a su vez se fusiona con las obras de arte con las que se trabajó, y
una segunda sinergia que establece al grupo como comunidad de
interpretación, en la que a partir de la resignificación de las obras
de arte hacia significados vinculados a la realidad particular de
los participantes, éstos se reconocen como autores conjuntos de
este proceso y por tanto como una seña más del grupo.

La tesis mencionada es crucial en torno al marco teórico que informará también nuestra metodología y análisis de los aprendizajes. La Dra. Gómez comprende el patrimonio como un vínculo entre sujeto y objeto y no como una cualidad intrínseca de los objetos. Alejar el protagonismo del objeto hacia el vínculo, supone una iniciativa por parte del sujeto que decide conceder significados patrimoniales a los objetos. El patrimonio deja de ser un conjunto de objetos, para pasar a ser un proceso cultural que afecta a las identidades culturales, tanto a nivel individual como colectivo y, por tanto, susceptible de ser afrontado desde la educación.

A la hora de la evaluación de aprendizajes esta tesis inspira para considerar como elemento diferenciador, significativo y esencial, la importancia grupal en la doble dimensión de: generación de vínculos progresivos a medida que se experimenta la acción /experiencia y la resignificación de la obra artística en el contexto del grupo de estudiantes.

También en la Universidad de Valladolid en 2016 se presentó la tesis de la Dra. Sánchez Ferri titulada: Memoria, identidad y comunidad: evaluación de programas de educación patrimonial en la Comunidad de Madrid. 
En nuestra evaluación de aprendizajes y en el marco teórico han sido de principal interés las aportaciones específicas sobre los temas de la memoria, conformadora de identidades individuales, y la transmisión, que las transformará en colectivas, que son los ejes de una investigación que explora en profundidad la Dra. Sánchez Ferri, en tres principios: memoria, identidad y comunidad.

\section{Tabla 14}

Tesis de Ana Sánchez. Fuente: TESEO

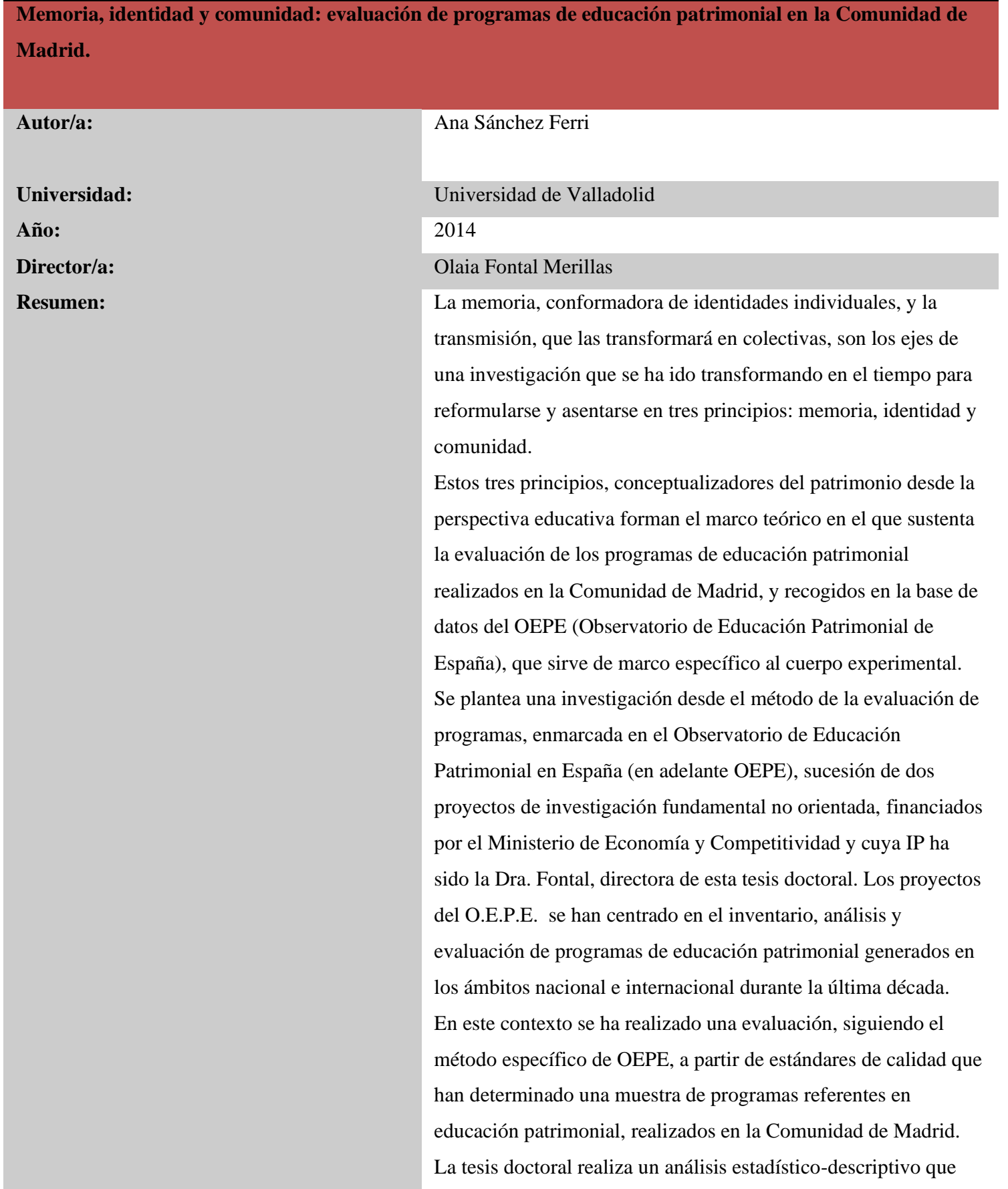


Se investiga en la evaluación de los programas de educación patrimonial realizados en la Comunidad de Madrid recogidos en la base de datos del OEPE, y en este trabajo en los de Castilla y León, que respectivamente sirven de marco específico al cuerpo experimental.

Ambas tesis coinciden en la una evaluación, siguiendo el método específico de OEPE, a partir de estándares de calidad que han determinado una muestra de programas referentes en educación patrimonial, realizados respectivamente en las comunidades de Castilla-León y en la Comunidad de Madrid. La tesis doctoral de la Dra. Sánchez Ferri nos inspira realizando un análisis estadístico-descriptivo que permite un conocimiento específico de los programas y además propone una evaluación de programas que determina los estándares de calidad de los programas de educación patrimonial.

Una tercera tesis es la presentada en la Universidad de Valladolid en 2014 por la Dra. Marín Cepeda titulada: Educación patrimonial y diversidad: evaluación de programas y definición de un modelo basado en los procesos de patrimonialización.

El trabajo de investigación se centra en el ámbito de la Educación Patrimonial y la diversidad de públicos; utiliza el paradigma sociocrítico y orienta el proceso a conocer, analizar y evaluar programas de Educación Patrimonial referentes, en el trabajo con la diversidad de públicos, para definir los criterios y estándares de calidad que determinan el éxito de la inclusión educativa. La relevancia de este estudio para nuestra tesis es la adopción de criterios y estándares de calidad en la evaluación de programas. Estándares en su caso vinculados a objetivos concretos que en la tesis de la Dra. Marín recogen especialmente el carácter inclusivo de los programas.

Tabla 15

Tesis de Sofía Marín. Fuente: TESEO 


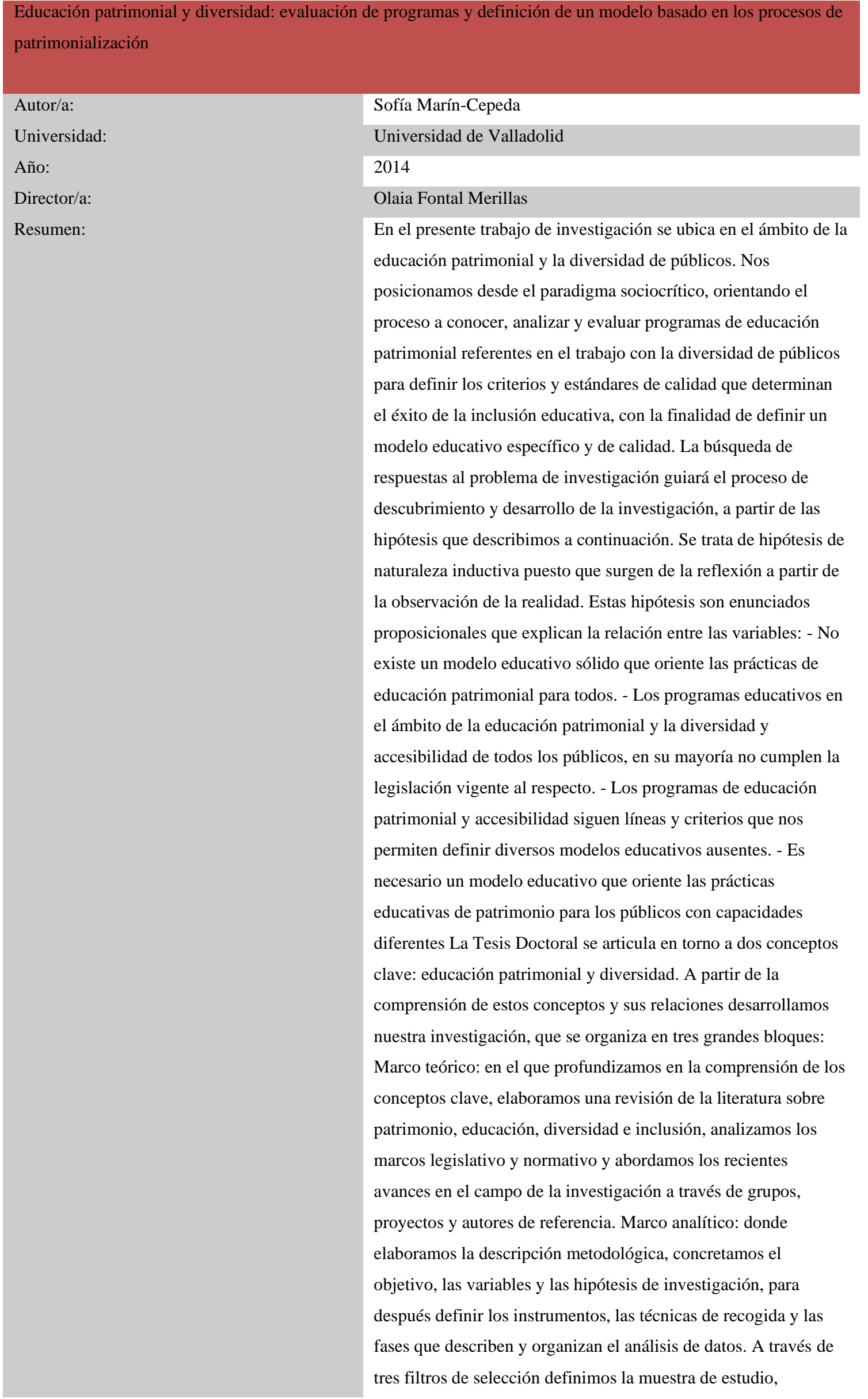




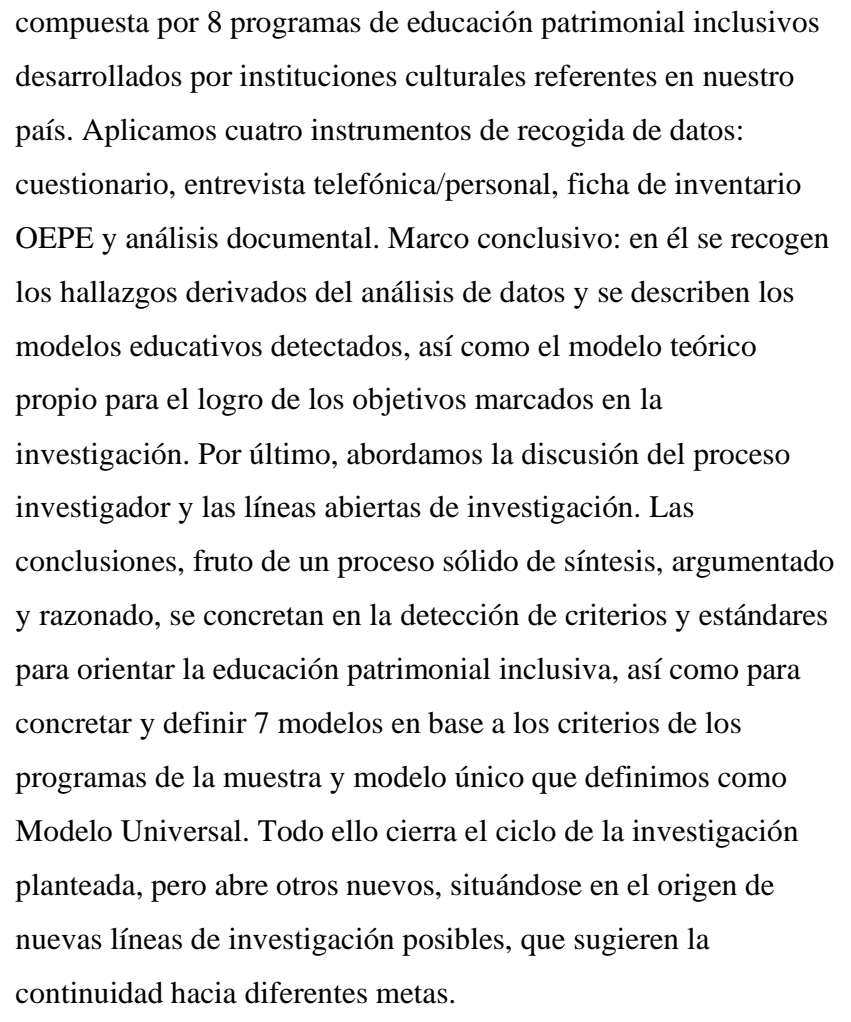

Se manejaron hipótesis de naturaleza inductiva puesto que surgen de la reflexión a partir de la observación de la realidad. Esto, unido al perfil sociocrítico de la tesis, aporta el necesario análisis diferencial de la adecuación (o su ausencia) de los programas a la legislación, y/o de las carencias específicas de los programas hacia públicos diversos. La metodología utilizada también se basa en variadas técnicas y recursos tanto cuantitativos como cualitativos, criterio con el que hemos coincidido.

También en la Universidad de Valladolid, en 2016 se presentó la tesis del Dr. de Castro Martín titulada: Cartografía autoetnográfica de una genealogía de programas de educación patrimonial desde la perspectiva del aprendizaje basado en proyectos y la investigación-acción.

Respecto a la evaluación de aprendizajes, esta tesis constituye un apoyo muy interesante al basarse en programas de educación patrimonial diseñados e implementados por el autor, que abarca desde los ocho proyectos descritos, al marco de 30 proyectos en que se inscribe, todo ello desarrollado en sus 20 años de práctica docente. Aporta de modo muy relevante la integración de recursos procedentes del área de las Ciencias Sociales y la Educación Artística incluyendo pautas para desarrollar proyectos de innovación educativa. 
Tabla 16

Tesis de Pablo de Castro. Fuente: TESEO

\begin{tabular}{|c|c|}
\hline \multicolumn{2}{|c|}{$\begin{array}{l}\text { Cartografía autoetnográfica de una genealogía de programas de educación patrimonial desde la perspectiva del } \\
\text { aprendizaje basado en proyectos y la investigación-acción }\end{array}$} \\
\hline Autor/a: & Castro Martín, Pablo L. de \\
\hline Universidad: & Universidad de Valladolid \\
\hline Año: & 2016 \\
\hline Director/a: & Ibáñez Etxeberria, Alex. Fontal Merillas, Olaia \\
\hline Resumen: & $\begin{array}{l}\text { La investigación describe un recorrido por diversos programas de } \\
\text { educación patrimonial diseñados e implementados por el autor } \\
\text { que, descritos a modo de estudio de caso y desde la perspectiva } \\
\text { de la investigación acción y el método auto etnográfico, } \\
\text { permiten, al tiempo, trazar la evolución de veinte años de su } \\
\text { práctica docente. Aunque se centra en el análisis de ocho } \\
\text { proyectos que comparten su interés por la divulgación, estudio y } \\
\text { conservación del patrimonio cultural presenta, en realidad, un } \\
\text { grupo de proyectos más complejo, pues se acerca a la treintena de } \\
\text { propuestas. } \\
\text { Como base de este planteamiento aparece también la pretensión } \\
\text { de definir su propia identidad docente, fruto del afán de una } \\
\text { búsqueda constante. Por otro lado, el autor propone unas sencillas } \\
\text { pautas para desarrollar proyectos de innovación educativa, } \\
\text { aunando recursos procedentes del área de las Ciencias Sociales y } \\
\text { la Educación Artística. }\end{array}$ \\
\hline
\end{tabular}

Respecto al marco teórico y a la metodología nos encontramos en la investigación con el caso de estudio, la investigación acción y el método auto etnográfico.

El carácter eminentemente experiencial y diacrónico de la investigación, nos aporta un bagaje extenso para analizar la dinámica de grupos y formación de identidades, tanto individuales como grupales. Igualmente es interesante, un feedback constante respecto a la reformulación teórica y la formación constructivista de la identidad de los investigadores y/o docentes.

En 2014 se presenta la tesis de la Dra. Gillate, del Grupo del País Vasco titulada Programas de educación patrimonial en contextos informales: análisis y valoración de su influencia en el alumnado de eso de la zona minero-industrial de Bizkaia. 
Inserta en el Grupo del País Vasco, incide en el enfoque sociocrítico y en las aportaciones de las pedagogías y contextos no formales de educación. También vemos el enfoque territorializado y local en todo el proceso de la investigación.

Tabla 17

\section{Tesis de Iratxe Gillate. Fuente: TESEO}

\begin{tabular}{|c|c|}
\hline \multicolumn{2}{|c|}{$\begin{array}{l}\text { Programas de Educación Patrimonial en contextos informales: análisis y valoración de su influencia en el } \\
\text { alumnado de ESO de la zona minero-industrial de Bizkaia }\end{array}$} \\
\hline Autor/a: & Iratxe Gillate Aierdi \\
\hline Universidad: & Universidad del País Vasco. \\
\hline Año: & 2014 \\
\hline Director/a: & Ibáñez Etxeberria, Alex. Madariaga Orbea, José María \\
\hline Resumen: & $\begin{array}{l}\text { La enseñanza-aprendizaje de las Ciencias Sociales y la Historia en la Educación } \\
\text { Secundaria, a pesar de los intentos innovadores de las décadas de los } 80 \text { y } 90 \text {, sigue } \\
\text { manteniendo una estructura tradicional que la convierte en aburrida y no útil para el } \\
\text { alumnado. Las dificultades para la modernización de esta área se encuentran en el } \\
\text { currículum, en la formación del profesorado y en los materiales utilizados para su } \\
\text { enseñanza. Entre el profesorado en activo gran parte busca en los contextos informales de } \\
\text { educación complementar su enseñanza teórica con la práctica y para esta tarea el } \\
\text { patrimonio y la Educación Patrimonial son muy utilizados. Por lo tanto, para estudiar } \\
\text { Ciencias Sociales e Historia la utilización del patrimonio a través de programas de } \\
\text { aprendizaje de Educación Patrimonial consigue que el aprendizaje del alumnado sea } \\
\text { significativo. Pero, en general, este tipo de programas se utiliza, pero no se realizan } \\
\text { evaluaciones sobre sus resultados por lo que no sabemos hasta donde consiguen sus } \\
\text { objetivos y los del profesorado. En esta investigación queremos conocer si la participación } \\
\text { del alumnado de la ESO en tres programas de aprendizaje de Educación Patrimonial } \\
\text { produce cambios en la concepción y valoración del patrimonio, los conocimientos } \\
\text { históricos y patrimoniales, la motivación y el autoconcepto social, y la identificación con } \\
\text { lo local. De este modo hemos llegado a la conclusión de que hay diferentes niveles de } \\
\text { modificabilidad en las variables investigadas tras la realización de este tipo de programas } \\
\text { de Educación Patrimonial en los que los más modificables son los conocimientos } \\
\text { patrimoniales e históricos seguidos de la valoración patrimonial, mientras que la } \\
\text { concepción y percepción patrimonial, y el autoconcepto social y la motivación son los más } \\
\text { difíciles de modificar con este tipo de programa de Educación Patrimonial. }\end{array}$ \\
\hline
\end{tabular}

Su relevancia para la presente tesis, se basa en que versa sobre la evaluación de aprendizajes. La autora después de la recogida de datos concluye con una correlación de estos con los diferentes objetivos que se pretenderían analizar: la concepción y valoración del patrimonio, los conocimientos históricos y patrimoniales, la motivación y el autoconcepto social, y la identificación con lo local. 
Es relevante señalar que los aspectos más centrados en los contenidos son más exitosos en cuanto a objetivos logrados; y este nivel de éxito disminuye según nos vamos trasladando hacia variables más sutiles o complejas (el auto concepto social y la motivación). Este hecho nos debe interpelar sobre cómo construir rediseños teóricos de los programas y de la propia teoría para paliar dicho desequilibrio.

El mismo año 2016 y en el mismo grupo de investigación la Dra. Maldonado defiende su tesis Educación patrimonial y redes sociales. Análisis y evaluación de acciones en los medios de comunicación social para la definición de una cartografía educativa. Desde el punto de vista teórico, tiene especial interés el analizar un medio tan contemporáneo como son las redes sociales que, por su actualidad, todavía carecen de análisis epistemológicos numerosos, aunque sí crecientes; y, en conexión, el cuestionamiento de si este medio es propicio para nuestras áreas científicas/ educativas y nuestras estrategias: la Educación Patrimonial, la difusión patrimonial, el proceso educativo de calidad, etc. La Dra. Maldonado estudia estas tensiones en las diferentes fases del paradigma secuencial provenientes de la tesis de la Dra. Fontal: comunicacióndifusión-transmisión, interpretación-facilitación, apropiación-aprehensión, sensibilización, patrimonialización e identización.

Tabla 18

Tesis de Stella Maldonado. Fuente: TESEO

\begin{tabular}{|c|c|}
\hline \multicolumn{2}{|c|}{$\begin{array}{l}\text { Educación patrimonial y redes sociales. Análisis y evaluación de acciones en los medios de comunicación } \\
\text { social para la definición de una cartografía educativa. }\end{array}$} \\
\hline Autor/a: & María Stella Maldonado López \\
\hline Universidad: & Universidad de Valladolid \\
\hline Año: & 2016 \\
\hline Director/a: & Fontal Merillas, Olaia. Ibáñez Echeverría, Alejandro. \\
\hline Resumen: & $\begin{array}{l}\text { En pleno siglo XXI, los espacios de aprendizaje en torno al patrimonio se expanden con } \\
\text { fuerza, abriendo los contextos a una participación e interacción mucho más real por parte } \\
\text { de las personas. El que esto suceda se debe primordialmente a dos causas: por un lado, el } \\
\text { desarrollo de las tendencias educativas constructivas que ponen al individuo como } \\
\text { generador y constructor de su propio proceso de aprendizaje en interacción con otras } \\
\text { personas y elementos y con el medio; y, por otro lado, el surgimiento de las tecnologías de } \\
\text { la comunicación y el conocimiento que han ido evolucionando de la simple consumición } \\
\text { de las mismas, hasta la producción de nuevos discursos partiendo de éstas. }\end{array}$ \\
\hline & Estas son algunas de las ideas presentes esta investigación, adscrita al Observatorio de \\
\hline
\end{tabular}


Educación Patrimonial en España (OEPE) de la Universidad de Valladolid.

El patrimonio es uno de los ejes que articula la tesis doctoral y junto a él, los procesos que van desde la comunicación hasta la educación y que desembocan en la construcción de los aprendizajes. Todo ello dentro de un contexto determinado: las plataformas sociodigitales.

La investigación, de carácter descriptivo y exploratorio, se inicia con el planteamiento de unas cuestiones que aportan la base para armar tanto la parte teórica como la práctica: ¿son las redes sociales un territorio apto para el desarrollo de procesos de aprendizaje?, ¿se pueden utilizar las plataformas 2.0 como contextos de educación patrimonial?, ¿qué tipo de comunicación y lenguajes se desenvuelven en redes sociales facilitando el conocimiento, la interacción y el disfrute en torno al patrimonio? y, por último, si el objeto de estudio de la educación patrimonial son las formas de relación que se establecen entre personas y patrimonio ¿los medios de comunicación social como contextos para la creación de vínculos son espacios idóneos para el desarrollo de estas relaciones?

Partiendo de estas motivaciones se construyen los dos marcos que dan cuerpo al estudio: por un lado, el teórico y, por otro, el empírico-conclusivo.

En la parte empírica se ha utilizado como metodología la evaluación comprensiva y basada en estándares de Stake (2006) que concede valor a la experiencia y al conocimiento del investigador, combinando aspectos interpretativos en base a criterios cuantificables. Esta metodología enlaza con las bases de la sociología comprensiva abordada en el marco teórico como estudio de los hechos sociales que rodean al individuo y de los cuales forma parte; con esta interrelación se ha pretendido completar la secuencia de conocer para comprender, comprender para valorar y valorar para mejorar la práctica. Una práctica que se concretaría en la posterior realización de una acción educomunicativa en el marco de las redes sociales en torno al patrimonio.

El análisis de la situación se ha hecho en las redes sociales Facebook y Twitter como plataformas generalistas de mayor uso. Un análisis observacional en torno a las dimensiones de la educación patrimonial (comunicación-difusión-transmisión, interpretación-facilitación, apropiación-aprehensión, sensibilización, patrimonialización e identización) con el interés de saber qué se está haciendo, cómo y por quién, y si son desarrollables los procesos de patrimonialización en estos contextos de aprendizaje relativamente nuevos.

Metodológicamente se comparte con esta tesis, la influencia del enfoque de la evaluación comprensiva y basada en estándares de Stake (2006) que concede valor a la experiencia y al conocimiento del investigador, combinando los resultados cuantitativos con un nivel interpretativo, y fundamentándose en la sociología comprensiva. 
Siguiendo con el grupo de Valladolid, en 2018 se defiende la tesis de la doctora Pablos González: Evaluación de programas de educación patrimonial para personas con trastorno del espectro autista (T.E.A ${ }^{7}$.) en museos.

Como foco diferencial se encuentra el análisis de la diversidad funcional de las personas, relacionada con la Educación Patrimonial y el ámbito específico de los museos. Se debe destacar la defensa teórica de la concepción integral de la persona y las conclusiones socio-críticas acerca de la plausible reforma de los marcos metodológicos para democratizar los espacios estudiados y a la par, los programas de Educación Patrimonial.

Tabla 19

Tesis de Laura de Pablos. Fuente: TESEO

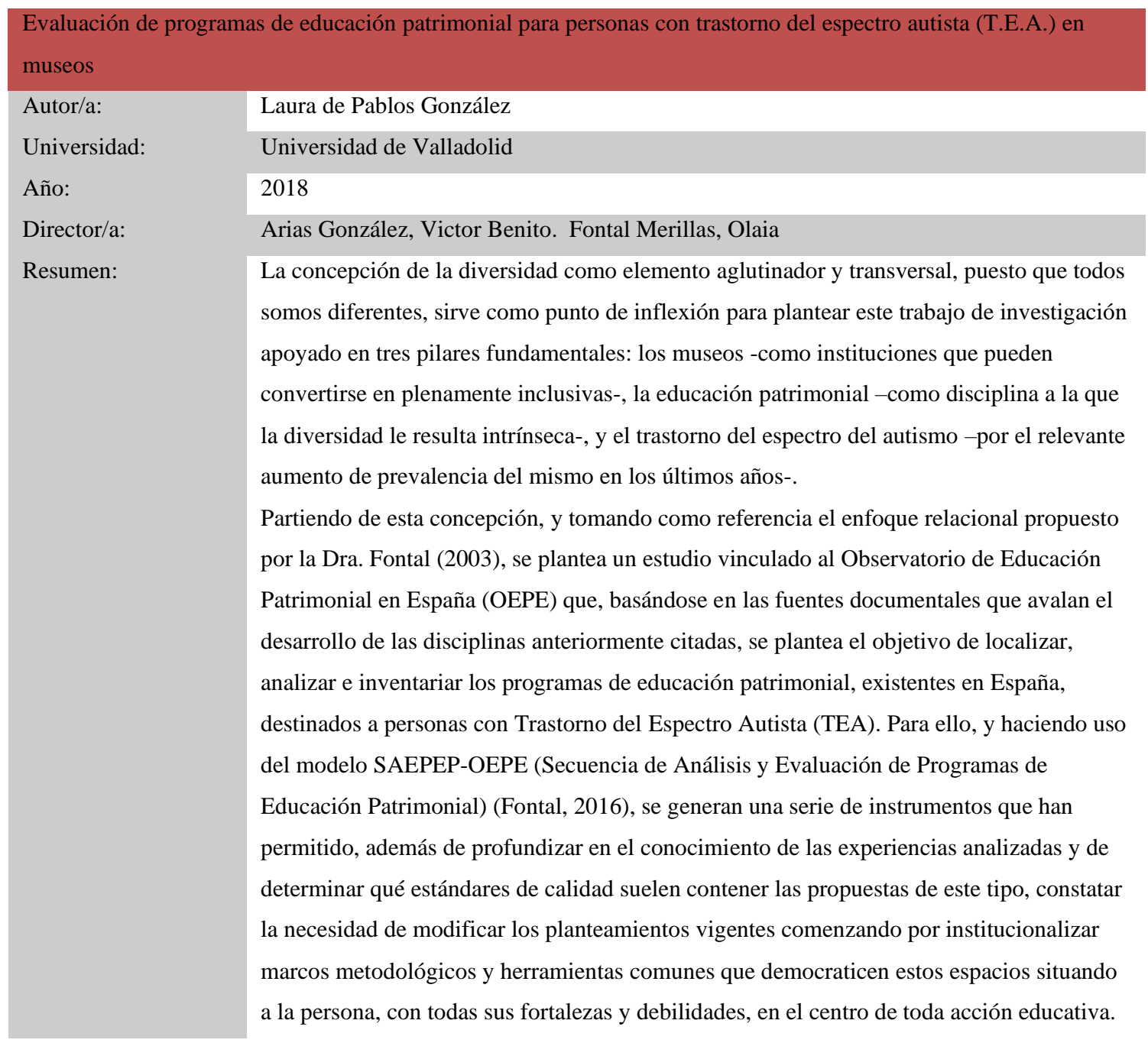

${ }^{7}$ Trastorno del Espectro Autista 
Metodológicamente nos inspira la utilización del método SAEPEP-OEPE (Secuencia de Análisis y Evaluación de Programas de Educación Patrimonial) de nuestro mismo grupo de investigación. Coincidimos en el trabajo de inventario y recogida de programas, aunque en su caso circunscrito a los TEA y posteriormente, en la determinación de estándares de calidad. Por último, es relevante el propósito de inferir conclusiones y lanzar propuestas de reforma que, en círculos concéntricos, abarquen tanto a los diferentes agentes, como a los marcos normativos, institucionales y teórico-intelectuales relacionados con la Educación Patrimonial.

El mismo año 2018 y en el mismo grupo de investigación, se presenta la tesis de la Dra. García Ceballos, elaborada con el compendio de tres publicaciones. Seguimos la línea de evaluación de programas, y la determinación de estándares de calidad. Han sido reveladoras sus conclusiones acerca de las carencias de los programas en aspectos como: la implementación didáctica, la coherencia interna del diseño, la aplicación de feedback continuado entre prácticas y teoría, o la difusión externa de los mismos.

Tabla 20

Tesis de Silvia García Ceballos. Fuente: TESEO

Evaluación de programas en educación patrimonial. Indicadores de calidad a través del método SAEPEP-OEPE y
su instrumento basado en estándares EBEB-OEPE.
$\begin{aligned} & \text { Autor/a: } \\ & \text { Universidad: }\end{aligned}$
$\begin{aligned} & \text { Año: } \\ & \text { Director/a: }\end{aligned}$
$\begin{aligned} & \text { Resumen García Ceballos } \\ & \text { Arias González, Víctor. Fontal Merillas, Olaia }\end{aligned}$
$\begin{aligned} & \text { El patrimonio nos brinda diversas posibilidades educativas; por ello, el conocimiento de } \\ & \text { las prácticas, la evaluación de los programas y la localización de propuestas de calidad son } \\ & \text { objetivos primordiales en el ámbito de la educación patrimonial. La revisión de la } \\ & \text { literatura, proyectos, tesis doctorales y textos institucionales conforman el marco teórico, } \\ & \text { del que se infiere que la evaluación de programas es una de las principales ausencias de la } \\ & \text { disciplina y se detecta la necesidad de diseñar instrumentos y sistemas de evaluación que } \\ & \text { permitan ejercer un adecuado análisis de las prácticas que responda a la objetividad y la } \\ & \text { comparación insesgada de los programas. } \\ & \text { El marco epistemológico se conforma por compendio de publicaciones, que equivalen a } \\ & \text { tres estudios cuyo objetivo común ha sido la evaluación de programas educativos mediante } \\ & \text { la aplicación del método secuencial para el análisis y evaluación de programas de } \\ & \text { educación patrimonial, del Observatorio de Educación Patrimonial en España (SAEPEP- } \\ & \text { OEPE). El análisis se ha efectuado sobre tres muestras de programas n=85, n=15, n=223. } \\ & \text { Cada uno de los estudios se centra en diferentes contextos y categorías del patrimonio. El }\end{aligned}$


primero de ellos atiende a programas que presenten "indicadores de inclusión", desarrolla un estudio estadístico descriptivo que analiza los estándares que mayor nivel de calidad alcanzan y señala los susceptibles de mejora. El segundo de ellos responde a una muestra más reducida extraída del contexto cultural de São Paulo; se trata de un estudio de caso sobre un programa referente derivado de la evaluación basada en estándares. El tercero de ellos, centrado en el patrimonio arqueológico, transita por la evaluación de estándares para profundizar en un estudio de caso que, en relación con los estudios anteriormente citados, articula un decálogo de actuación prospectivo para definir nuevos modelos educativos de futuro y sostenibilidad.

Cada uno de los estudios aporta un paso más en la secuencia procedimental del método de evaluación que (1) permite conocer los estándares que mayor nivel de calidad presentan y los que son susceptibles de mejora, (2) discrimina los programas educativos que mayor calidad presentan, localizando ejemplos de buenas prácticas y (3) analiza pormenorizadamente los programas para extraer claves de actuación futura, incidiendo en la mejora de la práctica educativa y el avance de la disciplina.

Finalmente, la triangulación de los resultados obtenidos nos lleva a concluir que: (a) un alto número de programas no explicitan o profundizan en su estructura didáctica; (b) un alto número de programas no encuentra consonancia entre las partes que conforman el diseño educativo; (c) acciones como dar visibilidad a un proyecto, evaluar su efecto o reflexionar sobre la adecuación de su enfoque educativo son acciones clave en la mejora de la calidad educativa. Adicionalmente, la discusión de los estudios ha derivado en una línea de continuidad, la validación del instrumento clave en la secuencia procedimental (Evaluación basada en estándares básicos -EBEB-OEPE-), que supone un aporte relevante a la materia, la escala Q-Edutage; una herramienta objetiva que tributa rigor y planificación a la materia.

El rigor estadístico lo aporta el citado método SAEPEP-OEPE (Secuencia de Análisis y Evaluación de Programas de Educación Patrimonial) y en esta tesis se añade el interés de aplicar la innovación de la herramienta $Q$-edutage, instrumento estadístico propio que añade rigor y sistematicidad a la secuenciación del análisis.

\subsection{Análisis conjunto de referentes: conclusiones}

Por una parte, observamos bastantes referentes centrados en la fundamentación conceptual de la Educación Patrimonial, como elemento autónomo con peso específico suficiente. Esto se enmarca en una voluntad fundacional de dicha disciplina, la cual no había contado en España con esa diferenciación necesaria en anteriores décadas de siglo XX.

A partir de esta fundación de la disciplina los investigadores han podido lanzar numerosos estudios de caracterización y evaluación de los diversos programas existentes en España. Se está pudiendo sistematizar este panorama bastante 
diversificado por cuestiones territoriales, administrativas o sociológicas, que mencionamos posteriormente.

Respecto a la evaluación de aprendizajes es de destacar el amplio porcentaje de referentes de las Ciencias Sociales y de la Historia, áreas tradicionalmente vinculadas al patrimonio.

En segundo término, también observemos que la Educación Patrimonial se encuentra en un cruce de caminos entre el Arte, la Educación, la Psicología, la Sociología y otras disciplinas. Así pues, nuestros referentes estudiados reflejan los correspondientes retos de cada una de esas áreas de conocimiento en las últimas décadas.

En España la Educación Patrimonial en su dimensión sociológica recoge la ebullición de las Autonomías en el último cuarto del siglo XX, promoviéndose estudios sobre elementos patrimoniales intrínsecamente autonómicos o locales, entendidos como la construcción (o reconstrucción) de una identidad propia de esos territorios.

Paralelamente, se instauraban instituciones locales y múltiples Universidades territorializadas donde ubicar y promocionar estos planteamientos de estructura territorial del Estado.

Nuestros referentes ofrecen múltiples e interesantes investigaciones y actuaciones al respecto por ejemplo en Galicia, País Vasco, Cataluña, Murcia, Comunidad Valenciana o Andalucía. Es de destacar la elección histórica de épocas artísticas de referencia: en el País Vasco se ha estudiado como campo educativo histórico la Prehistoria, en Cataluña y la Comunidad Valenciana se ha estudiado el siglo XIX y XX, el Modernismo o en Galicia hay investigaciones sobre los Montes comunales.

Esta dinámica territorial ha motivado la formación de diferentes grupos de investigación en las Universidades españolas que están integrando tres elementos simultáneos: la voluntad fundacional de la disciplina a la que ya se ha referido anteriormente; el enfoque territorial de las investigaciones; y el auge de las TIC en lo que suponen de redefinición sistémica del mundo cultural y educativo.

Igualmente, la elección de qué poblaciones se estudian o se involucran de forma activa en los proyectos de investigación muestra en muchos casos el enfoque sociológico de pensamiento crítico adaptado a la Educación y en concreto a la Educación Patrimonial. Adentrándonos en los referentes estudiados en el siglo XXI, cabe destacar otras dos líneas de investigación y publicación apoyadas explícitamente por los programas de 
I+D de los sucesivos Ministerios y Consejerías autonómicas acordes a la dinámica de los tiempos:

De un lado (referentes que no hemos recogido en nuestro listado por exceder nuestra investigación) el apoyo a la implementación material, técnica o arquitectónica del Patrimonio, vinculado a los conceptos de Competitividad, Retorno Económico, Transferencia del Conocimiento y Rentabilidad, que se ha asentado en la socioeconomía del nuevo siglo.

Por otra parte, el apoyo estructural y también el auge investigador respecto de las TIC y multimedia asociadas a la Educación Patrimonial. Este apoyo se da bajo un doble criterio de promoción: primero, basándose en las posibilidades exponenciales de divulgación masiva que aportan al patrimonio o los recursos educativos, y segundo, sustentándose en el efecto de una creciente (también potencialmente exponencial) participación como agentes de los educandos debido al altísimo índice de penetración y ocupación del tiempo diario que las TIC tienen en las nuevas generaciones.

Los referentes igualmente abordan las encrucijadas de la Psicología y Pedagogía contemporáneas. En la dimensión pedagógica de la educación patrimonial no podemos olvidar los iconos como Freire y las teorías informalistas correspondiente a las metodologías y recursos más innovadores que recogen nuestros principales investigadores mencionados

En la dimensión psicológica, también sobresalen los legados fundamentales como Vygotsky y mencionar la tensión entre lo patrimonial, concepto que implica el diálogo con el pasado, y las psicologías más "posmodernas" de la construcción de la personalidad, reflejadas, por ejemplo, en métodos como las auto etnografías. Se destaca, además, el porcentaje de programas no formales de Educación Patrimonial sobre los que tratan varias tesis y referentes.

En la dimensión artística y de Historia del Arte se produce un fenómeno parecido al de la Sociología, el del auge del arte contemporáneo y sus Museos e instituciones en el último cuarto del siglo XX en España, donde la Educación Patrimonial tuvo que tomar posición ante esta nueva realidad social. Es de destacar que el auge museístico continúa en la actualidad ligado a las políticas territoriales sobre la industria turística y cultural, con iconos a nivel Estatal que transforman las ciudades en su conjunto como Cuenca y el arte contemporáneo, o museos como el MUSAC o el Guggenheim. 
Ya en el siglo XXI la tensión es sobre las nuevas formas de arte Multimedia y la difusión mediática del Arte tradicional. E, igualmente, la Educación Patrimonial está abordando como no puede ser de otra manera, estos retos que de forma rápida están calando en la sociedad y en los educandos. 
“Cambiar de horizontes, cambiar d método de vida y de atmósfera, es provechoso a la salud y a la inteligencia”

Gustavo Adolfo Becquer 


\section{CUERPO EMPÍRICO}

\section{MÉTODO DE INVESTIGACIÓN}

\subsection{INTRODUCCIÓN}

Las bases epistemológicas que sustentan la investigación en educación y, en concreto, en la Educación Patrimonial, es una tarea ardua y con poca posibilidad de obviar la justificación, ya que actualmente existe un interés continuo por la cientificidad de las investigaciones en educación. Este capítulo del presente documento se aborda describiendo todas las fases de la metodología utilizada, imbricándola con la teoría que la sustenta, dando así coherencia a todo el conjunto de la tesis.

Por un lado, la investigación en Educación Patrimonial posee un carácter en movimiento, ya que, como se ha visto, el concepto de patrimonio es un concepto cambiante con el tiempo, por ello, la Educación Patrimonial es una disciplina viva. Además, realizar investigación en educación patrimonial genera innovación educativa, por el carácter interdisciplinar y transdisciplinar de la misma, proyectos que, como se podrá descubrir, innovan por sus métodos físicos y didácticos, y con una concepción abierta del centro, de los agentes educativos y de la comunidad patrimonial.

Para el diseño de la presente investigación se acudió al modelo Rayuela (Jorrín-Abellán, 2014) que realiza un mapeado de todo el proceso de investigación, desde las preguntas de investigación, hasta los resultados y su interpretación (Figura 11). De esta manera se pudo diseñar el método de la investigación.

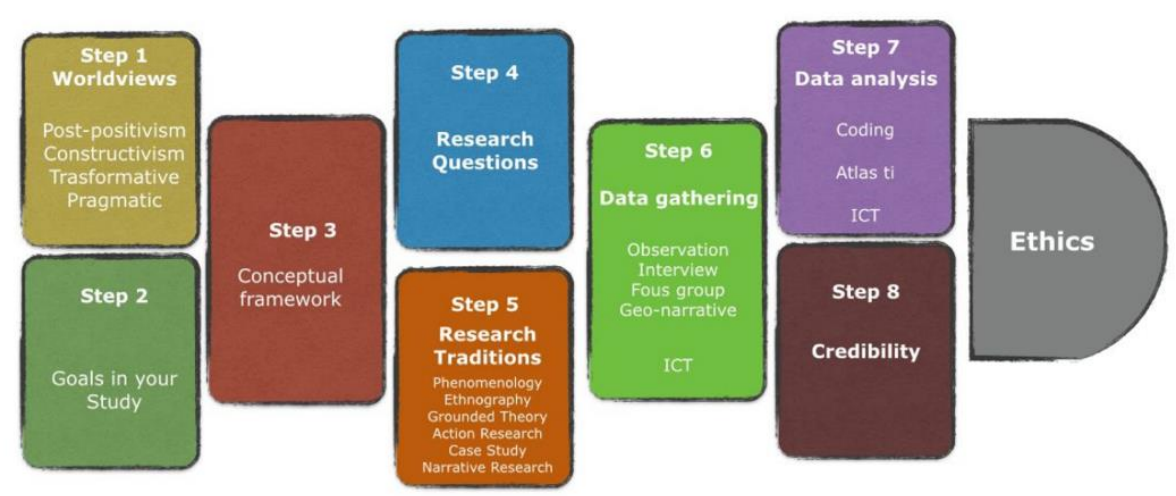

Qualitakive Research hopscotch
(Jorrin-Abellan, 2014) 
Figura 11. Modelo Hopscotch para el diseño de investigación, Jorrín-Abellán (2014). Fuente: http://hopscotchmodel.com

\subsection{Justificación y finalidad de la investigación}

En este estudio que se presenta, se ha utilizado una metodología de investigación mixta, que integra tanto métodos cuantitativos como métodos cualitativos, con la finalidad de dar una visión más completa del fenómeno estudiado, combinando análisis estadísticos junto con análisis de contenido en el marco de un estudio de caso. Los estudios mixtos parten de una visión pragmática de la realidad, en la que convergen filosofías que abogaban por la idea de que las ciencias sociales no pueden investigarse a través del método científico tradicional de forma única y las filosofías post-modernistas que defendían que la investigación en este campo social debe llevarse a cabo por procesos en los que impere el sentido común, el pensamiento práctico y la aplicabilidad de ambos. En el presente estudio, de gran complejidad y extensión, se ha optado por el uso de este tipo de métodos para poder tener una visión mucho mayor y reducir la complejidad del mismo. Es decir, no es una mezcla de métodos cuantitativos y cualitativos sin conciencia, sino que este tipo de metodología clarifica el diseño de manera que sea un escalón más en la comprensión del fenómeno. En este sentido, se tienen en cuenta los puntos aportados a la ciencia por Kuhn (2011) cuando habla de que los fenómenos no pueden explicarse por completo, ni son la realidad, sino que son una parte de un gran fenómeno que se explica desde el punto de vista subjetivo de la realidad que se percibe, según el contexto y la trayectoria científica, siendo las teorías finales complementarias entre sí para la explicación de dichos fenómenos. Cuando un investigador se enfrenta con la idea de usar metodología mixta ha de tomar dos decisiones importantes: por un lado, si quiere operar dentro del paradigma dominante o no, en su mayor parte de la investigación a realizar; y si quiere realizar la investigación en fases de una manera secuencial o de una manera simultánea. Así, se puede encontrar en la revisión sobre el tema, las clásicas siglas:

CUAL+cual; CUAL+cuan; CUAN+cual; CUAN+ cuan; $\mathrm{CUAL} \longrightarrow$ cual $\mathrm{CUAL} \longrightarrow$ cuan; $\mathrm{CUAN} \longrightarrow$ cual; $\mathrm{CUAN} \longrightarrow$ cuan; Siendo, CUAL= cualitativo y CUAN= cuantitativo, en mayúsculas si designa que es el método primario o predominante y minúsculas, el secundario, y en donde está el símbolo suma (+) se indica que ambos métodos se proceden de forma simultánea y la flecha $(\longrightarrow$ ) que el método secundario surge después que el primario. 
Los multi-métodos (multi-methods), multi-estrategia (multi-strategy) o metodología mixta (mixed-methodology) llegan de la mano de las ciencias del comportamiento sobre los años 50 con el concepto de triangulación como una operación múltiple en investigación (Campbell, Fiske, 1959). Pero hay que entender exactamente qué es lo que se entiende por triangulación, que no es lo mismo que la metodología mixta, sino un objetivo de entre muchos, de los multi-métodos. Este proceso de triangulación supone, como indica su nombre, formar un triángulo, en el que se esté ofreciendo una mirada del fenómeno estudiado desde lo cuantitativo, otra mirada desde lo cualitativo, y una convergencia de ambos.

Estos autores describieron varios tipos de triangulación:

1. La triangulación de datos o informantes: el investigador se basa en diferentes fuentes de datos y los distintos informantes que participan.

2. La triangulación de investigadores: varios investigadores realizan las observaciones del fenómeno en cuestión para corroborar resultados, así se pueden evitar sesgos en la investigación.

3. La triangulación teórica: retomada de Denzin (1990) cuando se refiere a probar distintas teorías y metodologías antagonistas la mayoría de las veces (p.511), aunque poco usada por la confusión de que se sintetiza en la crítica las epistemologías de base.

4. Triangulación metodológica: uso de distintos métodos en el diseño o en la recogida de datos, que puede ser entre métodos o dentro de los métodos, que Arias (1999) lo define como "combinación de dos o más recolecciones de datos con parecidas aproximaciones en el mismo estudio que miden la misma variable" (p 70).

Es decir, la triangulación es una convergencia de resultados obtenidos por distintos métodos o estrategias, incluso en la recolección de datos. Los métodos mixtos forman parte de un proceso más amplio, en el que la triangulación es una parte de ese proceso.

En el trabajo presente se ha optado por el uso de metodología mixta siguiendo las consideraciones de Creswell (2005): 
1. El enfoque que el investigador piensa que armoniza y se adapta mejor al planteamiento del problema.

En el caso que nos ocupa este estudio busca un entendimiento profundo de cómo se realiza la evaluación de los aprendizajes en el ámbito de lo formal y patrimonial en las etapas de los 11 a los 18 años.

2. El método que el investigador perciba que se ajusta mejor a las expectativas de los usuarios o lectores del estudio.

3. El enfoque con el cual el investigador prefiera y se sienta más cómodo.

4. La aproximación que el investigador considere racionalmente más apropiada para el planteamiento.

5. El método en que el investigador posea más entrenamiento.

Actualmente los métodos mixtos están muy difundidos y utilizados, quizá en exceso y con una praxis no exenta de errores tanto de diseño como de llevarlos a la práctica. Se conocen y desarrollan foros internacionales de todo tipo: congresos internacionales como el Mexed Methods International Conference, o el que se está gestando para 2020 en la Facultad de Educación y Trabajo Social de la Universidad de Valladolid; una asociación internacional de investigadores, la Mixed Methods International Research Association, MMIRA; libros sobre la temática, como el de Creswell y Plano (2011), o el de Tashakkori y Teddlie (2003), entre otros; una revista científica, la Journal of Mixed Methods Research, del Sage.

Así, para Creswell y Plano (2011) los métodos mixtos han de seguir una serie de puntos específicos e insalvables:

1. Recogida y análisis de los datos con rigurosidad, tanto los cualitativos como los cuantitativos.

2. Relación o integración de los dos tipos de datos de dos formas: simultánea, para combinarlos o fusionarlos; o secuencial, para insertar unos sobre otros.

3. Priorizar una de las dos formas o equilibrar la dominancia del paradigma

4. Llevar a cabo unas fases del programa de investigación

5. Utilizar los procedimientos sin olvidar la complejidad del contexto y el marco teórico empleado

6. Combinar los procedimientos de forma coherente con el plan de investigación 
En este trabajo, como se ha indicado, se utiliza la metodología mixta de investigación, basada en la cosmovisión pragmática de la propia investigadora, que parte de teorías de autores como Creswell (2014), Patton (1990), Morgan (2007), o Tashakkori y Teddlie (2010), que invitan a poner el foco en el problema de investigación desde distintos enfoques para poder generar conocimiento; así, en este trabajo, la metodología principalmente se basa en el marco teórico desarrollado sobre las teorías de educación patrimonial (memoria e identidad) y teorías de la evaluación tanto de programas como de aprendizajes, y los referentes en estos tres ámbitos, dentro de la comunidad de Castilla y León, en el espacio formal, concretamente en la Educación Secundaria Obligatoria y el Bachillerato.

\subsection{Problema de investigación. Hipótesis y objetivos}

\subsubsection{Problema de investigación}

Se podría definir el problema de investigación a través de los interrogantes: ¿Se está formando o sensibilizando al alumnado de Secundaria y Bachillerato de Castilla y León en educación patrimonial? Y si es así, ¿qué aprendizajes están desarrollándose en este proceso? ¿se está realizando evaluación de esos aprendizajes?

\subsubsection{Objetivos e hipótesis}

Siguiendo a Maxwell (2008) en el presente trabajo se definen tres tipos de objetivos, resumidos en la tabla 24:

Tabla 24

Objetivos del estudio basados en Maxwell (2008)

\begin{tabular}{lll}
\hline OBJETIVO PERSONAL & OBJETIVOS PRÁCTICOS & OBJETIVOS \\
& & INTELECTUALES \\
\hline Curiosidad como docente & Cambiar la situación & Comprender teoría y \\
& & práctica \\
\hline
\end{tabular}

Y siguiendo estos objetivos personales, prácticos e intelectuales, a la luz del marco teórico detallado, es conveniente profundizar en el trato que está recibiendo la educación patrimonial en la comunidad de Castilla y León, mediante dos estudios: por un lado, realizar una evaluación de los programas de educación patrimonial 
inventariados en la base de dato del OEPE; y por otro, profundizar sobre la naturaleza de los aprendizajes de la educación patrimonial y su evaluación (ambos en Castilla y León y, en Secundaria y Bachillerato).

El objetivo general de esta investigación, por tanto, se divide en dos: por un lado es, conocer si el alumnado de Secundaria y Bachillerato de Castilla y León está formándose en educación patrimonial y por otro, conocer cuáles son los programas específicos de mejor calidad que se están llevando a cabo en este nivel educativo.

De este objetivo, se destacan los siguientes objetivos específicos:

Objetivo 1.1. Inventariar programas de educación patrimonial a través de las fichas diseñadas para el inventario del OEPE

Objetivo 1.2. Examinar los programas de educación patrimonial del inventario del OEPE en la comunidad de Castilla y León, a través de los estándares básicos, para extraer los de mejor calidad en cuanto a su diseño Hipótesis 1. Los programas de educación patrimonial de Castilla y León se dirigen a público de ESO, bachillerato, o ambas

Hipótesis 2. Los programas de educación patrimonial de Castilla y León definen el patrimonio desde todas sus tipologías

Objetivo 1.3. Diseñar una rúbrica de estándares específicos sobre evaluación de aprendizajes en los programas de educación patrimonial de Castilla y León que son de buena calidad de diseño

Objetivo 1.4. Analizar la validez de criterio en el diseño de la rúbrica de estándares específicos sobre evaluación de aprendizajes en los programas de educación patrimonial de Castilla y León que son de buena calidad de diseño

Objetivo 1.5. Examinar los programas de educación patrimonial del inventario del OEPE en la comunidad de Castilla y León, de mejor calidad en cuanto a su diseño, a través de la rúbrica de estándares específicos sobre evaluación de aprendizajes Hipótesis 3: Los programas de educación patrimonial de Castilla y León de ESO, Bachillerato o ambas, desarrollan competencias de diversa tipología 
Hipótesis 4: Los programas de educación patrimonial de Castilla y León de ESO, Bachillerato o ambas, realizan una evaluación de aprendizajes de distintos tipos

Objetivo 2. 1. Analizar y profundizar en la normativa nacional educativa vigente en materia de patrimonio, tanto la ley de educación, como el plan nacional

Objetivo 2.2. Analizar la ley de la comunidad de Castilla y León en materia de patrimonio, tanto la ley de educación, como los planes autonómicos

Objetivo 2.3. Analizar la ley de la comunidad de Castilla y León en materia de evaluación del patrimonio, tanto la ley de educación, como los planes autonómicos

Objetivo 2.4. Extraer los estándares de evaluación específicos de la educación patrimonial en ESO y Bachillerato

\subsubsection{Proceso de investigación}

La metodología utilizada en este trabajo ha sido una metodología mixta de diseño anidado, en la que el estudio cualitativo predomina y el cuantitativo está anidado en el primero. Es decir, se puede decir que es un método mixto CUAL $\rightarrow$ cuan, siendo el método primario el cualitativo y, el secundario el cuantitativo; se realiza primero el secundario para luego llevar a cabo el primario.

La metodología de investigación se lleva a cabo a través de dos fases complejas, concretas y en la que el final de la fase I se anida a la fase II.

La primera fase, parte del Método Secuencial de Análisis y Evaluación de Programas de Educación Patrimonial (SAEPEP) en el seno del Observatorio de Educación Patrimonial en España (OEPE), que a su vez se lleva a cabo a través de siete subfases. La segunda fase, es un estudio de caso de la investigación que nos ocupa y con sus correspondientes pasos a seguir, según esta tradición de investigación. Es decir, en ese orden, primero se lleva a cabo el método SAEPEP-OEPE y se termina con el estudio de caso, de base cualitativa. 


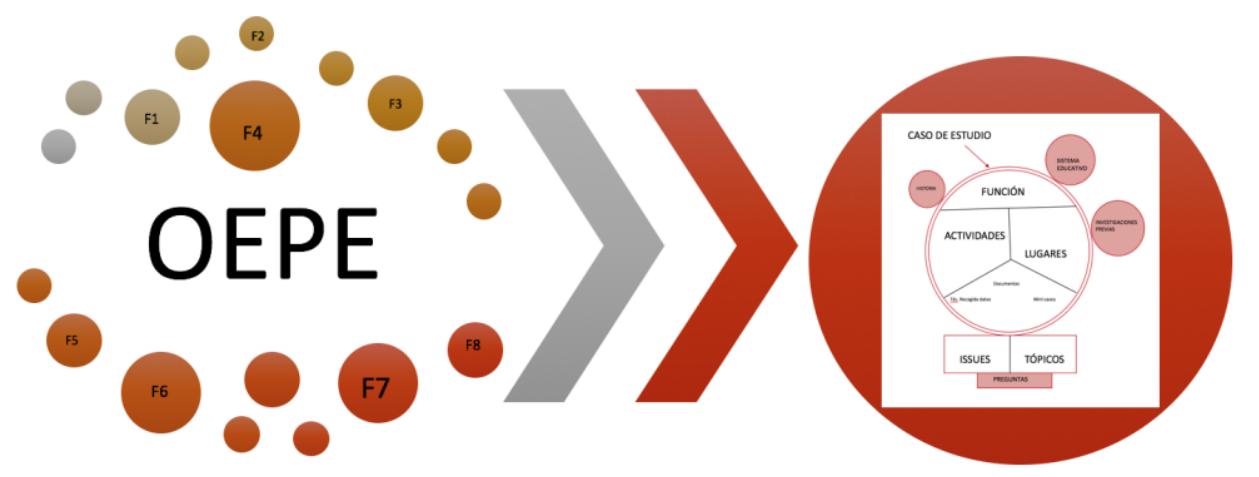

\section{Método Secuencial de Análisis y Evaluación de Programas de Educación Patrimonial}

\section{Estudio de Caso \\ FASE II}

FASE I

Figura 12. Proceso de investigación. Fuente: propia

4.3.3.1. FASE I, Evaluación de programas: la Q-Hedutage para evaluar por estándares

En la primera fase del estudio se utiliza la Secuencia de Análisis y Evaluación de Programas propuesta por el Observatorio de Educación Patrimonial en España. Es una secuencia de fases que va realizando una criba de programas de educación patrimonial en virtud de unos estándares de evaluación. En esta fase es en la que se realizan los análisis cuantitativos que dan respuesta a algunos interrogantes de la siguiente fase que es el estudio de caso.

Las subfases son las que siguen:

I. Fase I: Búsqueda y localización de programas.

Esta fase es el primer contacto que tiene el investigador con la base de datos del Observatorio. Se trata de la búsqueda de programas de educación patrimonial a través de distintos medios, bien localizados por Internet, bien por revisiones bibliográficas, incluidas las noticias divulgativas, o por foros de especialistas en la materia, como congresos, simposio, seminarios, o encuentros de diversa índole. La base de datos está integrada en la página principal del Observatorio, pero con entrada restringida a los usuarios y de uso exclusivo de los investigadores con intereses comunes en educación patrimonial.

II. Fase II: Discriminación mediante criterios de inclusión e inclusión en la base de datos. 
En esta fase se decide cuáles son los programas susceptibles de ser inventariados y cuáles no, en base a unos criterios que se consensuaron en la gestación de la base de datos, que se especifican en el manual del Observatorio. Así, se excluyen si: a) es un programa exclusivamente realizado por el museo para su público, b) o si es una web de museo que informa sobre el mismo, c) o si es un material cuyo único fin es el de informar sobre algún bien patrimonial, d) o una página web 1.0, que solo informa. El resto de casos estarían dentro de los criterios de inclusión.

III. Fase III: Inventario de Programas

Es un archivo que se lleva a cabo en una ficha de registro organizada y sistematizada que recoge información de los programas desde el diseño educativo hasta la difusión del mismo. Esta ficha se divide en cinco grandes apartados: localización, relación con otras fichas, descripción, diseño educativo y anexo documental (ver Fig. 13)

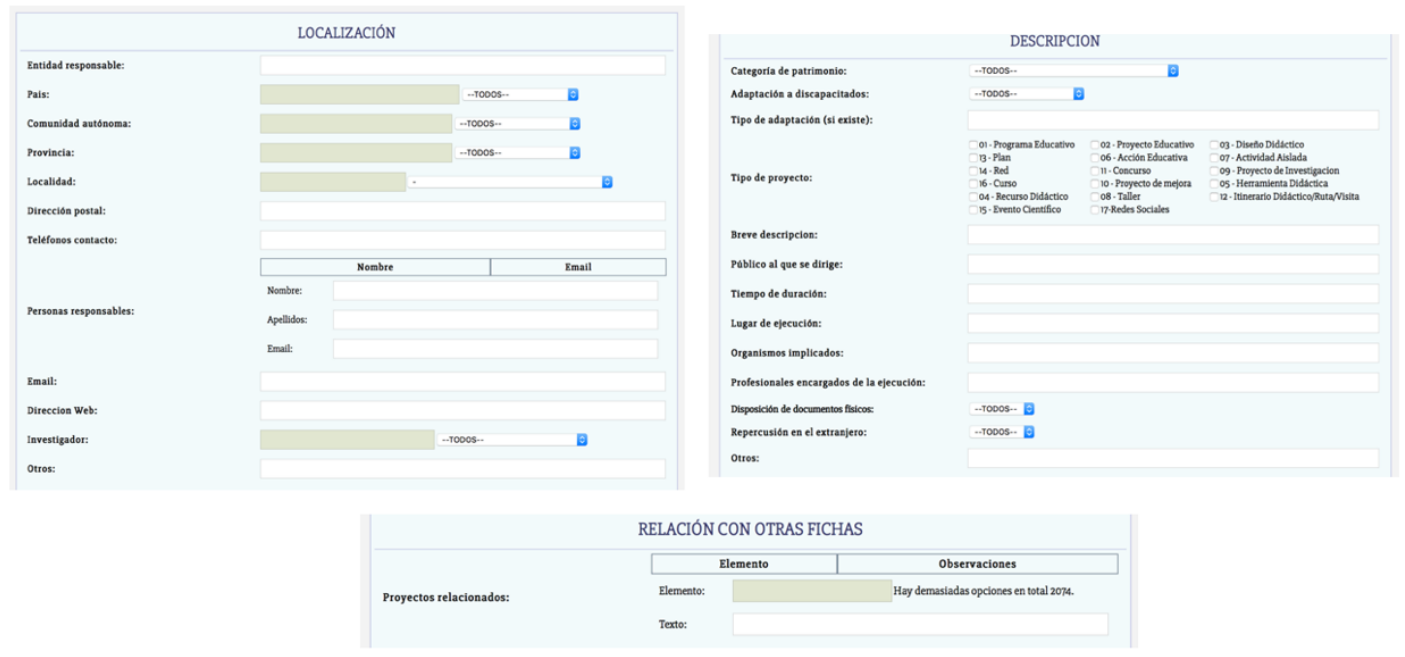

Figura 13. Secciones de la ficha del inventario del OEPE. Fuente: www.oepe.es

IV. Fase IV: Análisis estadístico descriptivo

Esta fase es aquella en la que se realiza un análisis descriptivo, en el cual se pueden descubrir características de los programas inventariados, así como describir a través de la estadística descriptiva las categorías a las que pertenecen los programas, la localización de los mismos, si se han realizado adaptaciones a todos los públicos a los que se dirigen, cómo se han diseñado en cuanto a los objetivos, las metodologías usadas 
o si se llega a cualquier tipo de población. Esta fase puede hacer una idea, una descripción de las partes inventariadas de los programas.

V. Fase V: Selección discriminatoria a través de la evaluación basada en estándares básicos En esta fase se utiliza un instrumento creado para la discriminación de programas a través de estándares básicos. Es una rúbrica con escala Likert y los 15 estándares básicos sobre dos dimensiones o estándares generales: a) la calidad de la información sobre los programas (metadatos), con ocho ítems y b) grado de concreción del diseño educativo, con siete ítems; todos deben obtener una puntuación de la escala que son: desde (1) no se alcanza, (2) se alcanza con condiciones, (3) se alcanza, hasta (4) se alcanza con calidad, (ver Fig. 14)

\begin{tabular}{|c|c|c|c|c|}
\hline Dimensiones y estándares & $\mathrm{A}$ & $\mathrm{B}$ & $\mathrm{C}$ & $\mathrm{D}$ \\
\hline \multicolumn{5}{|l|}{ 1. Calidad de la información sobre el programa (metadatos) } \\
\hline \multicolumn{5}{|l|}{ 1.1 Datos de identificación y localización del diseño } \\
\hline \multicolumn{5}{|l|}{$\begin{array}{l}\text { 1.2 Datos de contacto con la dirección y/o equipo de diseño, planificación e } \\
\text { implementación. }\end{array}$} \\
\hline \multicolumn{5}{|l|}{ 1.3 Descriptores que definen el programa. } \\
\hline \multicolumn{5}{|l|}{$\begin{array}{l}\text { 1.4 Concepción holística del patrimonio en su naturaleza (material e inmaterial) y en } \\
\text { sus cualidades (arqueológico, histórico, documental, artístico...). }\end{array}$} \\
\hline \multicolumn{5}{|l|}{$\begin{array}{l}1.5 \text { Especificación del tipo/tipología de proyecto desarrollado (programa educativo, } \\
\text { proyecto educativo, diseño educativo, acción educativa, actividad aislada etc.) }\end{array}$} \\
\hline \multicolumn{5}{|l|}{$\begin{array}{l}\text { 1.6 Descripción de las bases, principios y criterios sobre los que se establece el } \\
\text { programa }\end{array}$} \\
\hline \multicolumn{5}{|l|}{ 1.7 Concreción del público al que va dirigido } \\
\hline \multicolumn{5}{|l|}{$\begin{array}{l}\text { 1.8 Incorporación de anexos documentales (memoria, imágenes, vídeos, materiales } \\
\text { didácticos empleados etc.) }\end{array}$} \\
\hline \multicolumn{5}{|l|}{ 2. Grado de concreción del diseño educativo } \\
\hline \multicolumn{5}{|l|}{ 2.1 Justificación del proyecto } \\
\hline \multicolumn{5}{|l|}{ 2.2 Descripción de los objetivos a lograr en el desarrollo del programa } \\
\hline \multicolumn{5}{|l|}{ 2.3 Presentación de contenidos abordados en el programa } \\
\hline \multicolumn{5}{|l|}{ 2.4 Orientación metodológica y estrategias de enseñanza aprendizaje } \\
\hline \multicolumn{5}{|l|}{ 2.5 Definición de recursos, formatos, soportes y tecnología empleados } \\
\hline \multicolumn{5}{|l|}{ 2.6 Determinación de los sistemas o herramientas de evaluación } \\
\hline 2.7 Medición del impacto y repercusión de la propuesta & & & & \\
\hline
\end{tabular}

Figura 14. Rúbrica de dimensiones y estándares básicos del OEPE. Fuente: WwW.oepe.es

La creación de estos estándares básicos proviene de la Base de Datos del OEPE (Fontal, 2016) en la que, para llegar a los 15 ítems (tabla 14) se han realizado tres análisis de contenido y análisis estadístico descriptivo de tres muestras de programas de dicha base ( $\mathrm{n}=350, \mathrm{n}=644$ y $\mathrm{n}=1120$ ), unido a la revisión bibliográfica y los criterios determinados en los aspectos metodológicos del Plan Nacional de Educación y Patrimonio (Fontal y Juanola, 2015). En un principio era una escala con etiquetas cualitativas y se pasó posteriormente a una codificación ordinal cuantitativa. Toda la rúbrica detalla los 
criterios básicos para desarrollar un programa bien diseñado valorando la institución al cargo, la estructura de diseño didáctico, el tipo de programa y su difusión. Para cada programa se extrae un sumatorio de los estándares básicos en una puntuación total (Nitko, 2001). En la calibración de la escala Q-Edutage se realizaron los baremos de estas puntuaciones directas a estandarizadas. Una vez transformadas las puntuaciones a estandarizadas, la interpretación de los datos realizada es cualitativa, según la escala baremada con media 100 y desviación típica 15. De esta interpretación, se destacan una serie de programas que serán evaluados en la siguiente fase por los estándares específicos. En la Base de Datos se encuentran 333 programas de Castilla y León. Se delimitan en primer lugar, aquellos que van enfocados para el público de Secundaria y Bachillerato. Y a esos, que son 300 se evalúan a través de la rúbrica de estándares básicos, que resultarán que son los de mejor calidad y concreción de diseño en el programa.

VI. Fase VI: Evaluación de programas basada en estándares específicos Los estándares específicos son diseñados en función de las hipótesis planteadas en esta fase de estudio. Para que una rúbrica pueda ser válida como un instrumento de medición ha de cumplir:

1. Ser sencillo, viable y aceptado por pacientes, usuarios e investigadores (viabilidad).

2. Ser fiable y preciso, es decir, con mediciones libres de error (fiabilidad).

3. Ser adecuado para el problema que se pretende medir (validez de contenido).

4. Reflejar la teoría subyacente en el fenómeno o concepto que se quiere medir (validez de constructo).

5. Ser capaz de medir cambios, tanto en los diferentes individuos como en la respuesta de un mismo individuo a través del tiempo (sensibilidad al cambio).

En principio este estudio realiza un análisis del punto 3. Sobre la validez de contenido, es decir, sobre la opinión de expertos; así, fueron diseñados 23 estándares específicos y tras el estudio de la validez, fue sometido a la revisión de 17 jueces, que valoraron cada uno de ellos en una escala de 1 a 4, en términos de:

$\checkmark$ Coherencia: el ítem mide lo que pretende medir, es adecuado para medir la evaluación

$\checkmark$ Claridad de la redacción: está redactado de manera clara 
$\checkmark$ Relevancia: importancia para medir la evaluación

$\checkmark$ Observabilidad: grado en que se considera que la acción descrita en el ítem es observable y puede ser valorada de forma objetiva por cualquier observador Para analizar el acuerdo entre los jueces se calcularon los coeficientes ponderados de concordancia de Bangdiwala $\left(B^{\mathrm{W}_{\mathrm{N}}}\right)$ (Bangdiwala, 1987), así quedaron definidos 14 estándares específicos (ver figura 15):

\begin{tabular}{|c|c|c|c|c|}
\hline DIMENSIONES Y ESTÁNDARES ESPECÍFICOS & A & B & $\mathrm{C}$ & $\mathrm{D}$ \\
\hline 1. Qué evaluar & - & - & - & - \\
\hline 1.1. Se evalúa el concepto de patrimonio en todas sus tipologías: cultural, construido, intangible, o natural. & & & & \\
\hline $\begin{array}{l}\text { 1.2. Concreción teórica: se adecúa la evaluación a los objetivos propuestos y hay una estructura didáctica } \\
\text { adecuada }\end{array}$ & & & & \\
\hline 1.3. Innovación educativa: en la evaluación tiene en cuenta procesos, conceptos, actitudes, valores & & & & \\
\hline 1.4. Coherencia teórica y didáctica: la evaluación es sumativa y formativa & & & & \\
\hline 1.5. Incorporación de distintos agentes educativos: evaluación de todos los agentes que intervienen & & & & \\
\hline 2. Cómo evaluar & - & - & - & - \\
\hline 2.1. Inclusión de formas de evaluación específicas: autoevaluación y coevaluación & & & & \\
\hline $\begin{array}{l}\text { 2.2. Adecuación al currículo nacional y autonómico: sigue estándares de evaluación que se propone en } \\
\text { currículo o el plan nacional de educación y patrimonio }\end{array}$ & & & & \\
\hline $\begin{array}{l}\text { 2.3. Flexibilización del diseño para distintas situaciones: se evalúa de distintas formas, en distintas } \\
\text { situaciones }\end{array}$ & & & & \\
\hline $\begin{array}{l}\text { 2.4. Coordinación entre agentes educativos implicados: todos los que forman parte del proyecto conocen las } \\
\text { formas de evaluar }\end{array}$ & & & & \\
\hline 2.5. Continuidad temporal: es una evaluación continua a lo largo del programa y más allá de él & & & & \\
\hline $\begin{array}{l}\text { 2.6. Reajuste en los procesos didácticos: se utilizan rúbricas, entrevistas, pequeños cuestionarios, exámenes, } \\
\text { el feedback alumno-profesor, u otras }\end{array}$ & & & & \\
\hline 3. Resultados & - & - & - & - \\
\hline $\begin{array}{l}\text { 3.1. Valores adquiridos en el proceso: se explican valores que se adquieren con las competencias } \\
\text { patrimoniales }\end{array}$ & & & & \\
\hline 3.2. Diversidad de competencias aprendidas: señalan las competencias adquiridas en el programa & & & & \\
\hline $\begin{array}{l}\text { 3.3. Diversidad de competencias desarrolladas: se desarrollan a lo largo del programa competencias } \\
\text { determinadas }\end{array}$ & & & & \\
\hline
\end{tabular}

Figura 15. Rúbrica de estándares específicos. Fuente: elaboración propia.

VII. Fase VII: Casos de estudio: análisis en profundidad de los programas que se han ido seleccionando en la criba de las seis fases anteriores, a través de la documentación que se presenta en la base de datos, puesta en contacto con los agentes implicados en los programas, entrevistándolos, observaciones de la puesta en práctica, cuestionarios, en definitiva, recaudando datos para la fase II. En esta fase se han estudiado cinco programas de Educación Patrimonial, que serán los mini-casos en la Fase II del estudio de caso: 
1. Proyecto DOCEO: enseñar, aprender en Pintia a través de la arqueología

2. El camino de Santiago en Educación Infantil

3. Programa Pintia de Innovación educativa

4. Todos los caminos conducen al libro

5. SOUVENIRS

Es el final de la primera etapa que se fusiona a la siguiente en la que se realiza un estudio de caso, como metodología de tradición cualitativa. En esta fase se produce el anidamiento entre la metodología cuantitativa y la cualitativa para producir la mixta. Hay que tener en cuenta que la siguiente fase el método de mayor envergadura, de tradición cualitativa, es el que va a tener la finalidad de esclarecer y comprender cómo se está llevando a cabo la evaluación de aprendizajes en la enseñanza del patrimonio en Secundaria y Bachillerato en la comunidad de Castilla y León.

4.3.3.2. FASE II. Evaluación de los aprendizajes: Estudio de caso

Se establece una distinción común entre lo que se escala analíticamente y lo que se juzga holísticamente (Stake y Munson, 2016). La metodología utilizada en esta tesis es de corte mixto anidado. La fase cuantitativa es la que se anida en la más importante, que es la cualitativa; la primera, se ha utilizado en la evaluación de los mejores programas de educación patrimonial en cuanto a calidad y en cuanto a que son los mejores en la evaluación de aprendizajes. En esta segunda parte, se realiza un estudio de caso sobre la evaluación de aprendizajes en secundaria y bachillerato en Castilla y León.

Se realiza un estudio de caso único. Es una metodología de investigación que a principios del siglo XX no ha cobrado un estatus legítimo en ciencias sociales quizá por la falta de protocolos y estructuración (Yin, 2002).

El paradigma bajo el que se articula el estudio de caso es de corte cualitativo, el cual enfoca los fenómenos en educación como realidades múltiples y heterogéneas, intentando comprender los sucesos dentro del aula y las experiencias del alumnado, del profesorado y de los demás agentes educativos implicados. Tras un estudio de las comparaciones realizadas por Yazan (2015), en el que describe las semejanzas y diferencias entre tres autores modelo del estudio de caso (ver Tabla 25):

Tabla 25 
Comparativa del estudio de caso entre Merrian, Stake y Yin realizada por Yazan.

Fuente: Yazan (2015)

\begin{tabular}{|c|c|c|c|}
\hline & Merriam & Stake & Yin \\
\hline $\begin{array}{l}\text { EPISTEMOLOGÍA Y } \\
\text { COMPROMISOS }\end{array}$ & Constructivismo & $\begin{array}{l}\text { Constructivismo y } \\
\text { existencialismo (no } \\
\text { determinismo) }\end{array}$ & Positivismo \\
\hline DEFINICIÓN & $\begin{array}{l}\text { El caso es "una cosa, una } \\
\text { sola entidad, una unidad } \\
\text { alrededor de la cual hay } \\
\text { límites" (p. 27) y puede ser } \\
\text { una persona, un programa, un } \\
\text { grupo, una política específica } \\
\text { y así sucesivamente. El } \\
\text { estudio de caso cualitativo es } \\
\text { "una descripción intensiva, } \\
\text { holística y el análisis de un } \\
\text { acotado fenómeno, como un } \\
\text { programa, una institución, } \\
\text { una persona, un proceso, o } \\
\text { una unidad social" (p. xiii). }\end{array}$ & $\begin{array}{l}\text { El caso es "un específico, } \\
\text { para un complejo } \\
\text { funcionamiento de una cosa", } \\
\text { más específicamente "Un } \\
\text { sistema integrado" el cual } \\
\text { "tiene un límite y piezas de } \\
\text { trabajo" e intencional (en } \\
\text { ciencias sociales y servicios } \\
\text { humanos) (p. 2). El estudio } \\
\text { de caso cualitativo es un } \\
\text { "Estudio de la particularidad } \\
\text { y la complejidad de un solo } \\
\text { caso, llegando a entender su } \\
\text { actividad dentro de } \\
\text { importantes circunstancias" } \\
\text { (p. xi) }\end{array}$ & $\begin{array}{l}\text { El caso es "un fenómeno } \\
\text { contemporáneo dentro de su } \\
\text { contexto real de vida, } \\
\text { especialmente cuando los } \\
\text { límites entre un fenómeno y el } \\
\text { contexto no son claros y el } \\
\text { investigador tiene poco control } \\
\text { sobre el fenómeno y contexto" } \\
\text { (p. 13). }\end{array}$ \\
\hline TIPOS DE E.C. & $\begin{array}{l}\text { Particularista (centrándose } \\
\text { en situación particular, } \\
\text { evento, programa, o } \\
\text { fenómeno); Descriptivo } \\
\text { (rindiendo un rico, gruesa } \\
\text { descripción de la } \\
\text { fenómeno en estudio); } \\
\text { Heurística (iluminando la } \\
\text { comprensión del lector de } \\
\text { fenómeno en estudio). }\end{array}$ & $\begin{array}{l}\text { Holístico (considerando la } \\
\text { interrelación entre el } \\
\text { fenómeno y su contexto); } \\
\text { Empírico el estudio sobre su } \\
\text { observación en el campo); } \\
\text { Interpretativo (descansando } \\
\text { sobre su intuición y ver } \\
\text { investigación básicamente } \\
\text { como investigador-sujeto } \\
\text { Interacción); Enfático } \\
\text { (reflejando lo vicario } \\
\text { experiencias de los sujetos en } \\
\text { una perspectiva émica). }\end{array}$ & $\begin{array}{l}\text { diseño único } \\
\text { diseño holístico, } \\
\text { diseño único integrado, } \\
\text { diseño múltiple holístico, y } \\
\text { diseño integrado múltiple }\end{array}$ \\
\hline $\begin{array}{l}\text { DISEÑO Y } \\
\text { COMPONENTES }\end{array}$ & $\begin{array}{l}\text { Realizar revisión de } \\
\text { literatura, construyendo un } \\
\text { marco teórico, identificando } \\
\text { un problema de } \\
\text { investigación, elaboración y } \\
\text { agudizar las preguntas de } \\
\text { investigación, y } \\
\text { seleccionando la muestra } \\
\text { (muestra deliberada). }\end{array}$ & $\begin{array}{l}\text { Estructura conceptual del } \\
\text { caso: función, issues, } \\
\text { declaraciones temáticas... }\end{array}$ & $\begin{array}{l}\text { Partes: preguntas; sus } \\
\text { proposiciones, Si alguna; su (s) } \\
\text { unidad (es) de análisis; la } \\
\text { vinculación lógica los datos a } \\
\text { las proposiciones; y los criterios } \\
\text { para interpretando los } \\
\text { hallazgos. }\end{array}$ \\
\hline RECOGIDA DE DATOS & $\begin{array}{l}\text { Entrevistas, observar, } \\
\text { analizar y documentos }\end{array}$ & $\begin{array}{l}\text { Observación, entrevista y } \\
\text { revisión de la recopilación de } \\
\text { herramientas. } \\
\text { Simultaneidad de recogida y } \\
\text { análisis de datos }\end{array}$ & $\begin{array}{l}\text { Documentación, archivo, } \\
\text { registros, entrevistas, } \\
\text { observaciones directas y } \\
\text { participantes, observación física } \\
\text { y artefactos para realizarla. } \\
\text { Examinar, clasificar, tabular y } \\
\text { otras pruebas, recombinando } \\
\text { datos cuantitativos como } \\
\text { evidencia cualitativa para las } \\
\text { proposiciones iniciales del } \\
\text { estudio }\end{array}$ \\
\hline ANÁLISIS DE DATOS & $\begin{array}{l}\text { Seis estrategias analíticas: } \\
\text { análisis etnográfico, análisis } \\
\text { narrativo, } \\
\text { análisis fenomenológico, } \\
\text { método comparativo } \\
\text { constante, } \\
\text { análisis de contenido, y } \\
\text { analítica inducción }\end{array}$ & $\begin{array}{l}\text { Dos formas estratégicas de } \\
\text { analizar datos: Agregación de } \\
\text { categorías e Interpretación } \\
\text { Directa. "Cada investigador } \\
\text { necesita, a través de la } \\
\text { experiencia y Reflexión, para } \\
\text { encontrar las formas. de } \\
\text { análisis que funcionan para él } \\
\text { o ella" (p. 77) }\end{array}$ & $\begin{array}{l}\text { Cinco técnicas dominantes para } \\
\text { el análisis de datos: Modelo } \\
\text { coincidente, explicación } \\
\text { construcción, series de análisis } \\
\text { temporales, } \\
\text { modelos de lógica de } \\
\text { programas, y síntesis del caso } \\
\text { cruzado. }\end{array}$ \\
\hline VALIDEZ Y FIABILIDAD & $\begin{array}{l}\text { Metodología cualitativa se } \\
\text { acerca de manera diferente a } \\
\text { validez y fiabilidad del } \\
\text { conocimiento producido en } \\
\text { investigación. Seis }\end{array}$ & $\begin{array}{l}\text { Triangular datos: } \\
\text { triangulación de fuente de } \\
\text { datos, triangulación } \\
\text { investigadora, triangulación } \\
\text { teórica y triangulación }\end{array}$ & $\begin{array}{l}\text { Cuatro tipos: } \\
\text { validez de constructo (a través } \\
\text { de la triangulación de múltiples } \\
\text { fuentes de evidencia, cadenas } \\
\text { de evidencia, y miembro }\end{array}$ \\
\hline
\end{tabular}




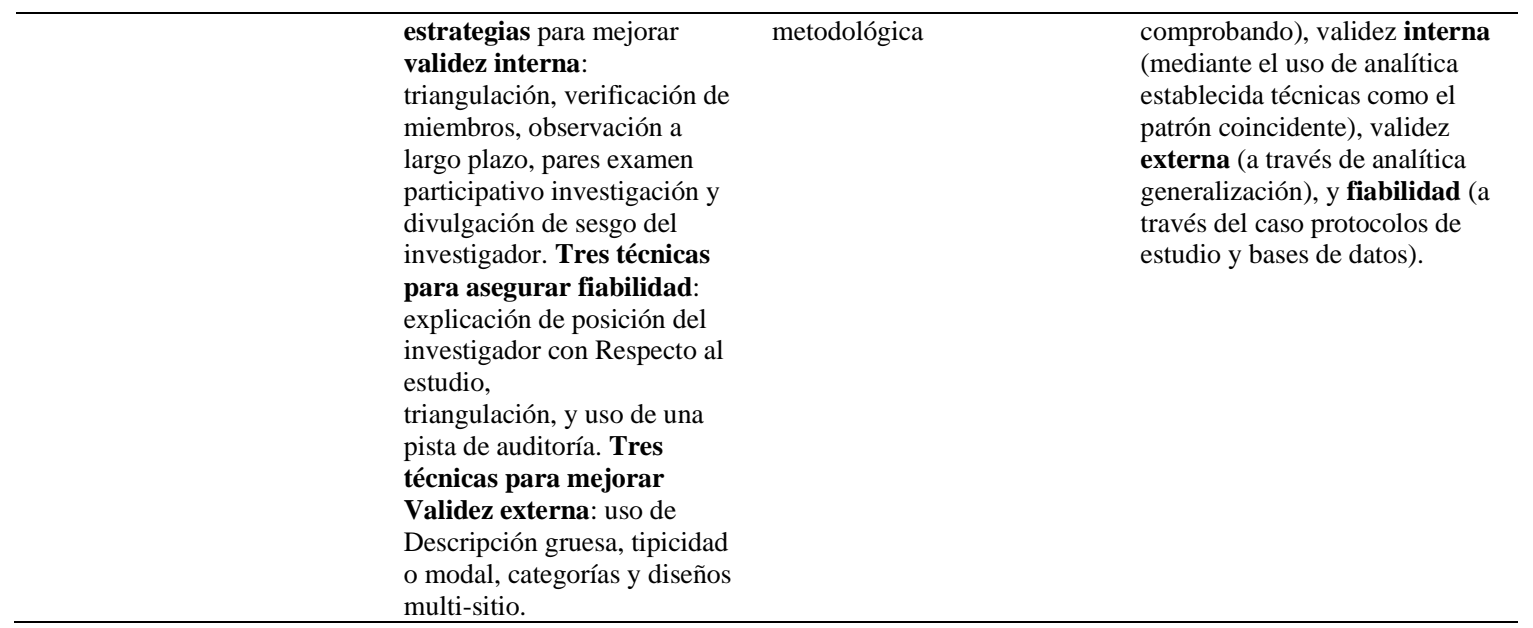

En esta fase de investigación la posición que se toma como investigadores y el Worldview es muy cercano a Merriam (1998), pues entendemos que el principal objetivo de un investigador cualitativo es el entender el conocimiento construido por las propias personas que intervienen en el estudio, principal aspecto que suscribe el paradigma constructivista. Se concibe el conocimiento como algo que se va construyendo en la sociedad y que surge de las prácticas educativas. Por lo tanto, se conceptualiza la realidad social como generada y construida por personas y que existen en gran medida dentro de la mente de las personas. "Los esfuerzos de investigación son orientados a la búsqueda de interpretaciones históricamente situadas y derivadas de la cultura del mundo de la vida social" (Crotty, 1998, p. 67). Sin embargo, se utiliza el esquema o estructura conceptual de caso de Stake (1995) y dado que la orientación de esta investigación es también más alineada al pragmatismo de Dewey, el actual análisis abarca la instrumentalidad de los conjuntos de estrategias, directrices y herramientas sugerido por Yin (2002).

Si se toma en cuenta la trayectoria propia como investigadora, se podrá comprobar que, en el primer artículo, como investigadora educativa emergente, epistemológicamente me posiciono muy estrechamente suscrita al paradigma constructivista. El conocimiento se construye socialmente y surge de las prácticas sociales de los pueblos; por lo tanto, conceptualizo la realidad social como generada y construida por personas y que existe en gran medida dentro de las mentes de las personas, en palabras de Merrian "la investigación es, después de todo, producir conocimiento sobre el mundo, en nuestro caso, el mundo de la práctica educativa" (Merriam, 1998, pág. 3). Sin embargo, dado que mi orientación también está más alineada con el pragmatismo de Dewey, el análisis 
actual abarca la instrumentalidad de los conjuntos de estrategias, directrices y herramientas sugeridas por Yin (2002).

\section{Componentes del caso (figura)}

Como se ha referido, se utiliza en ambos casos la estructura conceptual de Stake, un esquema que ayuda a la organización y ordenamiento de las partes del caso.

Esta estructura consta de las partes (ver figura 16):

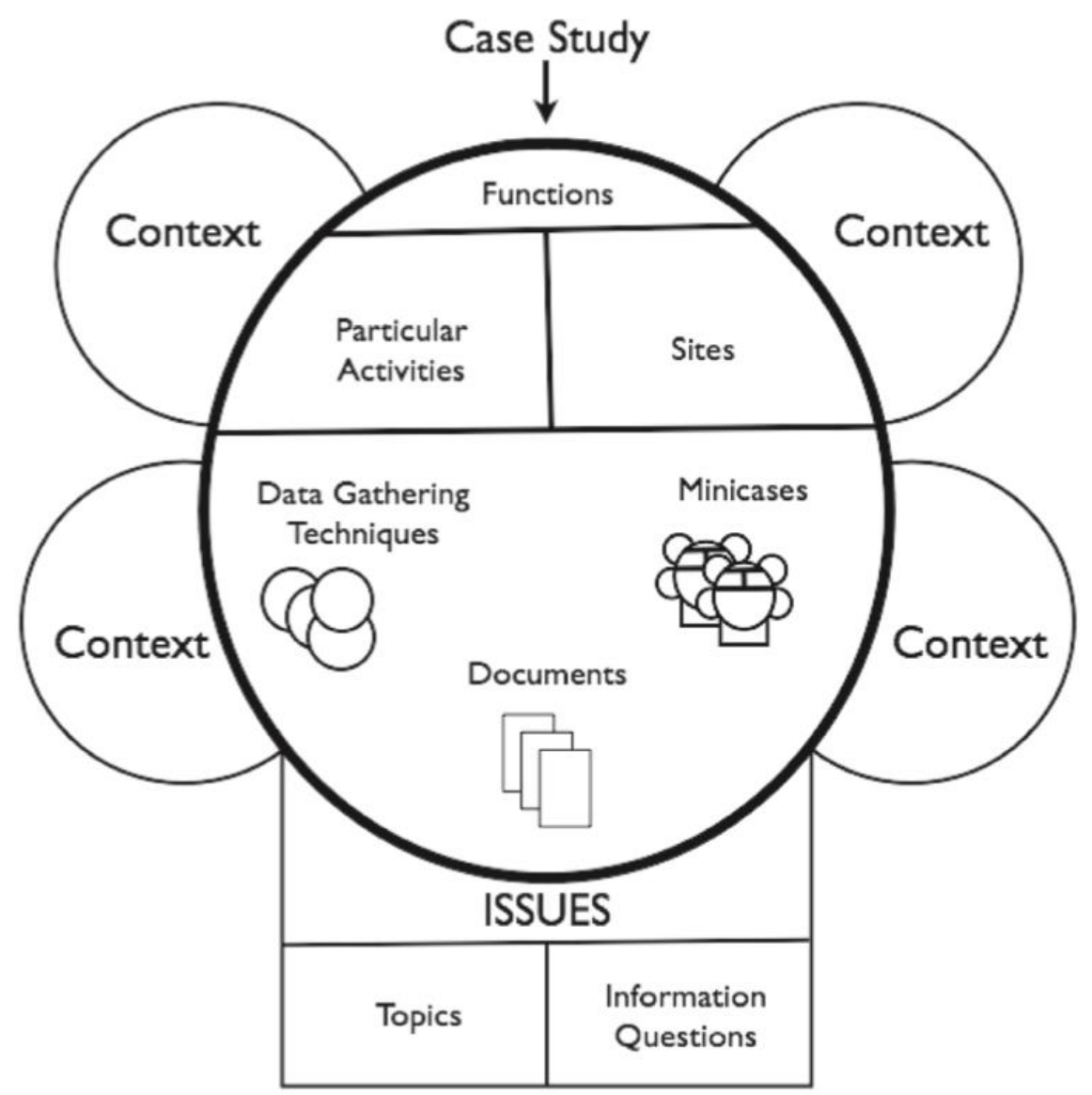

Figura 16. Estructura conceptual del caso. Fuente: Stake (1995)

A) Un círculo central grande con los datos:

1. Función del caso

2. Actividades particulares

3. Lugares

4. Documentos

5. Informantes

6. Técnicas de recogida de datos 
7. Mini-casos

B) Un círculo pequeño con la Historia

C) Un círculo pequeño con el contexto

D) Bajo el círculo grande varios cuadrados:

- Issues

- Declaraciones temáticas o tópicos

- Preguntas informativas

El caso que se propone es, por un lado, "La evaluación por competencias en Educación Plástica en Primaria" y por otro, "La evaluación de aprendizajes en Educación Patrimonial en Secundaria y Bachillerato en Castilla y León”. Ambos casos tienen su propia estructura, sus propias partes, pero que confluyen para un mismo fin:

comprender cómo es la evaluación de aprendizajes en Educación Patrimonial en Castilla y León. 
CASO: La evaluación por competencias en Eđucación Plástica en Primaria

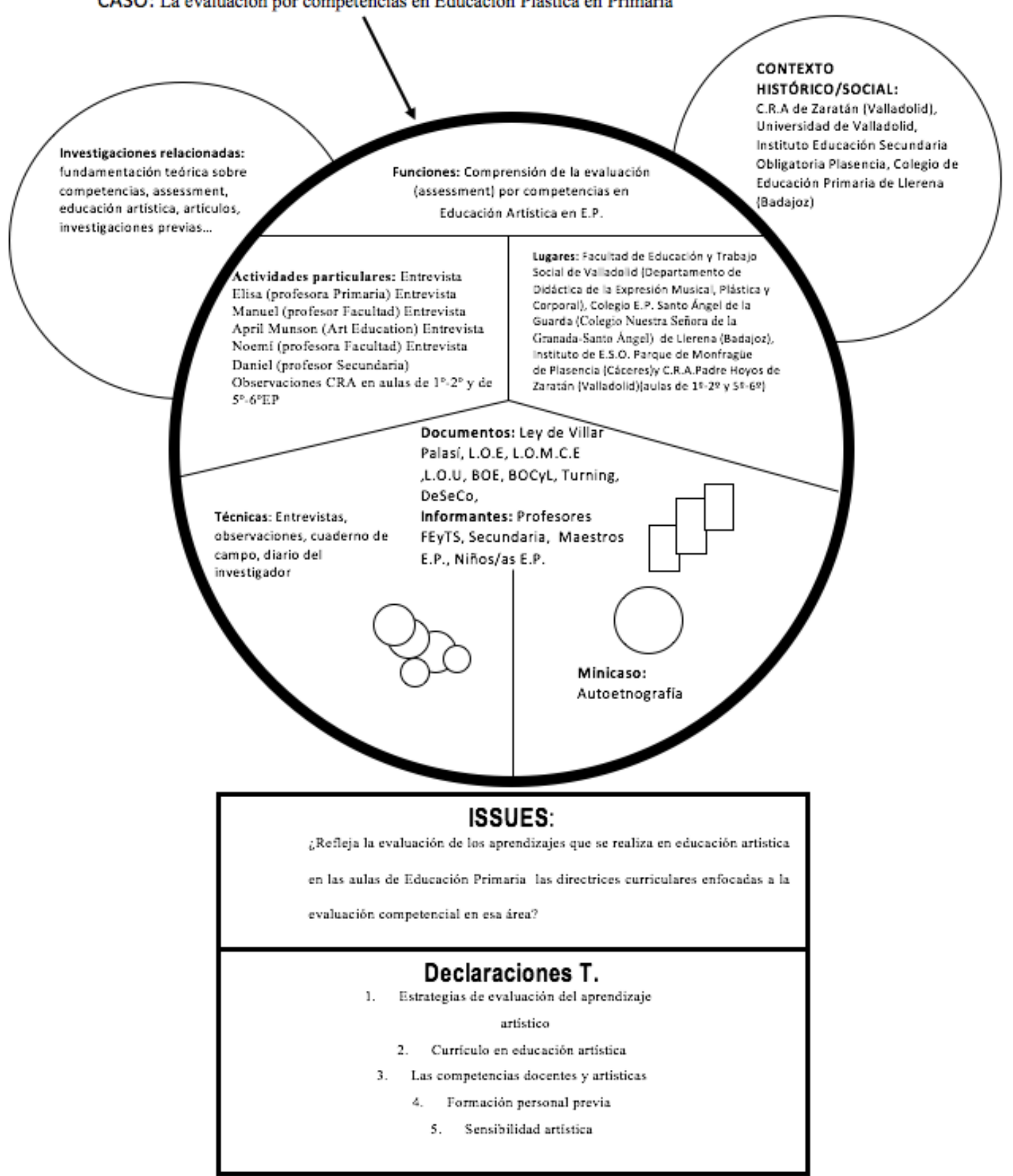

Figura 17. Estructura conceptual del Caso 1 de la investigación. Fuente: Sánchez, 2015 


\section{CASO: La Evaluación de Aprendizajes en Educación Patrimonial en Secundaria y Bachillerato de Castilla y}

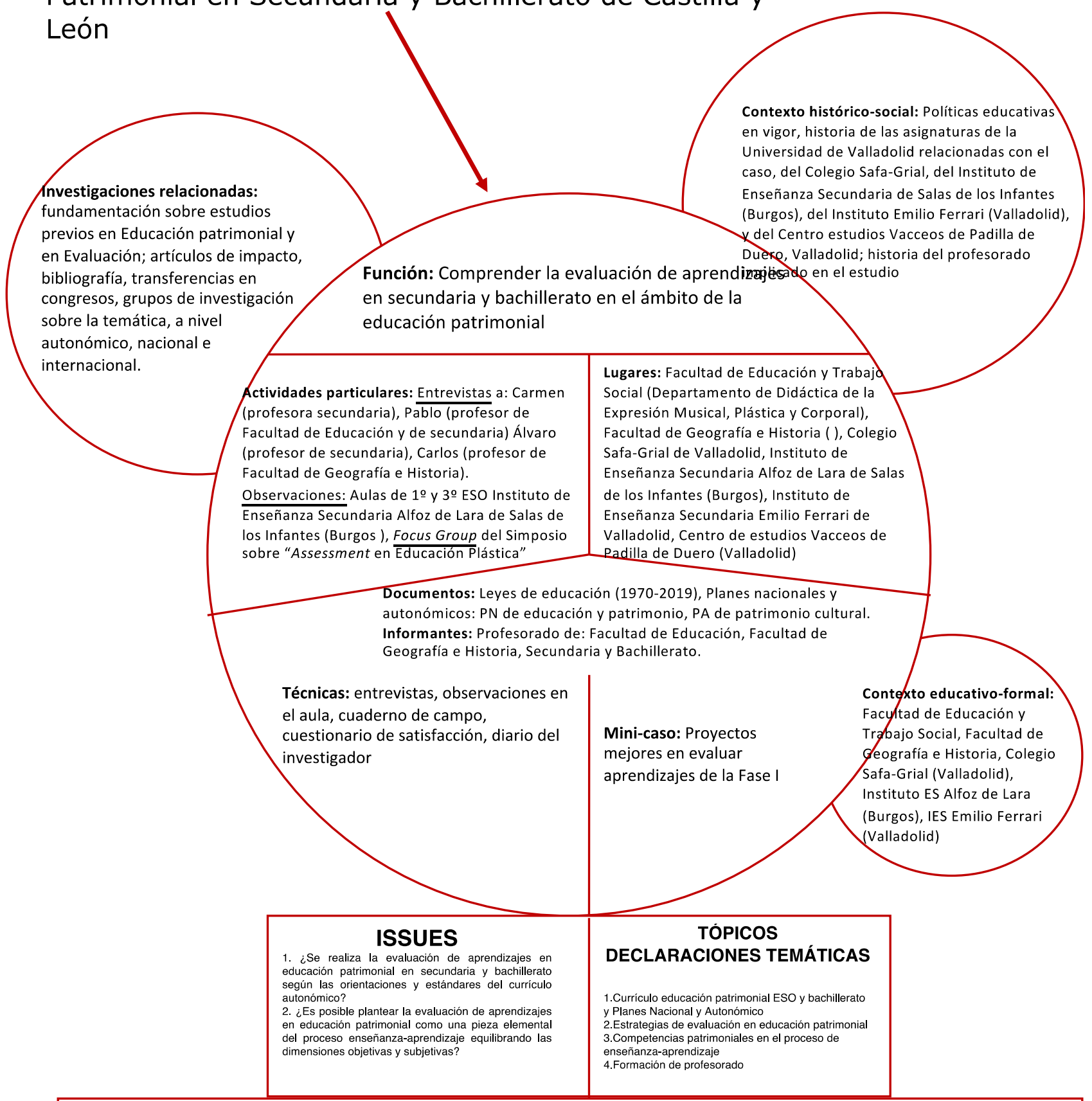

\section{PREGUNTAS DE INVESTIGACION}

1. ¿Cuáles son las recomendaciones de los expertos sobre la evaluación en educación patrimonial? ¿Existen pautas o patrones para evaluar EP? ¿Existe alguna guía para ello? ¿hay estándares 2. ¿Se evalúa en educación patrimonial? ¿Cómo se evalúa? ¿Se siguen algunos criterios de evaluación? ¿Qué tipo de evaluación es? ¿de procesos? ¿de resultados? ¿formativa, sumativa, global? ¿qué instrumentos y procedimientos se utilizan?

3.De las competencias que se deberían desarrollar en educación patrimonial, ¿en qué incide el profesorado de ESO y bachillerato? ¿se evalúan las tres dimensiones de las competencias o solo la procedimental? ¿cómo gestiona el docente el desarrollo competencial de sus alumnos? ¿y el suyo propio? ¿y el de sus compañeros? Cuando evalúan, ¿tienen en mente alguna finalidad concreta o evalúan con miras al progreso de cada alumno? ¿prefieren que sea una disciplina que ellos descubran o se enseña en qué consiste la EP? La evaluación que se realiza en el aula ¿forma parte de un proceso? ¿de cuál? Si no así, ¿qué importancia tiene la evaluación para el profesorado? ¿y para el alumnado? ¿Se les explica bien en qué consiste evaluar? ¿Y lo que se quiere evaluar?

4. ¿Como ha sido formado en su nivel de ESO y bachillerato el profesorado de hoy? ¿tiene formación específica en EP? ¿Qué proyectos conoce? ¿Ha creado alguno? ¿Tiene formación libre o reglada sobre la EP? ¿y en cuestión de evaluar los aprendizajes? ¿está formado? ¿cuál es su experiencia? ¿qué beneficios y qué limitaciones encuentra en el proceso de evaluar los aprendizajes

Figura18. Estructura conceptual del Caso 2 de la investigación. Fuente: Sánchez, 2019 
Cada parte de esta estructura debe describirse para ír entendiendo cómo se ha construido el caso, para comprender la visión caleidoscópica de los informantes, el contexto, los documentos, los referentes de investigación, etc. En cada una de las descripciones se debe detallar todos los componentes hasta que no quepa duda para el receptor del mensaje. Y en la medida que se van recopilando datos, se va desarrollando el caso, pues, apoyándonos en Yin, "la forma en que los investigadores tratan estos aspectos del control de calidad" (Yin, 2002, p. 19) es sumamente crucial en cada paso de la investigación del estudio de caso.

\section{Presentación de los informantes}

Uno de los aspectos importantes a tener en cuenta en los estudios de casos es la presentación de los informantes (Jorrín-Abellán, 2006) para que se contextualice su pertenencia a dicho estudio y, además, para que el lector realice una idea más clara de las particularidades del caso que se estudia, la importancia de la visión de las personas en torno a él y las relaciones que dichos informantes mantienen con el objeto de estudio, transferidas en las evidencias que producen. En los estudios de caso realizados se entrevista a varios informantes, que se presentan a continuación. En el primer y tercer artículos de investigación, los informantes fueron:

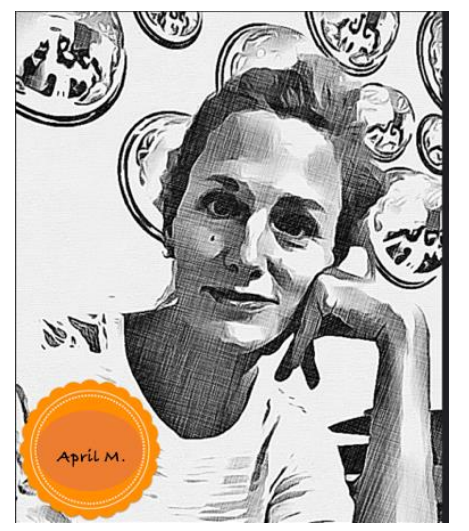

APRIL MUNSON. "Soy mujer, profesora, amiga, investigadora, de Kentucky, muchas cosas... Soy también un aprendiz. El aprendizaje es un valor cargado, un proceso profundamente contextualizado. Cada nuevo pensamiento o idea, y la experiencia tienen que ser un puente que existe en la persona que aprende. Un maestro en formación aprenderá acerca de los diversos enfoques de la gestión de la clase, pero sin entender las necesidades humanas, contratados por un plan de gestión del aula; cualquier nuevo plan es incoherente y no asimilado. Los estudiantes (profesores en formación, y en última instancia a sus estudiantes) aprenden mejor cuando se les ofrece el espacio para entender e imaginar lo que las teorías, las ideas y filosofías parecen en la práctica. Siento que los estudiantes son capaces de explorar y examinar críticamente la nueva información y experiencias cuando se les da el apoyo y la autonomía para hacerlo. A medida que las experiencias de aprendizaje están ancladas 
en los valores personales y contextos, el alumno puede empezar a tomar posesión de sus entendimientos.

Mi investigación se centra en la evaluación de la calidad en el aula de arte, y que se extiende a mi propia enseñanza. Creo que puedo cambiar como profesora con cada curso, cada clase. Invito a los estudiantes para ofrecer sugerencias tanto sobre el contenido del curso y mi estilo de enseñanza, y de trabajar para responder a esas sugerencias a través de cambios en mi plan de estudios y reflexionar sobre mis prácticas de enseñanza, hacer cambios cuando sea necesario. Mi enseñanza ha mejorado a través de las sugerencias de los estudiantes, y he visto el aprendizaje del estudiante cómo ha profundizado, al ver a sus preocupaciones e ideas implementadas en el aula. Me he comprometido a ser un miembro activo en las comunidades profesionales para que mis entendimientos e ideas de la enseñanza, el aprendizaje, la investigación y el campo de la educación artística sigan evolucionando.”

Profesora de Art Education, de Educación artística, en el College of Arts. El programa en el que está trabajando, es de la Facultad de Educación, a pesar de que ella es de otra Facultad y de otro Departamento. Actualmente imparte clases tanto en cursos de Doctorado como en cursos de Grado: coordinar el Prácticum, (más que en el último año) y docencia en Teoría y de Perspectiva Crítica.

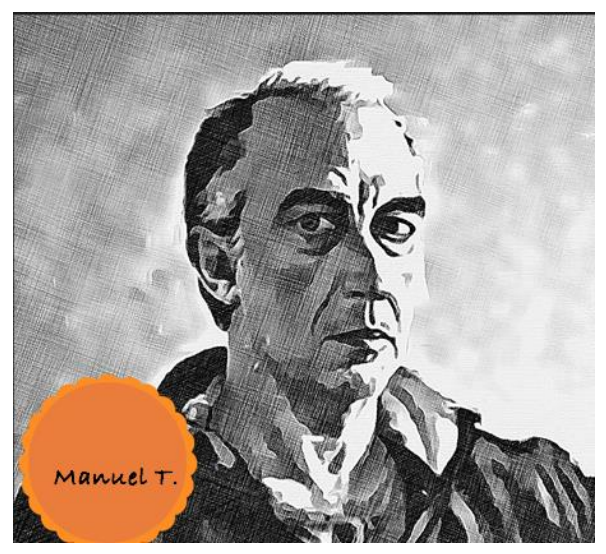

\section{MANUEL TAMARIZ}

Licenciado en Bellas Artes por la Universidad de Sevilla.

Pintor, ilustrador y escultor.

Dando clases particulares y en academias de enseñanzas no regladas desde el año 1992. En 1997 comienza colaboración con el Dto. de Didáctica de la Expresión Musical , Plástica y Corporal, En la Facultad de Educación y Trabajo Social, de La Universidad de Valladolid que continúa intermitente mente hasta la actualidad.

Ha colaborado como ilustrador en publicaciones de la Junta de Castilla y León, en Editoriales como Quirón, La esfera de Los Libros, El Mundo, Susaeta y otras. Como Pintor tiene una larga lista de exposiciones con menciones en importantes certámenes como La Bienal Unión Fenosa o El certamen de Arte que organiza el Colegio de Ingenieros de Caminos, Canales y Puertos. 
También posee conocimientos de modelado, talla en madera y vaciado, con los que ha creado algunas obras en volumen a demanda.

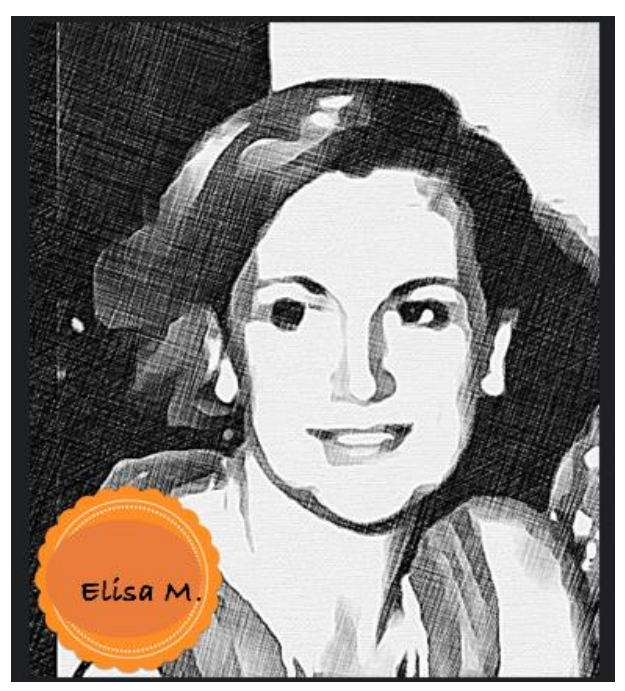

ELISA MARTÍN. Profesora de Educación Primaria y $1^{\circ}$ y $2^{\circ}$ de Secundaria en el Colegio Nuestra Señora de la Granada-Santo Ángel de Llerena, Badajoz, en concreto de asignaturas como Matemáticas, Conocimiento del Medio y Física y Química. Fue mi profesora en los años 1981-1984 en los que yo cursaba la $2^{\text {a }}$ Etapa de Educación Primaria, en esas mismas asignaturas y en Plástica y Pretecnología. En la actualidad se siente una maestra cansada y superada por las exigencias de las evaluaciones competenciales que piden los currícula actuales, pero encuentra en el Arte una escapada a esa ansiedad producida por los métodos evaluativos que no entiende ni comparte. Actualmente está retirada y se dedica a las artes plásticas en profundidad, concretamente a la pintura.

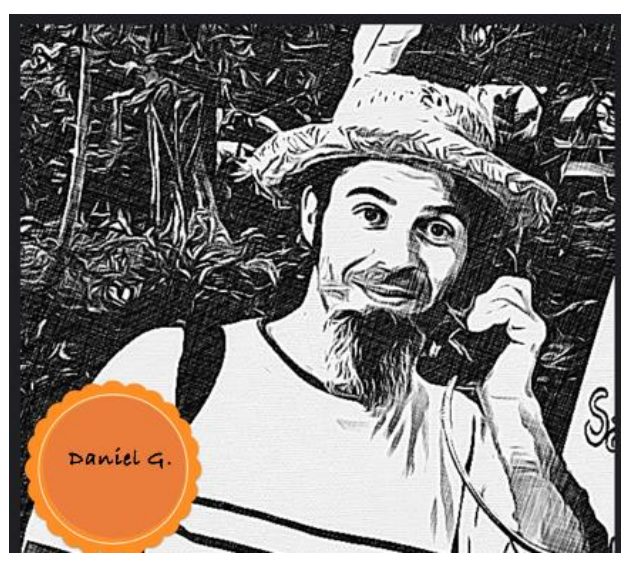

DANIEL GIL SEGURA (Barcelona, 1975). Su más temprana vocación fue la de payaso. Pero pronto, a causa de una sobrealimentada autoestima (gracias, mamá), se dedicó incansablemente a garabatearlo todo y pronto decora con ahínco los márgenes de los libros de texto y las carpetas de los compañeros de EGB y BUP. Después de estudiar Bellas Artes en Salamanca (de realizar las preceptivas exposiciones y conseguir sus prometedores primeros $-\mathrm{y}$ últimos- premios) se aparta del mundillo artístico y retoma su primera inclinación para dedicarse a la docencia (el trabajo estable más parecido al de payaso, que garantiza un escenario y un público con buena disposición a la risa). Desde su labor docente o fuera de ella, y aplicando estrictamente la máxima de "quien mucho abarca poco aprieta", ha desarrollado funciones de escenógrafo y de atrezo para diferentes obras teatrales, de titiritero, de ilustrador para diversas publicaciones, de diseñador gráfico, de músico y 
cantautor, de director de cortometrajes amateur, de actor de teatro y de improvisación, de gestor cultural y de ocasional artista plástico. También es un activista social y medioambiental y colabora con su trabajo y su tiempo con múltiples organizaciones y asociaciones.

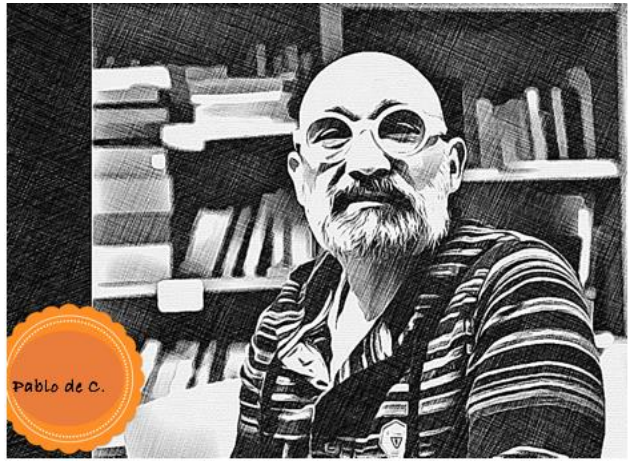

\section{PABLO DE CASTRO MARTÍN. Doctor en}

Didáctica de la educación artística

Licenciado en Filosofía y Letras por la Universidad de Valladolid (UVa), especialidad de Geografía e Historia, subespecialidad de $\mathrm{H}^{\mathrm{a}}$ del Arte. Estudios de doctorado en UVa y Università degli Studi $\mathrm{Ca}^{\prime}$ Foscari di Venezzia (Italia).

Premio extraordinario de doctorado 2016. Premio Extraordinario de Licenciatura en 1998 por su investigación "Arte monumental funerario de época barroca en Castilla y León”. Fundación Hispania Nostra para la conservación del patrimonio, donde colaboró en la elaboración del libro "El Patrimonio Cultural en el Consejo de Europa. Textos, conceptos y concordancias" (1999).

Desde 1999 ha ejercido la docencia de $\mathrm{H}^{\mathrm{a}}$ del Arte, $\mathrm{H}^{\mathrm{a}}$ de España e $\mathrm{H}^{\mathrm{a}}$ Contemporánea en Colegio Marista Centro Cultural Vallisoletano, Colegio Amor de Dios y Colegio Safa-Grial (actualidad).

Ha diseñado numerosos proyectos de innovación educativa, premiados en convocatorias como Los Nueve Secretos (Fundación del Patrimonio Histórico de Castilla y León), Concurso Viatores (Fundación Siglo), Premios Vaccea (UVa), Festival Internacional de Cine de Valencia o Patrimonio en la piel [Observatorio de Educación Patrimonial en España (OEPE) + Instituto del Patrimonio Cultural de España (IPCE) + Fundación Alberto Jiménez-Arellano], entre otras, o se constatan en colaboraciones con instituciones como Galería Espacio Líquido (Gijón), Instituto Cervantes de Nueva Delhi, Museo Patio Herreriano de Arte Contemporáneo Español, Museo Nacional de Escultura o Centro de Estudios Vacceos Federico Wattenberg (UVa).

Cofundador de la Asociación Bocallave. Iniciativas Culturales, con la que ha promovido diferentes propuestas artísticas en pos de la descentralización del sistema-arte.

Cofundador del colectivo de profesores El Punto Rojo, que investiga y propone nuevas fórmulas para la enseñanza de las artes en las enseñanzas regladas. Artista plástico y visual fijo-discontinuo. Sus obras han podido verse en diferentes exposiciones individuales y colectivas. 


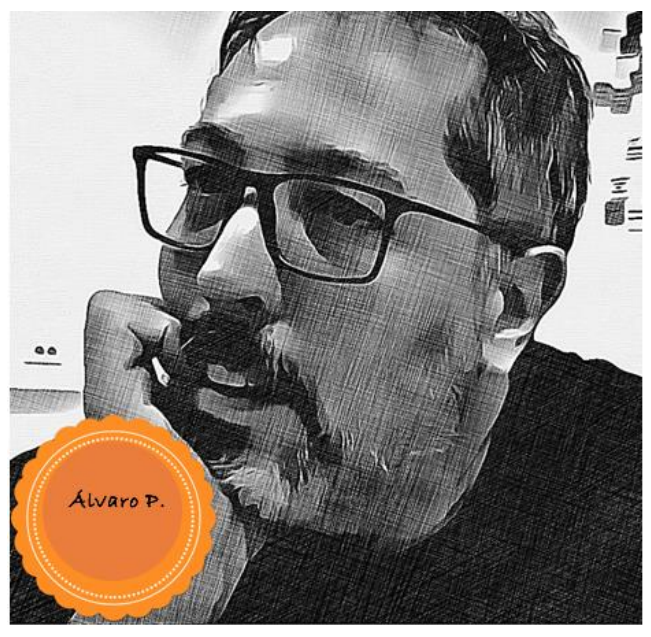

ÁLVARO PÉREZ MULAS. Álvaro Pérez

Mulas (1967) trabaja en varios ámbitos, principalmente fotográficos y escultóricos, pero buscando la interdisciplinariedad y la experimentación, centrándose en la comunicación y la relación entre medios.

Nacido en Zamora, España, Álvaro Pérez Mulas se formó en la Facultad de Bellas Artes de Salamanca, además de aprender de su padre escultor, Hipólito Pérez Calvo. Sus intereses pronto aumentaron desde la escultura de su infancia hacia las otras formas de creación que fue descubriendo en la facultad, especialmente la fotografía y el mundo audiovisual. Y este cambio se cristalizó en Amsterdam, donde se empapó de la realidad del arte contemporáneo.

Ha mostrado su trabajo artístico en galerías, museos y espacios culturales en el entorno de su ciudad natal y donde he residido la mayor parte de su vida, Salamanca y Valladolid, así como en el resto de Castilla y León y Madrid y en muchas ciudades españolas. Y también en diferentes espacios en París, Gante, Nueva Delhi, Nueva York, Los Ángeles o Miami.

En paralelo ha desarrollado una labor de innovación en educación artística con un grupo de compañeros, con los que forma el Colectivo El Punto Rojo. Su planteamiento de la educación artística hace que no se pueda diferenciar de la labor creativa.

La obra de Pérez Mulas se centra en las nociones de realidad y representación, la percepción y las alteraciones a las que está expuesta, la interrelación de medios o la dualidad de la presencia y la huella de la falta.

"Me he educado con un padre artista. En casa y en clase. Así que para mi el arte se convirtió en el medio natural de expresión. Aunque frente a la visión tradicional en la que el artista elige un campo de trabajo, la escultura en el caso de mi padre, mi planteamiento es diametralmente opuesto. Considero que el medio se debe adaptar a la 
idea que se quiera transmitir. Así me he encontrado trabajando con fotografía, escultura, video arte, instalación, performance, pintura o cómic, lo que necesitase en cada caso.

La materialización de mis obras no deja de ser una forma de dar salida a un diálogo interior, a través de las cuales intento responderme a mí mismo acerca del devenir y las consecuencias que el transcurso del tiempo causa en el hombre y su entorno, o la transcendencia y el poso que dejamos en nuestra ausencia.

Y además también ejerzo como docente, lo que ha sido realmente beneficioso para mi trabajo ya que estas dos facetas son las dos caras de una única moneda. Mi obra plástica se ve mediatizada por mis planteamientos educativos y estos completamente inundados por los procesos creativos artísticos. Por ello cuando hablo de mi trabajo no diferencio dos campos de acción. Seguramente ahí esté el origen de mi interés por el sistema perceptivo y su interpretación sesgada basada en intereses creados, tanto como para cuestionarlo como para aprovecharlo utilizándolo como punto de partida; o la relación entre los medios, principalmente los visuales y los literarios."

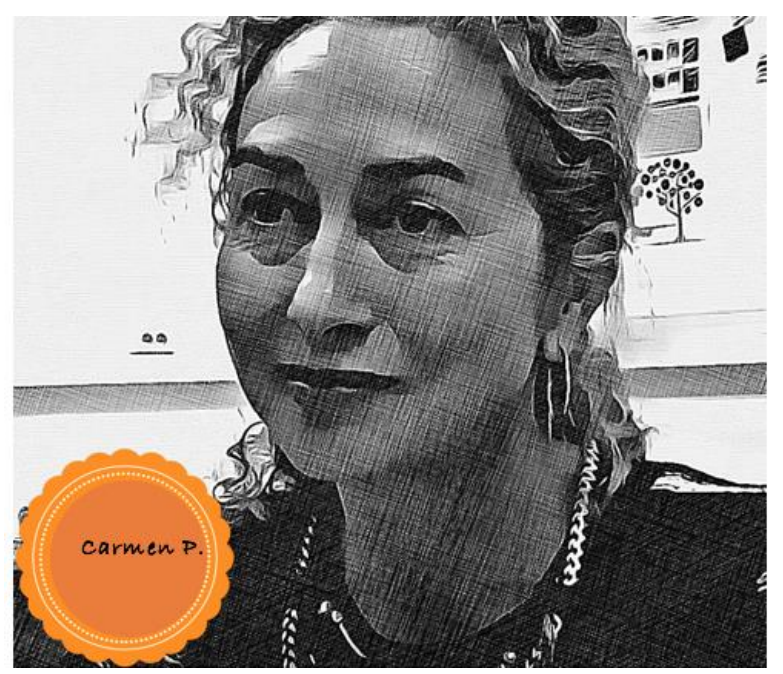

CARMEN PALENZUELA LÓPEZ. Carmen María Palenzuela López nace y vive en Valladolid. Licenciada en Bellas Artes por la Universidad de Salamanca. Profesora de Educación Secundaria, Bachillerato y Escuela de Artes. Ha impartido cursos y talleres de pintura, dibujo y creatividad en diferentes centros públicos y privados. Colaboraciones en escenografía y coreografía para teatro y danza, diseño e ilustración. Ha participado en diversos encuentros artísticos en el medio rural en Castilla y León, destacando la colaboración en la creación y desarrollo del proyecto de arte Encuentros en Urex de Medinacelli, Soria.

Comisaria de la exposición de graffiti All day, everyday en el Museo de Arte Contemporáneo Español Patio Herreriano de Valladolid. Autora de artículos y conferencias en torno al arte público independiente. Autora del libro Espacios para la 
Libertad. Graffiti en el entorno ferroviario de Valladolid. Actualmente en la Presidencia de la Asociación de Artistas Visuales de Castilla y León AVACyL. Desde el año 2005 realiza varias exposiciones individuales y colectivas.

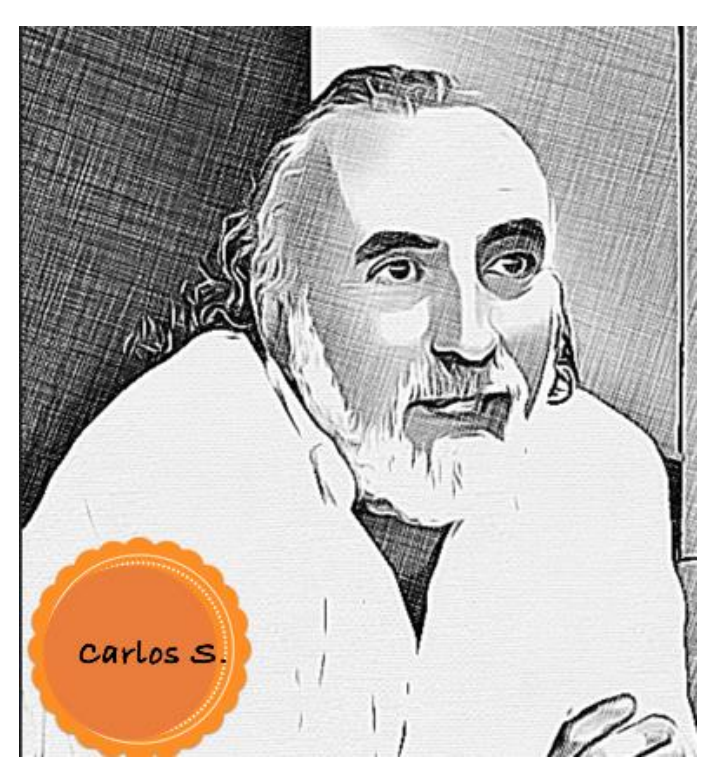

\section{CARLOS SANZ MÍNGUEZ}

Licenciado en Filosofía y Letras (División: Geografía e Historia, sección Historia). Doctor en Filosofía y Letras (Especialidad de Arqueología). Sus investigaciones se han centrado en el único cementerio vacceo conocido y publicado, el de Las Ruedas de Pintia, donde la documentación de decenas de miles de objetos y la obtención de más de trescientos conjuntos cerrados le han permitido aplicar los presupuestos de la

Arqueología de la Muerte, ensayando por vez primera para el mundo vacceo una reconstrucción social a través del registro funerario. Gracias a la estratigrafía horizontal definida en este cementerio ha podido establecer igualmente la secuencia del armamento vacceo (en especial para los puñales de tipo Monte Bernorio y de filos curvos), dar carta de naturaleza vaccea a las llamadas "cerámicas torneadas negras bruñidas" y caracterizar diversos elementos de idiosincrasia vaccea, en especial las denominadas "producciones singulares" de naturaleza excisa (cajitas, sonajas, pies, barcas, etc), o la orfebrería, con réplicas de barro simbólicas en el ámbito funerario. Trabajos destacados también son los referidos al vino y al banquete en el registro cotidiano del hábitat y simbólico de la muerte, documentando el vino más viejo de la Ribera del Duero en copas del siglo IV a.C., pero sobre todo su contexto social funerario y habitacional ("la estancia del banquete"). No han faltado los estudios dirigidos al género y a la infancia que, poniendo el foco en tumbas destacadas de mujeres e individuos infantiles (tumbas 127a, 127b, 128 y 153 entre otras), le han permitido comprobar las distinciones en relación al sexo y la edad. Ha progresado también en el conocimiento del mundo cotidiano mediante la excavación y publicación de los niveles sertorianos de las viviendas localizadas en la ciudad de Las Quintanas, advirtiendo en estos contextos habitacionales cómo el mundo mágico encuentra aquí 
también su representación, mediante la práctica de complejos sacrificios animales o la amortización bajo los suelos de genuinas reliquias. También ha puesto en evidencia, por vez primera en una ciudad del territorio vacceo, los sistemas defensivos de estos oppida, al excavar la muralla y los fosos de la de Pintia, que participan de modelos de poliorcética mediterránea inspirados en Filón de Bizancio. A los aspectos de la introducción del torno alfarero en las tierras vacceas y a los sistemas de producción cerámica ha dedicado también varios trabajos y la documentación del horno de Carralaceña, el más grande y mejor conservado en su género de toda Europa. Numerosas publicaciones y proyectos de investigación avalan su trayectoria y debe destacarse la restauración patrimonial llevada a cabo en el paisaje funerario de la necrópolis de Las Ruedas de Pintia (declarada BIC en 1993) para facilitar su conservación y su comprensión a través de las visitas guiadas programadas desde el CEVFW durante todo el año a demanda. Por esta labor ha merecido diversos reconocimientos a nivel individual o del Centro que dirige; así: primer premio (ex equo) del III Premio Intenacional de Ensayo "Nuestra Tierra, nuestro trabajo" otorgado por la Asociación Aldeamayor Emprende, Ayuntamiento de Aldeamayor de San Martín y Junta de Castilla y León; Premio “Renacimiento de la Ribera del Duero”, en la V edición, otorgado por la Asociación Cultural La Olmeda, de Valcabado de Roa (Burgos), por su labor de difusión científica, junio de 2008; Placa de Honor otorgada por los Amigos del Teatro de Valladolid por su labor de difusión científica, diciembre de 2008; Racimo de Honor otorgado por el Ayuntamiento de Serrada y la Fundación Serrada Blanco del Arte 2008, por su labor de difusión científica, mayo de 2009; Premio de la Asociación Socio-Cultural "La Revilla”, de Padilla de Duero por el trabajo y la dedicación desarrollada durante treinta años en la Zona Arqueológica de Pintia, julio de 2009; y "Premio Diálogo" 2011 del Ateneo Cultural “Jesús Pereda” como reconocimiento a la trayectoria individual en el mundo de la cultura que ha favorecido el avance social y cultural en la Comunidad de Castilla y León, mayo de 2010. 


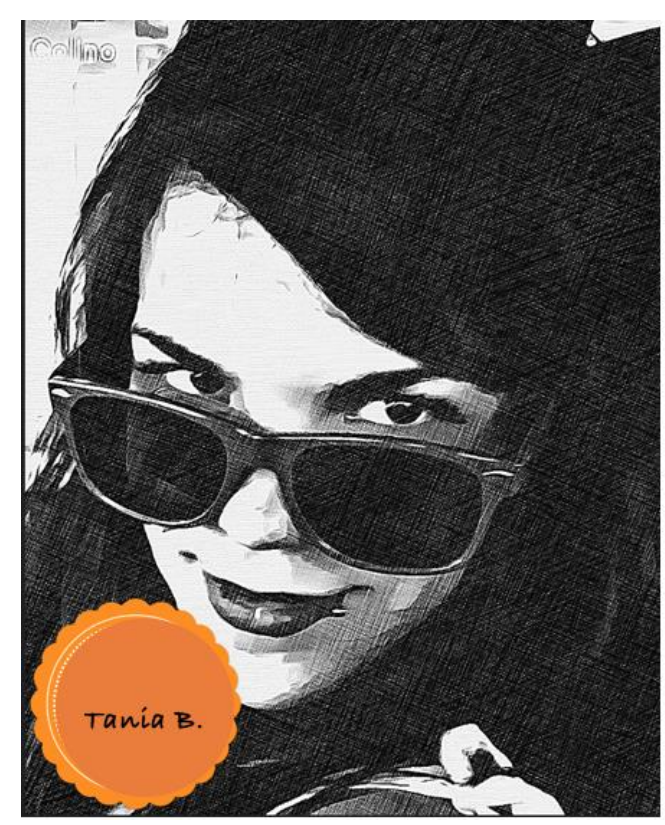

TANIA BALLESTEROS COLINO.

Docente castellanoleonesa especializada en educación del patrimonio y las nuevas tecnologías, cuya trayectoria investigadora y profesional se centra en la didáctica del patrimonio y el emprendimiento. Terminó sus estudios de grado con la investigación La educación desde las TIC: aportes de la Educación Patrimonial, dirigida por la Dra. Olaia Fontal, obteniendo la máxima calificación de acuerdo con el RD.1125/2003. En la actualidad, dirige la sección de programas pedagógicos de una iniciativa empresarial centrada en el ocio saludable y cultural en entornos rurales; y evalúa y coordina el programa educativo de patrimonio arqueológico DOCEO del Centro de Estudios Vacceos Federico Wattenberg de la Universidad de Valladolid (CEFW). También, ha participado en proyectos de emprendimiento como TIMMIS Emprendedurismo (en las ediciones 2017/2018 y 2018/2019), de carácter multidisciplinar caracterizado por la innovación en el fomento del emprendimiento dentro del área transfronteriza hispano-lusa, cofinanciado por el Fondo Europeo de Desarrollo Regional (FEDER) a través del programa Interreg (POCTEP). Además, ha colaborado en numerosas iniciativas y proyectos culturales y de investigación en el ámbito educativo, patrimonial y artístico como es el caso de "Distrito 11", desarrollado en el Laboratorio de las Artes de Valladolid LaVa. Esta iniciativa promovida por el Laboratorio de experimentación y creación artística bit:LAV culminó en el desarrollo de la plataforma digital bit.ly/d11va, germen de la exposición colectiva "Procesos, nexos, memoria" que aborda una amplia gama de matices patrimoniales presentes en la arquitectura, fotografía, creación, diseño, nuevas tecnologías, música y un largo etcétera; y con la impartición de talleres para el Ayuntamiento de Valladolid. Asimismo, cuenta con experiencia en el sector turístico, destacando entre ellos los trabajos para la Villa Romana de Almenara-Puras de la Diputación de Valladolid. 


\subsection{ANÁLISIS DE DATOS}

Para el análisis de datos se ha utilizado, a nivel cualitativo el análisis de contenido de las entrevistas, observaciones de aula, documentos, investigaciones referentes y cuestionarios. En todos los casos, se utilizó el software Nudist*vivo, en dos versiones, la 10 y la 11. El uso del software ayudó a la organización en categorías y códigos para el posterior análisis de datos. Además, es un instrumento que devuelve estadística descriptiva de dichos datos, lo cual, es de utilidad para el análisis cualitativo, que se enriquece con el de nudos o categorías. Se podría decir que existen tres formas de afrontar el análisis de los datos, desde nuestra cosmovisión:

En primer lugar, el análisis a nivel macro: Stake (1995) destaca la presencia de un intérprete que vaya observando el desarrollo del caso, que es la propia investigadora, alguien que recoja con objetividad lo que está ocurriendo, y que a la vez examine su significado y reoriente la observación para precisar o sustanciar esos significados.

A mitad del estudio, en un nivel meso, la investigadora del caso puede modificar e incluso sustituir las preguntas iniciales. Esto se realiza de forma pragmática, en función de las orientaciones que se les dan a las preguntas, o si se relacionan o no con las declaraciones temáticas. El fin principal es comprender el caso en su totalidad.

$>$ Y ya, a nivel micro, si las primeras preguntas no funcionan, si aparecen temas nuevos, se cambia el diseño, es lo que Parlett y Hamilton (1976) llamaron enfoque progresivo o el esquema de Jorrín -Abellán y Rubia-Avi para organizar esa reducción anticipada de los datos:

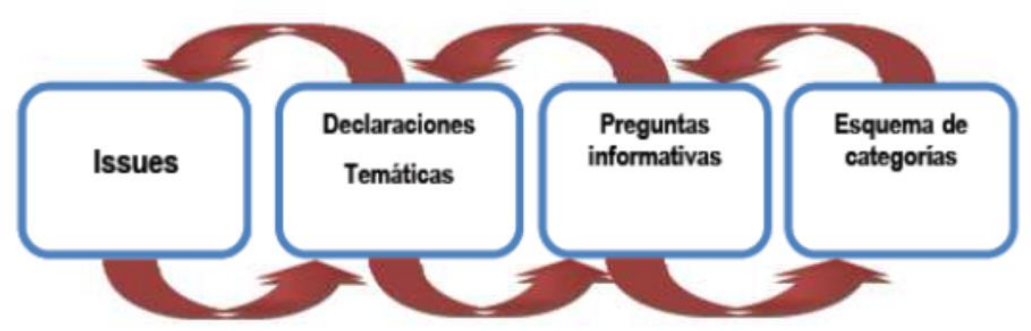


Figura 19. Ejemplo de reducción anticipada tomada de Jorrín I. y Rubia B. en Procesamiento e interpretación de los datos en la investigación. Material docente del Máster de Investigación aplicada a la educación (2012).

Esta comprensión se realiza a modo de catalejo. La realidad del caso se va enfocando según se va limitando el mismo. Así se va comprendiendo, poniendo el foco en aquello que el caso vaya requiriendo. Los análisis se realizan a través de las categorías émic o étic, según el caso. A continuación, se describen los resultados a través de los artículos de investigación. 


\section{NORMATIVA DE TESIS POR COMPENDIO}

Los artículos que se anexan a continuación siguen la norma vigente:

RESOLUCIÓN de 8 de junio de 2016, del Rectorado de la Universidad de Valladolid, por la que se ordena la publicación del Acuerdo del Consejo de Gobierno de 3 de junio de 2016, por el que se aprueba la normativa para la presentación y defensa de la tesis doctoral en la Universidad de Valladolid.

Artículo 4. Modalidad de tesis doctoral por compendio de publicaciones.

1. En la modalidad por compendio de publicaciones el candidato deberá aportar un mínimo de tres artículos científicos que hayan sido aceptados o publicados en un medio de impacto, según los criterios de la ANECA para el área de conocimiento en la que se presenta la tesis, dentro del período en el que el alumno haya estado matriculado en el Programa de Doctorado, siempre que dichas publicaciones merezcan la consideración de trabajos originales elaborados por el candidato.

ACUERDO PARA LA INTERPRETACIÓN DE LOS ARTÍCULOS 3.2 Y 4.1 DE LA NORMATIVA PARA LA ADMISIÓN Y DEFENSA DE LA TESIS DOCTORAL DE LA UNIVERSIDAD DE VALLADOLID

(Aprobado por la Comisión de Doctorado en su reunión de 22 de junio de 2018)

\begin{tabular}{|l|l|}
\hline DOCTORADO EN INVESTIGACIÓN TRANSDISCIPLINAR EN EDUCACIÓN \\
\hline CÓDIGO & 5600916 \\
\hline
\end{tabular}

\section{ARTÍCULO DE REVISTA}

1. El artículo deberá estar publicado en una revista indexada en alguno de los listados que se indican a continuación, en el rango que se precisa. Las revistas electrónicas estarán sujetas a los mismos criterios que las demás.

\begin{tabular}{|c|c|}
\hline LISTADOS DE REVISTAS & $\begin{array}{c}\text { POSICIÓN EN EL } \\
\text { RANGO }\end{array}$ \\
\hline Journal Citation Reports, Social Sciences Edition & \\
\hline Journal Citation Reports, Science Edition & \\
\hline Journal Citation Reports, Emerging Sources Citation Index & \\
\hline Arts and Humanities Citation Index & \\
\hline Scimago Journal Rank (SJR) & \\
\hline & \\
\hline Revistas certificadas por la ANEP/FECYT & \\
\hline
\end{tabular}




\begin{tabular}{|c|c|}
\hline $\begin{array}{c}\text { Clasificación Integrada de Revistas Científicas (CIRC) } \\
\text { European Reference Index for the Humanities and Social Sciences } \\
\text { (ERIH Plus) }\end{array}$ & A+, A y B \\
\hline CAHRUS Plus & B, C y D \\
\hline Google Scholar Metrics, en el ámbito de Educación & $\begin{array}{c}\text { con un índice H5 de al } \\
\text { menos 5 }\end{array}$ \\
\hline Latindex & $\begin{array}{c}\text { Al menos 30 criterios } \\
\end{array}$ \\
\hline
\end{tabular}




\subsection{RESULTADOS: COMPENDIO DE ARTÍCULOS DE INVESTIGACIÓN}

Artículo 1: Estudio de caso sobre la evaluación por competencias en Educación Artística: Aportaciones a la Educación Patrimonial.

\section{Datos de contacto:}

Inmaculada Sánchez-Macías

Universidad de Valladolid (España)

e: inmaculada.sanchez.macias@uva.es

Iván M. Jorrín-Abellán

Professor of Educational Research

Bagwell College of Education-Department of Secondary and Middle Grades Education Kennesaw, (Atlanta, USA)

e: ijorrina@kennesaw.edu / ivan.jorrinabellan@kennesaw.edu

Revista: Estudios Pedagógicos

Indexación:

- Academic One File

- CLASE

- Dialnet

- Directory of Open Access Scholarly Journals in Education

- DOAJ

- EBSCO

- Educator's Reference Complete

- Equipu

- Google Académico

- Latindex (Directorio y Catálogo)

- Informe (revistas en español) 
- Infotrac Custom

- International bibliography of book reviews: IBR

- International bibliography of periodical literature: IBZ

- Revistas Científicas de América Latina y el Caribe - Redalyc

- Revistas Electrónicas UACh

- Scientific Electronic Library Online - Scielo

- Scopus

Ciencias Sociales

D 


\title{
Estudio de caso sobre la evaluación por competencias en Educación Artística: Aportaciones a la Educación Patrimonial.
}

\section{Case Study on Competence-based Evaluation in Arts Education: Contributions to Patrimonial Education.}

\section{RESUMEN}

En este artículo presentamos un estudio de caso centrado en analizar si la evaluación de los aprendizajes en el área de Educación Artística en Educación Primaria, refleja las directrices curriculares LOE-LOMCE para la evaluación por competencias en el área. El trabajo realizado arroja luz sobre multitud de aspectos relacionados con la evaluación de competencias en el área de Educación Artística. Entre ellos destacan los desajustes que existen en la concepción de la evaluación de los profesionales de la Educación Artística, su práctica evaluadora diaria y sus conexiones con el currículo oficial. Entendiendo la Educación Artística como piedra angular de la Educación Patrimonial (Fontal, 2016), en el trabajo que presentamos nos atrevemos a extrapolar las tensiones identificadas en la praxis metodológica de la Educación Artística en Educación Primaria, al ámbito de los debates teóricos que se suscitan tanto a nivel pedagógico como social/sociológico en el conjunto de la Educación Patrimonial.

Palabras clave: evaluación de aprendizajes, Educación Artística, Educación Patrimonial, estudio de caso.

\begin{abstract}
In this article we present a case study focused on analyzing whether the learning assessment in the area of Artistic Education in Primary Education, reflects the LOELOMCE curricular guidelines for the evaluation by competences in the area. The work carried out sheds light on a multitude of aspects related to the evaluation of competences in the area of Artistic Education. These include the mismatches that exist in the conception of the evaluation of the professionals of the artistic education, its daily evaluating practice and its connections with the official curriculum. Understanding artistic education as a cornerstone of heritage education (Fontal, 2016), in the work we present we dare to extrapolate the tensions identified in the methodological praxis of
\end{abstract}


artistic education in primary education, within the scope of the theoretical debates that arise both pedagogical and social / sociological in the whole of Heritage Education.

Keywords: Assessment, Art Education, Heritage education, Case study

\section{INTRODUCCIÓN}

El trabajo que presentamos trata de arrojar luz sobre la forma en que se están evaluando los aprendizajes en el área de Educación Artística en Educación Primaria. Para ello centraremos nuestra atención en analizar si los procesos de evaluación que se implementan en las aulas, reflejan las directrices curriculares LOE-LOMCE ${ }^{8}$ para la evaluación por competencias en el área.

Según Efland (2002) la función del arte a través de la historia cultural de la humanidad ha sido la construcción de la realidad. La enseñanza artística, ha ayudado a los alumnos a comprender su mundo social y cultural. Es por ello, que apreciar el arte y las manifestaciones artísticas nos ha ayudado a entender mejor nuestro entorno, contextualizando los hechos que en él acontecen. De ahí la importancia de nuestro estudio; comprender cómo se evalúan los aprendizajes en la Educación Artística en la etapa de Primaria es imprescindible para el desarrollo integral y global de las personas; y como señala en el Boletín Oficial del Estado (n 117, 2014), "la distribución de la Educación Artística facilitará al alumnado ír creciendo en su desarrollo, acompañando e interrelacionando conocimientos de otras áreas y fortaleciendo su desarrollo competencial, conformándose un aprendizaje globalizado" (p.44559).

El objeto de estudio se centra, por tanto, en analizar si la evaluación de los aprendizajes que se está realizando en el área de Educación Artística, refleja las directrices curriculares enfocadas a la evaluación por competencias en ese área. Para su análisis se ha optado por utilizar el método del Estudio de Caso, dado que nos interesa comprender en profundidad la realidad que nos ocupa.

Comenzaremos nuestro artículo con un marco teórico en el que se apoya nuestro estudio, y que plantea tres aspectos principales: un estado de la cuestión de la Educación Artística para situarnos en las teorías y aproximaciones que están influyendo en la actualidad en este ámbito de conocimiento; la relevancia, aproximaciones y formación

\footnotetext{
8 LOE: Ley Orgánica 2/2006, de 3 de mayo, de Educación.

Fuente: https://www.boe.es/buscar/pdf/2006/BOE-A-2006-7899-consolidado.pdf 
inicial docente en y para la evaluación de los aprendizajes en estas asignaturas; y por último, cómo se forma en España a los futuros profesionales que serán los responsables de impartir la docencia en Educación Artística. Tras el marco teórico, describimos el marco metodológico de nuestra investigación siguiendo los pasos de (Jorrín-Abellán, 2016) en su modelo para la generación de diseños de investigación de corte cualitativo, optando por el estudio de caso propuesto por (Stake, 1995), dado que se alinea bien con la cosmovisión constructivista aportada por los investigadores.

Y finalizaremos con el análisis de los resultados y las conclusiones y reflexiones finales en las que aportamos luz sobre la evaluación de aprendizajes en Educación Plástica y su aportación a los debates teóricos de la Educación Patrimonial.

\section{MARCO CONCEPTUAL}

Tal y como se muestra en la figura 1, el marco conceptual de sustento del estudio propuesto consta de tres componentes fundamentales: a) La Educación Plástica y el lugar secundario al que se la ha relegado en la educación primaria; b) la evaluación de aprendizajes basado en competencias (concepto de competencia y su sentido en el ámbito educativo actual), y finalmente; c) la formación de profesorado en nuestro sistema universitario y cómo influye ésta en la forma de evaluar del futuro maestro de E. Plástica. A continuación, pasamos a describir pormenorizadamente cada uno de estos componentes. 


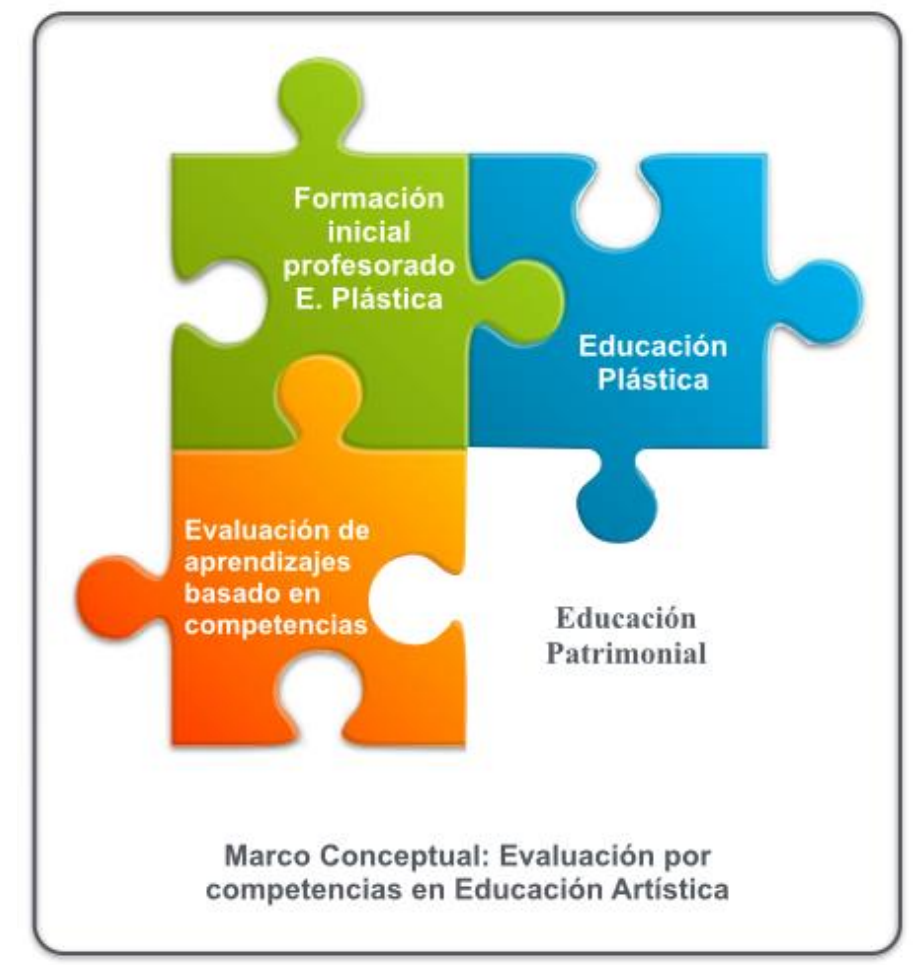

Figura 1: Marco conceptual del estudio, diseño propio.

Estos tres componentes mantienen una relación a modo de puzzle en la que podemos apreciar que tanto la Educación Plástica, como la Educación Patrimonial que la engloba, se ven influenciadas por la formación inicial del profesorado que se va a encargar en el futuro de la docencia de dichas asignaturas. El tercer componente muestra a su vez, el impacto que la formación de los futuros maestros de Educación Plástica en Primaria, va a tener en su manera de evaluar los aprendizajes.

\subsection{EDUCACIÓN ARTÍSTICA/PLÁSTICA.}

Un breve recorrido histórico por las distintas concepciones de la asignatura que nos ocupa, nos guiará hasta la situación actual de la Educación Artística, para así poder comprender mejor la pertinencia, relevancia y necesidad del estudio que planteamos en este trabajo.

El final del siglo XX y principios del XXI se ven marcados por una evolución de la concepción de lo artístico en paralelo con los progresos y retrocesos sociales, las teorías y aproximaciones de otras disciplinas fuertemente relacionadas con el arte, como es la Psicología o la Sociología.

Desde finales del XIX, con Cizek en Viena, Marion Richardson en Inglaterra y sus homólogos en EEUU (Efland, 2002) y la definición de su expresión libre o autoexpresión creativa, la pedagogía del arte ha ido sufriendo numerosos cambios en 
consonancia con los modelos de sociedad y las legislaciones vigentes en cada momento. Bruner en 1972 con su libro "Educando la Visión Artística" defiende la necesidad de un concepto amplio de Educación Artística, siendo precursor de lo que más tarde se conoce por Educación Artística como Disciplina (EACD), sugerido por Marín-Viadel, (1987), (Discipline Based Art Education). La Educación Artística como disciplina fue concebida en 1984 por Dwaine Greer, antigua presidenta del Paul Getty Institute for Educators on the Visual Arts, (DBAE). DBAE rompe con las concepciones anteriores porque trata de impartir una visión completa del arte mediante el estudio de cualquier obra determinada o tipo de trabajo por medio de cuatro disciplinas diferentes, adaptados a las edades y niveles específicos de calidad: producción del arte, historia del arte, crítica del arte y estética.

Unos años más tarde surge el currículo constructivista basado en los preceptos de Piaget (1992) y el currículo multicultural, con representantes como Kincheloe y Steinberg en su libro "Cambiando el multiculturalismo" (1997), hundiendo sus raíces en el postmodernismo, donde se pretende formar personas críticas con el sistema social, prestando especial atención a la diversidad cultural en el arte.

Durante los últimos años se han ido desarrollando una diversidad de currícula como el reconstructivista, el posmoderno, la Teoría Crítica, la Pedagogía de Arte Crítica, la Educación Artística basada en la Cultura Visual (VCAE) con Freedman y su “Teaching visual culture: curriculum, aesthetics and the social life of art," y el más reciente currículo basado en la Modernidad Líquida, que se entiende como una época en la que la formación continuada no debería dedicarse exclusivamente al fomento de las habilidades técnicas y a la educación centrada en el trabajo, sino, sobre todo, a formar ciudadanos que recuperen el espacio público de diálogo y sus derechos democráticos, pues un ciudadano ignorante de las circunstancias políticas y sociales en las que vive será totalmente incapaz de controlar el futuro de éstas y el suyo propio (Bauman, 2007).

En la actualidad la Educación Artística en España, se encuentra en una situación en la que se está asistiendo a un cruce de propuestas que se mezclan entre sí, lo que da lugar a diversas teorías y prácticas artísticas encontradas. Estas propuestas de enfoques multiculturales, críticos y autocríticos proponen un currículo de la Educación Artística abierto a la pluralidad, flexibilidad, a la multiplicidad de manifestaciones artísticas, así como al desarrollo de colectivos minoritarios y de las artes populares.

Este hecho influye en nuestra investigación en un aspecto importante, ya que la confluencia de aproximaciones en la comprensión de la Educación Artística, debería ser 
tenida en cuenta a la hora de orientar a futuros maestros hacia una visión más interdisciplinar del área.

Así, la Educación Artística puede entenderse desde una visión integradora, fomentando una adecuada y necesaria conexión con otros conocimientos científicotécnicos, sin convertirse en una simple área instrumental. Para que esto ocurra, los implicados en el proceso educativo deben trabajar de forma conjunta, fomentando la integración de las diferentes disciplinas educativas, para brindar con ello la relevancia que los procesos de aprendizaje requieren (Salgado, 2012). Para ello, habría que tener muy presente la formación del profesorado que imparte las asignaturas relacionadas con la educación artística en nuestro país.

A este respecto, cabe señalar que la situación actual del área sigue alertando sobre cuestiones cronificadas, divididas entre las visiones históricas que minusvaloran el área al abogar por concepciones reduccionistas ("hacer dibujo", "hacer manuales"), y la falta de horas lectivas en el currículum de las áreas artísticas; aspecto este último que contradice los postulados teórico-epistemológicos defendidos en la actualidad, como mencionábamos anteriormente.

En la actualidad en el área de Educación Artística en el currículo de Primaria, en España, sigue siendo el maestro generalista el que imparte la docencia (Bamford, 2006), o el Graduado en Educación Primaria con mención generalista. El tiempo del que dispone para desarrollar el currículo (por ejemplo, en Castilla y León son dos horas semanales, al menos para E. Musical; o en Extremadura, son dos horas a la semana, una para E. Plástica y una para E. Musical), es muy escaso para llevar a cabo programas tan amplios y en los que los objetivos a trabajar son muy diversos (Robinson, 1999; Sharp y Le Mátais, 2000), máxime cuando las horas lectivas están compartidas entre Plástica y Visual con la Educación Musical, asignaturas con lenguajes propios y distintos.

\subsection{EVALUACIÓN DE APRENDIZAJES EN E. ARTÍSTICA}

Una vez presentada una aproximación histórica a la evolución del concepto de Educación Artística, resulta importante para nuestro trabajo centrarnos en la forma en que en la actualidad se evalúan los aprendizajes en el área. En esta sección nos acercaremos a la cuestión desde los planteamientos generales propios de la evaluación educativa, para posteriormente centrarnos en la evaluación de aprendizajes, aspecto crítico en nuestra investigación. 
En el año 2000 se reúne el Consejo de Lisboa en sesión especial del Consejo Europeo, para reforzar la economía y la cohesión social europeas, con el objetivo estratégico de promover una conversión progresiva de la economía de mercado en una economía basada en el conocimiento; fomentando la modernización del estado de bienestar social y de los sistemas educativos. Es en este contexto donde se plantea el término de "competencia clave", como cualificación básica que se debe tener en cuenta en la educación y formación para la vida y el trabajo en la sociedad del conocimiento. El Consejo de Lisboa marca, por tanto, el inicio del marco común europeo sobre competencias. Posteriormente como elaboración técnica dentro del Espacio Europeo de Educación Superior (EEES) se desarrolló el Proyecto Tunning (2003) promovido por un centenar de universidades de los países integrantes de la Unión Europea, con el objetivo de rediseñar los distintos currícula a partir de la citada Declaración de Bolonia. El Proyecto Tunning da importancia a las competencias ya que responde con ellas a lo que debería saber, entender y ser capaz de hacer un estudiante para ser contratable. El cuestionario propuesto por el proyecto proponía tres tipos de competencias: instrumentales, interpersonales y sistémicas.

En nuestro trabajo se ha asumido la definición de "competencia" propuesta por Sánchez-Macías (2014) donde se definen como "el conjunto de capacidades instrumentales y actitudinales, habilidades, aptitudes y disposiciones que se adquieren, se desarrollan y evolucionan para dirigir un proceso con el fin de solucionar ciertos problemas en cualquier aspecto de la vida."

Nos centramos a continuación en lo que se conoce en el mundo anglosajón como “assessment” o evaluación de los aprendizajes. A la evaluación, la Pedagogía tradicional la consideraba sólo como un acto final desprendido de todas las acciones propias de la enseñanza y el aprendizaje, es decir, se tomaba únicamente en consideración la valoración de los productos finales del aprendizaje. Esta concepción estática y sumativa de la evaluación, pone en evidencia un concepto de educación también estática y centrada en los productos, no en los procesos. Una de las razones que justifica este hecho viene ocasionada por la confusión que en el mundo de lo educativo observamos entre los conceptos de evaluación y calificación. Esta confusión se ha reforzado como consecuencia de la influencia ejercida por las tendencias sociales neoliberales, y su repercusión directa en los sistemas educativos, donde la acreditación de resultados se convierte en necesidad para el acceso al mundo laboral. 
Así mismo resulta importante recordar que la evaluación de aprendizajes, en su versión más tradicional, se apoya fuertemente en una comprensión clasista de los sistemas educativos, donde la evaluación se convierte en instrumento de selección social.

En la actualidad observamos que la concepción de la evaluación de aprendizajes se ha visto afectada por numerosas aproximaciones teóricas provenientes de campos diversos, este es el caso de: a) las teorías sobre la empleabilidad del educando (Formichella y London, 2005); b) los avances de la Pedagogía contemporánea hacia modelos participativos; c) la Incorporación de las TIC (Mishra \& Koehler, 2006); d) las aportaciones de la evaluación ecológica (Tikunoff, 1979) y finalmente e) las aportaciones de la evaluación interdisciplinar (Legrand,1970).

Estas aproximaciones teóricas aportan una base necesaria para comprender la evolución del concepto de evaluación a lo largo de los últimos años. No obstante, la evaluación de aprendizajes tiene sus raíces teóricas en la psicología cognitiva, y especialmente en la definición que Vigotsky ofreció, de la zona de desarrollo próximo (ZDP). Ésta se entiende como "la distancia en el nivel real de desarrollo, determinado por la capacidad de resolver independientemente un problema, y el nivel de desarrollo potencial, determinado a través de la resolución de un problema bajo la guía de un adulto o en colaboración con otro compañero más capaz" (Vigotsky, 1988, p.133). Es decir, la aplicación de esta aproximación nos lleva a plantear una evaluación centrada en los procesos, que se convierte por tanto en herramienta clave para el desarrollo del aprendizaje.

En segundo lugar, la concepción moderna de la evaluación también se apoya en las teorías sociológicas de la educación, centradas en la dimensión social del hecho educativo entendido en los varios círculos de influencia desde y hacia la sociedad circundante al centro educativo. Podemos mencionar a este respecto, la escuela teórica anglosajona de Reino Unido y EEUU, que resalta el enfoque en el desarrollo específico de cada aprendizaje "situado" (Lave y Wenger, 1991) en un contexto, primando su evolución particular sobre la importación de patrones o herramientas externas de evaluación "prefabricadas". En consonancia resaltan ese concepto educativo dinámico por encima de las técnicas específicas del propio assessment. Como escuela teórica de esta concepción moderna de la evaluación, destaca la Assessment for Learning, (AFL).

Por su parte, la escuela francófona (Canadá, Suiza...) ha incidido sobre el concepto de contrato didáctico, en que cada parte educativa, profesor y alumnos pactan, 
según sus expectativas y objetivos, el desarrollo de los aprendizajes. Se percibe la evaluación como una regulación constante influenciada por los intereses particulares que aporta cada alumno a la misma. Como autor de esta escuela destaca Perrenoud (2009). Defiende unos principios generales educativos como son la educación continua, la importancia del feedback y la intercomunicación. Entiende por tanto la evaluación como un hecho contextual, valorando los procesos por encima de los logros, y planteando diversos instrumentos de evaluación y de diálogo.

Esta escuela, con sustento teórico en el Learning by doing de Dewey (1900), propone la utilización de técnicas específicas de apoyo a la evaluación de los aprendizajes, como el caso de estudio, y la solución de problemas concretos. También plantea el uso de ciertos elementos de monitorización de los avances y logro de objetivos. Para ello plantea el uso de numerosas técnicas de recogida de información para la evaluación del aprendizaje que se utilizan en la actualidad, como por ejemplo el uso de la observación sistemática, las rúbricas, los portfolios, las entrevistas, cuestionarios, cuadernos de clase, informes; así como el empleo de tecnologías mediante el uso del e-portfolio, las e-rúbricas, Learning Analytics, y el peer and on-line assessment.

Estas propuestas se alinean bien con los requisitos y demandas de la evaluación por competencias, aunque demandan un gran esfuerzo y formación específica de los docentes.

\subsection{FORMACIÓN DE PROFESORADO E INFLUENCIA EN LA FORMACIÓN DE FUTUROS MAESTROS}

La formación inicial de los futuros docentes de Primaria viene marcada por la Ley Orgánica de Educación (L.O.E), que ofrece la que se establece que para ejercer la docencia de las enseñanzas artísticas será necesario estar en posesión del título de Licenciado, Ingeniero o Arquitecto, o del título de Grado correspondiente en la educación primaria. También se reconoce la habilitación de otras titulaciones que pudiera establecer el Gobierno para determinados módulos. También menciona que excepcionalmente, se podrá incorporar a profesionales, atendiendo a su cualificación y a las necesidades del sistema educativo, no necesariamente titulados, de nacionalidad extranjera. (Ley Orgánica 2/2006 de Educación. Título III, Capítulo II “Profesorado de las distintas enseñanzas” y Capítulo III "Formación del profesorado"). Como vemos, las orientaciones proporcionadas por la legislación vigente a este respecto, establecen que 
casi cualquier profesional con formación artística puede convertirse en docente del área, salvo en el caso de la educación primaria, donde se requiere la titulación de maestro.

En el terreno que nos ocupa cabe mencionar que el futuro maestro suele enfrentarse al estudio de la materia con unas concepciones básicas y a veces erróneas, que determinarán su aprendizaje en los años de formación para la docencia, así como el aprendizaje de sus alumnos cuando ejerza su práctica profesional. Esta falta de especialización del profesorado, unida a los amplios objetivos definidos en el área, provoca en muchas ocasiones, que los docentes no sepan qué enseñar y cómo hacerlo (Eisner, 1995).

Desde nuestro punto de vista, la situación en las Escuelas y Facultades de Magisterio de nuestro país es precaria en lo referido a la formación de futuros maestros en el área de Educación Artística. Para poder enseñar a los futuros docentes cómo fomentar los aprendizajes en el área de educación artística, deberían haberse formado previamente de manera holística, habiéndose ejercitado en las distintas dimensiones, destrezas, y habilidades que implica el área, aspecto que no se tiene en cuenta en las Universidades españolas.

Por un proceso natural, las capacidades y competencias que se desarrollan con la Educación Artística, concretamente con la Educación Plástica en Primaria, se frenarán si no se educan o se siguen desarrollando de una forma adecuada. Si los maestros que forman en esta etapa no están preparados para ello, provocarán un estancamiento del desarrollo de las habilidades artístico-creativas de los niños, como ha ocurrido con la mayoría de los adultos que no han recibido apoyo en el campo de la Educación Plástica y Visual cuando fueron niños. Por tanto, resulta clara la influencia que la formación inicial del profesorado en el área tiene en el futuro desarrollo de las generaciones venideras.

Los tres elementos desarrollados en esta segunda sección configuran el marco conceptual de sustento del estudio que presentamos a continuación. La evolución de la concepción de la educación plástica y el lugar secundario al que se la ha relegado en la educación primaria, la evolución de la evaluación de aprendizajes basado en competencias y, finalmente las carencias en la formación inicial de futuros maestros, constituyen la base de los argumentos de sustento de la necesidad y relevancia de nuestro estudio. 


\section{METODOLOGÍA}

En este apartado describimos pormenorizadamente la metodología empleada en el estudio desarrollado. Para ello seguiremos los pasos definidos por (Jorrín-Abellán, 2016) en su modelo para la generación de diseños de investigación de corte cualitativo.

\subsection{APROXIMACIÓN GENERAL DE INVESTIGACIÓN}

Resulta importante definir en primera instancia la aproximación general seguida en la investigación que hemos llevado a cabo. Dentro de las tres principales aproximaciones existentes en el campo de las ciencias sociales (cuantitativa, cualitativa y métodos mixtos), hemos optado por una aproximación interpretativa de corte cualitativo. Por ello la finalidad última del trabajo realizado no pasa por explicar el fenómeno objeto de estudio, sino que, por el contrario, pretendemos alcanzar una comprensión profunda del mismo.

Por tanto, el estudio realizado pretende comprender si la evaluación que en la actualidad se desarrolla de los aprendizajes en el área de Educación Artística en Educación Primaria, refleja las directrices curriculares LOE-LOMCE para la evaluación por competencias en el área.

\subsection{POSICIONAMIENTO DEL INVESTIGADOR O COSMOVISIÓN.}

Tal y como menciona Creswell (2013), los investigadores cualitativos aportan a sus estudios, de forma ineludible, su particular manera de entender cómo funcionan las cosas en nuestro mundo y la forma en que se construye el conocimiento (Worldview). La dimensión epistemológica y ontológica que aporta el investigador influirá fuertemente en las decisiones metodológicas que tome en la fase de diseño de sus investigaciones. Por ello, resulta de vital importancia definir y reconocer nuestra forma de entender el mundo.

La aproximación interpretativa que hemos seguido se alinea con la cosmovisión de corte constructivista que como investigadores aportamos al proceso. Siguiendo esta cosmovisión, defendemos la construcción social del conocimiento fruto de la interacción social.

De igual forma entendemos que el propio contexto social en el que se ha desarrollado nuestro estudio, ha condicionado las interpretaciones que hemos realizado, y que por ello nos posicionamos subjetivamente ante el fenómeno objeto de estudio. Por 
este motivo el peso de la investigación desarrollada, de corte constructivista, recae en los significados que, sobre el fenómeno social estudiado, han construido los participantes en la misma. De esta manera los investigadores tan solo hemos interpretado los significados que nuestros participantes han generado.

\subsection{TRADICIÓN DE INVESTIGACIÓN}

De entre las principales tradiciones de investigación que encontramos en investigación cualitativa, hemos optado por emplear el estudio de caso, dado que nos permite comprender en profundidad un fenómeno en funcionamiento, delimitado espacio-temporalmente.

En el estudio de casos existen a su vez distintas conceptualizaciones, tal y como identifica Yazan (2015). De ellas optamos por la propuesta por (Stake, 1995), dado que se alinea bien con la cosmovisión constructivista aportada por los investigadores.

Tal y como describiremos en las secciones siguientes, nuestro estudio vendrá delimitado por la experiencia que como estudiante ha tenido la investigadora principal. Por ello el estudio se ha desarrollado en: La Facultad de Educación y Trabajo Social de la Universidad de Valladolid (centro en el que la investigadora principal ha cursado estudios de grado y máster); un C.R.A ${ }^{9}$ en la localidad de Zaratán (centro en el que la investigadora realizó el Prácticum I); un instituto de Educación Secundaria en Plasencia (centro donde trabaja un compañero de Bellas Artes como profesor); y un centro de Educación Primaria en la localidad de Llerena (Badajoz) (centro donde cursó la E.G.B la investigadora).

\subsection{ESTRUCTURA CONCEPTUAL DEL CASO}

A continuación, desgranamos los componentes del estudio de caso desarrollado, conforme al esquema de estructura conceptual definido por Stake (1995) (Ver figura 2).

El círculo central rodeado de una línea gruesa, plantea los límites del caso mencionados en la sección anterior, así como las principales características del estudio (i.e. funciones, lugares de actividad, informantes, técnicas de recogida de datos, etc).

Del círculo central parten dos semicírculos que nos permiten definir los contextos del caso que influyen en sus raíces y comprensión; y, por último, en la base del círculo,

\footnotetext{
${ }^{9}$ C.R.A: centro rural agrupado
} 
encontramos las tensiones de investigación (Issues), los tópicos y las preguntas informativas, que nos han permitido iluminar la complejidad del fenómeno estudiado.

De entre el conjunto de elementos estructurales que conforman el estudio de caso, nos centraremos a continuación en la descripción de sus funciones, los informantes, las técnicas de recogida de datos empleadas, las tensiones de investigación y las estrategias para el análisis de los datos.

La función principal del estudio fue la de intentar comprender si la evaluación por competencias que en la actualidad se viene desarrollando en el área de Educación Artística en Educación Primaria, se alinea con las directrices curriculares establecidas en la legislación vigente.

Para ello definimos una tensión de investigación central (o issue) de la siguiente forma: ¿Refleja la evaluación de los aprendizajes que se realiza en Educación Artística en el aula de Primaria las directrices curriculares enfocadas a la evaluación competencial en esa área? Esta tensión se centra eminentemente en el análisis de lo que sucede en la realidad de las aulas en relación a la evaluación por competencias. Al definirla teníamos en mente el documento puente que el profesorado elabora para vincular la normativa vigente con sus prácticas de aula. Los indicadores de logro que en él se definen van a permitir al docente definir unos indicadores de logro para posteriormente poder evaluar las competencias mostradas por su alumnado al desarrollar el currículo. Es decir, la intención era averiguar si lo que los curricula proponen es lo que se realiza en el aula en cuanto a la evaluación de aprendizajes.

De la tensión definida surge el siguiente aserto de investigación que se debe verificar posteriormente mediante el análisis de los datos: Consideramos que en el aula de Educación Artística de Primaria no se realiza evaluación de aprendizajes por competencias según se propone en el currículo oficial.

Para poder iluminar la tensión planteada y así dar respuesta al aserto anterior definimos una serie de temas de interés, declaraciones temáticas o tópicos que nos permitieran enfocar la recogida y el análisis de los datos. Éstas habilitarán la definición de un primer esquema de categorías de análisis de los datos. En el estudio establecimos las siguientes:

a) Formación inicial y profesional de los informantes: Esta declaración temática pretende indagar en las relaciones existentes entre la formación de los maestros y profesores entrevistados y su elección para la enseñanza de artes plásticas, así como las influencias de su formación en su lenguaje plástico. 
b) Las competencias docentes y artísticas de los informantes: Basándonos en la definición de competencia propuesta por (Sánchez-Macías, 2014), esta declaración temática nos ayuda a valorar el conjunto de competencias que el profesorado debe desarrollar a nivel artístico y docente para la enseñanza de esta disciplina.

c) Estrategias de evaluación del aprendizaje artístico: Mediante esta declaración pretendemos analizar las estrategias que puede poner en marcha el profesorado para realizar evaluación de aprendizajes en la educación artística. Más concretamente, valoramos si los docentes emplean estrategias propias o si por el contrario utilizan estrategias propuestas por otros.

d) Currículo en Educación Artística: Esta declaración temática se definió con el objeto de analizar los currícula publicados hasta la fecha, concretamente sobre la Plástica en Educación Artística en la etapa de Primaria. Es importante este tópico porque alrededor de él surgen ramificaciones que aclaran competencias, evaluaciones y otros aspectos de la docencia.

Los informantes y las técnicas de recogida de datos empleadas en el estudio se resumen en la tabla 1.

En lo relativo a las estrategias empleadas para el análisis de los datos, cabe mencionar que seguimos un proceso de codificación abierta de datos mediante el uso de la herramienta de análisis Nudist*Vivo 10. En primer lugar, comenzamos analizando la autoetnografía narrativa generada por la autora principal del estudio, desde las categorías de análisis etic marcadas por las cuatro declaraciones temáticas propuestas en el estudio. Este análisis arrojó un conjunto de categorías de análisis de carácter emic, que posteriormente se aplicaron al análisis del resto de entrevistas. La tabla 2 muestra las categorías de análisis emanadas del proceso. 


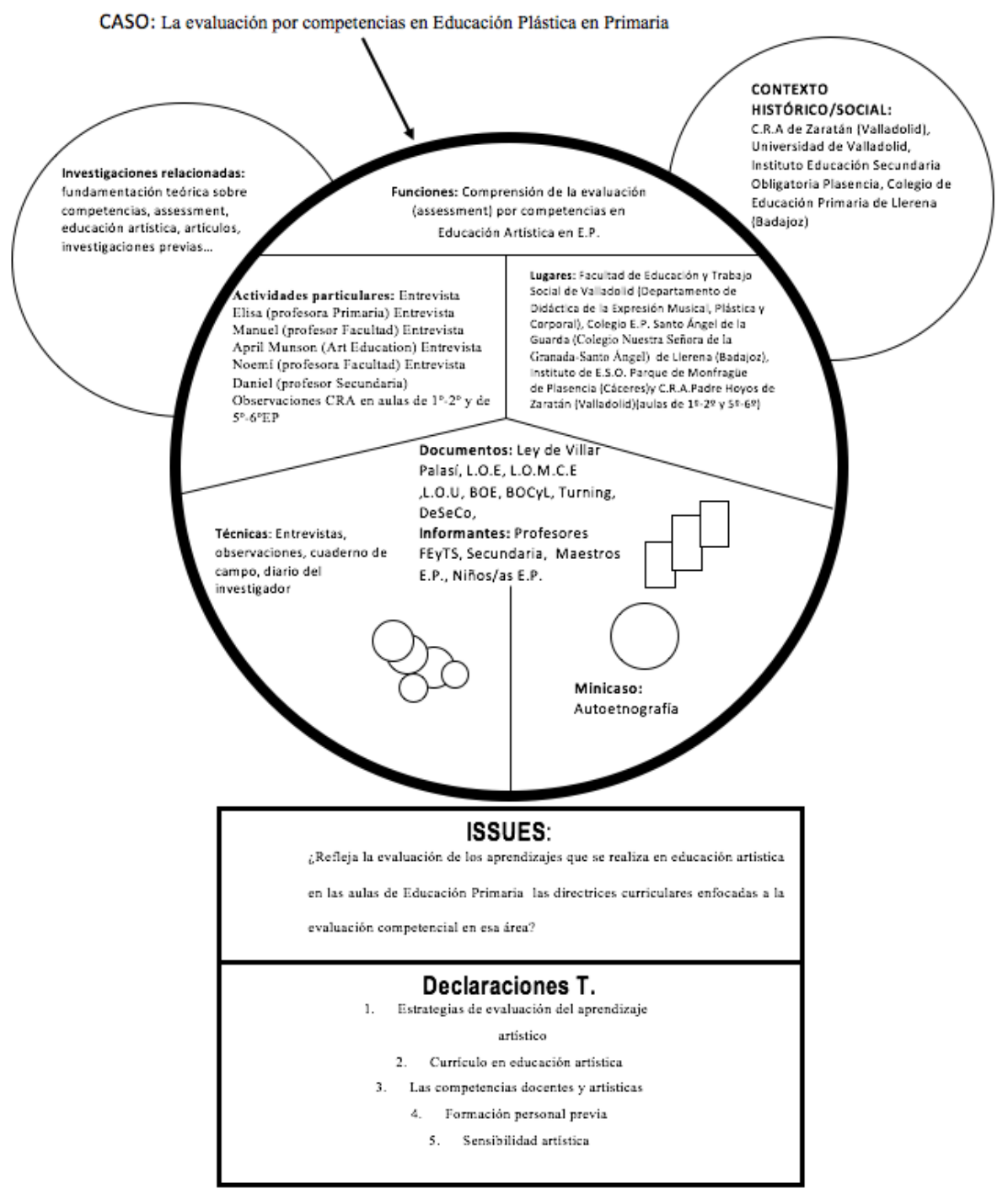

Figura 2: Estructura Conceptual del Estudio de Caso. Diseño propio.

Tabla 1

Fuentes y técnicas de recogida de datos

\begin{tabular}{llll}
\hline Técnicas & Fuentes e Informantes & \multicolumn{2}{c}{ CantidadMes/Período/Año } \\
\hline Entrevistas & -Profesora de Primaria (Colegio EP Santo Ángel de & 1 & Diciembre 2013 \\
& la Guarda, Llerena, Badajoz) & 1 & Mayo 2014 \\
& -Profesor de Secundaria (Centro ESO Parque de & & \\
& Monfragüe, Plasencia, Cáceres) & & \\
& - Profesorado (dos) de Universidad Valladolid & 3 & $\begin{array}{l}\text { Marzo, Abril y Mayo de } \\
2014\end{array}$ \\
\hline Observaciones & & 2 & Mayo 2014 \\
& Aula de $1^{\circ}-2^{\circ}$ EP & 2 & \\
& Aula de $5^{\circ}-6^{\circ}$ EP & & \\
\hline
\end{tabular}




\begin{tabular}{|c|c|c|c|}
\hline Consulta Documentos & Biblioteca, profesorado universitario (Uva) & 4 & $\begin{array}{l}\text { Noviembre 2013-Mayo } \\
2014\end{array}$ \\
\hline $\begin{array}{l}\text { Cuaderno de campo } \\
\text { (autoetnografía) }\end{array}$ & Investigadora & 1 & $\begin{array}{l}\text { Diciembre 2013-Mayo } \\
2014\end{array}$ \\
\hline
\end{tabular}

Tabla 2

Categorías de análisis Étic y Émic

Categorías Étic Categorías Émic

1.Formación personal previa

1.Formación

formación\profesorado

formaciónlalumnado

formaciónlartista

formación\creatividad

formaciónไsensibilidad

formaciónlestrategias comunicativas

\begin{tabular}{ll}
\hline 2.Las competencias docentes y artísticas & 2.Familia y entorno
\end{tabular}

3.Estrategias de evaluación del aprendizaje artístico

3.Estrategias de evaluación

4.Currículo en educación artística

4.Curriculolcorporal

-currículolmúsica

-currículolplástica

\section{PRINCIPALES RESULTADOS DEL ESTUDIO DE CASO}

Por motivos obvios de espacio, en esta sección nos centraremos en mostrar algunos de los principales resultados obtenidos dentro de cada una de las cuatro declaraciones temáticas que han guiado el análisis.

\subsection{FORMACIÓN INICIAL Y PROFESIONAL DE LOS INFORMANTES.}

Dentro de esta primera declaración temática hemos obtenido tres resultados fundamentales.

En primer lugar, el profesorado universitario y de secundaria entrevistado hace referencia a una dualidad vocacional, y en algunos casos incluso a una triple identidad, 
que se manifiesta entre sus roles como artistas, docentes, e investigadores, y la influencia de éstos en la forma en que gestionan la evaluación de aprendizajes en las asignaturas que imparten en la formación de futuros maestros. Los informantes comparten su identidad de docentes con la de artistas e investigadores, tal y como se desprende de los argumentos siguientes:

"Yo me veo como un artista que comparte sus conocimientos con los demás, es decir, soy artista y soy docente."

(Entrevista Profesor FEYTS-UVa\10-Mayo-

2014)

“...el perfil es el del que vimos en clase que es el artista- docente -investigador. Entonces son las $\underline{\text { tres figuras, porque el artista cuando crea investiga, el artista cuando da clases investiga, hay una }}$ especie de relación entre esas tres figuras, (...)"

(Entrevista Profesora FEYTS-UVal21-

Mayo2014)

Esta dualidad vocacional puede resultar importante a la hora de entender las prácticas evaluadoras que desarrollan en sus aulas dado que éstas varían sustancialmente en función de la dimensión vocacional que prime en cada caso.

En segundo lugar, nuestros informantes mencionan la existencia de tensiones a la hora de equilibrar en su docencia la impartición de contenidos técnicos y la didáctica de esos contenidos.

“O sea la formación artística la considero clave, y también la formación didáctica; porque aquí en Educación hay que tener claro que no educamos a artistas o sea lo que hacemos es...cómo los alumnos pueden trabajar la educación artística en el aula. Entonces, yo una competencia artística la tengo que tener, pero también una competencia en ¿Cómo enseñar?” (Entrevista Profesora FEYTS-UVal21-Mayo-2014)

Esta tensión evidencia la influencia que en su forma de evaluar tiene la importancia que cada docente brinda a la enseñanza-aprendizaje de contenidos, generalmente de corte conceptual, frente a la didáctica de los mismo, más centrada en procedimientos y actitudes.

En tercer lugar, nuestros informantes reconocen la existencia de diferencias claras en la formación que se imparte en Educación Plástica en Primaria y en Secundaria. Atribuyen este hecho a las diferencias en la formación didáctica inicial con la que cuenta el profesorado de primaria y secundaria en nuestro país. 
“...Que es diferente, que eso, en Secundaria...se enseñan sobre todo contenidos, entonces los

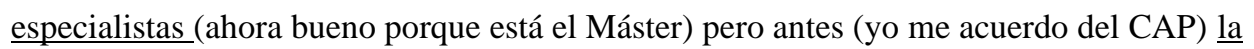
formación didáctica que tenían era casi nula y cuando entraban en el aula se encontraban con el pastel de que no tenían ni idea de cómo enfrentarse a los problemas del día a día en el aula..."

(Entrevista Profesora FEYTS-UVal21-

Mayo2014)

Como se ha comprobado en la legislación actual, los profesionales no especializados en la Educación Artística pueden ser docentes de estas asignaturas en la Secundaria. Las carencias en la formación didáctico-pedagógica de estos profesionales pueden constituir una de las razones por las que en secundaria se enseñen y evalúen más contenidos técnicos que en la primaria.

\subsection{LAS COMPETENCIAS DOCENTES Y ARTÍSTICAS DE LOS INFORMANTES.}

En esta segunda declaración encontramos una serie de competencias clave que los propios informantes han puesto en valor y consideran que han de ser trabajadas y, por tanto, evaluadas:

La primera de ellas es la creatividad, entendida tanto como capacidad, proceso y producto. Para nuestros informantes la creatividad permite elaborar respuestas originales, novedosas, alternativas. En todas las profesiones tiene cabida un ejercicio creativo de las mismas. Respecto al alumno, para desarrollar su creatividad, se incide en la eliminación de obstáculos formales:

\footnotetext{
“...la creatividad es una pella de barro que no tiene forma, le damos la forma que nosotros queremos por nuestros intereses. El que es artista su creatividad la va a volcar en crear ese concepto que es un poquito ambiguo muchas veces o abstracto quiero decir, que se llama la belleza" (Entrevista Profesor FEYTS-UVal10-Mayo2014)
}

Como hemos comprobado por las distintas evidencias de los informantes, la creatividad será una competencia que habrá que desarrollar y, por tanto, evaluar; para su desarrollo han de eliminarse los obstáculos formales, sirviendo de motivación el propio proceso, que es el fin de la evaluación de los aprendizajes.

Otra competencia mencionada por nuestros informantes es la sensibilidad, entendida ésta como la capacidad de saber responder al lenguaje propio de lo plástico y visual, y de tener una intención estética. Mencionan igualmente que, aunque existe un componente innato relacionado con la sensibilidad, ésta se puede educar, y que 
determinados ambientes educativos son más propicios que otros para hacerlo. También advierten sobre las trabas formales al desarrollo de la sensibilidad que suponen los enfoques rígidos de evaluación o la rigidez temporal que implica la adquisición de competencias.

"La sensibilidad es algo que se puede desarrollar, bajo mi punto de vista y de los estudios que encontramos esa es una capacidad que se puede desarrollar lo que pasa es que, volvemos a lo mismo, tienes que saber cómo enseñarla, que la sensibilidad no es el uso de materiales, sino que es una especie como de relación, crear como una serie de actitudes, valores, gustos, apreciaciones... es algo más...” (Entrevista Profesora FEYTS-UVa\21-Mayo-2014)

La competencia comunicativa, es otra de las competencias destacadas por nuestros informantes en lo relativo a la gestión de grupos y su dinamización. También en su vertiente de trabajo en equipo (comunicación entre docentes); así como competencia discente a desarrollar por el alumno. La propia dinámica de las clases contaría con un diálogo procesual y continuo entre el profesor y el alumno, aunque esta forma de hacer conlleve más lentitud en la aplicación del programa de una asignatura. Además, esta competencia adquiere gran importancia en la forma de evaluar los aprendizajes puesto que la comunicación y el feedback entre profesorado y alumnado es imprescindible para poder comprobar los cambios o aprendizajes que se van adquiriendo y desarrollando.

"Yo creo que sobre todo hace falta herramientas comunicativas, y de gestión de los grupos, de organización, desde mi punto de vista..." (Entrevista profesor de Secundaria\18-Mayo-2014)

Otra competencia a la que nuestros informantes dan importancia es la inteligencia emocional, entendida como la gestión de emociones en pos del equilibrio emocional, una adecuada expresión de las mismas y elaborar estrategias de resolución de conflictos. Abogan, por tanto, por la promoción de la participación continua del alumnado como agente fundamental en el aula. A la hora de enfrentarse a la evaluación de los aprendizajes, nuestros informantes plantean la necesidad de tener en cuenta la forma en que el alumnado gestiona sus emociones a lo largo del proceso de enseñanzaaprendizaje, y si supera los obstáculos con resiliencia, etc.

"Bueno, algunas ya las he comentado en la pregunta de antes: $\underline{\text { ser buen comunicador, tener }}$ competencias en cuanto a inteligencia emocional, para poder comunicar no solamente en los contenidos sino también en las emociones que los chavales tienen, viven en cada momento y poder resolver conflictos, no solamente atajando y mandando al chaval a jefatura de estudio ..." (cont.) (Entrevista Profesor de Secundaria\18-Mayo-2014) 
Por último, otra competencia que nuestros informantes creen que es importante en el proceso educativo, es la autonomía. Es la competencia que permite transformar las ideas en actos. La que permite al alumnado asumir gran parte de la iniciativa a la hora de auto-organizarse, por ejemplo, en la resolución de conflictos, sin una ayuda excesiva de su círculo más cercano. Nuestros informantes han manifestado prestar atención a si el alumnado actúa por iniciativa propia o si necesita continuamente de la ayuda del profesorado o de los demás compañeros o familias.

“...sino intentando resolver los conflictos para que los alumnos aprendan a resolverlos; 0 mejor aún, intentando buscar la forma que los chavales sean capaces de resolverlos, sin que el profesor sea el que dirija todo el proceso. ...” (Entrevista Profesor de Secundarial 18Mayo-2014)

\subsection{FORMAS Y ESTRATEGIAS DE EVALUACIÓN}

La tercera declaración temática hace referencia las formas y estrategias de evaluación que nuestros informantes implementan en sus aulas.

En primer lugar, encontramos que la totalidad de nuestros informantes defienden la evaluación continua y formativa, como estrategia definitoria de su práctica evaluadora. Parece haber acuerdo en el hecho de que la evaluación de procesos, más allá de la unicidad de la evaluación sobre resultados finales, es fundamental en esta área de conocimiento. No obstante, vuelven a salir a la luz los obstáculos con los que se encuentran los formadores de futuros docentes para realizar el tipo de evaluación que consideran la más adecuada (los tiempos, las ratios, el currículo...):

"...me encuentro con sus producciones, que han sido tuteladas porque yo voy siguiendo la realización del trabajo en el aula, me gusta que sea en el aula..." (Entrevista Profesor FEyTSUva\10-Mayo-2014)

"Procuro que lo hagan en la clase, pero dado los programas que tenemos pues no puedes limitarte a eso, entonces si los traen hechos pues se evalúa igual el producto final." (Entrevista Profesor FEyTS-Uva\10-Mayo-2014)

Un segundo aspecto que nuestros informantes mencionan acerca de los procedimientos de la evaluación que implementan, es el uso del feedback y el diálogo. No obstante, encuentran reticencias por parte del alumnado que en muchas ocasiones solo busca la nota que califique su producto final. Por otro lado, el profesorado universitario y de secundaria admite no enseñar explícitamente cómo se 
evalúa, a su alumnado. Este aspecto es realmente interesante para nuestro estudio dado que nos permite observar una carencia curricular que hace que en numerosas ocasiones los futuros docentes imiten la manera en que ellos han sido evaluados. No obstante, uno de nuestros informantes, una profesora universitaria estadounidense, menciona que en su caso sí que enseña explícitamente cómo evaluar.

...pequeñas evaluaciones y además de un tú a tú con el alumno y oral porque dice que es lo que más funciona..."

\section{(Entrevista Profesora FEYTS-UVal}

21Mayo2014)

“¿Desde el punto de vista filosófico? (...)” Habitualmente no pongo una nota a un trabajo (...) doy feedback textual o verbal, pero feedback en lugar de una nota, que es algo muy complicado para ellos porque ellos quieren tener una nota, (...)" (Entrevista Profesora universitaria USAI2Mayo2014)

“...yo quiero que ellos reenfoquen un poco su labor como estudiantes y se centren en la calidad de lo que están aprendiendo y en apropiarse de su aprendizaje en lugar de que se centren en la nota final.” (Entrevista Profesora universitaria USAI2Mayo2014)

“...en el micro assessment lo que haces es olvidarte un poco de la nota final y centrarte en $\underline{\text { cómo van sucediendo las cosas en el aula, ellos lo van haciendo consigo mismos, aprenden a }}$ cómo evaluar y a evaluarse a sí mismos, sí, pero además desde una doble vertiente, desde la disposición y el progreso del alumno y la tuya propia, en ese momento concreto en el que estas enseñando algo.” (Entrevista Profesora universitaria USAI2Mayo2014)

En tercer lugar, destacamos las reticencias mostradas por nuestros informantes a la hora de implementar sistemas numéricos de evaluación (calificación) como herramienta principal de evaluación de los aprendizajes de su alumnado. Algunos de ellos plantean cuestiones morales y de justicia ligados a la trascendencia histórica de la nota numérica. Otros mencionan que el sistema les ha atrapado en su quehacer como docentes y se encuentran con un problema del que no pueden escapar y difícil de solucionar, ya que están obligados al final a calificar a cada alumno:

"No son una evaluación de poner nota, ojo, cuando hablas de evaluación yo hablo de valoración,

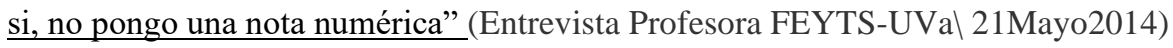

“...; y otra evaluación que es la que debo hacer por mi profesión, porque los alumnos tienen que tener una calificación a lo que hacen. Para mí esa información no es útil, o muy poco, la tengo que poner, pero realmente nunca he estado cómodo con ese sistema" (Entrevista Profesor de Secundarial18Mayo2014) 
“...y siempre hay y en esto no nos podemos escapar en Arte nunca, los que evaluamos Arte un ingrediente que es subjetivo, difícil adjudicarle una nota numérica..." (Elementos internos\} Entrevista Manuel\10Mayo2014)

“...yo no les quiero dar una nota, que es algo muy complicado para ellos, porque ellos quieren tener una nota, ...” (Entrevista Profesora universitaria USAI2Mayo2014)

El cuarto y último aspecto de esta declaración temática está relacionado con la evaluación mediante ítems diferenciales que maticen específicamente los aprendizajes a mejorar. Cuanto se utilizan, por ejemplo, rúbricas para evaluar por competencias, éstas han de subdividirse en diferentes dimensiones que permitan valorar si una competencia ha sido adquirida. Para valorar el nivel de adquisición de una competencia, se deben elaborar una serie de indicadores que la hagan medible. A pesar de su relevancia, es un aspecto que nuestros informantes no realizan, a pesar de usar rúbricas como estrategia de evaluación.

Por otro lado, en las entrevistas realizadas se han mencionado otras estrategias novedosas como el micro assessment (Stake y Munson, 2008) (micro-evaluación), que pretende que cada proceso de evaluación sea una experiencia única e individualizada, aglutinando elementos formales (contenidos) y otros elementos de carácter informal (actitudes, emociones, competencias, destrezas, etc) presentes en un proceso educativo en el campo de la educación artística. Esta aproximación requiere que el formador de futuros maestros dedique parte del currículum a enseñar a evaluar en el área. Esta forma de evaluación difiere además de aproximaciones más tradicionales, en que se aleja de procedimientos estandarizados de evaluación, buscando fórmulas que tienen que ver con la interacción situacional entre el formador y el futuro docente (i.e. uso de ejemplos de la vida cotidiana del discente).

Finalmente, en esta declaración temática, queremos destacar que algunos de nuestros informantes plantean el uso de una evaluación de aprendizajes heterodoxa, en períodos y marcos no lectivos, sin el apremio del sistema oficial, quizá bastante más motivador para el alumnado, aunque mucho más difícil de alinear con el sistema oficial de evaluación.

"A la hora de evaluar, tengo una serie de ítems, que van de lo más formal, de lo más básico a lo más conceptual...” (Entrevista Profesor FEyTS-Uval 10Mayo2014) 
"yo intento no utilizar calificaciones numéricas en los trabajos de clase; los valoro estableciendo una serie de ítems..." (Entrevista Maestra de Primarial26Diciembre2013)

“...aprender a preguntar mejor a los niños para que entiendan mejor lo que les estás preguntando, entonces, dice que muchas de las cosas que se incluyen en las rúbricas habituales de assessment ella las utiliza porque le funcionan pero que tienen mucho más que ver con esa concepción general de entender lo que está allí como una experiencia única.”(Entrevista Profesora universitaria USA12Mayo2014)

\subsection{CURRÍCULO EN EDUCACIÓN ARTÍSTICA}

En nuestro estudio de caso los informantes entrevistados han valorado una serie de competencias docentes y artísticas para poder realizar una adecuada evaluación de aprendizajes. Sin embargo, en el análisis de la legislación actual, aparecen competencias que no han sido tenidas en cuenta por los informantes y viceversa. Si unificamos las competencias que aparecen en la legislación con las que han sido propuestas por nuestros informantes, obtenemos la particular lista que mostramos a continuación: a) Desarrollo de la creatividad; b) Desarrollo de la sensibilidad; Desarrollo de la competencia comunicativa; Desarrollo de la inteligencia emocional; Desarrollo de la autonomía personal; Conocimientos y procedimientos relacionados con la práctica educativa, técnicas, fundamentos, etc; Desarrollo de habilidades relacionadas con la praxis (interpretar, saber buscar información, sentido y finalidad de la práctica, etc) y Desarrollo de un compromiso ético.

Dentro de esta declaración temática resulta también interesante mencionar las siguientes paradojas que hemos encontrado.

La primera podría formularse sucintamente como: "El currículo no nos gusta, sigamos el currículo". Es decir, nuestros informantes cumplen las orientaciones propuestas por el currículo, sin embargo, declaran abiertamente encontrarse con contradicciones en la práctica docente. Los docentes se esfuerzan por seguir las competencias del currículo pero los centros educativos no poseen recursos pedagógicos para desarrollar correctamente dichas competencias, por lo cual, el seguimiento del currículo es individualista y apoyado en competencias más generales como es la creatividad.

Un segundo aspecto a este respecto, es la potenciación de las competencias transversales también en educación artística. Nuestro estudio pone de manifiesto la gran relevancia que los informantes dan a las competencias transversales en educación 
plástica, de entre las que destacan: aprender a aprender, competencia comunicativa, autonomía personal y autonomía tutelada de los grupos, etc.

La integración de diferentes valores simbólicos, culturales y sociales pueden servirnos para aplicar los contenidos artísticos a otras áreas y por lo tanto que esta disciplina adquiera el lugar que le corresponde en relación al resto de las materias curriculares. "El arte es un campo de conocimiento que se conecta con otras áreas dentro del currículo y que requiere de docentes con nuevos perfiles" (Jiménez, Aguirre y Pimentel, 2009, p.11).

Otro aspecto relacionado con la estructura del currículum oficial con el que nuestros informantes se enfrentan, es el distanciamiento de los elaboradores de las normas respecto al conocimiento in situ y la dinámica práctica de la enseñanza real. Respecto a las metodologías de evaluación, la mayoría de nuestros informantes reconocen evaluar los procesos y las actitudes más que los productos finales, aunque también reconocen que éstos deben tenerse en cuenta para dar respuesta a los requisitos del sistema educativo actual. Nuevamente los docentes intentan seguir las orientaciones curriculares sobre la evaluación de aprendizajes en E. Plástica (también de la E. Patrimonial), sin embargo, y aquí encontramos la paradoja, tampoco el currículo desarrolla la metodología específica para esa evaluación, con lo cual, las adaptaciones de dichas evaluaciones son también individualistas. El currículo expresa qué hay que evaluar, pero no dice cómo evaluarlo.

La evaluación de procesos y actitudes se recoge sólo de forma genérica en la norma. Por el contrario, la crítica viene por el excesivo peso que sigue teniendo en la misma los exámenes tradicionales y la secuenciación estricta de los contenidos y las pruebas.

La segunda paradoja tiene que ver con la convicción general de que la evaluación ha de centrarse en los procesos y actitudes, pero no se sabe bien cómo. Es decir, hay una gran distancia entre las convicciones teórico-personales-profesionales de los docentes y el déficit de metodologías disponibles en la praxis, para evaluar competencias en educación artística. El currículum no explica la forma de realizar la evaluación de los procesos y actitudes. Los docentes en la práctica siguen una cierta secuenciación: primero hay un convencimiento teórico del docente que genera métodos y una búsqueda individual de recursos (semi-anárquica, o poco documentada); posteriormente busca un apoyo en las innovaciones que parten de los diseños curriculares; y, por último, añade un feedback de su praxis específica, etc. 
Analizando esta dinámica se podría concluir que la evaluación es un proceso que parece descoordinado, sin circulación de información entre los investigadores, los legisladores, la dirección de los centros y los docentes; y mucho menos con las familias, los agentes sociales o los creadores artísticos.

La tercera paradoja está relacionada con la praxis del profesor artístico (también profesor de contenidos patrimoniales) que podríamos decir se ha instalado en el hacer de manera poco reflexiva. Parece que la costumbre ha ido calando hasta que en ciertos casos se duda de la necesidad de establecer puentes con la teoría y la metodología pedagógica.

\section{CONCLUSIONES Y TRABAJO FUTURO}

Tal y como mencionábamos al inicio de este trabajo, una de las intenciones del mismo pasa por intentar aplicar los resultados obtenidos al campo de la Educación Patrimonial. Para ello debemos matizar que entendemos la Educación Patrimonial tal y como se plantea en Fontal (2016), quien nos invita a hacer un recorrido por los textos curriculares de las tres últimas décadas, en el que ha podido llegar a los siguientes planteamientos: a) Existe una estrecha vinculación entre Educación Artística y patrimonio en la Educación Primaria; b) La formación de maestros debe incluir la formación en Educación Patrimonial; c) El área universitaria de Didáctica de la Expresión Plástica ha ido consolidando una línea de investigación en Educación Patrimonial; d) El Plan Nacional de Educación y Patrimonio (PNEyP), permitirá consolidar la investigación, innovación y formación en Educación Patrimonial durante la próxima década; e) La Educación Patrimonial es rentable en términos sociales, culturales e identitarios (p.116-119).

Nuestro estudio de caso se ha centrado en el ámbito de la Educación Artística, que como menciona igualmente (Fontal, 2016), “...tiene una estrecha vinculación con la Educación Patrimonial en Primaria. Tanto la Educación Artística como las Ciencias Sociales tienen una vinculación demostrada con la Educación Patrimonial, ya que son ambas quienes desarrollan contenidos sobre el patrimonio." (p.116).

Como la Educación Plástica y Visual pertenecen al ámbito de la Educación Artística, y ésta a la Educación Patrimonial, podríamos extrapolar nuestras conclusiones al terreno abonado de los debates teóricos y sociales del tratamiento del patrimonio en la Educación Primaria. 
Así pues, las conclusiones generales emanadas del estudio de caso desarrollado, que podrían aplicar al campo de la Educación Patrimonial serían:

- Los informantes destacan el compromiso humano como eje de una motivación progresiva y continua en la profesión docente, cuestión que podría aplicar fácilmente al desarrollo curricular de la Educación Patrimonial en primaria.

- Por otro lado, los resultados de nuestro estudio muestran que resultaría recomendable que los maestros, profesores y formadores de futuros maestros en Educación Artística, equilibrasen los contenidos curriculares con la didáctica de esos contenidos, para fomentar una educación integral donde la evaluación de los aprendizajes pueda ser global y más equitativa. La Educación Patrimonial podría beneficiarse igualmente de este principio emanado de las entrevistas con nuestros informantes.

- Nuestros informantes han valorado como importantes un conjunto plural de competencias para el desarrollo de la educación artística. Unas son artísticas y otras de carácter didáctico-docente, tal y como mostramos en la sección anterior. No obstante, y aunque todas ellas merecen igual atención, los docentes ponen especial énfasis en el desarrollo y la promoción de competencias transversales, investigadoras, sistémicas y comunitarias, todas ellas ligadas a la pedagogía más contemporánea. Este hecho resulta interesante dado el impacto que tiene a la hora de establecer estrategias y recursos para evaluarlas. La propia Educación Patrimonial, considerada eminentemente como un área transversal, podría beneficiarse de este hecho al asumir que uno de sus componentes esenciales es la educación artística, tal y como se muestra en la figura 3. 


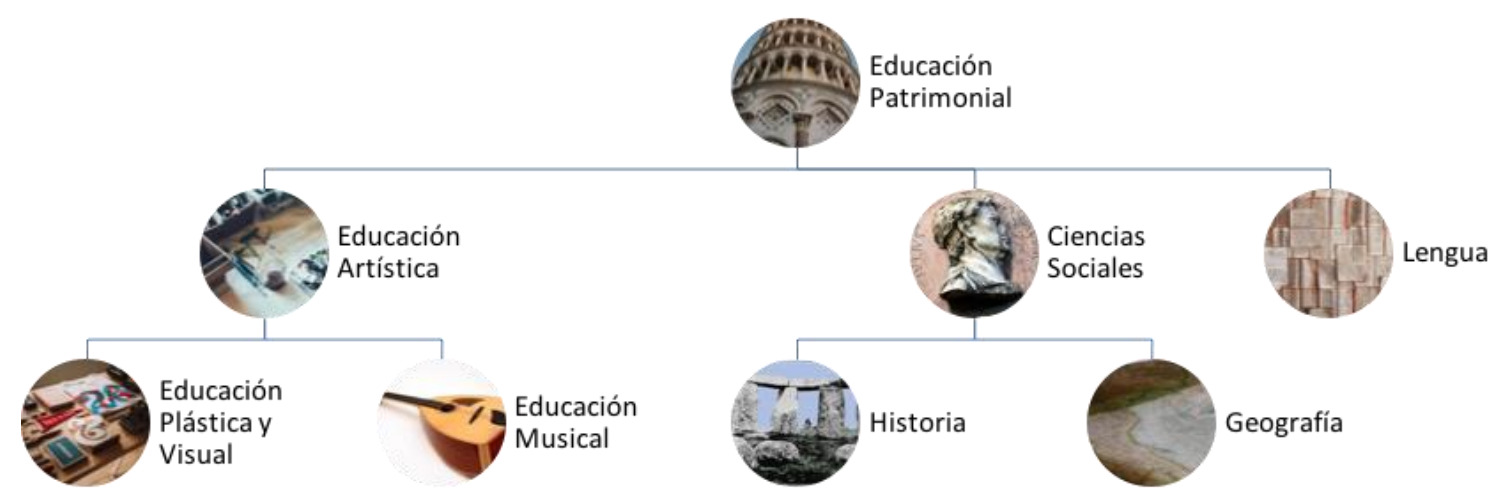

Figura 3. Transversalización de la Educación Patrimonial. Elaboración propia a partir de Fontal 2016

La figura anterior muestra las tres áreas curriculares más importantes dentro de la Educación Patrimonial, aunque dado su carácter transversal, podría abarcar otras. A este respecto, y dentro del trabajo futuro que podría emanar de estudios como el planteado en este artículo, sería interesante plantear estudios en profundidad sobre las concepciones de patrimonio que tiene el profesorado y alumnado de las materias que conforman la Educación Patrimonial. Este tipo de investigaciones permitiría vislumbrar la relación histórica y sociológica del diálogo entre el patrimonio y la escuela española a lo largo de las últimas décadas. Por ejemplo, se podrían promover estudios sobre el enfrentamiento entre un legado histórico concebido como corpus rígido proclive al adoctrinamiento del educando, y la visión contemporánea del patrimonio como exploración multifacética y global de las manifestaciones artísticas.

Igualmente se podrían promover estudios centrados en el análisis de la forma en que la praxis docente refleja la inclusión de aspectos relacionados con el patrimonio en los currícula, la evaluación por competencias y/o la formación inicial que los futuros docentes tienen a este respecto.

En nuestro trabajo hemos analizado la tensión existente entre las demandas curriculares establecidas por la legislación actual, las inercias de las instituciones educativas, y las prácticas docentes innovadoras. Tal y como muestran algunos de los 
datos presentados en la sección de resultados, la rigidez propia del currículo oficial, así como la escasez de recursos existentes para su aplicación en lo relativo a la evaluación de los aprendizajes, hacen que los docentes aboguen por procesos de evaluación/calificación de corte sumativo que muchas veces implican una escisión entre las distintas asignaturas que conforman la Educación Artística. Desde nuestro punto de vista, la Educación Patrimonial podría ayudar a solventar estas tensiones desde tres aspectos fundamentales:

En primer lugar, ayudando a promover la interacción entre asignaturas y/o áreas de conocimiento. En segundo término, facilitando la permeabilidad de la Escuela al medio social, fomentando así la idea de que el legado histórico pertenece a todas las generaciones y que ha de ser aprehendido por el educando en cualquier espacio social donde se manifieste. Y tercera, la de ayudar a entender al alumno como participante además de observador o sujeto pasivo de las manifestaciones artísticas.

\section{REFERENCIAS BIBLIOGRÁFICAS}

Bamford, A. (2006). The wow factor: Global research compendium on the impact of the arts in education. Waxmann Verlag.

Bauman, Z. (2007). Tiempos líquidos: vivir en una época de incertidumbre. Barcelona: Tusquets.

BOE núm. 106 de 4/5/2006, páginas 17158 a 17207. LOE: Ley Orgánica 2/2006, de 3 de mayo, de Educación.

BOE núm. 117 de 20/06/2014, páginas 44181 a 44768. ORDEN EDU/519/2014, de 17 de junio, por la que se establece el currículo y se regula la implantación, evaluación y desarrollo de la educación primaria en la Comunidad de Castilla y León.

BOE núm. 238 de 4/10/1990, páginas 28927 a 28942. LOGSE: Ley Orgánica 1/1990, de 3 de octubre de 1990, de Ordenación General del Sistema Educativo.

BOE núm. 295 de 10/12/2013, páginas 97858 a 97921. LOMCE: Ley Orgánica 8/2013, de 9 de diciembre, para la mejora de la calidad educativa.

BOE núm. 52, de 1 de marzo de 2014, páginas 19349 a 19420. Real Decreto 126/2014, de 28 de febrero, por el que se establece el currículo básico de la Educación Primaria. Sec. I. p. 19349- 19419.

Bruner, J. (1972). El Proceso de educación. México: Ed. Uteha. 
Creswell, J. W. (2013). Research design: Qualitative, quantitative, and mixed methods approaches. Sage publications.

Dewey, J. (1900). Psychology and social practice. Psychological review, vol.7(2), 105.

Domingo, M., Fontal, O. y Ballesteros, P. (2013). Plan Nacional de Educación y

Patrimonio. Madrid: Ministerio de Educación, Cultura y Deporte: Secretaría de Estado de Cultura.

Efland, A. D. (2002). Una historia de la educación del arte. Tendencias intelectuales y sociales en la enseñanza de las artes visuales. Barcelona: Paidós.

Eisner, E. W. (1995). Educar la visión artística. Barcelona: Paidós Ibérica.

Fontal-Merillas, O. (2016). El patrimonio a través de la educación artística en la etapa de primaria. Arte, Individuo y Sociedad, vol.28(1), 105-120.

Formichella, M. M. y London, S. (2005). Reflexiones acerca de la noción de empleabilidad. Argentina: Consejo Nacional de Investigaciones Científicas y Técnicas. Recuperado el 18/11/2013 de: http://www.aaep.org.ar/espa/anales/works05/formichella_london.pdf.

Greer, D. F. (1984). Industrial organization and public policy. Macmillan Publishing Company.

Jiménez, L., Aguirre, I., y Pimentel, L. G. (2009). Educación artística, cultura y ciudadanía. Organização dos Estados Ibero-americanos para a Educação, a Ciência ea Cultura. Organización de Estados Iberoamericanos para la Educación, la Ciencia y la Cultura. Madrid: Fundación Santillana.

Jorrín-Abellán, Iván M. (2016). Hopscotch Building: A Model for the Generation of Qualitative Research Designs, Georgia Educational Researcher: Vol. 13: Iss. 1, Article 4. DOI: 10.20429/ger.2016.130104.

Kincheloe, J. L. y Steinberg, S. R. (1997). Changing multiculturalism. Open University. Lave, J. y Wenger, E. (1991). Situated learning: Legitimate peripheral participation. Cambridge university press.

Legrand, J. (1970). Guía del trabajo cotidiano en el aula. Buenos Aires: Kapelusz.

Lipovetsky, G. (1990). El imperio de lo efímero. La moda y su destino en las sociedades humanas. Madrid: Anagrama.

Marín-Viadel, R. (1987). ¿Medir los resultados o comprender los procesos? Icónica: revista de las artes visuales, didáctica e investigación, (9), 41-62. 
Mishra, P. y Koehler, M. J. (2006). Technological pedagogical con- tent knowledge: A framework for teacher knowledge. Teachers College Record, vol.108(6), 10171054.

Perrenoud, Ph. (2009). Enfoque por competencias, ¿una respuesta al fracaso escolar? Revista Interuniversitaria de Pedagogía Social, vol.16, 45-64.

Piaget, L., Lorenz, K. y Erikson, E. (1992). Juego y desarrollo. Méjico: Grijalbo.

Robinson, K., 1999. Culture, Creativity and the Young: Developing Public Policy. Cultural Policies Research and Development Unit Policy Note N². Estrasburgo: Consejo de Europa.

Salgado-García, E. (2012). Enseñanza para la comprensión en la educación superior: la experiencia de una universidad costarricense. Revista iberoamericana de educación superior, vol.3(8), 34-50.

Sánchez-Macías, I. C. (2014). La evaluación por competencias en Educación Plástica en Primaria: Un estudio de caso. (Trabajo Fin de Máster). Valladolid. Universidad de Valladolid. Facultad de Educación y Trabajo Social.

Sharp, C. y Le Métais, J., (2000). The Arts, Creativity and Cultural Education: An International Perspective.

Stake, R. E. (1995). The Art of Case Study Research. Thousand Oaks: Sage Publications.

Stake, R. y Munson, A. (2008). Qualitative assessment of arts education. Arts \& Education Policy Review, vol.109(6),13-22. Recuperado de http://aprilmunson.wikispaces.com/file/view/Qualitative+Assessment+in+Arts+ Education.doc.pdf.

Tikunoff, W. J. y Griffin, G. A. (1979). Interactive research and development on teaching study: Final report. The Laboratory. Far West Laboratory for Educational Research and Development.

Vygotsky, L. S. (1988). Aprendizagem e desenvolvimento intelectual na idade escolar. __et al. Linguagem, desenvolvimento e aprendizagem. São Paulo: Ícone: EDUSP.

Yazan, B. (2015). Three approaches to case study methods in education: Yin, Merriam, and Stake. The Qualitative Report, vol.20(2), 134-152.

WEBGRAFÍA:

-Consejo de Lisboa: http://www.europarl.europa.eu/summits/lis1_es.htm

-Parlamento europeo, recomendaciones: 
http://eurlex.europa.eu/LexUriServ/site/es/oj/2006/1_394/1_39420061230es00100018.pf -Proyecto Tunning:

http://acreditacion.unillanos.edu.co/contenidos/cpacitacion_docente_2semestre_2007/co mpetencias_proyectotuning.pdf 
Artículo 2: \#Souvenirs1936

Transmedia y procesos de identización en el aprendizaje de la Guerra Civil Española

\section{Datos de contacto:}

Pablo de Castro Martín

Universidad de Valladolid / Colegio Safa-Grial pabloluis.castro@uva.es, tartesos.pablo@gmail.com

Inmaculada Sánchez-Macías Universidad de Valladolid

inmaculada.sanchez.macias@uva.es

Esta investigación ha sido posible gracias a la financiación recibida desde MINECO/FEDER a través del proyecto de Evolución de programas y evaluación de aprendizajes en los ámbitos no formal e informal de la Educación Patrimonial (EDU2015-65716-C2-2-R)

Revista: Revista interuniversitaria de Formación del Profesorado (RIFOP) ISSN 0213-8646 | E-ISSN 2530-3791

The Revista interuniversitaria de Formación del Profesorado (RIFOP) appears in the following databases, journal evaluation platforms and national and international selective directories.

- Emerging Sources Citation Index (Clarivate Analytics - Web of Science)

- Sello de calidad de la FECYT

- ERIH PLUS

- DOAJ

- EBSCO (Fuente Académica Premier)

- IRESIE

- GOOGLE SCHOLAR (h5 - index 12; h5 median 16).

- CIRC (clasificación B en Sociales y C en Humanas) 
- MIAR (ICDS: 10 puntos)

- Latindex - 35

- DICE

- RESH (Revistas Españolas de Ciencias Sociales y Humanas)

- ISOC (Base de datos bibliográficas del CSIF)

- Dialnet (Cuartil 1 en Dialnet Métricas en el ámbito de Educación 49/225, índice de impacto 0,424$)$.

- REDALyC

- Psicodoc

- REBIUN (Red de Bibliotecas Universitarias)

- In-Recs

- Universia

- DULCINEA

- COPAC

- REDINET

- e-revist@s

Educación $2018 \quad \underline{40 / 222}$

IMPACTO $2018 \underline{0,547}$ 


\section{\#Souvenirs 1936 \\ Transmedia y procesos de identización en el aprendizaje de la Guerra Civil Española}

\section{RESUMEN}

Este artículo presenta el impacto del proyecto \#Souvenirs19361 en el aprendizaje de 107 alumnos de $2^{\circ}$ de Bachillerato del colegio Safa-Grial (Valladolid). El método que se ha utilizado en este trabajo es cualitativo, analizándose el contenido de la información que vierte el alumnado a las RRSS (Twiter, Instagram, YouTube), junto a las autoevaluaciones, coevaluaciones y heteroevaluaciones recogidas sobre las tareas de recreación de escenas de la Guerra Civil y la investigación de los sucesos en la ciudad en que viven y les identifica. Los resultados muestran cómo un proyecto de innovación docente hace que el alumnado sea el centro de su propio aprendizaje, adquiera y desarrolle las competencias propias del último curso de bachillerato, como la digital (cápsulas digitales sobre escenas de guerra y uso de realidad aumentada: Eduloc, Geoaumentaty, códigos QR) o la competencia lingüística para narrar las historias. Esta investigación arroja luz sobre los beneficios de este tipo de acciones pedagógicas basadas en el aprendizaje significativo, al tiempo que impone algunas limitaciones y abre vías para nuevos estudios futuros como el diseño de evaluación de aprendizajes en apps de realidad aumentada o la evolución de los resultados de un proyecto estable en diferentes generaciones de alumnos.

PALABRAS CLAVE: Narrativa; Transmedia; Educación Patrimonial; Identización. 


\title{
\# Souvenirs1936
}

\section{Transmedia and identity processes in the Spanish Civil War learning}

\begin{abstract}
This article presents the impact of the project \#Souvenirs1936 in the learning of 107 students of the 2nd year of the Baccalaureate of the Safa-Grial school (Valladolid). The research methodology used has been the qualitative modality, analyzing the content of the information that students have in the social networks (Twiter, Instagram, YouTube), together with the self-evaluations, coevaluations and hetero-evaluations collected on the tasks of recreation of scenes from the Civil War and everything that happens in the city in which they live and identifies them. The results show how a teacher innovation project promotes that students are the center of their own learning, acquire and develop the skills of the last year of high school, especially digital (digital capsules on scenes of war and use of augmented reality: Eduloc, Geoaumentaty, QR codes) or the linguistic competence to tell the stories. This research sheds light on the benefits of this type of pedagogical actions based on meaningful learning, while it imposing some limitations and opens avenues for future studies such as the design of appraisal appraisals in augmented reality apps, or the evolution of the results of a stable project in different generations of students from the same center and even from different centers.
\end{abstract}

KEYWORDS: Narrative; Transmedia; Heritage Education; Identity. 


\section{Introducción}

El aprendizaje basado en proyectos (ABP) va camino de imponerse como una de las metodologías preferidas para favorecer la consecución de los objetivos en las diferentes etapas educativas, incluso en ámbitos tan diversos como el formal e informal. Además, resulta especialmente interesante para desarrollar en el aula el área de las Ciencias Sociales mediante proyectos de carácter transdisciplinar, en los que la verdad revelada de los conocimientos y competencias requeridas se puede obtener empleando diferentes mecanismos, a su vez afines a otras áreas.

La rápida evolución y disponibilidad de las tecnologías de la información y la comunicación (TIC) y su sencilla aplicación al ABP conceden una gran versatilidad a los proyectos educativos, pues permiten favorecer la utilización de las metodologías de investigación basada en las artes y los procesos de identización para la obtención de los resultados.

Dado que el proyecto \#Souvenirs1936 integra todos estos aspectos en su desarrollo, nos parece que se trata de un buen ítem de estudio para deducir algunas conclusiones en torno a cómo responden los estudiantes ante el uso de las herramientas transmedia, el modo en que se asocian con actividades propuestas en clave identitaria y cómo afrontan la construcción colectiva del conocimiento. El proyecto \#Souvenirs1936

\#Souvenirs1936 es un proyecto educativo en el que los alumnos de $2^{\circ}$ de Bachillerato del Colegio Safa-Grial (Valladolid) estudian la historia de la Guerra Civil Española, desde la supuesta construcción de los recuerdos de aquellos que participaron en ella. Su origen se encuentra en la necesidad de encontrar otro modo de abordar la reflexión, en clave educativa, sobre acontecimientos históricos muy relevantes, huyendo desde el libro de texto hacia los materiales didácticos alternativos y autoproducidos, tanto como hacia la construcción colectiva del conocimiento.

Existió un proyecto previo que abordó la Segunda Guerra Mundial (De Castro, 2016, p. 497-498) el cual evolucionó hacia el proyecto definitivo sobre el periodo bélico acaecido en España entre 1936 y 1939.

El conflicto reúne gran atención en los programas educativos, como prueba el hecho de que se refieran a él una buena cantidad de los contenidos, criterios de evaluación y estándares de aprendizaje evaluables del programa de la materia de Historia de España de segundo de Bachillerato (BOCyL 6/2013). En concreto, el bloque 10 lleva por título 
La Segunda República. La Guerra Civil en un contexto de Crisis Internacional (19311939) (RD 1105/2014, 2015, p. 326).

El trabajo en \#Souvenirs1936 comienza con una aproximación a los contenidos curriculares mediante la lectura de apuntes y la elaboración de mapas mentales, que permiten una primera percepción del contexto y los más importantes acontecimientos de la guerra. Luego, el proyecto emplea procesos de patrimonialización para que los participantes se identifiquen con el objeto de estudio, al establecer una relación entre aquellos y los bienes patrimoniales "en términos de conformación de la identidad, propiedad, pertenencia, emoción.” (Calaf y Fontal, 2010, p. 14).

Muchas de las actividades apuestan por la inmersión del alumnado en aquello que está estudiando, mediante procesos de apropiación simbólica (Gómez Redondo, 2013, p. 290) que permiten conceptualizar los contenidos del currículo en una serie de materiales fotográficos e instalaciones artísticas que, concebidas como cápsulas del tiempo, simulan auténticos testimonios de la época.

En cada supuesto depósito creado sobre un escenario bélico, la identización legitima la antigüedad de los objetos que -rescatados del desván de los abuelos, de la vitrina del salón o creados ex profeso- encuentran su respaldo en relatos, cartas de una correspondencia o cuadernos de diario, también ficticios (storytelling).

Este planteamiento permite entender \#Souvenirs1936 dentro de un modelo simbólicosocial de educación patrimonial, que reconoce "la importancia del patrimonio cultural en la construcción de procesos simbólicos que contribuyen a configurar nuestra identidad" y se sirve del "valor simbólico o asociativo del patrimonio como vehículo para la transmisión de valores culturales, territoriales e identitarios" (Fontal, 2003,147). Esta línea también se apoya en el aprendizaje significativo y por descubrimiento desarrollando las competencias perceptiva, interpretativa y representativa, según propone Sánchez (2012, p. 81-82), lo que refuerza esa sensación de paternidad respecto al proceso de trabajo e investigación y mejora los procesos de patrimonialización. Esta cápsula del tiempo, además de introducir la investigación con metodologías artísticas (Marín, 2005) sirvió de coartada para asignar a los estudiantes el papel de investigador/conservador de museo pues, tras conceptualizar su investigación sobre la guerra en estas instalaciones, luego las diseccionaban, una a una, a través de unas fichas de catalogación inspiradas en aquellas con que se procesan los materiales arqueológicos. 
Así, van cobrando cada vez más importancia las metodologías artísticas, relevantes tanto para canalizar las inquietudes derivadas de los procesos de apropiación simbólica como para que la investigación basada en las artes enriquezca el plano de conocimiento, ya de los participantes en la experiencia -estudiantes y docentes- ya de la propia investigacióneducativa (Eisner, 1998).

Tras construir subjetivamente las diversas narrativas, cada grupo abordó la contextualización gráfica y sonora de estos episodios. Por un lado, aireando los baúles de los desvanes familiares, construyeron sus propias imágenes de la guerra mediante fotografías en las que se caracterizaron como los ficticios personajes de su relato, los protagonistas históricos de la guerra o replicaron las más famosas instantáneas tomadas por los reporteros que la cubrieron para las agencias internacionales. Por otra parte, con el fin de llegar a una percepción más profunda de la guerra, pero también con el ánimo de construir su conocimiento colectivo a partir de las fuentes audiovisuales, se propuso la creación de películas documentales. La primera narraría cada batalla asignada a partir de fotografías originales del conflicto, unos breves subtítulos informativos y una música de la época que la contextualizaba sonoramente. La segunda, un documental a partir de testimonios obtenidos mediante entrevistas informales realizadas a sus abuelos o a los informantes que interrogaron en centros para la tercera edad. Solo unos pocos de estos testimonios transmitieron datos de primera mano - por cronología, ya resulta difícil encontrar gente que viviera la guerra-, casi todos hablaron a partir de los recuerdos transmitidos dentro de sus familias. En definitiva, \#Souvenirs1936 adquirió la forma de lo que Marín (2005), define como “investigación basada en las artes visuales" (Arts Based Visual Research) o "arteinvestigación educativa", una metodología artística de investigación que utiliza un conjunto de imágenes para analizar un problema social existente en profundidad, resolver alguno de los problemas educativos de hoy en día o señalar otros nuevos que hayan pasado desapercibidos, en especial los referidos a los procesos de enseñanzaaprendizaje en contextos escolares y/o sociales. Estas metodologías aprovechan los conocimientos profesionales de las diferentes especialidades artísticas (arquitectura, cine, dibujo, danza, música, novela, performance, (representación), poesía, teatro, vídeo, etcétera), tanto para el planteamiento y definición de los problemas como para la demostración de las conclusiones y la presentación de los resultados finales. (...) son una nueva forma de hacer investigación en ciencias humanas 
y sociales que trabajan de forma paralela y semejante a la creación artística. (Marín, 2011, p.16).

En una fase posterior, el proyecto se enriqueció al abordar el estudio de los episodios de la Guerra Civil acaecidos en la ciudad de Valladolid, mediante la creación de itinerarios y píldoras audiovisuales.

\section{Transmedia en \#Souvenirs1936}

\#Souvenirs1936 también abordó la difusión de los resultados apoyándose en códigos QR (Coma, 2013), apps (Salles, 2013) y las RRSS utilizadas por los propios alumnos. Así, en la línea de Cabero (2015, p. 23), el proyecto le concede gran importancia al empleo de las tecnologías para el empoderamiento y la participación (TEP) y coincide con su recomendación de futuro para la utilización de las tecnologías en el ámbito educativo: comunicación, conocimiento y participación. En la línea de Sasson (2006), a través de Oliva-Gimeno y Torres-Mendoza (2017), al hablar de la revolución digital, compartimos que la educación no puede ni debe renunciar a esta y debe dejar oír su voz (p. 23).

Las colecciones de caracterizaciones fotográficas se canalizaron a través de Instagram, fundamentalmente, y Twitter, en menor medida. Instagram es la red social preferida por los adolescentes, pues posibilita publicar fotos, vídeos y texto, muy por encima de los 280 caracteres que permite Twitter.

En coincidencia con Moreno (2015), el proyecto, para conseguir una narrativa adecuada, se beneficia la versatilidad de lo transmedia que "utiliza la sede física, la sede virtual, la sede virtual en movilidad y otros recursos digitales y analógicos, como las publicaciones en papel, para aumentar el conocimiento y hacerlo accesible a todas las personas" (p.89).

El diseño previo de las etiquetas (\#hashtag) que acompañaban a cada publicación no solo permitió identificar el trabajo de cada grupo, también lanzaba al ciberespacio atajos de búsqueda sobre el tema de trabajo y planteaba una ruta de acceso al docente para seguir las aportaciones de cara a su evaluación.

El proyecto también usó apps para la construcción de los conocimientos. Instagram, Twitter y YouTube alojaron los contenidos y canalizaron la difusión de sus trabajos que, realizados mediante la metodología de investigación basada en las artes, construyeron recuerdos al tiempo que los convertían en su 
patrimonio. Un patrimonio que, además, sería compartido con sus compañeros realizando una exposición en el colegio y que utilizaba códigos QR para dar acceso in situ al material audiovisual.

Una vez concluida su investigación sobre los escenarios paradigmáticos de la guerra, se abordó el desarrollo de estos acontecimientos en su propia ciudad. El discurso se elaboró desde la concepción de una colección de materiales audiovisuales, textos informativos e itinerarios interpretativos creados estableciendo puntos de interés en el mapa urbano (Grevtsova, 2013). Soportada por aplicaciones para dispositivos móviles, esta información ha permitido dar a conocer los principales episodios y escenarios del enfrentamiento en Valladolid, sirviéndose del geoposicionamiento del terminal para diseñar rutas, en Eduloc (Guevara y Colomer, 2017), e implementar contenidos en el plano urbano usando realidad aumentada, con GeoAumentaty. Se trataba de que visitaran el lugar exacto, pero también de dotar a su acción del sentido de utilizar la educación patrimonial para la formación de ciudadanos críticos (Lucas y Estepa, 2016; Lucas y De Alba, 2017).

Resulta significativo que, además, los alumnos participantes se vieran inmersos en una evolución de la gestión de su propio proceso de aprendizaje, pues experimentaron el paso de ser consumidores pasivos de información y recursos a ser creadores de contenidos y materiales diversos (Schaffert y Hilzensauer, 2008). Desde su relación con la tecnología y, muy especialmente, con la tecnología como medio y fin para construir aprendizajes polifónicos, es fácil concluir con Fernández (2010), citado por Villamizar (2018, p.7), que "los jóvenes de ahora forman parte de una generación transmedia que ha sustituido el bolígrafo por la cámara de vídeo y que imita creaciones ya existentes para contar su propia historia, lo cual implica también capacidad autodidacta."

\section{La evaluación de aprendizajes en \#Souvenirs1936}

Otro de los tópicos importantes en nuestro estudio es la evaluación de los aprendizajes y su comprensión. La concepción de la evaluación de aprendizajes se ha visto afectada por numerosas aproximaciones teóricas provenientes de campos diversos, este es el caso de: a) las teorías sobre la empleabilidad del educando (Formichella y London, 2005); b) los avances de la Pedagogía contemporánea hacia modelos participativos; c) la incorporación de las TIC (Mishra y Koehler, 2006); d) las aportaciones de la evaluación ecológica (Tikunoff, 1979) y, finalmente, e) las aportaciones de la evaluación interdisciplinar (Legrand,1970). 
Dentro del aprendizaje situado (Lave y Wenger, 1991) en un contexto, en su versión moderna sobre la evaluación, destaca la escuela Assessment for Learning (AFL). Por su parte, desde la escuela francófona, con Perrenaud (2009) a la cabeza, se destaca el concepto de contrato didáctico, en el que cada parte educativa (profesor y alumnos) pacta, según sus expectativas y objetivos, el desarrollo de los aprendizajes. Se percibe así la evaluación como una regulación constante influenciada por los intereses particulares que aporta cada alumno a la misma y entiende, por tanto, la evaluación como un hecho contextual, valorando los procesos por encima de los logros, y planteando diversos instrumentos de evaluación y de diálogo.

La cosmovisión de la educación de los autores de esta investigación se enmarca dentro de un modelo constructivista, moldeado por autores clásicos como Piaget y Vigotsky (1978), los psicólogos de la Gestalt, Bartlett, Bruner, así como el filósofo de la educación John Dewey. Las ideas de Vigotsky han sido retomadas por varios investigadores contemporáneos que abogan por una reconceptualización transformadora de algunos conceptos sobre la educación y la investigación en educación (Bloom, Harris y Ludlum, 1991; Clay y Cazden, 1990; Goodman y Goodman, 1990; McLane, 1990; Schickedanz, 1999). Hoy no se discute que las posturas constructivistas del aprendizaje tienen implicaciones decisivas para la enseñanza, pues lo equiparan con la creación de significados a partir de experiencias. De este modo, el aprendizaje humano será una actividad que el sujeto realice a través de su experiencia con el entorno. Aunque hay varias interpretaciones de lo que significa la teoría (constructivista), casi todas coinciden en que supone un cambio notable colocar en el centro de la empresa educativa los esfuerzos del estudiante por entender (Woolfolk, 1999; citada por Pimienta, 2007, p. 9).

Por ello, se insiste en la necesidad de plantear problemas retadores desde la actitud de que "profesores y alumnos se asuman epistemológicamente curiosos" (Freire, 1997), que sean identificados en su propio contexto (personal, familiar, comunitario, laboral-profesional, ambiental-ecológico, político, cultural, artístico, etc.) para que, de esta forma, los estudiantes naveguen en un escenario complejo que lleve al análisis, la comprensión y la interacción de variables, tanto como a tener una mayor vinculación con la realidad y a generar el compromiso de perseguir un mundo mejor (Tobón, Pimienta y García, 2010).

En \#Souvenirs1936 la evaluación contó con un amplio desarrollo que estableció diferentes rasgos en función de determinadas características. Así, se planificaron 
diferentes acciones dependiendo de los participantes implicados: autoevaluación (individual), coevaluación (grupal) y heteroevaluación (la efectuada por el profesorado sobre los diferentes resultados del proyecto); también se abordaron diversos modos de evaluación según su funcionalidad: formativa o sumativa; desde el plano temporal se establecieron la evaluación inicial o de diagnóstico y la final; incluso, realizando el análisis desde el punto de vista de su intencionalidad, se establecieron las categorías de promoción, acreditación académica, certificación o mejora de los procesos; además, se diseñó una rúbrica para cada actividad, según los objetivos sobre ella planteados en el proyecto y las competencias implicadas. Todas estas fórmulas le fueron explicadas al alumnado por el profesorado en el momento de echar a andar \#Souvenirs1936 y con motivo de los procesos de evaluación del programa.

Posteriormente, se valoró el conjunto de competencias que cada estudiante demostró en la asignatura de Historia de España durante la clásica evaluación final del curso -en su convocatoria ordinaria- y, para ello, se acudió a las destrezas demostradas durante el desarrollo del proyecto \#Souvenirs1936 por cada estudiante. Así, la competencia de comunicación lingüística se calificó a partir de las narrativas escritas para contextualizar las cápsulas del tiempo; para la competencia matemática y en ciencias y tecnología se valoró su capacidad para entender el complejo sistema de calificación que suponía la heteroevaluación -evaluación de las investigaciones y los materiales finales, de la acción en redes sociales y a través de las aplicaciones de itinerarios y realidad aumentada-; respecto a la competencia digital se valoró la capacidad para divulgar los materiales de su proyecto en RRSS, así como para producir y editar los documentales; se empleó el resultado de su autoevaluación respecto a su intervención en el proyecto para valorar la competencia de aprender a aprender. Paralelamente, de las diferentes rúbricas de coevaluación se extrajo la consideración que cada uno tenía sobre su competencia social y cívica, tanto como aquella acerca de su sentido de iniciativa y espíritu emprendedor; por último, la competencia sobre su conciencia y expresiones culturales se dedujo del trabajo de caracterización fotográfica y la concepción de su cápsula del tiempo. 


\section{Método}

\section{Participantes}

El trabajo de investigación que presentamos tiene como objeto conocer el impacto (a nivel de procesos de identización, evaluación verdadera y trabajo en equipo) que han producido las tecnologías de información y comunicación (TIC) y las transmedia en el aprendizaje de la Guerra Civil Española (1936-1939) a través de \#Souvenirs1936, proyecto de innovación docente aplicado en 107 estudiantes de $2^{\circ}$ de Bachillerato del Colegio Safa- Grial de Valladolid (España).

\section{Instrumento}

Se ha optado por una metodología de carácter cualitativo pues, como menciona Creswell (2013), los investigadores cualitativos aportan a sus estudios, de forma ineludible, su particular manera de entender cómo funcionan las cosas en nuestro mundo y la forma en que se construye el conocimiento (Worldview). En nuestro estudio indagamos en las concepciones y reacciones de los alumnos que cursan la materia de Historia de España en $2^{\circ}$ de bachillerato, en cuanto a la metodología utilizada por el profesor y la orientación que se ha utilizado para evaluar sus aprendizajes. Para todo ello ha sido empleado un análisis del contenido y de los tópicos presentes en las aportaciones de los participantes en el proyecto, que fueron extraídas de varias fuentes: entrevistas semiestructuradas, cuestionarios, aportaciones a través de las RRSS, protocolos de coevaluación y autoevaluación y rúbricas de evaluación ejercitadas sobre las diferentes actividades del proyecto (como los relatos escritos, por ejemplo), que fueron diseñadas para llevar a cabo un estudio sobre las competencias y aprendizajes adquiridos.

La recogida de datos se realizó tanto on-line como en papel. Para facilitar la codificación y categorización de esta información se ha utilizado el software Nudist.vivo 10.

\section{Procedimiento}


El trabajo de campo se ha realizado durante el curso académico 2017-2018, tras obtenerse el correspondiente visto bueno de la dirección del centro educativo, los preceptivos consentimientos del alumnado y la elaboración de un protocolo de entrevista estructurada común.

Los cuestionarios se realizaron al finalizar el proyecto. Las entrevistas fueron parte de las coevaluaciones y autoevaluaciones. Durante el propio proyecto, en la realización de las distintas actividades se recogieron las evaluaciones de las mismas.

El análisis de contenido de las entrevistas, las coevaluaciones y autoevaluaciones está focalizado en unas categorías de análisis en torno a la metodología de trabajo en el aula, definidas con anterioridad: identización, trabajo colaborativo, evaluación de aprendizajes y transmedia (las mismas que vamos a emplear para realizar el análisis en el apartado siguiente).

\section{Análisis y resultados}

Los resultados obtenidos al evaluar las competencias básicas planteadas en el proyecto \#Souvenirs1936, que fueron también trasladados al mecanismo de evaluación habitual en bachillerato, pueden considerarse como bastante buenos, en su conjunto. Todas ellas se encuentran por encima de la valoración de 7 puntos sobre 10, con la única excepción de la puntuación relativa a la competencia digital; es probable que esta baja calificación se deba a la preferencia de los propios participantes hacia Instagram como la red social para divulgar sus proyectos, en vez de duplicar su presencia en las redes a través de un perfil en Twitter, como era requerido -apenas hay publicaciones en esta red-. Cabe destacar las elevadas puntuaciones de su competencia lingüística, derivadas de los relatos y diarios sobre los escenarios de la guerra, que bien podrían venir a complementar aquellas de la competencia sobre conciencia y expresiones culturales. Respecto a los resultados de la vertiente transmedia del proyecto, el hashtag \#Souvenirs1936 en las redes observamos una gran actividad, como se deduce de la interpretación de la Tabla 1.

\section{Tabla 1}

Recuento de publicaciones y visualizaciones en las RRSS 


\section{Análisis de los procesos de identización}

En esta categoría se enmarcan aquellas evidencias recogidas en los cuestionarios, que vamos a ir presentando en función de los diferentes tópicos que destilan. Por ejemplo, algunos de ellos vierten opiniones de las que se sigue una apropiación simbólica de los conceptos del currículo para la transmisión del patrimonio:

"Me ha servido para poder enseñar, por ejemplo, a mi hermano pequeño que cerca de donde vivimos ocurrieron grandes masacres". [Autob.OCRE.D.DMR] ${ }^{10}$

“Algún día compondré una canción sobre lo que vivió mi bisabuelo allí y será apoteósica" [Autob.AZUL.B.STP]

"Puedo hacer un tour especializado de la Guerra Civil en mi ciudad a cualquier visitante que se preste”. [Autob.ROJO.B.MGL]

Por otro lado, las palabras de algunos de los participantes muestran claramente el establecimiento de conexiones identitarias:

"Extender mis conocimientos sobre la ciudad en la que vivo, lo que me ha permitido ver otra cara de su pasado y valorar el carácter de esta localidad con mayor admiración y dentro del respeto por lo que aconteció aquí’. [Autob.OCRE.D.DMR]

"Me ayuda a entender mejor a mi familia". [Autob.VERDE.D.GPP]

Algunas otras opiniones verbalizan características de pertenencia (“...prestarle más atención al corazón de mi ciudad natal". [Autob.MAGEN.B.MCL]) o de propiedad ("Creo fielmente que es una oportunidad de encontrar nuestra propia versión de la Historia para sacar nuestras propias conclusiones". [Autob.MAGEN.B.MCL]).

${ }^{10}$ Se ha optado por sangrar los párrafos que referencian las evidencias de la investigación en aras de una mejor interpretación formal del texto. 
No faltan testimonios que muestran lo emotivo que ha sido para algunos de los estudiantes participar en el desarrollo del proyecto:

"Me ha dado conciencia sobre el sufrimiento de las personas en esta guerra, y me ha ayudado a entender a mis abuelos". [Autob.ROJO.B.MGL]

"El saber agradecer lo que se tiene y conocer lo que pasaron nuestras generaciones anteriores es fundamental para valorar todo aquello que tendremos en un futuro o que tenemos en el presente y no recaer en el error de un conflicto igual" [Autob.OCRE.D.DMR].

\section{Análisis del trabajo colaborativo}

\#Souvenirs1936 es un claro ejemplo de trabajo colaborativo. Además de llevar a cabo las investigaciones grupales sobre las principales batallas del conflicto, también se abrió una línea de responsabilidad común para ofrecer el más completo panorama de la guerra creando vídeos documentales, recuerdos fotográficos fingidos y ajuares supuestamente encontrados que, al final del proceso, serían expuestos en las zonas comunes del colegio.

Los datos que permiten evaluar esta categoría proceden de dos documentos de coevaluación. El primero empleó preguntas, consensuadas entre los participantes, que debían contestarse con cuatro posibles respuestas (1 Nunca, 2 A veces, 3 Mucho, 4 Siempre) para recabar información sobre aspectos relativos al proceder de los estudiantes durante la investigación y el trabajo en colaboración (Tabla 2). Cada una de las cuestiones tenía asignado un valor porcentual en la valoración final. Las calificaciones (8 puntos sobre 10) demuestran que se sintieron cómodos realizando este tipo de trabajo y que su intervención les satisfizo también en lo colectivo.

\section{Tabla 2}

Relación de preguntas que constituían el documento de coevaluación 1 
El segundo documento diseccionó el trabajo de cada participante como miembro del equipo. El 100\% resultaría de sumar las valoraciones de todos los integrantes, sobredimensionando el valor del trabajo de alguno -más allá de lo que sería el reparto equitativo- si fuera preciso y, en consecuencia, penalizando el trabajo de otros. El trabajo colaborativo conlleva ventajas e inconvenientes que se hacen especialmente visibles cuando su resultado va a ser evaluado de manera incisiva. A continuación, se presentan algunas de las impresiones recogidas en los cuestionarios que fluyen en esta línea:

“...no solo cuenta la nota del profesor sobre el proyecto; también es importante saber qué opinan los integrantes del grupo sobre tu participación. Además, la autoevaluación ha servido para recapacitar sobre tu trabajo, lo que has aprendido o lo que te ha costado realizarlo. Todas esas notas (la del profesor, evaluación grupal y la autoevaluación) suman y no se deja de lado ninguna opinión del trabajo realizado”. [Autob.OCRE.D.DMR]

"Me parece que es una buena manera de evaluar nuestro trabajo, tener en cuenta la opinión y referencia de todos los participantes". [CUEST.P6.R39]

Pero también deducen que el trabajo colabarativo permite el desarrollo de otras actitudes en clave positiva:

"Si necesito algo de algún miembro del equipo se lo pediré sin miedo a que me ignore, pues el grupo sirve para ayudarnos mutuamente y levantarnos cuando nos caemos" [Autob.MAGEN.B.MCL]

\section{Análisis de la evaluación de los aprendizajes}

Los resultados unifican las tres formas de evaluación utilizadas: autoevaluación, coevaluación y heteroevaluación -que incluye la valoración de cada actividad del proyecto y las preguntas abiertas incluidas en los exámenes trimestrales-. 
Del estudio de los cuestionarios se concluye que buena parte del alumnado se vio constantemente sorprendido por la metodología de trabajo propuesta ("es un método diferente que nunca había realizado y está bien que tenga diferentes partes y métodos de evaluación”. [CUEST.P9.R19]) y que valoran como oportuno el modo en que se han evaluado sus aprendizajes:

“Los porcentajes están bien repartidos”. [CUEST. P6.R18]

"Me ha parecido que la forma de evaluar es la más justa que se puede hacer". [CUEST.P6.R40]

“Los criterios eran claros y justos”. [CUEST.P6.R39]

Aunque no tienen muy claras las diferencias entre evaluar y calificar - quizá por la confusión producida en la práctica real sobre pretender una evaluación verdadera y conformarse con una calificación propia del bachillerato- son conscientes de que una evaluación de estas características forma parte de sus aprendizajes; de hecho, así lo verbalizaron en sus formularios:

“Calificar me resulta más frívolo, teniendo en cuenta únicamente valores cuantificables. Pero evaluar creo que es más justo, pues no tiene en cuenta solo los resultados, sino el proceso de aprendizaje, y los valores no cuantificables, como nuestro punto de vista y el buen o mal trabajo en equipo". [CUEST.P7.R23]

“No sé cuál es la diferencia”. [CUEST.P7.R54, R70]

“La evaluación concretamente es la mejor parte del trabajo". [CUEST.P7.R35]

Incluso cuando se les preguntó sobre si el método de evaluación utilizado favorecía su aprendizaje, los resultados arrojaron una percepción afirmativa en un 90,7\% de los entrevistados, contándose entre los argumentos más notables los siguientes: 
"Porque viendo la utilidad futura de cada cosa que hemos hecho podemos aplicarla a diferentes campos y así terminar por aprender lo que estemos haciendo".

[CUEST.P9.R12]

"Es un buen método para evaluar no solo la capacidad de memoria del alumnado sino también la capacidad de cada alumno para poder entender la Historia de otra forma". [CUEST.P9.R15]

Por otro lado, destacamos el hecho de que, trabajando por proyectos, en especial mediante metodologías alternativas (artísticas, transmedia...), los participantes se sienten protagonistas del propio proceso de aprendizaje. Sus palabras son también elocuentes en este sentido:

"Porque es una manera de prepararnos un determinado tema de forma diferente. Nosotros somos nuestros propios profesores y los implicados en abastecernos de suficiente información para completar todo con éxito". [CUEST.P9.R20]

"Porque investigas, y no es solo coger un libro o apuntes y estudiártelo todo de memoria, sino que te ayuda a entender un montón de aspectos que hasta el momento ni siquiera conocías”. [CUEST.P9.R65]

Su respuesta sobre si les gustaría que esta forma de evaluar fuese extensible a otras asignaturas, 76 de los 107 contestaron con un sí rotundo.

Finalmente, para cerrar este tránsito por la evaluación de sus aprendizajes, conviene señalar que su análisis también propone cambios sobre el modo de implementar el proyecto, casi siempre relacionados con la carga de trabajo y el escaso tiempo del que dicen disponer para las tareas de que se compone. Estas son algunas de esas opiniones:

"Es un trabajo un poco largo y costoso y yo creo que cambiaría el hacerlo en $2^{\circ}$ de Bachillerato porque casi no hay tiempo para esto". [CUEST.P11.R20]

"No creo que se debería hacer un proyecto de este calibre en segundo de bachillerato debido a todo lo que tenemos que hacer y al poco tiempo. Desde mi punto de vista, se 
debería hacer en primero (donde también deberíamos cursar Historia)”.

[CUEST.P11.R65]

\section{Análisis en torno al transmedia en \#Souvenirs 1936}

Esta parte del análisis arranca de que los participantes pertenecen a una población nativa en la cultura digital y con un sorprendente escaso dominio de algunas aplicaciones de las empleadas en \#Souvenirs1936 o de ciertos procesos de trabajo con RRSS, como recogen algunas de sus opiniones:

"Hay partes bastante complicadas como la de los vídeos o las aplicaciones de Eduloc y Geoaumentaty". [CUEST.P11.R51]

"En clase trabajamos con el tarro y los objetos realizando fotos para clasificarlos. Aprendimos tanto a emplear la iluminación y las sombras como a enfocar con cámara y ver una realidad desde varios ángulos para elegir la mejor. Nos caracterizamos de la batalla con objetos que teníamos en casa o habíamos comprado/fabricado. Aprendimos a usar el croma y nos caracterizamos según las imágenes del pasado, representando sentimientos y situaciones que invadían ese tiempo y lugar. En casa editamos las fotos y las subimos a nuestra cuenta de Instagram".

[Autob.OCRE.D.DMR]

“Aprendí a hacer difusión en WhatsApp para que todo el mundo viera nuestro trabajo y, ahora que estoy participando en un concurso que requiere votos, se lo estoy mandando a todo el mundo y voy súper bien". [Autob.AMARI.B.STP]

En sus evaluaciones muestran capacidad para criticar la versatilidad de las apps utilizadas, sus inconvenientes...

"Lo de Geoaumentaty y Eduloc son aplicaciones que todavía les falta algo para mejorar". [CUEST.P11.R24]

\section{Discusión y conclusiones}


A lo largo de la presente investigación, hemos descubierto el positivo impacto educativo de un proyecto de innovación en educación patrimonial que utiliza las RRSS para investigar, participar y transmitir; incluso el alumnado se vio sorprendido por una metodología innovadora que impactó en su manera de aprender rompiendo la rutina de enseñanza-aprendizaje basada en la memorización.

Si García-Valcárcel, Basilotta y López (2013), en su estudio relativo al empleo de las TIC en el aprendizaje colaborativo en la enseñanza Primaria y Secundaria de Castilla y León, especificaban que:

en cuanto a las principales limitaciones para implementar en el aula metodologías de aprendizaje colaborativo, se han señalado algunas cuestiones que tienen implicación en el desarrollo del currículo como el empleo de más tiempo, una cierta pérdida de control, la diferente implicación de los estudiantes o las dificultades para evaluar el proceso de aprendizaje y los resultados obtenidos por cada alumno (p.72).

En nuestro estudio sobre \#Souvenirs 1936 hemos podido verificar algunos de estos aspectos y cuestionar otros.

Resulta innegable que se necesita más tiempo del que dispone el alumnado en el curso escolar para tareas de mucha envergadura -el actual ecosistema (escolar, familiar y social) de bachillerato no parece preocuparse tanto por los aprendizajes adquiridos como por la nota de corte o la memorización de cara a una prueba externa que no contempla este tipo de planteamientos educativos en su resolución-. En cambio, no se ha percibido sensación de pérdida de control en ningún momento y se ha constatado un elevado grado de implicación en el trabajo grupal.

Está claro que la evaluación de aprendizajes es una tarea ardua que pocos profesores son conscientes de llevar a cabo adecuadamente en sus aulas. En \#Souvenirs1936 se ha conseguido realizar con éxito mediante esa concepción constructivista que fija el centro de interés en el educando.

Por otro lado, el aprendizaje colaborativo ha sido otro aspecto relevante del proyecto. La narración que ellos han realizado usando RRSS ha supuesto que terceros hayan explicado sus propias experiencias espontáneamente, favoreciendo un aprendizaje en comunidad y una transferencia de conocimiento a la sociedad que enriquece más el proyecto. 
El programa desvela también limitaciones pues, en futuras implementaciones habría que rediseñar cómo evaluar la interacción con GeoAumentaty y Eduloc. Se ha comprobado que emplear ambas aplicaciones resulta redundante pues ofrecen soluciones similares. Esta duplicidad tampoco garantiza la visibilidad en red de los contenidos a través de alguna de ellas, pues a la propia inestabilidad de Eduloc -que dificulta el uso de sus prestaciones para diseñar itinerarios y juegos de pistas durante su utilización- hay que añadir que GeoAumentaty -también inestable- incrementa las posibilidades de difusión de la información recabada empleando un formato tan atractivo para los estudiantes como es la realidad aumentada.

A modo de prospectiva, una posible investigación futura podría ir en la línea de indagar sobre las diferencias existentes en la adquisición y desarrollo de competencias de distintas generaciones a lo largo del tiempo, tomando como piedra angular del estudio el mismo proyecto educativo \#Souvenirs 1936, en este caso-, lo que también permitiría comprobar los diversos ritmos presentes en el avance de las TIC y en la pedagogía imperante.

\section{Referencias}

Bloom, D.; Harris O.L. y Ludlum D.E. (1990). Reading and writing as sociocultural activities. Topics in Language Disorders, 11(3), 14-27.

Cabero, J. (2015). Reflexiones educativas sobre las tecnologías de la información y la comunicación (TIC). Tecnología, ciencia y educación, 1, 19-27.

Calaf, R. y Fontal, O. (2010). Cómo enseñar arte en la escuela. Madrid: Síntesis.

Clay, M.M. y Cazden C.B. (1990). A Vygotskian interpretation of reading recovery. En L.C. Moll (ed.), Vigotsky and education. New York, Cambridge University Press.

Coma, L. (2013). Dinamizar y digitalizar la ciudad: itinerarios urbanos, dispositivos móviles y códigos QR. Hermus, (2), 63-68.

Creswell, J.W. (2013). Research design: Qualitative, quantitative, and mixed methods approaches. Sage publications.

De Castro Martín, P. (2016). Cartografía autoetnográfica de una genealogía de programas de educación patrimonial desde la perspectiva del aprendizaje basado 
en proyectos y la investigación acción. (Tesis doctoral inédita). Universidad de Valladolid.

Decreto 52/2007, de 17 de mayo, por el que se establece el currículo de la Educación Secundaria Obligatoria en la Comunidad de Castilla y León.

Decreto 6/2013, de 31 de enero, por el que se modifica el Decreto 40/2007, de 3 de mayo, por el que se establece el currículo de la Educación Primaria en la Comunidad de Castilla y León y el Decreto 52/2007, de17 de mayo, por el que se establece el currículo de la Educación Secundaria Obligatoria en la Comunidad de Castilla y León.

Eisner, E. (1998). El ojo ilustrado. Indagación cualitativa y mejora de la práctica educativa. Barcelona: Paidós.

Fontal, O. (2003). La educación patrimonial: teoría y práctica para el aula, el museo e Internet. Gijón: Trea.

Fontal, O. (coord.) (2013). La educación patrimonial. Del patrimonio a las personas. Gijón: Trea.

Fontal, O. (2013). Estirando hasta dar vuelta al concepto de patrimonio. En Fontal, O. (coord.). La educación patrimonial. Del patrimonio a las personas. Gijón: Trea. 9-22.

Formichella, M.M. y London, S. (2005). Reflexiones acerca de la noción de empleabilidad. Argentina: Consejo Nacional de Investigaciones Científicas y Técnicas. Recuperado el 18/11/2018 de: http://www.aaep.org.ar/espa/anales/works05/formichella_london.pd f.

García-Valcárcel, A., Basilotta, V., y López, C. (2014). Las TIC en el aprendizaje colaborativo en el aula de Primaria y Secundaria. Comunicar, 21(42), 65-74.

Gómez, M.C. (2013). Procesos de patrimonialización en el arte contemporáneo: diseño de un artefacto educativo para la identización. Tesis doctoral inédita. Universidad de Valladolid.

Goodman, Y.M. y Goodman, K.S. (1990). Vigotsky in a whole language perspective. En L.C. Moll (ed.), Vigotsky and education. New York, Cambridge University Press.

Guevara, J.M. y Colomer, J.C. (2017), Minecraft y Eduloc, en historia y geografía. Íber, $86,16-23$.

Grevtsova, I. (2013). El patrimonio urbano al alcance de la mano: arquitectura, urbanismo y apps. Hermus, 2, 36-43. 
Lave, J. y Wenger, E. (1991). Situated learning: Legitimate peripheral participation. Cambridge university press.

Legrand, J. (1970). Guía del trabajo cotidiano en el aula. Buenos Aires: Kapelusz. Ley Orgánica 8/2013, de 9 de diciembre, para la mejora de la calidad educativa. LOMCE. «BOE» núm. 295, de 10 de diciembre de 2013 Referencia: BOE-A2013-12886

Lucas, L. y Estepa, J. (2016). Identidad, valores cívicos y participación ciudadana en la didáctica del patrimonio. Aprendizaje y enseñanza. En Molina-Puche, S., Escribano-Miralles, A. y Díaz-Serrano, J. (eds). Patrimonio, identidad y ciudadanía en la enseñanza de las Ciencias Sociales. Murcia. Universidad de Murcia, 89-100.

Lucas, L. y De Alba, N. (2017) Educación patrimonial para formar ciudadanos críticos. Íber, 89, 26-31.

Marín, R. (Ed.) (2005). Investigación en Educación Artística: Temas, métodos y técnicas de indagación sobre el aprendizaje y la enseñanza de las artes y culturas visuales. Granada: Universidad de Granada y Universidad de Sevilla.

Marín, R. (2011). Las Metodologías Artísticas de Investigación y la Investigación Educativa Basada en las Artes Visuales (sobre el paisaje de la Depresión Cuadrada de Bruce Nauman). En Roldán, J. y Marín Viadel, R. (Eds.) (2011). Metodologías artísticas de investigación en educación (14-39). Málaga: Ediciones Aljibe.

McLane, J.B. (1990). Writing as a social process. En L.C. Moll (Ed.), Vigotsky and education. New York, Cambridge University Press.

Mishra, P. y Koehler, M.J. (2006). Technological pedagogical con- tent knowledge: A framework for teacher knowledge. Teachers College Record, 108(6), 10171054.

Moreno, I. (2015). Interactividad, interacción y accesibilidad en el museo transmedia. Zer-Revista de Estudios de Comunicación, 20(38) 87-107.

Oliva-Gimeno, M., Torres-Mendoza, M. (2017). La comunicación transmedia en las ciudades: disfrutar y educar. Comhumanitas: Revista Científica de Comunicación, 8(2), 33-49.

Perrenoud, Ph. (2009). Enfoque por competencias, ¿una respuesta al fracaso escolar? Revista Interuniversitaria de Pedagogía Social, 16, 45- 64. 
Real Decreto 1105/2014, de 26 de diciembre, por el que se establece el currículo básico de la Educación Secundaria Obligatoria y del Bachillerato.

Salles, N. (2013). Las apps y el aprendizaje del patrimonio basado en la indagación. Hermus, 2, 92-98.

Sánchez, M. (2012) El patrimonio urbano como recurso para desmontar estereotipos históricos. El modelo del Real Sitio de San Lorenzo. Íber, 70, 79-86.

Schaffert, S., y Hilzensauer, W. (2008). On the way towards Personal Learning Environments: Seven crucial aspects. Elearning papers, 9, 1- 10.

Schickedanz, J.A. (1999). More than the ABC's: The early stages of reading and writing. NAEYC, Washington D.C.

Tikunoff, W.J. y Griffin, G.A. (1979). Interactive research and development on teaching study: Final report. The Laboratory. Far West Laboratory for Educational Research and Development. USA.

Tobón, S., Pimienta, J. y García, J. (2010). Secuencias didácticas: Aprendizajes y evaluación de competencias. México: Pearson Educación.

Vigotsky, L.S. (1978) Mind in society. Cambridge, MA: Harvard University Press.

Villamizar, L. (2018). Estado del arte sobre la utilización de transmedia para el desarrollo de recursos educativos. (Trabajo de Grado). Universidad Nacional Abierta y a Distancia. Bogotá: UNAD. 
Artículo 3: La evaluación de Aprendizajes: una práctica pendiente en Educación Patrimonial

\section{Datos de contacto:}

Inmaculada Sánchez-Macías

Universidad de Valladolid

inmaculada.sanchez.macias@uva.es

Olaia Fontal Merillas

Universidad de Valladolid

olaia.fontal@uva.es

Jairo Rodríguez-Medina

Universidad de Valladolid

Jairo.rodriguez.medina@uva.es

\section{Revista:}

ISSN 0213-8646 | E-ISSN 2530-3791

Revista: Revista interuniversitaria de Formación del Profesorado (RIFOP) ISSN 0213-8646 | E-ISSN 2530-3791

The Revista interuniversitaria de Formación del Profesorado (RIFOP) appears in the following databases, journal evaluation platforms and national and international selective directories.

- Emerging Sources Citation Index (Clarivate Analytics - Web of Science)

- Sello de calidad de la FECYT

- ERIH PLUS

- DOAJ

- EBSCO (Fuente Académica Premier) 


\section{- IRESIE}

- GOOGLE SCHOLAR (h5 - index 12; h5 median 16).

- CIRC (clasificación B en Sociales y C en Humanas)

- MIAR (ICDS: 10 puntos)

- Latindex - 35

- DICE

- RESH (Revistas Españolas de Ciencias Sociales y Humanas)

- ISOC (Base de datos bibliográficas del CSIF)

- Dialnet (Cuartil 1 en Dialnet Métricas en el ámbito de Educación 49/225, índice de impacto 0,424$)$.

- REDALyC

- Psicodoc

- REBIUN (Red de Bibliotecas Universitarias)

- In-Recs

- Universia

- DULCINEA

- COPAC

- REDINET

-e-revist@s

Educación $2018 \quad \underline{40 / 222}$

IMPACTO $2018 \quad \underline{0,547}$ 


\section{La evaluación de Aprendizajes: una práctica pendiente en Educación Patrimonial}

\section{RESUMEN}

En este artículo se presenta un estudio de Mixed-Metodology centrado en analizar cuáles son los mejores programas patrimoniales en cuanto a su diseño y la evaluación de aprendizajes que proponen y, por otro lado, si ésta, en Educación Patrimonial de Secundaria y Bachillerato, refleja las directrices curriculares para la evaluación de aprendizajes en el área. Es un estudio mixto anidado, en el que se analiza la validez de criterio de 17 jueces que han evaluado programas de educación patrimonial de Secundaria y Bachillerato, en el campo de la evaluación de los aprendizajes. Los programas mejor valorados forman parte del estudio de caso sobre la comprensión de la evaluación de lo patrimonial en estas etapas educativas, inscrito en la comunidad de Castilla y León.

El trabajo realizado nos aporta conocimiento sobre multitud de aspectos: se destaca la formación de profesorado poco especializada en la materia y de interés personal, el uso de prácticas evaluativas autoaprendidas, al margen de las directrices curriculares, ya que la normativa plantea intencionalidad teórica pero poco prácticas, o la praxis educativa que se sustenta en relacionar las asignaturas y encontrar métodos de microevaluaciones individualizadas, que orienten al profesorado sobre dónde ubicar al aprendizaje relacionado con el patrimonio.

Palabras clave: educación patrimonial; evaluación de aprendizajes; evaluación de programas; metodología mixta

\section{The Assessment: a pending subject in Heritage Education}

\section{ABSTRACT}

This article presents a Mixed-Methodology study focused on analyzing which are the best Heritage programs in terms of their design and the assessment they propose and, on the other hand, if this, in Heritage Education of high school and prior to university, reflects the curricular guidelines for the assessment in the area. It is a nested mixed 
study, in which the criterion validity of 17 judges who have evaluated Heritage Education programs of high school and prior to university, in the field of assessment is analyzed. The best rated programs are part of the case study on the understanding of the Heritage Evaluation in these educational stages, registered in the community of Castilla y León.

The work carried out provides us with knowledge on a multitude of aspects: it highlights the training of faculty not very specialized in the subject and of personal interest, the use of self-appraised appraisal practices, outside the curricular guidelines, since the norm raises theoretical intentionality but little practices, or the educational praxis that is based on relating the subjects and finding methods of individualized micro-assessment, that guide the teaching staff on where to locate the learning related to the Heritage.

KEYWORDS: Assessment; Evaluation; Heritage Education; Mixed Methodology

\section{Introducción}

El presente trabajo aporta luz, por un lado, sobre el panorama actual en el campo de la evaluación de programas, concretamente los diseñados para la educación patrimonial en el ámbito formal, tanto en los niveles de Educación Secundaria Obligatoria, como en Bachillerato. Y, por otro lado, sobre la evaluación de aprendizajes, que subyace de esos programas referentes. Por tanto, destacamos tres tópicos o temas que sustentan este estudio: educación patrimonial, evaluación de programas y evaluación de aprendizajes.

\section{Educación patrimonial}

Esta parcela de la educación que se encarga de enseñar qué es el patrimonio, es un campo que en los últimos años ha sufrido un gran impulso a nivel nacional, derivado principalmente de las investigaciones, llevadas a cabo desde varias Universidades españolas. El concepto de patrimonio posee tintes de gran diversidad de colores y matices, según desde el ámbito que se defina. Por ejemplo, desde el punto de vista de la Política o normativa vigente, el patrimonio es lo que las leyes decreten a nivel internacional, nacional o autonómico; o desde ópticas de la Historia, el patrimonio va dejando huella con el paso del tiempo a través del legado monumental, artístico y 
arquitectónico; o desde otros campos, como la Economía, se le da importancia al valor económico del patrimonio (Fontal, 2016); o según la Antropología, el patrimonio tiene que ver con la cultura y con la naturaleza (Zamora, 2011).

Es un concepto en constante redefinición, cambiante con las sociedades y sujeto a las leyes propias de la globalización. Su definición ha sufrido cambios también en nuestro país, parejos a las grandes convenciones internacionales, en el seno de la Organización de las Naciones Unidas para la Educación, la Ciencia y la Cultura, (UNESCO, 1972). Es una organización que se ocupa de la educación patrimonial, entre otros asuntos, a nivel internacional.

Desde la perspectiva del presente estudio, se aborda el patrimonio como un constructo sistémico, integrador y complejo, con manifestaciones de carácter histórico, artístico, etnológico, científico-tecnológico y natural (Estepa y Cuenca, 2006), pero que da importancia principalmente a las personas, -pues sin personas no existe el patrimonio (Fontal, 2003, 2013)- y a procesos de apropiación simbólica del objeto patrimonial y de identización (Gómez 2011, 2012).

El estudio y la investigación en el campo de la Educación Patrimonial a nivel nacional, viene de la mano de instituciones como el Instituto del Patrimonio Cultural de España (IPCE), con el Plan Nacional de Educación y Patrimonio, y desde la universidad, a través de proyectos de Investigación, Desarrollo e Innovación, como el Observatorio de Educación Patrimonial en España (OEPE).

Y en un nivel autonómico, de la comunidad de Castilla y León, hay varias instituciones que están implicadas en todo aquello que concierne a la educación en patrimonio, como la Fundación Santa María la Real del Patrimonio Histórico, Fundación Villalar, Fundación las Médulas o la Fundación de Patrimonio Natural de Castilla y León, entre otras.

Además, se pueden mencionar acciones que se concretan de las propuestas del Plan Nacional de Educación y Patrimonio en la comunidad, como cursos o congresos internacionales: bienal de ARPA o las jornadas de Gestión de emergencias del Patrimonio de Castilla y León.

El Plan PAHIS del Patrimonio Cultural de Castilla y León 2020 se complementa con otros planes sectoriales paralelos como el Plan Jacobeo 2021, el Plan de investigación, 
conservación y difusión en materia de Arqueología (2018-2024), o el Plan de inspección de los Bienes culturales de Castilla-León (2017-2020).

No se puede olvidar un aspecto crucial en este estudio: la formación del profesorado de Secundaria y Bachillerato, sujeta a aquellas Universidades que hayan optado por incorporar la enseñanza del patrimonio en sus planes de estudio. En España existen algunas en distintas disciplinas, como en las Artes, Historia, Historia del Arte o en otros niveles educativos, Educación Primaria de Granada, y en la Comunidad de Castilla y León, en Valladolid.

\section{Evaluación de programas y evaluación de aprendizajes}

En otras lenguas, como las del mundo anglosajón, se distingue entre Evaluation, que es la evaluación educativa, sobre programas educativos, o formas de educación en distintos contextos, como centros educativos acogidos a normas estatales, u otros centros no formales; y Assessment, que se define como medición de resultados de los alumnos a través de pruebas estandarizadas con el fin de elaborar rankings a nivel de aula, de centro, locales, regionales, estatales e internacionales.

Hay aspectos importantes encontrados en la revisión bibliográfica sobre evaluación a tener en cuenta para el entendimiento de dicho concepto:

1. Guba y Lincoln $(1982,1989)$ establecieron la clasificación de las "cuatro generaciones de la evaluación", aunque actualmente se han extendido hasta cinco: a) Técnica, b) Descriptiva, c) de Juicio, d) Sensible y e) Ecléctica.

2. Hasta 1930 predominaba el término medición. Con la llegada de Tyler (1969) cobra protagonismo la evaluación, Tyler es reconocido como el padre de la evaluación educativa; la evaluación es antepuesta a la medición.

3. A partir de 1957 la evaluación se asocia a la toma de decisiones, para mejorar los programas educativos, pero no directamente a los individuos sujetos de aprendizaje.

4. Después de 1973 la evaluación empieza a entenderse como herramienta de empoderamiento de los sujetos. Se introduce el concepto de evaluación educativa; el constructivismo impregna la evaluación de aprendizajes. Una se nutre de la otra. 
5. Actualmente vivimos en la quinta generación o generación ecléctica donde la evaluación educativa se tiñe de muchos calificativos dependiendo de las funciones que intenta desempeñar.

6. La evaluación no ha conseguido diferenciar claramente los terrenos de la medición, la calificación y la evaluación. Ocurre que muchas de las prácticas que se llaman evaluación contienen a su vez prácticas de calificación o medición.

7. En el mundo anglosajón existen muchas palabras que distinguen matices dentro del mismo concepto: accountability, appraisal, arousal, self-evaluation, evaluation, assessment.

Aunque en la práctica se especifiquen diferencias claras entre evaluación educativa y evaluación de aprendizajes, como ambas se nutren mutuamente, acaban difuminadas entre sí. Pero es importante tal distinción para el diseño metodológico de ambos tipos de evaluación.

Como en el caso del tópico anterior, la formación de profesorado es crucial en este estudio, sujeta a la formación particular y poco específica en las universidades.

\section{Evaluación de programas y evaluación de aprendizajes en Educación Patrimonial: referentes}

Los referentes nacionales que podemos encontrar en evaluación de programas sobre patrimonio, se encuentran incorporadas en el marco del OEPE y grupos de investigación relacionados. Dentro de este grupo de investigación se han realizado tesis que evalúan programas de tecnología móvil, programas en contextos informales, programas en la comunidad de Madrid, programas sobre diversidad, programas sobre redes sociales, programas de arte contemporáneo o programas específicos de patrimonio inmaterial.

En cuanto a la evaluación de los aprendizajes, se desarrollan en los últimos años una corriente colateral que se interesa sobre el fin último de un programa de educación de calidad: que evalúe los aprendizajes generados en el programa, siendo el tercer proyecto del OEPE, (Ref. EDU 2015/65716-C2-1-R), en el marco en el que se investiga sobre el conocimiento de la naturaleza de los procesos de adquisición y alcance de los aprendizajes generados en los programas referentes en educación patrimonial. 
Problema de investigación y objetivos

Se define el problema de investigación como:

"la educación patrimonial del alumnado de Secundaria y Bachillerato no se tiene en cuenta, por parte de los agentes educativos, que está inmersa a lo largo del currículo, ni se realiza la evaluación de aprendizajes, ni existen estándares definidos de esa evaluación”.

Siguiendo a Maxwell (2008) y para la resolución de este problema, en el presente trabajo se definen tres tipos de objetivos:

Por un lado, el objetivo personal de realizar este trabajo es el de satisfacer la curiosidad personal de conocer el estado en que se encuentra la evaluación de aprendizajes en un campo aún desconocido por muchos docentes de Secundaria y Bachillerato como es la Educación Patrimonial.

Los objetivos prácticos, centrados en cambiar la situación de desconocimiento en este ámbito de las ciencias sociales, por una parte, y por otra, en la falta de puesta en práctica de evaluar los aprendizajes dentro de ese ámbito que es la educación patrimonial, queja que el propio profesorado mantiene en muchos foros académicos.

Y, por último, los objetivos intelectuales que se focalizan en comprender a nivel teórico y conceptual cómo es la evaluación de aprendizajes en la educación patrimonial en secundaria y bachillerato, una revisión de referentes que continúa más allá del presente trabajo.

\section{Metodología}

Para una investigación compleja como la presente, hay que tener en cuenta, en primer lugar, las bases epistemológicas que sustentan la investigación en educación, con todos los obstáculos que conlleva, aún hoy día, realizar trabajos y pesquisas en las ciencias sociales, si se pone el foco sobre su carácter científico. Este interés continuo por la cientificidad de las investigaciones en educación, concretamente en la educación patrimonial como disciplina joven, está siendo el punto de mira en los últimos trabajos referentes. Se trata de abordarlo describiendo todas las fases de la metodología utilizada, imbricándola con la teoría que la sustenta, dando así coherencia a todo el conjunto del trabajo.

En este estudio que se presenta, se ha utilizado una metodología de investigación mixta, que integra tanto métodos cuantitativos como métodos cualitativos, con la 
finalidad de dar una visión más completa del fenómeno estudiado, combinando análisis estadísticos junto con análisis de contenido en el marco de un estudio de caso.

Los estudios mixtos parten de una visión pragmática de la realidad, en la que convergen filosofías que abogaban por la idea de que las ciencias sociales no pueden investigarse a través del método científico tradicional de forma única y las filosofías post-modernistas que defendían que la investigación en este campo social debe llevarse a cabo por procesos en los que impere el sentido común, el pensamiento práctico y la aplicabilidad de ambos. Es decir, no es una mezcla de métodos cuantitativos y cualitativos sin conciencia, sino que este tipo de metodología clarifica el diseño de manera que sea un escalón más en la comprensión del fenómeno. En este sentido, se tienen en cuenta los puntos aportados a la ciencia por Kuhn (1962, 1972, 1982) cuando explica que los fenómenos no pueden entenderse por completo, ni son la realidad, sino que son una parte de un gran fenómeno que se explica desde el punto de vista subjetivo de la realidad que se percibe, según el contexto y la trayectoria científica, siendo las teorías finales complementarias entre sí para la explicación de dichos fenómenos.

Actualmente los métodos mixtos están muy difundidos y utilizados, quizá en exceso y con una praxis no exenta de errores tanto de diseño como de llevarlos a la práctica. Se han propuesto foros internacionales de todo tipo: congresos internacionales como el Mexed Methods International Conference; una asociación internacional de investigadores, la Mixed Methods International Research Association, MMIRA; libros sobre la temática o una revista científica, la Journal of Mixed Methods Research, del Sage.

Cuando un investigador se enfrenta con la idea de usar metodología mixta ha de tomar dos decisiones importantes: por un lado, si quiere operar dentro del paradigma dominante o no, en su mayor parte de la investigación a realizar; y si quiere realizar la investigación en fases de una manera secuencial o de una manera simultánea.

Los multi-métodos (multi-methods), multi-estrategia (multi-strategy) o metodología mixta (mixed-methodology) llegan de la mano de las ciencias del comportamiento sobre los años 50 con el concepto de triangulación como una operación múltiple en investigación (Campbell y Fiske, 1959), que no es lo mismo que la metodología mixta, sino un objetivo de entre muchos, de los multi-métodos. 
La triangulación teórica, por ejemplo, retomada de Denzin (1990) cuando se refiere a probar distintas teorías y metodologías antagonistas la mayoría de las veces (p.511), aunque poco usada por la confusión de que se sintetiza en la crítica las epistemologías de base; o la triangulación metodológica: uso de distintos métodos en el diseño o en la recogida de datos, que puede ser entre métodos o dentro de los métodos, que Arias (1999) lo define como "combinación de dos o más recolecciones de datos con parecidas aproximaciones en el mismo estudio que miden la misma variable" (p.15).

Es decir, la triangulación es una convergencia de resultados obtenidos por distintos métodos o estrategias, incluso en la recolección de datos. Los métodos mixtos forman parte de un proceso más amplio, en el que la triangulación es una parte de ese proceso.

Así, para realizar este trabajo, y siguiendo a Creswell y Plano (2011), los métodos mixtos han de cumplir una serie de pautas específicas e insalvables:

1. Recogida y análisis de los datos con rigurosidad, tanto los cualitativos como los cuantitativos.

2. Relación o integración de los dos tipos de datos de dos formas: simultánea, para combinarlos o fusionarlos; o secuencial, para insertar unos sobre otros.

3. Priorizar una de las dos formas o equilibrar la dominancia del paradigma

4. Llevar a cabo unas fases del programa de investigación

5. Utilizar los procedimientos sin olvidar la complejidad del contexto y el marco teórico empleado

6. Combinar los procedimientos de forma coherente con el plan de investigación.

En este trabajo, como se ha indicado, se utiliza la metodología mixta de investigación, basada en la cosmovisión pragmática de los propios investigadores, que parte de teorías de autores como Creswell (2014), Patton (1990), Morgan (2007), o Tashakkori y Teddlie (2010), que invitan a poner el foco en el problema de investigación desde distintos enfoques para poder generar conocimiento; así, en este trabajo, la metodología principalmente se basa en el marco teórico desarrollado sobre las teorías de educación patrimonial (memoria e identidad) y teorías de la evaluación tanto de programas como de aprendizajes, y los referentes en estos tres ámbitos, dentro de la comunidad de Castilla y León, en el espacio formal, concretamente en la Educación Secundaria Obligatoria y el Bachillerato. 


\section{Procedimiento}

La metodología utilizada ha sido una metodología mixta de diseño anidado, en la que el estudio cualitativo predomina y el cuantitativo está anidado en el primero (ver Figura 1).

El proceso de investigación se lleva a cabo a través de dos fases complejas, concretas y en la que el final de la fase I se anida a la fase II.

La primera fase, parte del Método Secuencial de Análisis y Evaluación de Programas de Educación Patrimonial en el seno del Observatorio de Educación Patrimonial en España, que a su vez se lleva a cabo a través de siete subfases.

La segunda fase, es un estudio de caso de la investigación que nos ocupa y con sus correspondientes pasos a seguir, según esta tradición de investigación.

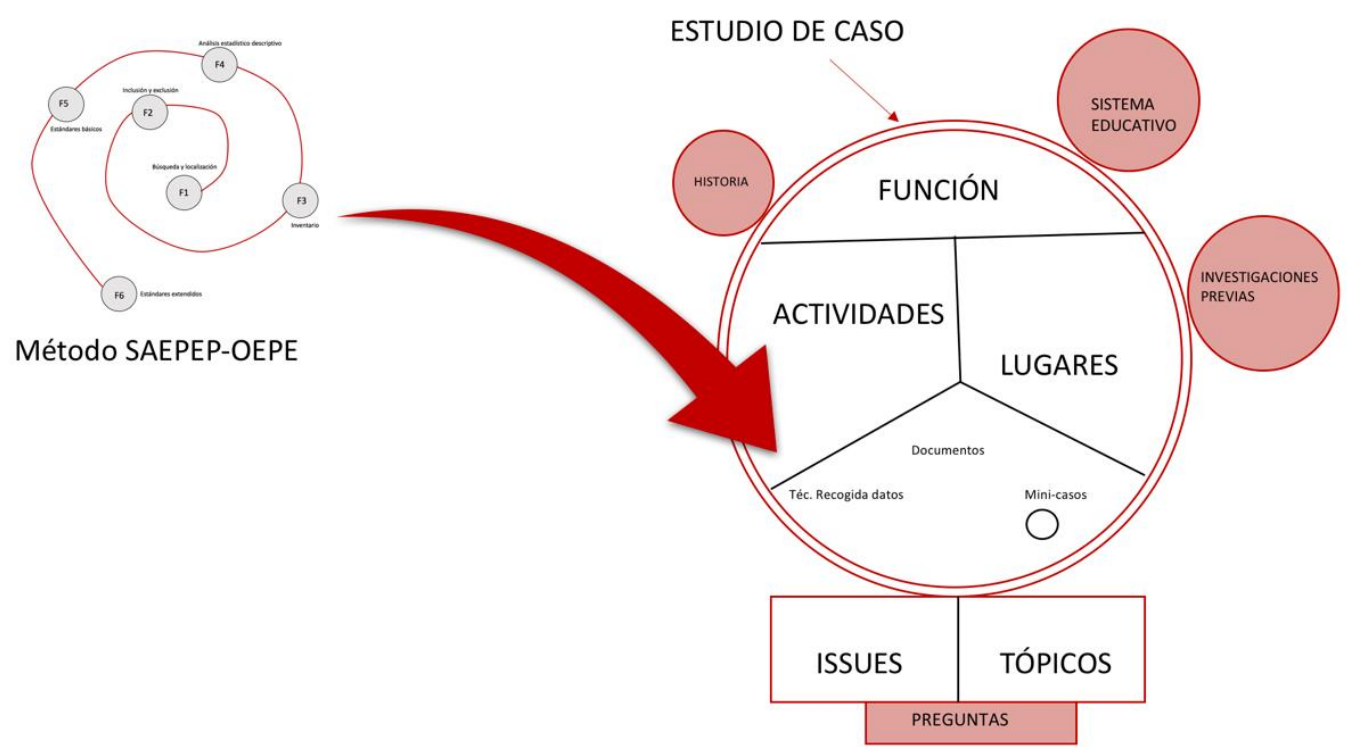

Figura 1. Mixed-Metodology: Método Secuencial de Análisis y Evaluación de Programas de Educación Patrimonial en el seno del Observatorio de Educación Patrimonial en España anidado en el Estudio de Caso. Fuente: propia.

FASE I. Evaluación de programas: la Q-Edutage para evaluar a través de estándares

En la primera fase del estudio se utiliza la Secuencia de Análisis y Evaluación de Programas (SAEPEP-OEPE) propuesta desde el Observatorio de Educación Patrimonial en España (Fontal 2016). Es una secuencia de fases que va realizando una discriminación de programas de educación patrimonial en virtud de unos estándares de 
evaluación. En esta fase es en la que se realizan los análisis cuantitativos que dan respuesta a algunos interrogantes de la siguiente fase que es el estudio de caso.

Las hipótesis de partida en esta fase son:

- Los programas de educación patrimonial se dirigen al alumnado de ESO, bachillerato, o ambas

- Los programas de educación patrimonial definen el patrimonio desde todas sus tipologías

- Los programas de educación patrimonial desarrollan competencias clave y específicas

- Los programas de educación patrimonial realizan una evaluación verdadera y diversa de los aprendizajes

Las subfases son las que siguen:

Fase 1: Búsqueda y localización de programas.

Esta fase es el primer contacto que tiene el investigador con la base de datos del Observatorio. Se trata de la búsqueda de programas de educación patrimonial a través de distintos medios. La base de datos está integrada y es de uso exclusivo de los investigadores con intereses comunes en Educación Patrimonial.

Fase 2: Discriminación mediante criterios de inclusión y exclusión en la base de datos.

En esta fase se decide cuáles son los programas susceptibles de ser inventariados y cuáles no, en base a unos criterios que se consensuaron en la gestación de la base de datos, que se especifican en el Observatorio. Así, se excluyen si: a) es un programa exclusivamente realizado por el museo para su público, b) o si es una web de museo que informa sobre el mismo, c) o si es un material cuyo único fin es el de informar sobre algún bien patrimonial, d) o una página web 1.0, que solo informa. El resto de casos estarían dentro de los criterios de inclusión.

Fase 3: Inventario de Programas

Es un archivado que se lleva a cabo en una ficha de registro organizada y sistematizada que recoge información de los programas desde el diseño educativo hasta la difusión del mismo. Esta ficha se divide en cinco grandes apartados: 
localización, relación con otras fichas, descripción, diseño educativo y anexo documental (ver Figura 2).

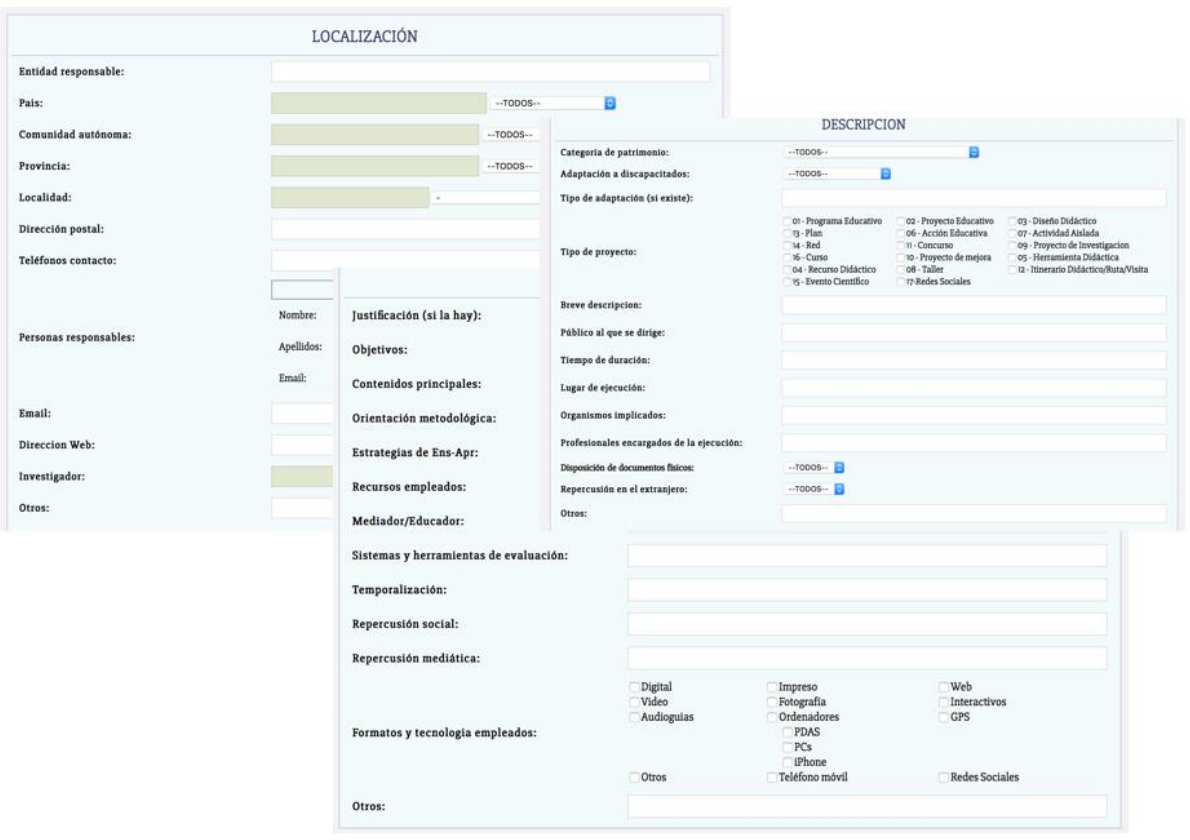

Figura 2. Fichas de inventario utilizada en la Base de Datos de OEPE. Fuente: www.oepe.es

Fase 4: Análisis estadístico descriptivo

Esta fase es aquella en la que se realiza un análisis descriptivo, en el cual se pueden descubrir características de los programas inventariados, así como describir a través de la estadística descriptiva las categorías a las que pertenecen los programas, la localización de los mismos, si se han realizado adaptaciones a todos los públicos a los que se dirigen, cómo se han diseñado en cuanto a los objetivos, las metodologías usadas o si se llega a cualquier tipo de población. Esta fase puede hacer una idea, una descripción de las partes inventariadas de los programas.

Fase 5: Selección discriminatoria a través de la evaluación basada en estándares básicos

En esta fase se utiliza un instrumento creado para la discriminación de programas a través de estándares básicos. Es una rúbrica con escala Likert y los 14 estándares básicos sobre dos dimensiones o estándares generales (Q-Edutage): a) la calidad de la información sobre los programas (metadatos), con siete ítems y b) grado de concreción del diseño educativo, con siete ítems; todos deben obtener una puntuación de la escala 
que son: desde (D) no se alcanza, (C) se alcanza con condiciones, (B) se alcanza, hasta (A) se alcanza con calidad, (ver Figura 3).

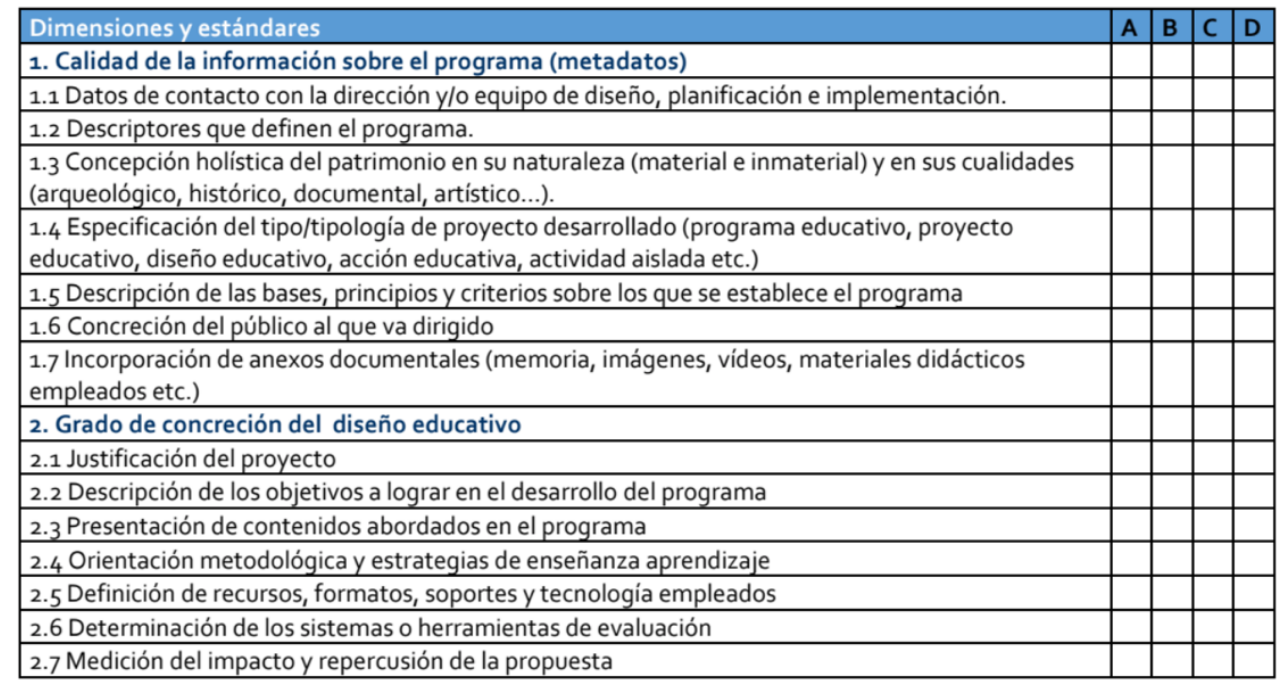

\begin{tabular}{|l|}
\hline A: Se alcanza con calidad \\
\hline B: Se alcanza \\
\hline C: Se alcanza con condiciones \\
\hline D: No se alcanza \\
\hline
\end{tabular}

Figura 3. Rúbrica de estándares básicos para la discriminación de programas de calidad. Fuente: www.oepe.es, Fontal, 2018.

La creación de estos estándares básicos proviene de la Base de Datos del OEPE (Fontal, 2016) en la que, se crearon 15 ítems y se han realizado tres análisis de contenido y análisis estadístico descriptivo de tres muestras de programas de dicha base $(n=350, n=644$ y $n=1120)$, unido a la revisión bibliográfica y los criterios determinados en los aspectos metodológicos del Plan Nacional de Educación y Patrimonio (Fontal y Juanola, 2015). En un principio era una escala con etiquetas cualitativas y se pasó posteriormente a una codificación ordinal cuantitativa. Una vez calibrada, la tabla de estándares pasa a 14 ítems.

Toda la rúbrica detalla los criterios básicos para desarrollar un programa bien diseñado valorando la institución al cargo, la estructura de diseño didáctico, el tipo de programa y su difusión. Para cada programa se extrae un sumatorio de los estándares básicos en una puntuación total (Nitko, 2001). En la calibración de la escala $Q$ Edutage se realizaron los baremos de estas puntuaciones directas a estandarizadas, con media 100 y desviación típica 15. De esta interpretación, se destacan una serie de programas que serán evaluados en la siguiente fase por los estándares específicos. 
Fase 6: Evaluación de programas basada en estándares específicos

Los estándares específicos han sido diseñados en función de las hipótesis planteadas en esta fase de estudio y los referentes encontrados, tanto de estudios de investigación, como las normativas vigentes, atendiendo a la evaluación de aprendizajes: el momento que se hace, la forma de hacerla, quién la realiza, los aprendizajes que se esperan adquirir, según la etapa de la ESO o Bachillerato, etc.

En principio fueron diseñados 23 ítems sobre la evaluación de aprendizajes, pero tras el acuerdo entre jueces, la tabla de estándares específicos se redujo a 14 ítems.

Fase 7: Casos de estudio

Análisis en profundidad de los programas que se han ido seleccionando en la criba de las seis fases anteriores, a través de la documentación que se presenta en la base de datos, puesta en contacto con los agentes implicados en los programas, entrevistándolos, observaciones de la puesta en práctica, cuestionarios, en definitiva, recaudando datos para la fase II.

En esta fase se produce el anidamiento entre la metodología cuantitativa y la cualitativa. Hay que tener en cuenta que en esta fase el método de mayor envergadura, de tradición cualitativa, es el que va a tener la finalidad de esclarecer y comprender cómo se está llevando a cabo la evaluación de aprendizajes en la enseñanza del patrimonio en Secundaria y Bachillerato en la comunidad de Castilla y León.

FASE II. Evaluación de los aprendizajes: Estudio de caso

Se establece una distinción común entre lo que se escala analíticamente y lo que se juzga holísticamente (Stake y Munson, 2008). En esta segunda parte, se realiza un estudio de caso sobre la evaluación de aprendizajes de Educación Patrimonial en Secundaria y Bachillerato en Castilla y León.

Se realiza un estudio de caso único. Es una tradición de investigación que a principios del siglo XX no había cobrado aún un estatus legítimo en ciencias sociales, quizá por la falta de protocolos y estructuración (Yin, 2002).

En esta fase de investigación la posición que se toma como investigadores y el Worldview es muy cercano a Yazan (2015), pues se pretende que el principal objetivo de un investigador cualitativo sea entender el conocimiento construido por las propias personas que intervienen en el estudio, principal aspecto que suscribe el paradigma 
constructivista (Stake, 1995 y Merriam, 1998). Se concibe el conocimiento como algo que se va construyendo en la sociedad y que surge de las prácticas educativas. Por lo tanto, se conceptualiza la realidad social como generada y construida por personas y que existen en gran medida dentro de la mente de las personas. "Los esfuerzos de investigación son orientados a la búsqueda de interpretaciones históricamente situadas y derivadas de la cultura del mundo de la vida social” (Crotty, 1998, p. 67). Sin embargo, dado que la orientación de esta investigación es también más cercana al pragmatismo de Dewey (1938), el actual análisis abarca la instrumentalidad del grupo de estrategias, directrices y herramientas (Yin, 2002).

\section{Resultados}

En la Base de Datos del Observatorio de Educación Patrimonial en España se ha intervenido en el inventariado de 333 programas en la comunidad de Castilla y León, teniéndose en cuenta los criterios de inclusión y exclusión determinados por las normas del método SAEPEP-OEPE.

Un primer análisis estadístico descriptivo nos devuelve los siguientes resultados: de las 17 tipologías en los que se pueden clasificar los distintos programas de Educación Patrimonial, 29,78\% son proyectos educativos, $21,27 \%$ son programas educativos, $10,63 \%$ son diseño didáctico, $8,51 \%$ son evento científico y un $6,38 \%$ se clasifica como concurso. Y dentro de la clasificación del tipo de patrimonio, existe un porcentaje alto de $82 \%$ que pertenece a los programas que se encuadran dentro de patrimonio material e inmaterial a la vez.

De este análisis a través de los estándares básicos, han sido seleccionados 47 programas que están encaminados a la enseñanza Secundaria y Bachillerato y que son los de mejor calidad y concreción de diseño en el programa. Estos 47 programas son el resultado de escoger los que están en la media y por encima de ella.

En cuanto a los estándares específicos, el conjunto inicial de 23 ítems fue sometido a la revisión de 17 jueces, que valoraron cada uno de ellos en una escala de 1 a 4 , en términos de coherencia, claridad de la redacción, relevancia y observabilidad. Para analizar el acuerdo entre los jueces se calcularon los coeficientes ponderados de concordancia de Bangdiwala $\left(B^{\mathrm{W}_{\mathrm{N}}}\right)$ (Bangdiwala, 1987). El índice de acuerdo $B^{W}{ }_{N}$ de Bangdiwala permite la representación gráfica del grado de acuerdo y proporciona una medida de la fuerza del mismo. En esta representación, los cuadrados negros muestran 
el acuerdo observado, en tanto que los cuadrados grises representan el acuerdo parcial. La zona blanca de cada rectángulo es la representación gráfica del desacuerdo.

Como se puede observar en la Figura 4, los coeficientes ponderados de concordancia de Bangdiwala (Bangdiwala, 1987) obtenidos fueron: $B^{\mathrm{W}}{ }_{\mathrm{N}}=.753$ $($ coherencia $) ; B^{\mathrm{W}}{ }_{\mathrm{N}}=.833($ claridad $) ; B^{\mathrm{W}}{ }_{\mathrm{N}}=.845($ relevancia $) ; \mathrm{y} B^{\mathrm{W}}{ }_{\mathrm{N}}=.872$ (observabilidad). Para interpretar los coeficientes de concordancia, Muñoz y Bangdiwala (1997), proponen los siguientes criterios: valores comprendidos entre .000 у .200 indican un nivel de acuerdo pobre; entre .201 y .400, acuerdo débil; entre .401 y .600 , moderado; entre .601 y .800 , bueno; y superiores a .801 , indican un nivel de acuerdo excelente. Estos índices de acuerdo sugieren que los ítems, globalmente, pueden considerarse suficientemente coherentes, observables, relevantes y que la claridad de la redacción es adecuada para evaluar los programas de educación patrimonial en relación a la evaluación de aprendizajes en las etapas de Secundaria y Bachillerato.
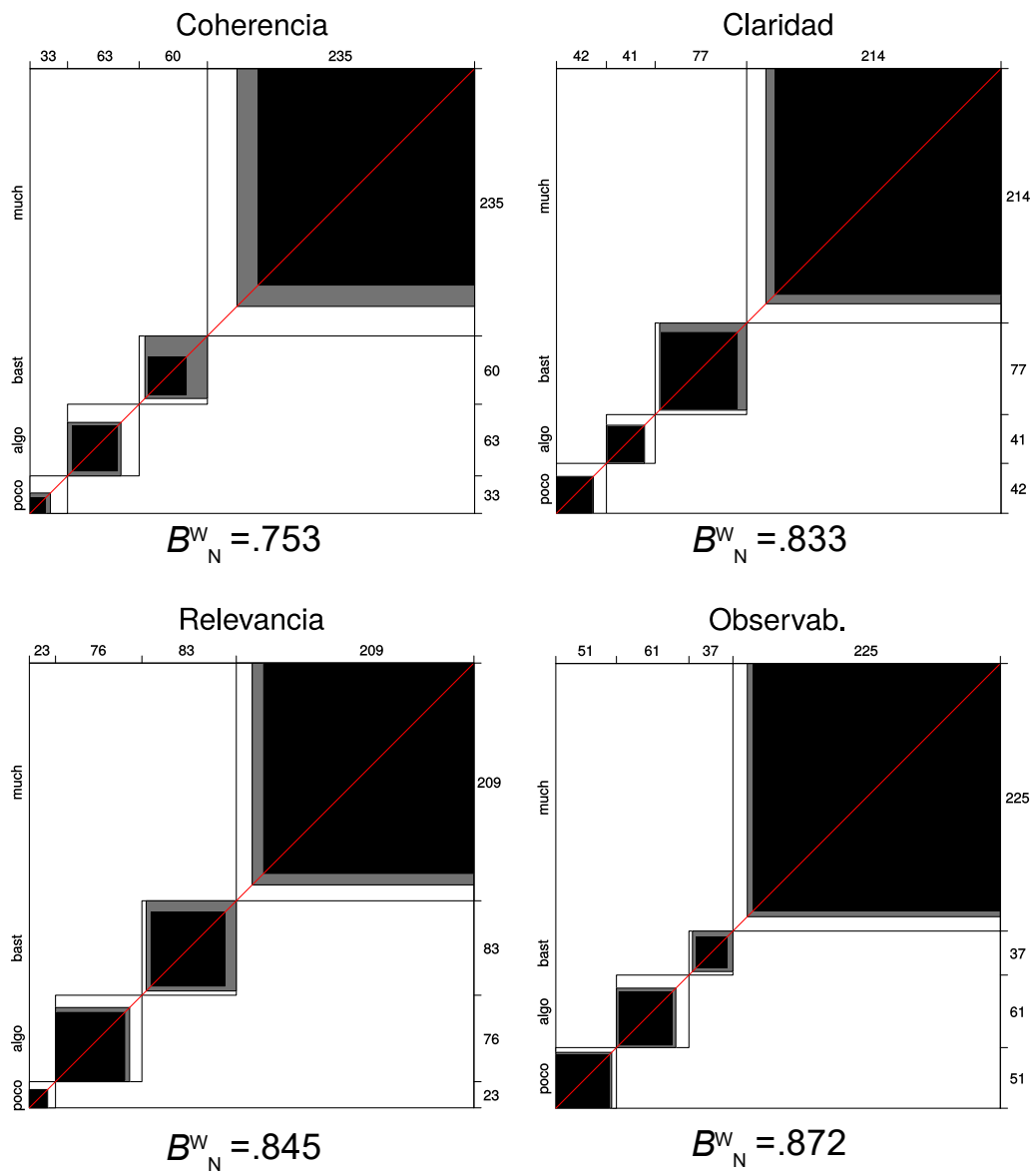

Figura 4. Resultados del análisis de concordancia entre jueces de Bangdiwala 
De los 47 programas seleccionamos los cinco con mejor puntuación en los estándares específicos. Estos programas se anidarán en el estudio de caso, como parte de él y son los mini-casos.

La estructura conceptual del caso está basada en el esquema que propone Stake (1995) para sus investigaciones de estudio de caso (Figura 5).

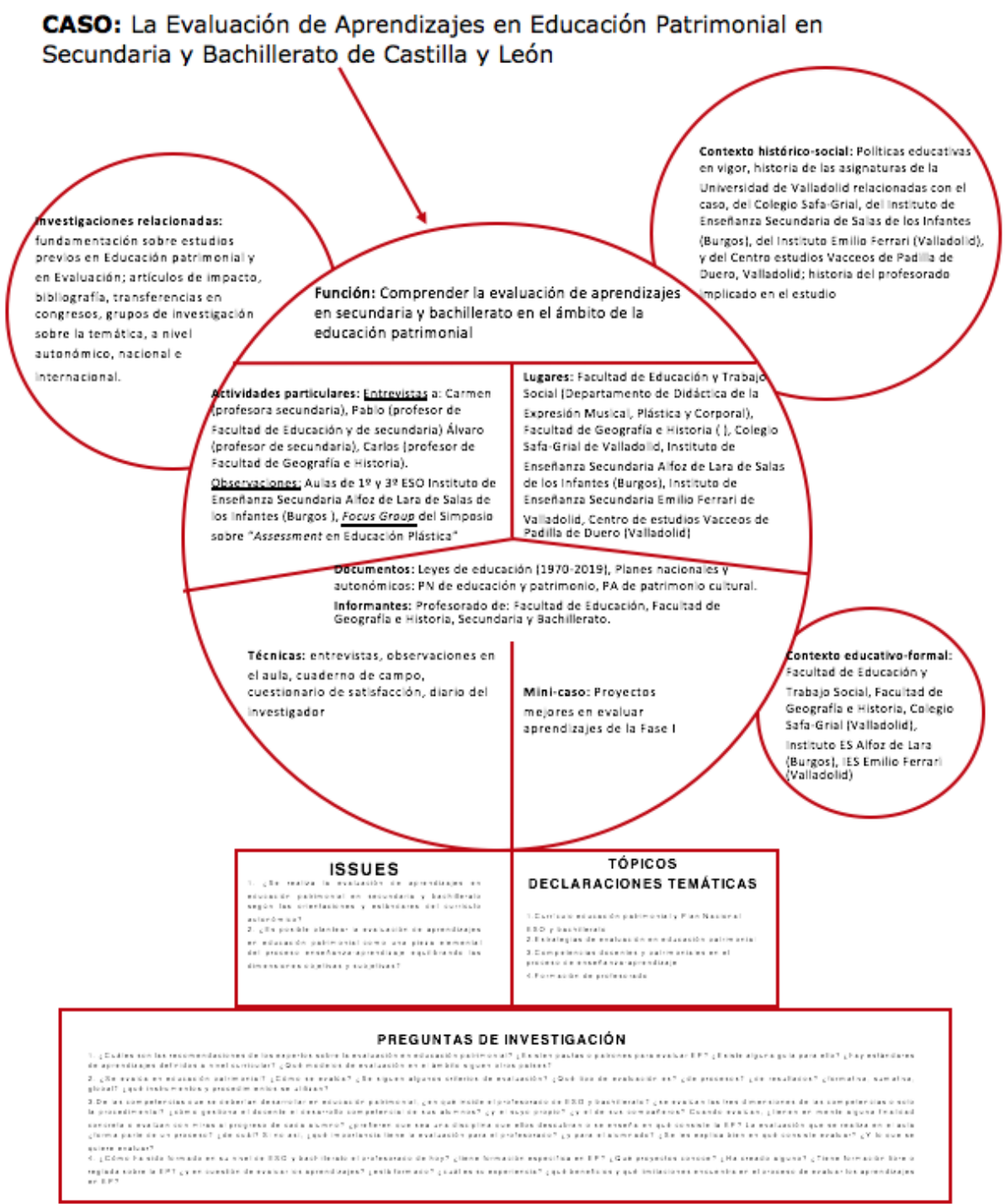

Figura 5. Estructura conceptual del caso. Fuente: propia, a partir de Stake, 1995.

En el círculo central del caso se puede comprobar en la parte superior, que se describe la función principal del caso, que al ser de naturaleza intrínseco e instrumental (Stake, 1995), nos permite comprender un proceso como es la evaluación de los aprendizajes en el ámbito de la Educación Patrimonial. Además, en el mimo círculo se encuentran las actividades particulares realizadas (entrevistas semiestructuradas, 
observaciones en el aula,focus-group), los lugares donde se realizaron (Valladolid y Burgos), los documentos (referentes, normativa de ESO y Bachillerato, Planes Nacionales y Autonómicos), los informantes (profesorado, alumnado) y los mini-casos (los programas seleccionados en la Fase I).

De este círculo sobresalen tres semicírculos que son de contextualización del caso: investigaciones referentes, historia y contexto social. Debajo del círculo grande, las Issues de investigación y las declaraciones temáticas. Se han definido dos Issues: 1. ¿Se realiza la evaluación de aprendizajes en Educación Patrimonial en Secundaria y Bachillerato según las orientaciones y estándares del currículo autonómico? Y 2. ¿Es posible plantear la evaluación de aprendizajes en Educación Patrimonial como una pieza elemental del proceso enseñanza-aprendizaje equilibrando las dimensiones objetivas y subjetivas?

Los resultados del análisis realizado desde $\mathrm{N}^{*}$ vivo.11 se detallan a partir de estas declaraciones temáticas: a) currículo en ESO y Bachillerato y Planes nacional y autonómico sobre Educación Patrimonial; b) competencias patrimoniales en el proceso de enseñanza-aprendizaje; c) estrategias de evaluación en Educación Patrimonial y d) formación de profesorado.

\section{a) Currículo y Planes}

El Plan Nacional de Educación y Patrimonio orienta sobre la forma que se ha de seguir el currículo vigente, además de dar pautas como diseñar el material didáctico sobre Patrimonio con mayor calidad o "fomentar la formación del profesorado en valor social, cultural, económico e identitario de los bienes culturales". (Domingo, Fontal y Ballesteros, 2010, p.8).

Desde las leyes educativas de ESO y Bachillerato, en sus objetivos generales proponen el "Conocer, valorar y respetar la historia, la aportación cultural y el patrimonio de España y de cada una de las Comunidades Autónomas” (p.32053).

Y se han encontrado alusiones al patrimonio en las leyes autonómicas, de manera transversal, en asignaturas como: En la ESO: Naturaleza, Geografía e Historia, Latín, Lengua Castellana y Literatura, Cultura Clásica, Educación Física, Educación Plástica, Visual y Audiovisual, Música, Lengua Gallega y en Bachillerato: Educación Física, Artes Escénicas, Historia del Arte, Historia de la Música, Biología, Economía y Griego. 
En ambas etapas educativas el concepto de patrimonio muestra interesantes aportaciones más allá de una visión obsoleta del patrimonio, ceñida a una sucesión de monumentos arquetípicos y sus características. Por el contrario, entiende el patrimonio inserto en las dinámicas sociales y de organización fluida de las sociedades. En este sentido explicita el disfrute del arte o el respeto general a lo patrimonial como reflexiones pedagógicas de fondo. Contraria a esta idea, el currículo está denostado por los profesionales por sus carencias en varios sentidos (fig.6):

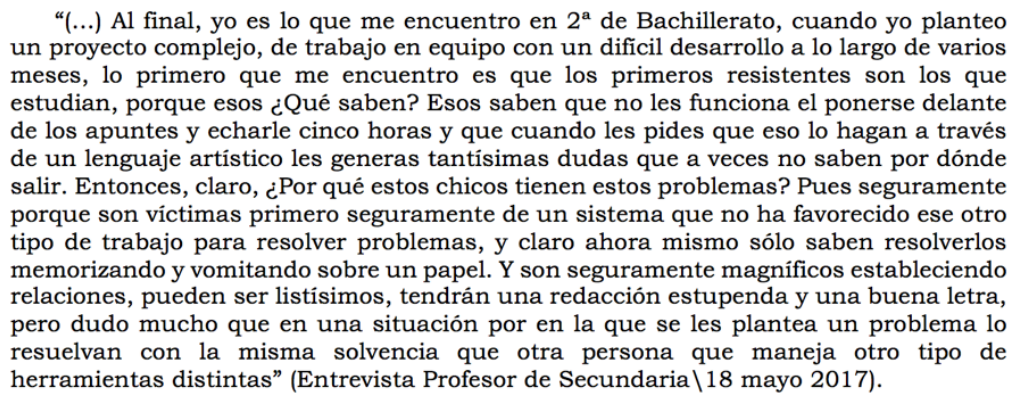

Figura 6. Evidencia 1 de la categoría Currículo y Planes

El currículo atiende a las cuestiones contemporáneas de la diversidad lingüística y cultural de todo el territorio nacional y el europeo. En general, es reflejo en todas las materias del enfoque autonomista de los contenidos que viene dándose a la educación desde la llegada de la democracia y esto se evidencia en la Tabla 1, en la que se han realizado búsquedas de palabras satélites del concepto de patrimonio (arte, cultura, identidad, memoria y patrimonio), dándose mayor protagonismo a la cultura y al arte.

\section{Tabla 1}

Resultado de conteo de palabras-satélite del concepto de patrimonio en la normativa autonómica de ESO y Bachillerato.

\begin{tabular}{lll}
\hline & $\begin{array}{l}\text { CURRICULUM } \\
\text { SECUNDARIA } \\
\text { CYL }\end{array}$ & $\begin{array}{l}\text { CURRICULUM } \\
\text { BACHILLERATO } \\
\text { CYL }\end{array}$ \\
\hline ARTE & 52 & 253 \\
CULTURA & 243 & 149 \\
IDENTIDAD & 24 & 4 \\
MEMORIA & 16 & 35 \\
PATRIMONIO & 31 & 51 \\
\hline
\end{tabular}




\title{
b) Competencias patrimoniales en el proceso de enseñanza-aprendizaje
}

Los informantes han descrito ciertas competencias que un docente en Educación

Patrimonial ha de desarrollar para la práctica en el aula: por un lado, el desarrollo de la sensibilidad, algo que se adquiere y desarrolla con el interés en disciplinas como las Artes (fig.7):

“(...) a raíz de sacarme el título de Monitor de Tiempo Libre se me abrió un abanico de oferta educativa en cuestiones de Tiempo Libre y participación, y a mí fundamentalmente todo lo que me interesó hacer era todo lo que tenía que ver con la sensibilidad, con las Artes Plásticas, incluso te diria también con lo que ahora damos en llamar Patrimonio, sin saber yo entonces que estaba trabajando en el Patrimonio" (Entrevista Profesor de Secundaria \18 mayo 2017).

Figura 7. Evidencia 1 sobre competencias patrimoniales en el proceso E-A.

Se analizan las prácticas y las competencias en su desarrollo hasta la actualidad:

“(...) llevo 18 años dedicándome a la educación y llevo 18 años recortando contenidos. Yo creo que eso es un sintoma. Si no impartimos tanto contenido y el curso dura lo mismo es porque estamos teniendo que hacer otras cosas. Entonces, quizá sí, lo procedimental está cada vez más presente, lo instrumental está cada vez más presente; pero a mi modo de ver ahí está el problema, en que hay un desajuste en cómo se incorpora lo procedimental y lo instrumental" (Entrevista Profesora de Secundaria 8 febrero 2018).

Figura 8. Evidencia 2 sobre competencias patrimoniales en el proceso E-A.

Competencias de aprender a hacer en muchas disciplinas, pero en cuanto al patrimonio personal, aprender a ser es una de las más llamativa, ya que el patrimonio ayuda al desarrollo de valores competenciales que en otros ámbitos no se aprenden

\section{c) Estrategias de evaluación en Educación Patrimonial}

En varios casos se habla de la evaluación de una forma controvertida, ya que se piensa que el sistema empuja a la calificación (fig. 9):

\begin{abstract}
“(...) hay una parte en la que se mira la ejecución técnica y hay otra parte del profesorado que trabaja más sobre otro tipo de conceptos adquiridos, no solamente esos, sino como has llegado, los procesos mentales que te han llevado a la realización de una obra o tarea. Y yo creo que eso generalmente en la educación, en el sistema educativo en el que estamos, no se evalúa. Se califica" (Entrevista Profesor de Secundaria $\backslash 11$ noviembre 2018).
\end{abstract}

Figura 9. Evidencia 1 sobre estrategias de evaluación en EP

Y se enfrentan a la complicación de evaluar todo aquello que es subjetivo dentro de las competencias (fig.10): 
“(...) siempre hay una evaluación de originalidad, creatividad que para mí es importante y tiene un porcentaje dentro de esa valoración final. Que es subjetivo, claro, y a lo mejor me cuesta crear esa rúbrica para acercarme" (Entrevista Profesor de Secundaria \18 mayo 2017).

Figura 10. Evidencia 2 sobre estrategias de evaluación en EP

El profesorado que trabaja dentro de los parámetros de la transdisciplinariedad, crítico

al sistema, analiza la evaluación y el proceso de la misma, teniendo en cuenta ideas

como el beneficio de cometer errores (fig.11):

\begin{abstract}
"No le llamo error porque hay una idea preconcebida que el error es malo. Para mí el aprendizaje es ver, a partir de lo que has hecho, cómo puedes evolucionar. Por eso como tenemos esa idea preconcebida de que el error es malo, el suspenso es malo. No, para mí el suspenso sirve como análisis de dónde tengo que buscar una corrección. Pero como hay tantas ideas preconcebidas de cómo las cosas son... Hay en determinados niveles que yo provoco el suspenso intencionadamente para que ellos sean conscientes de dónde tienen su error y corregirlo para seguir a partir de ahí..."” (Entrevista Profesora de Secundaria $\backslash 8$ febrero 2018).
\end{abstract}

Figura 11. Evidencia 3 sobre estrategias de evaluación en EP

Pero si la han llevado a cabo, engrandecen la evaluación como parte primordial en el proceso de enseñanza-aprendizaje (fig.12):

\begin{abstract}
"Estaba fuera de la corriente para muchas cosas, pero sin embargo la evaluación seguía estando en el cauce, en el centro, y me ha costado darme cuenta mucho, hemos tenido que hablar tu y yo mucho y yo ahora me creo mis evaluaciones, y, yo esto tampoco lo había pensado nunca: Hasta qué punto un buen mecanismo de evaluación refuerza tu proyecto o refuerza tu identidad como docente. La seguridad que te da saber que no estas siendo injusto..." (Entrevista Profesor de Secundaria $\backslash 11$ noviembre 2018).
\end{abstract}

Figura 12. Evidencia 4 sobre estrategias de evaluación en EP

\title{
d) Formación de profesorado
}

El docente en patrimonio ha de ser, no solo docente, sino también realizar otras

funciones importantes para enriquecer su labor como profesor en el aula (fig.13):

"Pues alguien que quiere trasmitir y que quiere trasmitir además en primera linea, en el sentido de no repetir. Yo creo que la parte interesante de la docencia es aportar algo propio, en el sentido de que, sin la investigación, la docencia está coja (...); trasmitir experiencias propias, esas experiencias propias tienen que ver con una investigación específica, inédita, por donde vas abriendo caminos" (Entrevista Profesor de Universidad $\backslash 22$ enero 2019)

Figura 13. Evidencia 1 sobre formación de profesorado

El profesorado que trabaja en patrimonio entiende que realiza proyectos que algunos de sus propios compañeros no entienden, se sienten un poco al margen de la ley

(fig.14): 
“(...) no me considero sólo profesor, sino que me considero un hacker de la educación.” (Entrevista Profesor de Secundaria $\backslash 18$ mayo 2017).

Figura 14. Evidencia 2 sobre formación de profesorado

La mayoría entiende que la docencia del patrimonio y lo que conlleva, incluida su evaluación dentro del aula es una tarea que tiene que ver con el interés personal, y no se enseña en ninguna facultad de las que han estudiado, (la mayoría son especialistas en Arte, Historia del Arte, o Historia). Los proyectos que diseña este tipo de profesorado con interés por el patrimonio y su evaluación, incluyen un plan evaluativo complejo que desarrolla el máximo de competencias, incluida la autoevaluación y coevaluación, como partes de aprender a ser personas críticas. (Mini-caso 1\11 marzo 2018).

\section{Conclusiones y discusión}

En Educación Patrimonial se han realizado estudios sobre evaluación de programas, unos con más pruebas de validez y fiabilidad que otros. Este trabajo ha incidido en dos aspectos: la validez de criterio y la fiabilidad, utilizando la escala $Q$-Edutage (Evolution).

Para evaluar aprendizajes en este ámbito, último criterio de calidad de un programa educativo, el docente tiene que aprender el proceso por sí mismo: la transversalidad de lo patrimonial, el contexto del alumnado, sus capacidades, conocer las competencias y los estándares de aprendizajes, el autoaprendizaje dirigido y salir de un currículo poco abierto que a veces deja la enseñanza del patrimonio en una declaración de intenciones. Desde la comunidad educativa se carece de educación en lo patrimonial como disciplina que cumple las consignas de las nuevas enseñanzas, en las que lo importante es la persona. Y la evaluación en este campo, afrontarla de forma sistémica, socializada y crítica, como una actitud en la forma de hacer educación. Aprender a evaluar aprendizajes forma parte de nuestro patrimonio.

\section{Referencias}

Arias, M. M. (1999). Triangulación metodológica: Sus principios, alcances y limitaciones. Investigación y Educación en Enfermería, 18(1), 13-26. 
Bangdiwala, S. I. (1987). A graphical test for observer agreement. Proceedings of the 45th International Statistical Institute Meeting, Amsterdam, 1, 307308.

Campbell, T., \& Fiske, W. (1959). Convergent and discriminant validation by multitrait-multimethod matrix. Psychological Bulletin, 56, 81-105.

Creswell, J. W., \& Plano Clark, V. L. (2011). Choosing a mixed methods design. Designing and Conducting Mixed Methods Research, 2, 53-106.

Creswell, J. W. (2014). A concise introduction to mixed methods research. California: SAGE publications.

Crotty, M. (1998). The foundations of social research. Thousand Oaks, California: SAGE Publications.

Denzin, N. K. (1990). Reading rational choice theory. Rationality and Society, 2(2), 172-189.

Dewey, J. (1938). Experience and education. New York: Collier.

Domingo, M., Fontal, O., y Ballesteros, P. (Coords.). (2013). Plan Nacional de Educación y Patrimonio. Madrid: Ministerio de Educación, Cultura y Deporte, Secretaría de Estado de Cultura.

Estepa, J., y Cuenca, J. M. (2006). La mirada de los maestros, profesores y gestores del patrimonio: Investigación sobre conceptos de patrimonio y su didáctica. En O. Fontal, y R. Calaf (Eds.). Miradas al patrimonio, (pp.51-71). Gijón: Trea.

Fontal, O. (2003). La educación patrimonial: Teoría y práctica para el aula, el museo e Internet. Gijón: Trea.

Fontal, O. (2013). La educación patrimonial: Del patrimonio a las personas. Gijón: Trea.

Fontal, O., y Juanola, R. (2015). La educación patrimonial: Una disciplina útil y rentable en el ámbito de la gestión del patrimonio cultural. Cadmo. International Journal of Educational Research, 23(1), 254-266.

Fontal, O. (2016). Educación patrimonial: Retrospectiva y prospectivas para la próxima década. Estudios Pedagógicos, 42(2), 415-436.

Fontal, O., García, S., Arias, B., y Arias, V. B. (2018). Evaluación de la calidad de programas de educación patrimonial: Construcción y calibración de la escala Q-Edutage. Revista de Psicodidáctica, 24(1), 31-38. 
Gómez-Redondo, C. (2011). El arte contemporáneo: Escenario para nuevas identidades. In Actas del II Congreso Internacional de arte, educación y cultura: Aportaciones desde la periferia.

Gómez Redondo, C. (2012). Identización: La construcción discursiva del individuo. Arte, Individuo y Sociedad, 24(1), 21-37.

Guba, E.G. \& Lincoln, Y. S. (1982). Establishing dependability and confirmability in naturalistic inquiry through an audit. $66^{\text {th }}$ American Educational Research Association Annual Meeting, 1-22. New York.

Guba, E.G. \& Lincoln, Y. S. (1989). Ethics: The failure of positivist science. The Review of Higher Education, 12(3), 221-240.

Kuhn, T. (1962). La estructura de las revoluciones científicas. México: FCE.

Kuhn, D. (1972). Mechanisms of change in the development of cognitive structures. Child Development, 43(3), 833-844.

Kuhn, T. (1982). Objetividad, juicios de valor y elección de teoría. La tensión esencial, 2, 344-364.

Maxwell. J.A. (2008). Designing a qualitative study. En L. Bickman \& D. J. Rog (Eds.), Handbook of applied social science research methods, 2, 214-253. Thousand Oaks, California: Sage Publications.

Merriam, S. B. (1998). Qualitative research and case study applications in education. Revised and expanded from "Case Study Research in Education". San Francisco, California: Jossey-Bass Publishers

Morgan, K. (2007). The learning region: institutions, innovation and regional renewal. Regional Studies, 41(S1), S147-S159.

Muñoz, S. R., \& Bangdiwala, S. I. (1997). Interpretation of Kappa and B statistics measures of agreement. Journal of Applied Statistics, 24(1), 105-112.

Nitko, A. J., \& Brookhart, S. M. (1996). Educational assessment of students. Englewood Cliffs, NJ: Merrill.

ORDEN EDU/362/2015, de 4 de mayo, por la que se establece el currículo y se regula la implantación, evaluación y desarrollo de la educación secundaria obligatoria en la Comunidad de Castilla y León. (BOCyL nº 86 de 8/5/2015 páginas 32051 a 32480). 
ORDEN EDU/363/2015, de 4 de mayo, por la que se establece el currículo y se regula la implantación, evaluación y desarrollo del bachillerato en la Comunidad de Castilla y León. (BOCyL no 86 de 8/5/2015 páginas 32481 a 32984).

Patton, M. Q. (1990). Qualitative evaluation and research methods. California: SAGE Publications.

Stake, R. E. (1995). The art of case study research. California: Sage Publications.

Stake, R., \& Munson, A. (2008). Qualitative assessment of arts education. Arts Education Policy Review, 109(6), 13-22.

Tashakkori, A., \& Teddlie, C. (Eds.). (2003). Sage handbook of mixed methods in social \& behavioral research. California: SAGE Publications.

Tyler, R. W. (Ed.). (1969). Educational evaluation: New roles, new means. Chicago: University of Chicago Press.

UNESCO, 1972, Convención para la Protección del Patrimonio Mundial, Cultural y Material, Aprobada en París el 21 de noviembre de 1972.

Yazan, B. (2015). Three approaches to case study methods in education: Yin, Merriam, and Stake. The Qualitative Report, 20(2), 134-152.

Yin, R. K. (2002). Estudio de caso. Porto Alegre: Bookman.

Zamora, E. (2011). Sobre patrimonio y desarrollo. Aproximación al concepto de patrimonio cultural y su utilización en procesos de desarrollo territorial. Pasos, 9, 101-113. 


\section{CONCLUSIVE BODY}

\section{CONCLUSIONS AND DISCUSSION}

\subsection{CONCLUSIONS OF ARTICLES AND DISCUSSION}

One of the purposes of the thesis, and further on of the three articles on which it is based, is to try to apply the results we got to the generic scope of Heritage Education. In the definition of what is Patrimonial Education we will follow the guiding thread proposed by Fontal (2016), which after three decades of investigation in curricular texts defends several postulates:

A. Regarding Artistic Education, this is one of the subjects most linked to Heritage Education, also the training of teachers is essential referred to Heritage Education. B. In the field of universities and legislative plans, the area of Didactics of Plastic Expression is relevant, which has opened a specific line of research in Heritage Education. In the legislative framework, the National Education and Heritage Plan (2013, PNEyP) is notable as a national reference for the promotion of research and training in Heritage Education.

C. Finally, from Sociology, research reveals that Heritage Education is profitable in social, cultural and identity terms.

Our case studies have been developed both in the areas of Artistic Education and Social Sciences, which have a proved relationship with Heritage Education, since they are both those that develop content about heritage.

Our concrete research in Visual and Plastic Education belongs to the field of Artistic Education, and by extension to Heritage Education, so our conclusions can be extended, based on the concrete results, towards the theoretical and social debates of heritage treatment in Primary Education.

Thus, the general conclusions emanating from the case study developed, which could apply to the field of Heritage Education would be:

1. The informants agree on highlighting the human commitment as the basis of a progressive and generative motivation in teaching, which directly affects the curricular design in Primary.

2. A second result of our studies shows that it would be advisable to balance between all educational agents the teaching of content with their didactics, all in order to achieve a comprehensive education with a more fair and balanced learning evaluation. This idea could be extended to the area of heritage education. 
3. Our informants have valued both the artistic and other teaching-learning competencies, and especially the transversal competences, researching, systemic and community based. These help to structure an educational design more fitted to a meaningful and complex evaluation with appropriate evaluation strategies and resources. Patrimonial Education, as a cross-cutting area, could benefit by directly focusing on more related disciplines in Artistic Education and in Social Sciences.

4. There are usually three of the three most important curricular areas within Heritage Education (Plastic, Social Sciences, Language), although given its transversal nature, it could cover others.

In all our work we have analysed the issue between the curricular demands established by current legislation, the inertia of educational institutions and innovative teaching practices. As some of the data presented in the results section show, the rigidity of the official curriculum, as well as the scarcity of existing resources for its application in relation to the evaluation of learning, make teachers promote processes of summative evaluation / qualification that often implies a split between the different subjects that make up Artistic Education. From our point of view, Heritage Education could help solve these tensions from three fundamental aspects:

A) First, helping to promote the interaction between subjects and / or areas of knowledge.

B) Secondly, facilitating the permeability of the School to the social environment, thus fostering the idea that the historical legacy belongs to all generations and that it must be apprehended by the student in any social space where it appears.

C) And third, to help students understand as a participant, as well as observer or passive subject of artistic manifestations.

In the statements of the informants the vocation of teachers usually coincides with that of artists or researchers, establishing a fruitful interaction between both facets that fertilizes both, as the educational praxis develops.

Everyone highlights the involvement and responsibility towards people, towards students as a key to teaching identity and driving constant innovation and research towards excellence.

Regarding Artistic Education, there is a claim of teaching techniques and materials, not only limited to Secondary Education, in addition to the traditional teaching based on content and focused on the theoretical. 
We can establish an enumeration of significant skills as a result of which the informants have considered most relevant, together with those proposed by the curriculum. These would be:

1. Development of creativity,

2. sensitivity development,

3. Development of communicative competence as a backbone of teaching in its aspects of group management, teacher-student feedback etc.,

4. development of emotional intelligence, also transverse in working with groups and individuals,

5. development of personal autonomy,

6. knowledge and procedures of everything related to educational practice, thus incorporating a research and dynamic vision of teaching: techniques, fundamentals of disciplines etc., development of skills related to praxis: interpreting, knowing how to find information, meaning and purpose of practice etc.,

7. and the development of an ethical commitment.

Regarding the evaluation approach, it focuses on the processes and attitudes rather than the final goals and aims to be global and continuous. Preferred techniques are exhaustive communicative feedback, evaluation by items and small evaluations of work items (micro-assessment). The numerical assessment (qualification) is also carried out, sometimes declaring criticism or distancing from it. Thus, the general conclusions obtained from the investigative process would be:

1. The informants highlight the human commitment as the axis of a progressive and continuous motivation in their teaching profession.

2. Artistic Education should balance curriculum content with the teaching of techniques and materials.

3. The teaching competences are plural, and all deserve to be developed with special emphasis on the transversal, research, systemic and community focused, all linked to the most contemporary pedagogy.

4. The evaluation of learning would focus processes and attitudes, being carried out continuously and globally.

Successive analyses of the study with informants reveal various paradoxes:

1) Our informants comply with the guidelines proposed by the curriculum; however, they openly declare that they encounter contradictions in teaching practice. Regarding the competences of the students, the Educational Administration starts first, through its 
theoretical and technical studies, of an analysis of the state of the matter. It is precisely when the legislator observes that a large number of different skills have a deficit in general in our system, the Administration draws up a generic law that addresses the issue with (theoretical) vocation of permanence.

2) Through our research we obtain evidence that educators develop a phase of detecting gaps in competencies in the material we have compiled. These skills are:

communicative competence, creativity, sensitivity, emotional intelligence and personal autonomy. In the case of the Administration, its previous studies on this subject are structural, that is, informed by all sciences; and the formulation of the competences written in the norm have the advantage of being plural, but the disadvantage of not delving into contemporary lines of Pedagogy (e.g. the education of emotional intelligence).

3) The enunciation of skills that informants are progressively developing, is obviously less encyclopaedic, but it has an interest and description focused on the particular skills that each informant masters in relation to their training and professional development. Teachers strive to follow the skills of the curriculum: development of communicative competence, development of emotional intelligence, development of personal autonomy, knowledge and procedures of everything related to educational practice: techniques, fundamentals of disciplines, development of skills related to praxis: interpreting, knowing how to find information, meaning and purpose of the practice and development of an ethical commitment. However, educational centres do not have an implementation of pedagogical resources to correctly develop these competences, therefore, the monitoring of the curriculum is individualistic and supported by more general skills such as creativity.

4) Transversal skills are specifically promoted among teachers of Plastic Education. Thus, we highlight that the most potent transversal skills in our collected material would be: learn to learn, communicative competence, personal autonomy and supervised autonomy of the groups, etc. Various values converge in art such as symbolic, cultural and social, which must influence to project artistic content to other areas and increase its specific weight by relating it to other subjects. "Art is a field of knowledge that links with other areas within the curriculum and requires teachers with new profiles" (Jiménez, Aguirre and Pimentel, 2009, 11).

5) Next, we do not want to forget the sociological factors that always affect the design and execution of the curricula, and that have appeared, sometimes, explicitly and others 
in a reading between the lines in the course of our investigation. In this sense we describe another reason for the distance between teachers and curriculum. The economicism factor that documents the latest regulatory reforms since the Lisbon declaration and the Bologna Plan of the beginning of the century is undeniable. The claims that we have collected based on the request for the enhancement of artistic education and specifically its reflection in the curriculum, from the proper titles to the increase in teaching hours, reveal a distancing bias with respect to curricular designs and certain official specific skills, let us mention explicitly those related to the knowledge and promotion of "business culture". If the balance between the two groups of skills is in favour of the most "economicist" With respect to cross-sectional and artistic ones, there cannot be a development provided with sufficient means of artistic matters or heritage education.

6) In close relationship, a critique of the distancing of educational legislators from in situ knowledge and practical dynamics of real education is detected. There is also a critique of the involvement of some family environments and of the management of educational centres, which hinders the systemic approach to education and by extension in the social sciences growing since the 1990s.

7) Regarding the evaluation methodology, there are intermittent movements of confluence and distancing between formal evaluation and alternative practices. The majority of informants opt theoretically for evaluating processes and attitudes and in practice combine this methodology with the evaluation of the final products for formal issues. In Plastic Education, teachers also try to follow the curricular guidelines, but the curriculum does not develop the specific methodology for that evaluation, so an individualist intervention is imposed. The evaluation of processes and attitudes is collected only in a generic way in the norm; On the contrary, the criticism comes from the excessive weight that traditional exams and strict sequencing of content and evidence still have in it.

In our studies on Plastic Education - with respect to the assessment or the theories of Stake or the Anglo-Saxon school of situated learning - a remarkable degree of follow-up of its same principles is observed: evaluation as learning, modulating it, tending towards planned and future objectives. Although, the use of concrete tools is different depending on the socio-temporal context of each informant.

Among the schools of Psychology and Pedagogy, the contemporaneity that is reflected in the studies of Plastic Education, has as background the Vigostkian Cognitivism and 
other more current currents: individuation of education / multifactorial (multiple factors of the student and his surroundings; systemic approach); ecological / situational evaluation (attention to territorial and present factors); or holistic evaluation, which includes elements of the previous two.

8) We find another paradox in the dichotomy of an ideal evaluation of processes and attitudes, but it is not well known how to execute. I mean there are a great leap between the theoretical-personal-professional convictions of teachers in this regard, and a deficit of methodologies available in praxis to evaluate skills in Art Education. The curriculum does not explain how to perform the evaluation of processes and attitudes. Teachers in practice follow a certain sequencing: first there is a theoretical conviction of the teacher that generates methods and an individual search for resources (semi-anarchic, or poorly documented); subsequently, it seeks support in the innovations that start from the curricular designs; and finally, add a feedback of your specific praxis, etc.

Observing this dynamic, it is presumed that evaluation is a process that seems uncoordinated, there is no circulation of information among researchers, legislators, the management of the centres and teachers; let alone with families, social agents or artistic creators. Above all, it highlights the distance between the didactic theory and its resources and the individual teachers.

If this approach to the state of the matter is recognized as true and that all this is a fact of historical journey in our country, it can be affirmed that the investigation is moving in the opposite direction, that is, coordinating all the agents Educational is a very conscious and arduous process.

9) There would be another parallel paradox. The praxis of the artistic teacher could conclude that it has been installed in the doing in a little reflexive way, as usual way of working. This intermediate point would have been observed observing the difficulties in systematization, on the one hand, and on the other, observing the inoperancy of anarchy, both referring to Artistic Education.

To evaluate learning in this area, the ultimate quality criterion of an educational program, the teacher has to learn the process for himself: the transversality of the heritage, the context of the students, their abilities, know the skills and standards of learning, the directed self-learning and leaving a little open curriculum that sometimes leaves the teaching of heritage in a declaration of intent. The education community lacks heritage education as a discipline that meets the slogans of the new teachings, in which the important thing is the person. And the evaluation in this field, to face it in a 
systemic, socialized and critical way, as an attitude in the way of doing education. Learning to evaluate learning is part of our heritage.

Regarding the selection of standards, we have concluded that the best rated programs in our study score high on standards of different types. That is to say, both in the type of standards closest to the curriculum, as objectives or methodology as in "contemporary" standards such as the application of ICT, and in theorizing standards as the foundation of the project etc. ...

This balance between the standards is based on everything said above about the importance of the level of individual involvement of the teacher regarding innovation and educational research in heritage education.

A committed teacher is in a balanced way with all the factors and sectors of the educational fact and will develop programs with attention to the curriculum design to coordinate with the legislator and the school institution. It is also the same with students, developing precise and innovative methodologies. And also, with parents, and society using ICT as tools for dissemination and educational extension. Finally, in line with your personal development and as a teacher you will make a deep theoretical reflection subject to redefinition through feedback.

Parallel to the precise selection of significant standards proposed in this thesis, several corresponding to the different "theoretical" groups indicated are chosen; some of those of greater institutional tone, others of those of media or systemic diffusion, others of theoretical framework, others of technical or methodological implementation.

In each of these groups there are some highly scored or relevant standards that will be chosen as a priority, such as:

Systemic:

"Incorporation of different educational agents: evaluation of all the agents involved." Institutional:

"Adaptation to the national and regional curriculum: it follows evaluation standards proposed in the curriculum or the national education and heritage plan"; "Diversity of skills learned", "Diversity of skills developed"

Theoretical framework:

"Values acquired in the process", "The concept of heritage is evaluated in all its typologies: cultural, built, intangible, or natural." "Theoretical concretion: the 
evaluation is adapted to the proposed objectives and there is an adequate didactic structure"

It should be said, however, with respect to barely scored standards, that this does not reveal little importance, but rather a potential to be developed with programs with a large technical component and complex elaboration and well implemented with means that can also meet these minority variables.

\subsection{LIMITATIONS, PROSPECTIVE AND FUTURE LINES}

The series of shortcomings that we observe in the future teacher of Plastic Education and of dysfunctions between the normative and the praxis and the numerous paradoxes that we describe induces us and motivates us to propose several future lines of work that may be interesting for the analysis and transformation of those aspects.

We present below those lines open to the future that we would consider studying, namely:

- First. Deepen the innovative assessment forms adapted to the requirements of artistic education. (Black, P. et all (2003); Martin-Kniep, G (2005)) It would be possible to specifically study cases of specialized assessment application in Spain, in which, consciously, following specific authors, concrete methodologies for the evaluation of learnings In this regard, a compilation of good practices in the assessment of artistic education could be developed. These good practices could serve as a basis for discussion and even initial and ongoing teacher training. The approach of this line could address the following contents: assessment tools, their application, results and comparatives.

-Second. Delve deeper into the state-of-the-art issue today, with special interest to art applied or applicable to education. In that way, the Anglo-American and French schools of which only master lines have been outlined should be elaborated in the absence of documenting them in their extensive bibliography.

The conjuncture of contemporary art in recent decades has an exponential advance of different techniques, styles, methods, supports etc. In parallel, his reflection in art education has needed to address all this conceptual and practical explosion. 
Regarding the specific curricular skills on contemporary art education (knowledge of styles and techniques or community participation, for example), we find evidence of the informants' interest in capturing them, although they have to circumscribe them especially to the classroom due to the lack of collective fabric and social interest towards contemporary art that is detected in the geographical area studied.

-Third. Proposals from teaching practice to theory. The study of the evidence invites us to mention a code of good practices observed wishing that they serve as feedback for teachers in general; we can mention here

the proposals of teamwork, in which the professors share the advances and experiences in contemporary education and evaluation.

The teacher must change his traditional role as a mere transmitter of knowledge, to become the mediator of learning, classroom manager, evaluator, researcher and innovator (Mendía 2004), taking into account the context in which his activity takes place. A wide range of teaching strategies should be renewed and used, turning the classroom into a creative space, and for this, the stimuli and opportunities offered to students must be increased (Darling-Hammond, 2001).

To theorize, we should compare the codes of good practice with the various theoretical schools (international and Spanish) in which this praxis is framed. And that comparison would have to contribute new theoretical elements of debate and questioning of diverse subjects.

Regarding the educational impact of an innovation project in heritage education in the area of social sciences that the RRSS uses to investigate, participate and transmit; Even the students were surprised by an innovative methodology that impacted their way of learning by breaking the teaching-learning routine based on memorization.

And García-Valcárcel, Basilotta and López (2013), in their study related to the use of ICT in collaborative learning in Primary Education and Castilla y León High School, specified that:

Regarding the main limitations to implement collaborative learning methodologies in the classroom, some issues that have implication in the development of the curriculum have been pointed out, such as the use of more time, a certain loss of control, the different involvement of students or students. difficulties in assessing the learning process and the results obtained by each student (p.72). 
In our study in the area of social sciences we have been able to verify some of these aspects and question others.

It is undeniable that more time is needed for students in the school year for large-scale tasks - the current ecosystem (school, family and social) of high school does not seem to worry as much about the lessons learned as the cut-off grade or memorization for an external test that does not include this type of educational approach in its resolution. Instead, I don't know he has perceived a sense of loss of control at any time and a high degree of involvement in group work has been observed.

It is clear that the evaluation of learning is an arduous task that few teachers are aware of doing properly in their classrooms. In the study in Social Sciences it has been successfully carried out through this constructivist conception that sets the centre of interest in the student.

On the other hand, collaborative learning has been another relevant aspect of the project. The narration that the students have done using Social Networks has meant that third parties have explained their own experiences spontaneously, favouring a learning in community and a transfer of knowledge to society that enriches the project more. As a prospective, a possible future investigation could be in line with inquiring about the differences in the acquisition and development of skills of different generations over time, taking as the cornerstone of the study the same educational project which would also allow check the different rhythms present in the advancement of ICT and in the prevailing pedagogy.

In Heritage Education, studies on program evaluation have been carried out, some with more validity and reliability tests than others. This work has influenced two aspects: criterion validity and reliability.

In this regard, and within the future work that could emanate from studies such as the one raised in these articles, it would be interesting to propose in-depth studies on the conceptions of heritage that teachers and students have of the subjects that make up Heritage Education. This type of research would allow us to glimpse the historical and sociological relationship of the dialogue between the heritage and the Spanish school over the last decades. For example, studies on the confrontation between a historical legacy conceived as a rigid corpus prone to the "indoctrination" of the student, and the contemporary vision of heritage as a multifaceted and global exploration of artistic manifestations could be promoted. 
Likewise, studies focusing on the analysis of the way in which the teaching practice reflects the inclusion of aspects related to heritage in the curricula, the evaluation by competences and / or the initial training that future teachers have in this regard could be promoted. 


\section{CUERPO CONCLUSIVO}

\section{CONCLUSIONES Y DISCUSIÓN}

\subsection{CONCLUSIONES DE LOS ARTÍCULOS Y DISCUSIÓN}

Una de las intenciones de la tesis, y por extensión de los tres artículos en que se basa, es intentar aplicar los resultados obtenidos al ámbito genérico de la Educación Patrimonial. En la definición de qué sea Educación Patrimonial seguiremos el hilo conductor que plantea Fontal (2016), que tras tres décadas de indagación en textos curriculares defiende varios postulados:

A. Respecto a la Educación Artística, ésta es una de las materias más vinculadas a la Educación Patrimonial, igualmente la formación de los maestros es fundamental referida a la Educación Patrimonial.

B. En el ámbito universitario y de Planes legislativos, es relevante el área de Didáctica de la Expresión Plástica, que ha abierto una línea de investigación específica en Educación Patrimonial. En el marco legislativo es destacable el Plan Nacional de Educación y Patrimonio (2013, PNEyP) como referencia nacional de promoción de la investigación y formación en Educación Patrimonial.

C. Por último, desde la Sociología, la investigación revela que la Educación Patrimonial es rentable en términos sociales, culturales y de identidad.

Nuestros estudios de caso se han desarrollado tanto en las áreas de Educación Artística como de Ciencias Sociales, las cuales tienen una vinculación demostrada con la Educación Patrimonial, ya que son ambas las que desarrollan contenidos sobre el patrimonio.

Nuestra investigación concreta en Educación Plástica y Visual pertenece al ámbito de la Educación Artística, y por extensión a la Educación Patrimonial, por lo que nuestras conclusiones pueden extenderse, partiendo de lo concreto de los resultados, hacia los debates teóricos y sociales del tratamiento del patrimonio en la Educación Primaria. 
Así pues, las conclusiones generales emanadas del estudio de caso desarrollado, que podrían aplicar al campo de la Educación Patrimonial serían:

1. Los informantes coinciden en destacar el compromiso humano como base de una motivación progresiva y generativa en la docencia, lo cual incide directamente en el diseño curricular en Primaria.

2. Un segundo resultado de nuestros estudios muestra que sería recomendable equilibrar entre todos los agentes educativos la enseñanza de contenidos con la didáctica de los mismos, todo ello en aras de alcanzar una educación integral con una evaluación de aprendizajes más justa y equilibrada. Esta idea podría extenderse al área de la Educación patrimonial.

3. Nuestros informantes han valorado tanto las competencias artísticas como otras de enseñanza-aprendizaje, y especialmente las competencias trasversales, investigadoras, sistémicas y comunitarias. Éstas ayudan a estructurar un diseño educativo más ajustado a una evaluación significativa y compleja con estrategias y recursos apropiados de evaluación. La Educación Patrimonial, como área trasversal, podría beneficiarse enfocando directamente como disciplinas más afines la Educación Artística y en Ciencias sociales.

4. Suelen ser tres las tres áreas curriculares más importantes dentro de la Educación Patrimonial (Plástica, CC. Sociales, Lengua), aunque dado su carácter transversal, podría abarcar otras.

En todos nuestros trabajos hemos analizado la tensión existente entre las demandas curriculares establecidas por la legislación actual, las inercias de las instituciones educativas y las prácticas docentes innovadoras. Tal y como muestran algunos de los datos presentados en la sección de resultados, la rigidez propia del currículo oficial, así como la escasez de recursos existentes para su aplicación en lo relativo a la evaluación de los aprendizajes, hacen que los docentes aboguen por procesos de evaluación/calificación de corte sumativo que muchas veces implican una escisión entre las distintas asignaturas que conforman la Educación Artística. Desde nuestro punto de vista, la Educación Patrimonial podría ayudar a solventar estas tensiones desde tres aspectos fundamentales:

A) En primer lugar, ayudando a promover la interacción entre asignaturas y/o áreas de conocimiento. 
B) En segundo término, facilitando la permeabilidad de la Escuela al medio social, fomentando así la idea de que el legado histórico pertenece a todas las generaciones y que ha de ser aprehendido por el educando en cualquier espacio social donde se manifieste.

C) Y tercera, la de ayudar a entender al alumnado como participante, además de observador o sujeto pasivo de las manifestaciones artísticas.

En las declaraciones de los informantes suele coincidir la vocación de docentes con la de artistas o investigadores, estableciéndose una interacción fecunda entre ambas facetas que fertiliza ambas, a medida que se desarrolla la praxis educativa.

Todos destacan la implicación y responsabilidad hacia las personas, hacia los alumnos como clave de identidad docente y motor de una constante innovación e investigación hacia la excelencia.

Respecto a la Educación Artística, hay una reivindicación de la docencia de técnicas y materiales, no solo circunscrita a la Educación Secundaria, además de la tradicional docencia basada en contenidos y enfocada a lo teórico.

Podemos establecer una enumeración de competencias significativas como resultado de las que los informantes han considerado más relevantes, unidas a las que el currículo nos propone. Estas serían:

1. Desarrollo de la creatividad,

2. desarrollo de la sensibilidad,

3. desarrollo de la competencia comunicativa como elemento vertebrador de la docencia en sus aspectos de manejo de grupos, feedback docente-alumno etc.,

4. desarrollo de la inteligencia emocional, también trasversal en el trabajo con grupos e individuos,

5. desarrollo de la autonomía personal,

6. conocimientos y procedimientos de todo lo relacionado con la práctica educativa, incorporando así una visión investigadora y dinámica de la docencia: técnicas, fundamentos de disciplinas etc., desarrollo de habilidades relacionadas con la praxis: interpretar, saber buscar información, sentido y finalidad de la práctica etc.,

7. y el desarrollo de un compromiso ético. 
Respecto al abordaje de la evaluación, ésta se centra en los procesos y actitudes más que en los resultados finales y pretende ser global y continua. Las técnicas preferidas son el feedback comunicativo exhaustivo, la evaluación por ítems y las pequeñas evaluaciones sobre elementos del trabajo (micro-assessment). La evaluación numérica (calificación) se realiza también, a veces declarando críticas o distanciamiento de la misma. Así pues, las conclusiones generales obtenidas del proceso investigador serían:

1. Los informantes destacan el compromiso humano como eje de una motivación progresiva y continua en su profesión docente.

2. La Educación Artística debería equilibrar los contenidos curriculares con la enseñanza de técnicas y materiales.

3. Las competencias docentes son plurales y todas merecen desarrollarse con especias énfasis en las trasversales, investigadoras, sistémicas y comunitarias, todas ellas ligadas a la pedagogía más contemporánea.

4. La evaluación del aprendizaje se centraría los procesos y actitudes, realizándose de manera continua y global.

Los sucesivos analisis del estudio con informantes nos revelan diversas paradojas:

1) Nuestros informantes cumplen las orientaciones propuestas por el currículo, sin embargo, declaran abiertamente encontrarse con contradicciones en la práctica docente. Respecto a las competencias del alumnado la Administración educativa parte en primer lugar, a través de sus estudios teóricos y técnicos, de un análisis del estado de la cuestión del asunto. Es precisamente cuando el legislador observa que una serie numerosa de competencias discentes presentan déficit en general en nuestro sistema, la Administración elabora una ley genérica que aborde el asunto con (teórica) vocación de permanencia.

2) A través de nuestra investigación obtenemos evidencias de que los educadores desarrollan una fase de detección de carencias sobre competencias en el material que hemos recopilado. Dichas competencias son: competencia comunicativa, creatividad, sensibilidad, inteligencia emocional y autonomía personal. En el caso de la Administración, sus estudios previos acerca de este tema son estructurales, es decir, informados por todas las ciencias; y la formulación de las competencias redactadas en la norma tienen la ventaja de ser plural, pero la desventaja de no ahondar en líneas 
contemporáneas de Pedagogía (ejemplo la educación de la inteligencia emocional).

3) La enunciación de competencias que los informantes progresivamente van desgranando, es obviamente menos enciclopédica, pero tiene un interés y descripción focalizados en las competencias particulares que domina cada uno de los informantes en relación a su formación y desarrollo profesional. Los docentes se esfuerzan por seguir las competencias del currículo: desarrollo de la competencia comunicativa, desarrollo de la inteligencia emocional, desarrollo de la autonomía personal, conocimientos y procedimientos de todo lo relacionado con la práctica educativa: técnicas, fundamentos de disciplinas, desarrollo de habilidades relacionadas con la praxis: interpretar, saber buscar información, sentido y finalidad de la práctica y desarrollo de un compromiso ético. Sin embargo, los centros educativos no poseen una implementación de recursos pedagógicos para desarrollar correctamente dichas competencias, por lo cual, el seguimiento del currículo es individualista y apoyado en competencias más generales como es la creatividad.

4) Las competencias trasversales son específicamente promovidas entre los docentes de Educación Plástica. Así destacamos quelas competencias trasversales más potenciadas en nuestro material recogido serían: aprender a aprender, competencia comunicativa, autonomía personal y autonomía tutelada de los grupos, etc. En el arte confluyen variados valores como los simbólicos, culturales y sociales, lo cual ha de influir para proyectar los contenidos artísticos a otras áreas y aumentar su peso específico relacionándolo con el resto de materias. "El arte es un campo de conocimiento que se conecta con otras áreas dentro del currículo y que requiere de docentes con nuevos perfiles" (Jiménez, Aguirre y Pimentel, 2009, 11).

5) A continuación, no queremos olvidar los factores sociológicos que siempre inciden en el diseño y ejecución de los currícula, y que han aparecido, a veces, explícitamente y otras en una lectura entre líneas en el trascurso de nuestra investigación. En este sentido describimos otra razón del distanciamiento entre docentes y currículo. Es innegable el factor de economicismo que documenta las últimas reformas normativas desde la 
declaración de Lisboa y el Plan Bolonia de principios de siglo. Las reivindicaciones que hemos recogido basadas en la petición de potenciación de la enseñanza artística y concretamente en su reflejo en el currículo, desde los títulos propios al aumento de horas lectivas, revelan un sesgo de distanciamiento respecto a diseños curriculares y ciertas competencias concretas oficiales, mencionemos explícitamente las referidas al conocimiento y fomento de la "cultura empresarial". Si el equilibrio entre ambos grupos de competencias se decanta hacia las más "economicistas" respecto a las trasversales y artísticas no podrá haber un desarrollo dotado de medios suficientes de las materias artísticas o la Educación patrimonial.

6) En estrecha relación se detecta una crítica del distanciamiento de los legisladores educativos respecto al conocimiento in situ y las dinámicas prácticas de la enseñanza real. Igualmente hay una crítica a la implicación de algunos entornos familiares y de la dirección de los centros docentes, lo cual dificulta el enfoque sistémico en educación y por extensión en las ciencias sociales creciente desde la década de los 90.

7) Respecto a la metodología de la evaluación, se dan movimientos intermitentes de confluencia y distanciamiento entre la evaluación formal y las prácticas alternativas. La mayoría de informantes se decantan teóricamente por evaluar procesos y actitudes y en la práctica combinan esta metodología con la evaluación de los productos finales para las cuestiones formales. En Educación Plástica también los docentes intentan seguir las orientaciones curriculares pero el currículo no desarrolla la metodología específica para esa evaluación, por lo cual se impone una intervención individualista. La evaluación de procesos y actitudes se recoge sólo de forma genérica en la norma; por el contrario, la crítica viene por el excesivo peso que sigue teniendo en la misma los exámenes tradicionales y la secuenciación estricta de los contenidos y las pruebas.

En nuestros estudios sobre Eduacion Plástica -respecto al assessment o las teorías de Stake o la escuela anglosajona del aprendizaje situado- se observa un notable grado de seguimiento de sus mismos principios: evaluación como aprendizaje, moduladora del mismo, tendente a objetivos previstos y futuros. Si bien, el uso de herramientas concretas es diferente según el contexto socio temporal de cada informante. 
Entre las escuelas de Psicología y Pedagogía, la contemporaneidad que se refleja en los estudios de Educación Plástica, tiene como antecedentes al Cognitivismo vigostkiano y otras corrientes más actuales: individuación de la educación/multifactorialidad (múltiples factores del alumno y su entorno; enfoque sistémico); evaluación ecológica/situacionista (atención a los factores territoriales y del presente); o evaluación holística, que engloba elementos de las dos anteriores.

8) Encontramos otra paradoja en la dicotomía de una evaluación ideal sobre procesos y actitudes pero que no se sabe bien cómo ejecutar. Es decir, hay un gran salto entre las convicciones teórico-personales-profesionales de los docentes al respecto, y un déficit de metodologías disponibles en la praxis para evaluar competencias en Educación Artística. El currículo no explica la forma de realizar la evaluación de los procesos y actitudes. Los docentes en la práctica siguen una cierta secuenciación: primero hay un convencimiento teórico del docente que genera métodos y una búsqueda individual de recursos (semi-anárquica, o poco documentada); posteriormente, busca un apoyo en las innovaciones que parten de los diseños curriculares; y por último, añade un feedback de su praxis específica, etc.

Observando esta dinámica se presume que la evaluación es un proceso que parece descoordinado, no hay circulación de información entre los investigadores, los legisladores, la dirección de los centros y los docentes; y mucho menos con las familias, los agentes sociales o los creadores artísticos. Sobre todo, destaca el distanciamiento entre la teoría didáctica y sus recursos y los docentes individuales. Si se reconoce como cierta esta aproximación al estado de la cuestión y que todo ello sea un hecho de recorrido histórico en nuestro país, se puede llegar a afirmar que en la investigación se avanza en el sentido contrario, es decir, coordinar a todos los agentes educativos es un proceso muy consciente y arduo.

9) Habría otra paradoja paralela. La praxis del profesor artístico podríamos concluir que se ha instalado en el hacer de manera poco reflexiva, como modo habitual de trabajo. A este punto intermedio se habría llegado observando las dificultades en la sistematización, por un lado, y por otro, observando la inoperancia de la anarquía, referidas ambas a la Educación Artística. 
Para evaluar aprendizajes en este ámbito, último criterio de calidad de un programa educativo, el docente tiene que aprender el proceso por sí mismo: la transversalidad de lo patrimonial, el contexto del alumnado, sus capacidades, conocer las competencias y los estándares de aprendizajes, el autoaprendizaje dirigido y salir de un currículo poco abierto que a veces deja la enseñanza del patrimonio en una declaración de intenciones. Desde la comunidad educativa se carece de educación en lo patrimonial como disciplina que cumple las consignas de las nuevas enseñanzas, en las que lo importante es la persona. Y la evaluación en este campo, afrontarla de forma sistémica, socializada y crítica, como una actitud en la forma de hacer educación. Aprender a evaluar aprendizajes forma parte de nuestro patrimonio.

Respecto de la selección de estándares hemos concluido que los programas mejor valorados en nuestro estudio puntúan alto en estándares de diverso tipo. Es decir, tanto en el tipo de estándares más cercanos al currículo, como objetivos o metodología como en estándares "contemporáneos" como la aplicación de TIC, y en estándares de teorización como fundamentación del proyecto etc...

Este equilibrio entre los estándares se fundamenta en todo lo dicho anteriormente sobre la importancia del nivel de implicación individual del maestro respecto a la innovación e investigación educativa en educación patrimonial.

Un docente implicado lo está de forma equilibrada con todos los factores y sectores del hecho educativo y elaborará en su caso programas con atención al diseño curricular para coordinarse con el legislador y la institución escolar. Igualmente lo está con el alumnado, elaborando metodologías precisas e innovadoras. E igualmente, con los padres, y la sociedad utilizando las TIC como herramientas de difusión y extensión educativa. Por último, en consonancia con su desarrollo personal y como docente hará una profunda reflexión teórica sujeta a la redefinición mediante el feedback.

Paralelamente en la selección precisa de estándares significativos que se plantea en esta tesis se eligen varios correspondientes a los diferentes grupos "teóricos" señalados; algunos de las de mayor tono institucional, otros de las de difusión mediática o sistémicas, otros de marco teórico, otros de implementación técnica o metodológica. 
En cada uno de estos grupos hay algunos estándares altamente puntuados o relevantes que se elegirán prioritariamente, como pueden ser:

\section{Sistémico:}

"Incorporación de distintos agentes educativos: evaluación de todos los agentes que intervienen".

\section{Institucional:}

“Adecuación al currículo nacional y autonómico: sigue estándares de evaluación que se propone en currículo o el plan nacional de educación y patrimonio"; "Diversidad de competencias aprendidas", "Diversidad de competencias desarrolladas"

\section{Marco teórico:}

"Valores adquiridos en el proceso", "Se evalúa el concepto de patrimonio en todas sus tipologías: cultural, construido, intangible, o natural." "Concreción teórica: se adecúa la evaluación a los objetivos propuestos y hay una estructura didáctica adecuada" Habría que decir no obstante respecto a estándares apenas puntuados, que ello no revela poca importancia, sino más bien un potencial a desarrollar con programas con gran componente técnico y de elaboración compleja y bien implementados con medios que puedan atender también a esas variables minoritarias.

\subsection{LIMITACIONES, PROSPECTIVA Y LÍNEAS FUTURAS}

La serie de carencias que observamos en el futuro docente de la Educación Plástica $\mathrm{y}$ de disfunciones entre lo normativo y la praxis y las numerosas paradojas que describimos nos induce y motiva a plantear varias líneas de trabajo futuras que puedan resultar interesantes para el análisis y transformación de esos aspectos. Exponemos a continuación esas líneas abiertas al futuro que nos plantearíamos estudiar, a saber:

- Primera. Profundizar en las innovadoras formas de assessment adaptadas a los requisitos de la educación artística. (Black, P. et all (2003); 
- Martin-Kniep, G (2005)) Cabría estudiar específicamente casos de aplicación especializada de assessment en España, en los que conscientemente, siguiendo autores concretos se esté implementando las metodologías concretas de la evaluación de aprendizajes. A este respecto cabría elaborar una recopilación de buenas prácticas en el assessment de la educación artística. Estas buenas prácticas podrían servir como base para la discusión e incluso la formación inicial y permanente del maestro. El enfoque de esta línea podría abordar los contenidos siguientes: herramientas del assessment, su aplicación, resultados y comparativas.

- Segunda. Profundizar en el estado de la cuestión del Arte actual, con especial interés al Arte aplicado o aplicable a la educación. De esa manera se debería profundizar en las escuelas angloamericana y francesa de las que sólo se han esbozado líneas maestras a falta de documentarnos en su amplia bibliografía. La coyuntura del arte contemporáneo en las últimas décadas cuenta con un avance exponencial de diferentes técnicas, estilos, métodos, soportes etc.

Paralelamente su reflejo en la educación artística ha necesitado abordar toda esta explosión conceptual y práctica.

Respecto a las competencias curriculares específicas sobre educación artística contemporánea (conocimiento de estilos y técnicas o participación comunitaria, por ejemplo), encontramos evidencias del interés de los informantes por plasmarlas, si bien han de circunscribirlas sobre todo al aula por la falta de tejido colectivo e interés social hacia el arte contemporáneo que se detecta en el ámbito geográfico estudiado.

- $\quad$ Tercera. Propuestas desde la práctica docente hacia la teoría. El estudio de las evidencias nos invita a mencionar un código de buenas prácticas observadas deseando que sirvan de feedback para los docentes en general; podemos mencionar aquí

las propuestas de trabajo en equipo, en que los profesores compartan los avances y experiencias en educación y evaluación contemporáneas.

El maestro ha de cambiar su papel tradicional como mero trasmisor de conocimientos, para convertirse en el mediador del aprendizaje, gestor de aula, evaluador, investigador e innovador (Mendía 2004), teniendo en cuenta el contexto en 
el que se desarrolla su actividad. Debe renovarse y utilizar una amplia gama de estrategias de enseñanza, convirtiendo el aula en un espacio de creación, y para ello, se han de aumentar los estímulos y las oportunidades que se ofrecen a los alumnos (Darling-Hammond, 2001).

Para teorizar habría que comparar los códigos de buenas prácticas con las diversas escuelas teóricas (internacionales y españolas) en las que se encuadra dicha praxis. Y esa comparación tendría que aportar nuevos elementos teóricos de debate y cuestionamiento de diversos temas.

Respecto al impacto educativo de un proyecto de innovación en educación patrimonial en el área de las Ciencias sociales que utiliza las RRSS para investigar, participar y transmitir; incluso el alumnado se vio sorprendido por una metodología innovadora que impactó en su manera de aprender rompiendo la rutina de enseñanza-aprendizaje basada en la memorización.

Si García-Valcárcel, Basilotta y López (2013), en su estudio relativo al empleo de las TIC en el aprendizaje colaborativo en la enseñanza Primaria y

Secundaria de Castilla y León, especificaban que:

en cuanto a las principales limitaciones para implementar en el aula metodologías de aprendizaje colaborativo, se han señalado algunas cuestiones que tienen implicación en el desarrollo del currículo como el empleo de más tiempo, una cierta pérdida de control, la diferente implicación de los estudiantes o las dificultades para evaluar el proceso de aprendizaje y los resultados obtenidos por cada alumno (p.72).

En nuestro estudio en el área de Ciencias sociales hemos podido verificar algunos de estos aspectos y cuestionar otros.

Resulta innegable que se necesita más tiempo del que dispone el alumnado en el curso escolar para tareas de mucha envergadura - el actual ecosistema (escolar, familiar y social) de bachillerato no parece preocuparse tanto por los aprendizajes adquiridos como por la nota de corte o la memorización de cara a una prueba externa que no contempla este tipo de planteamientos educativos en su resolución-. En cambio, no se ha percibido sensación de pérdida de control en ningún momento y se ha constatado un elevado grado de implicación en el trabajo grupal.

Está claro que la evaluación de aprendizajes es una tarea ardua que pocos profesores son conscientes de llevar a cabo adecuadamente en sus aulas. En el estudio en Ciencias 
Sociales se ha conseguido realizar con éxito mediante esa concepción constructivista que fija el centro de interés en el educando.

Por otro lado, el aprendizaje colaborativo ha sido otro aspecto relevante del proyecto. La narración que los alumnos han realizado usando RRSS ha supuesto que terceros hayan explicado sus propias experiencias espontáneamente, favoreciendo un aprendizaje en comunidad y una transferencia de conocimiento a la sociedad que enriquece más el proyecto.

A modo de prospectiva, una posible investigación futura podría ir en la línea de indagar sobre las diferencias existentes en la adquisición y desarrollo de competencias de distintas generaciones a lo largo del tiempo, tomando como piedra angular del estudio el mismo proyecto educativo lo que también permitiría comprobar los diversos ritmos presentes en el avance de las TIC y en la pedagogía imperante.

En Educación Patrimonial se han realizado estudios sobre evaluación de programas, unos con más pruebas de validez y fiabilidad que otros. Este trabajo ha incidido en dos aspectos: la validez de criterio y la fiabilidad.

A este respecto, y dentro del trabajo futuro que podría emanar de estudios como el planteado en estos artículos, sería interesante plantear estudios en profundidad sobre las concepciones de patrimonio que tiene el profesorado y alumnado de las materias que conforman la Educación Patrimonial. Este tipo de investigaciones permitiría vislumbrar la relación histórica y sociológica del diálogo entre el patrimonio y la escuela española a lo largo de las últimas décadas. Por ejemplo, se podrían promover estudios sobre el enfrentamiento entre un legado histórico concebido como corpus rígido proclive al "adoctrinamiento" del educando, y la visión contemporánea del patrimonio como exploración multifacética y global de las manifestaciones artísticas.

Igualmente, se podrían promover estudios centrados en el análisis de la forma en que la praxis docente refleja la inclusión de aspectos relacionados con el patrimonio en los currículos, la evaluación por competencias y/o la formación inicial que los futuros docentes tienen a este respecto. 


\section{REFERENCIAS BIBLIOGRÁFICAS Y BIBLIOGRAFÍA}

Abril, D. y Cuenca, J. M. (2016). Prehistoria y Arqueología en $1^{\circ}$ de ESO: análisis documental y propuesta didáctica para la explicación de la organización social pasada y actual Prehistory and Archaeology in 1st ESO: documental analysis and learning proposal for the knowledge of the past and present social organization. Clío: History and History Teaching., (42), 9.

Aceves, S. (2004). El conjunto conventual Franciscano de Tlaxcala en la Lista Indicativa. Hereditas, 9, 24-27.

Adell, J., Mengual-Andrés, S. y Roig-Vila, R. (2015). Presentación del Monográfico. Webquest: 20 años utilizando Internet como recurso para el aula. Edutec-e. Revista Electrónica de Tecnología Educativa, (52), 1-7.

Alcaraz, N. (2015). Aproximación Histórica a la Evaluación Educativa: De la Generación de la Medición a la Generación Ecléctica. Revista Iberoamericana de Evaluación Educativa, 8(1), 11-25.

Alcina, M.H., Aznar, R. y Soler, J.A. (2002). El MARQ de Alicante: El primer museo arqueológico del siglo XXI. En Nogales, T.-Álvarez, J.M. (Eds.). Museos Arqueológicos para el siglo XXI, (p.119-138). Badajoz.

Alvárez-Méndez, J.M. (2001). Evaluar para conocer, examinar para excluir. Madrid: Morata.

Álvarez, I. (2005). Evaluación como situación de aprendizaje o evaluación auténtica. Perspectiva educacional, 45, 45-67.

Álvarez, S., Carleos, C., Corral, N. y Prieto, E. (2018). Metodología docente y rendimiento en PISA 2015: Análisis crítico. Revista de Educación, 379, 85-105.

Allen, J.; Ramaekers, G. y Van Der Velden, R. (2003). La medición de las competencias de los titulados superiores. En Vidal García, J. (Ed.), Métodos de análisis de la inserción laboral de los universitarios, (pp. 31-54). León: Universidad de León.

ANECA (2003). Programa de convergencia europea. El crédito europeo. Madrid: Agencia Nacional de Evaluación de la Calidad y la Acreditación.

Anico, M. y Peralta, E. (2009). Heritage and identity. Engagement and Demission in the Contemporary World, Museum Meanings. Abingdon, Oxon, United Kingdom: Ed. Routledge. 
Ángelo, T.A. y Cross, K.P. (1993). Classroom assessment techniques: A handbook for college teachers ( $2^{\mathrm{a}}$ Ed.). San Francisco: Jossey-Bass.

AQU CATALUNYA (2004). Marc general per a la integració europea. Barcelona: Agència per a la Qualitat del Sistema Universitari de Catalunya.

Arias, M. M. (1999). Triangulación metodológica: Sus principios, alcances y limitaciones. Investigación y Educación en Enfermería, 18(1), 13-26.

Aron, R. H. (1978). Statistical forecasting models-II Oxidant concentrations in the Los Angeles basin. J. Air Polfuf. Control Ass, 28, 684-688.

Austin, B., Adesope, O., French, B., Gotch, C., Belanger, J. y Kubacka, K. (2015). Examining school context and its influence on teachers: Linking Talis 2013 with PISA 2012 student data. OECD Education Working Papers, No. 115, Paris: OECD Publishing.

Ausubel, D. (1983). Teoría del aprendizaje significativo. Fascículos de CEIF, 1, 1-10.

Ávila-Rodríguez, C. \& Castro-López, M., (2016). La salvaguardia del Patrimonio Cultural Inmaterial: Una aproximación a la reciente Ley $N^{\circ}$ 10/2015. Revista sobre Patrimonio Cultural: Regulación, Propiedad Intelectual e Industrial (RIIPAC), 5.

Aronson, J. (2005). The threat of stereotype. Educational Leadership, 62, 14-20.

Ashworth, G., Graham, B. y Tunbridge, J. (2007). Pluralising pasts: heritage, identity and place in multicultural societies. London: Pluto Press.

Bangdiwala, S. I. (1987). A graphical test for observer agreement. Proceedings of the 45th International Statistical Institute Meeting, Amsterdam, 1, 307308.

Bamford, A. (2006). The wow factor: Global research compendium on the impact of the arts in education. Waxmann Verlag.

Barrón, C. (2000). La evaluación basada en competencias en el marco de los procesos de globalización. México: Centro de Estudios de la Universidad, UNAM.

Bauman, Z. (2007). Tiempos líquidos: vivir en una época de incertidumbre. Barcelona: Tusquets.

Bartolomé, L. (1984). Aspectos sociales de la relocalización de población afectada por la construcción de grandes represas. En F. Suárez et al., (Ed.), Efectos sociales de las grandes represas en América Latina. Montevideo, Fundación Cultura Universitaria para CIDES (OEA) e ILPES (ONU). 
Becker, H. S. (1963). Outsiders: Studies in the sociology of deviance. New York: Free Press.

Bloom, David, Harris O. y Ludlum D.E. (1990). Reading and writing as sociocultural activities. Topics in Language Disorders, 11, (3), 14-27.

Boletín Oficial del Estado no 187, de 6 de agosto de 1970. (1970). LGE: Ley General de Educación 14/1970, de 4 de agosto y Financiamiento de la Reforma Educativa, 12525 a 12546.

Boletín Oficial del Estado no 154, de 27 de junio de 1980. (1980). Ley LOECE: Ley Orgánica 5/1980, por la que se regula el Estatuto de Centros Escolares, 14633 a 14636.

Boletín Oficial del Estado $n^{\circ} 159$, de 3 de julio de 1985. (1985). Ley LODE: Ley Orgánica 8/1985, reguladora del derecho a la educación.

Boletín Oficial del Estado n 278, de 21 de noviembre de 1995. (1995). Ley LOPEG:

Ley Orgánica 9/1995, de la participación, la evaluación y el gobierno de los centros docentes, 33651 a 33665 .

Boletín Oficial del Estado no 307, de 24 de diciembre de 2002. (2002). Ley LOCE: Ley Orgánica 10/2002, de Calidad de la Educación, 45188 a 45220.

Boletín Oficial del Estado no 238 de 4/10/1990. (1990). LOGSE: Ley Orgánica 1/1990, de 3 de octubre de 1990, de Ordenación General del Sistema Educativo, 2892728942.

Boletín Oficial del Estado no 106 de 4/5/2006. (2006). LOE: Ley Orgánica 2/2006, de 3 de mayo, de Educación, 17158-17207.

Boletín Oficial del Estado no 295 de 10/12/2013. (2013). LOMCE: Ley Orgánica 8/2013, de 9 de diciembre, para la mejora de la calidad educativa, 97858-97921

Boletín Oficial del Estado $n^{\circ}$ 52, de 1 de marzo de 2014. (2014). Real Decreto 126/2014, de 28 de febrero, por el que se establece el currículo básico de la Educación Primaria, 19349- 19419.

Boletín Oficial del Estado no 117 de 20/06/2014. (2014). ORDEN EDU/519/2014, de 17 de junio, por la que se establece el currículo y se regula la implantación, evaluación y desarrollo de la educación primaria en la Comunidad de Castilla y León, 44181- 44768.

Boletín Oficial de Castilla y León no 86 de 8/5/2015. (2015). ORDEN EDU/362/2015, de 4 de mayo, por la que se establece el currículo y se regula la implantación, 
evaluación y desarrollo de la educación secundaria obligatoria en la Comunidad de Castilla y León, 32051- 32480.

Boletín Oficial de Castilla y León no 86 de 8/5/2015. (2015). ORDEN EDU/363/2015, de 4 de mayo, por la que se establece el currículo y se regula la implantación, evaluación y desarrollo del bachillerato en la Comunidad de Castilla y León, 32481-32984.

Bordas, I. y Cabreras, F. (2001). Estrategias de evaluación de los aprendizajes centradas en el proceso. Revista española de pedagogía, 218, 25-48.

Bradfield, J. M., \& Moredock, H. S. (1957). Measurement and evaluation in education: an introduction to its theory and practice at both the elementary and secondary school levels. New York: The Macmillan Company.

Broadfoot, P. (1996). Education, assessment and society: A sociological analysis. Buckingham: Open University Pres.

Bruner, J. (1972). El Proceso de educación. México: Ed. Uteha.

Cabero-Almenara, J. (2015). Reflexiones educativas sobre las tecnologías de la información y la comunicación (TIC). Tecnología, ciencia y educación, 1, 1927.

Calaf, R. y Fontal, O. (2006). Metáforas para Conceptualizar el Patrimonio Ártístico y su Enseñanza. En R. Huerta y R. de la Calle (coords.) Espacios Estimulantes, Museos y Educación Artística. Valencia: Universitat de Valencia.

Calaf, R. y Fontal, O. (2010). Cómo enseñar arte en la escuela. Madrid: Síntesis.

Calviño, L. C., y López-Facal, R. (2019). Educación patrimonial: necesidades sentidas por el profesorado de infantil, primaria y secundaria. Revista interuniversitaria de formación del profesorado, (94), 97-114.

Campbell, D. y Stanley, J. (1982). Diseños experimentales y cuasi-experimentales en investigación educativa. Argentina: Amorrortu Editores.

Campbell, T., \& Fiske, W. (1959). Convergent and discriminant validation by multitrait-multimethod matrix. Psychological Bulletin, 56, 81-105.

Campbell, B. (1994). Practical aspects of authentic assessment putting the pieces together. Norwood, MA Christopher-Gordon.

Canto, J., Moral, F. y Gómez-Jacinto, L. (2004). Internet y desindividuación. Nuevas perspectivas sobre la desindividuación en la red: El modelo de identidad social 
de los fenómenos de desindividuación (SIDE). Revista de Psicología Social, 19(1), 93-106.

Hernández-Cardona, F. X. (2002). Dinámicas curriculares en ciencias sociales. La Reforma y su deconstrucción. Iber: Didáctica de las ciencias sociales, geografía e historia, (33), 78-94.

Hernández-Cardona, F. X. (2016). El Centre i l'entorn cultural: mitjans de comunicació, museus, biblioteques i oferta cultural diversa. Revista Catalana de Pedagogía, 200-201.

Carrow-Woolfolk, E. (1999), CASL: Comprehensive Assessment of Spoken Language. American Guidance Services. USA.

Carr, W. y Kemmis, S. (1988). Teoría crítica de la enseñanza. La investigación acción en la formación del profesorado. Barcelona: Martínez Roca.

Casal, S. M., Conti, A., Couturier, F. y Cragnolini, M. (2003). Patrimonio Arquitectónico de la ciudad de Buenos Aires: El patrimonio de las primeras décadas. Documento de Trabajo N ${ }^{\circ} 275$, Universidad de Belgrano. Disponible en: http://www.ub.edu.ar/investigaciones/. Buenos Aires, Argentina.

Clay, M.M. y Cazden, C.B. (1990). A Vygotskian interpretation of reading recovery. En L.C. Moll (Ed.), Vigotsky and education. New York: Cambridge University Press.

Cook, T. y Campbell, D. (1979). Quasi-experimentation. Design and analysis issues for field settings. Boston: Houghton Mifflin.

Cook, T. D. \& Reichardt, C. S. (1979). Beyond qualitative versus quantitative methods. In T. D. Cook \& C. S. Reichardt (Eds.), Qualitative and quantitative methods in evaluation research (pp. 7-32). Newbury Park, CA: Sage.

Coma, L. (2011). Actividades educativas y didáctica del patrimonio en las ciudades españolas. Análisis, estado de la cuestión y valoración para una propuesta de modelización. [Tesis doctoral]. Universidad de Barcelona. Barcelona, España.

Coma, L. (2013). Dinamizar y digitalizar la ciudad: Itinerarios urbanos, dispositivos móviles y códigos QR. Hemus, vol. 2, pp. 63-68. 
Consejo de Europa, (2015). Convenio marco del consejo de Europa sobre el valor del patrimonio cultural para la sociedad, $N^{\circ} 199$. Aprobada en Faro el 27 de octubre de 2005. Faro, Portugal.

Copeland, E. (2012). The Silver Fork Novel: Fashionable Fiction in the Age of Reform (Vol. 81). Cambridge University Press.

Cortés-Vázquez, J.A., Jiménez-Esquinas, G. y Sánchez-Carretero, C. (2017). Heritage and participatory governance: An analysis of political strategies and social fractures in Spain. Anthropology Today. Royal Anthropological Institute of Great Britain and Ireland: Wiley, 33 (1), 15-18.

Crooke, E. (2007). Museums and community: ideas, issues and challenges. London: Routledge.

Creswell, J. W., \& Plano Clark, V. L. (2011). Choosing a mixed methods design. Designing and Conducting Mixed Methods Research, 2, 53-106.

Creswell, J. W. (2013). Research design: Qualitative, quantitative, and mixed methods approaches. California: Sage publications.

Creswell, J. W. (2014). A concise introduction to mixed methods research. California: Sage publications.

Cronbach, L.J. (1963). Course improvement through evaluation. Teachers College Record, 64, 672- 683

Crotty, M. (1998). The foundations of social research. Thousand Oaks, California: Sage Publications.

Cuenca-López, J.M. (2003). El patrimonio en la didáctica de las ciencias sociales: Análisis de concepciones, dificultades y obstáculos para su integración en la enseñanza obligatoria. [Memoria para optar al grado de doctor]. Universidad de Huelva. Huelva, España.

Cuenca-López, J. M., Wamba, A. M. y Aguaded, J. S. (2006). Las actividades prácticas en museos de ciencia y centros de interpretación: ¿Cómo orientarlas desde una perspectiva holística? Alambique: Didáctica de las ciencias experimentales, (47), 74-81.

Cuenca-López, J. M. (2010). Máster y doctorado de didácticas específicas. líneas formativas y de investigación en didáctica de las ciencias sociales. En R. M. Ávila, P. Rivero y P. L. Domínguez (2010). Metodología de investigación en 
Didáctica de las Ciencias Sociales. Universidad de Zaragoza, Zaragoza. (p.369-379).

Cuenca-López, J. M. (2014). El papel del patrimonio en los centros educativos: Hacia la socialización patrimonial. Tejuelo: Didáctica de la Lengua y la Literatura. Educación, (19), 76-96.

Cuenca-López, J. M., Estepa-Giménez, J., \& Cáceres, M. J. M. (2017). Patrimonio, educación, identidad y ciudadanía. Profesorado y libros de texto en la enseñanza obligatoria. Revista de Educación, 375, 136-159.

Custer, R. (1998). Authentic Assessment. Basic Definition and Perspective. Illinois University, USA.

Darling-Hammond, L. \& Snyder, J. (2000). Authentic assessment in teaching context. Teaching and teacher Education, 16, 523-545.

Darling-Hammond, L. (1995). Authentic assessment in action. New York: Teachers College Press.

De Castro, P. (2016). Cartografía autoetnográfica de una genealogía de programas de educación patrimonial desde la perspectiva del aprendizaje basado en proyectos y la investigación acción. [Tesis doctoral inédita]. Universidad de Valladolid. Valladolid, España.

De Carli, S. (2006). La cuestión de la infancia. Entre la escuela, la calle y el shopping, Buenos Aires: Paidós.

De Carli, S. (2010). Notas para pensar la infancia en la Argentina (1983-2001). Figuras de la historia reciente. Belo Horizonte, 26 (1), Faculdade de Educação da Universidade Federal de Minas Gerais, Portugal.

Deleuze, G. (1994). Difference and Repetition, trans. Paul Patton, London: Athlone.

Denzin, N. K. (1990). Reading rational choice theory. Rationality and Society, 2(2), 172-189.

De Pablos, L. (2018). Evaluación de programas de educación patrimonial para personas con trastorno del espectro autista (TEA) en museos. [Tesis doctoral]. Universidad de Valladolid. Valladolid, España.

Dewey, J. (1938). Experience and education. New York: Collier.

Dewey, J. (1900). Psychology and social practice. Psychological review, vol.7(2), 105. 
DiBiase, D. (2014). Formative assessment professional development: Impact on teacher practice. Johnson \& Wales University, USA.

Domínguez, A. y Lopez-Facal, R. (2017). Patrimonios en conflicto, competencias cívicas y formación profesional en educación primaria. Revista de Educación, 375, 86-109.

Domingo, M., Fontal, O. y Ballesteros, P. (2013). Plan Nacional de Educación y Patrimonio. Madrid: Ministerio de Educación, Cultura y Deporte: Secretaría de Estado de Cultura. Madrid, España.

Efland, A. D. (2002). Una historia de la educación del arte. Tendencias intelectuales y sociales en la enseñanza de las artes visuales. Barcelona: Paidós.

Eisner, W.E. (1985). The art of educational evaluation. Londres: The Falmer Press.

Eisner, W.E. (1991). Educar la visión artística. Barcelona: Paidós Ibérica.

Elliot, J. (1993). El cambio educativo desde la investigación-acción. Madrid: Morata.

Enkvist, I. (2006). Repensar la educación. Ediciones internacionales universitarias.

Enkvist, I. (2010). El éxito educativo finlandés. Bordón. Revista de pedagogía, 62(3), 49-67.

Escudero, T. (2003). Desde los tests hasta la investigación evaluativa actual. Un siglo, el XX, de intenso desarrollo de la evaluación en educación. RELIEVE, 9(1), 1143.

Essomba, M. Á. (2008). 10 ideas clave: La gestión de la diversidad cultural en la escuela. Barcelona: Graó.

Estepa, J., Contreras, L. C., Wamba, A. M., Carrillo, J., y Jiménez, R. (1994). El diseño curricular y la formación del profesorado como nexos de investigación en didáctica de las ciencias experimentales, sociales y matemáticas. Revista Investigación en la Escuela, 24, 71-78.

Estepa, J., Domínguez, C. y Cuenca-López, J. M. (1998). La enseñanza de valores a través del patrimonio. Los valores y la didáctica de las Ciencias Sociales: Actas del IX Simposium de Didáctica de las Ciencias Sociales. Universitat de Lleida, (p. 327-336).

Estepa, J., Friera, F. y Piñeiro, R. (2001): Identidades y territorios: Un reto para la Didáctica de las Ciencias Sociales. Oviedo: Ediciones KRK. 
Estepa, J., y Cuenca, J. M. (2006). La mirada de los maestros, profesores y gestores del patrimonio: Investigación sobre conceptos de patrimonio y su didáctica. En O. Fontal, y R. Calaf (Eds.). Miradas al patrimonio, (pp.51-71). Gijón: Trea.

Estepa, J., Ferreras, M., López-Cruz, I. y Morón, H. (2011). Análisis del patrimonio presente en los libros de texto: Obstáculos, dificultades y propuestas. Revista de Educación, 355, 227-228.

Estepa, J. y Suárez, Á. S. (2014). La Educación Patrimonial en la Escuela y el Museo: Investigación y experiencias. Her\&Mus. Heritage \& Museography, (14), 9092.

Expósito, J. y Fernández Cano, A. (2002). La productividad en la investigación educativa española sobre evaluación de programas. Revista de Investigación Educativa, 20 (1), 113-129.

Facal, R., Miralles, P., Prats, J. y Gómez-Carrasco, C. J. (2017). Enseñanza de la historia y competencias educativas. Barcelona: Graó.

Falcón, R., Fontal, O., y Torregrosa, A. (2015). Le Patrimoine comme don du Temps. Sociétés (3): 115-124.

Fernández-Enguita, M. (1983). La enseñanza media, encrucijada del sistema escolar. Educación y Sociedad, 1, 55-85.

Fontal, O. (2003). La educación patrimonial: Definición de un modelo integral y diseño de sensibilización. [Tesis doctoral]. Universidad de Oviedo. Oviedo, España.

Fontal, O. (2003), La educación patrimonial: Teoría y práctica para el aula, el museo e Internet. Gijón: Trea.

Fontal, O. (2006). Claves del patrimonio cultural del presente y desde el presente para abordar su enseñanza. Pulso, 29, 9-31.

Fontal, O. (2007). El patrimonio cultural del entorno próximo: Un diseño de sensibilización para secundaria. Enseñanza de las ciencias sociales: Revista de investigación, (6), 31-48.

Fontal, O. (2010a). La investigación universitaria en Didáctica del Patrimonio: Aportaciones desde la Didáctica de la Expresión Plástica. II Congrés Internacional de Didàctiques. L'Activitat del Docent: Intervenció, Innovació, Investigació, 1-7. Girona: Universitat. 
Fontal, O. (2010b). Maestros y museos. Educar desde la invisibilidad. PULSO. Revista de Educación, (33), 237-239.

Fontal, O. y Marín-Cepeda, S. (2011). Enfoques y modelos de educación patrimonial en programas significativos de OEPE. Educación artística. revista de investigación (EARI), (2), 91-96.

Fontal, O., Pérez, S., y Martín-Cepeda, S. (2012). Manual de Educación Patrimonial. Gijón: Ediciones Trea.

Fontal, O. (2013a). La educación patrimonial: Del patrimonio a las personas. Gijón: Trea.

Fontal, O. (2013b). Estirando hasta dar vuelta al concepto de patrimonio. En Fontal, O. (coord.). La educación patrimonial. Del patrimonio a las personas. Gijón: Trea. 9-22.

Fontal, O. y Gómez-Redondo, C. (2015). Evaluación de Programas Educativos que abordan los procesos de patrimonialización. Didáctica de las Ciencias experimentales y sociales, 29, 89-118.

Fontal, O. e Ibáñez-Etxeberria, A. (2015). Estrategias e instrumentos para la educación patrimonial en España. Educatio siglo XXI, 33(1), 15-32.

Fontal, O., y Juanola, R. (2015). La educación patrimonial: Una disciplina útil y rentable en el ámbito de la gestión del patrimonio cultural. Cadmo. International Journal of Educational Research, 23(1), 254-266.

Fontal, O., Marín-Cepeda, S. y García-Ceballos, S. (2015). Educación de las artes visuales y plásticas en ecuación primaria Colección: Didáctica y Desarrollo. Ediciones Paraninfo, SA.

Fontal, O. (2016a). Educación patrimonial: Retrospectiva y prospectivas para la próxima década. Estudios Pedagógicos, 42(2), 415-436.

Fontal, O. (2016b). El patrimonio a través de la educación artística en la etapa de primaria. Arte, Individuo y Sociedad, 28(1), 105-120.

Fontal, O., Ibáñez-Etxeberria, A., Rodríguez, M. y Rivero, P. (2017). El patrimonio como contenido en la etapa de Primaria: Del currículum a la formación de maestros. Revista Electrónica Interuniversitaria de Formación del Profesorado, 20(2), 79-94. 
Fontal, O. y Martínez, M. (2017). Evaluación de programas educativos sobre Patrimonio Cultural Inmaterial. Estudios pedagógicos (Valdivia), 43(4), 69-89.

Fontal, O., García, S., Arias, B., y Arias, V. B. (2018). Evaluación de la calidad de programas de educación patrimonial: Construcción y calibración de la escala Q-Edutage. Revista de Psicodidáctica, 24(1), 31-38.

Fontal, O., \& Marín-Cepeda, S. (2018). Nudos Patrimoniales. Análisis de los vínculos de las personas con el patrimonio personal. Arte, Individuo y Sociedad, 30(3), 483.

Fontal, O., Sánchez-Macías, I. y Cepeda, J. (2018). Personas y patrimonios:

Análisis del contenido de textos que abordan los vínculos identitarios. MIDAS. Museus e estudos interdisciplinares, (9).

Formichella, M. M. y London, S. (2005). Reflexiones acerca de la noción de empleabilidad. Argentina: Consejo Nacional de Investigaciones Científicas y Técnicas. $\quad$ Recuperado el 18/11/2016 de: http://www.aaep.org.ar/espa/anales/works05/formichella_london.pdf.

García-Ceballos, S. (2018). Evaluación de programas en educación patrimonial. Indicadores de calidad a través del método SAEPEP-OEPE y su instrumento basado en estándares EBEB-OEPE. [Tesis doctoral]. Universidad de Valladolid. Valladolid, España.

García, N. y Criado, A. (1999). Los usos sociales del patrimonio cultural. Consejería de Cultura. Junta de Andalucía, España.

García-Valcárcel, A., Basilotta, V. y López, C. (2014). Las TIC en el aprendizaje colaborativo en el aula de Primaria y Secundaria. Comunicar, 21(42).

Gazzola, P., \& Pane, R. (1964). Proposte per una carta internazionale del restauro. Il monumento per l'uomo Atti del II Congresso Internazionale del Restauro (pp. 25-31). Venezia: ICOMOS.

Gil, P. e Ibáñez-Etxeberria, A. (2013). Percepción de utilidad y grado de satisfacción del alumnado de formación del profesorado con el Método del Caso. Aula abierta, 41(3), 79-90.

Giménez, J. E., Ruiz, R. M. Á., \& Listán, M. F. (2008). Primary and secondary teachers' conceptions about heritage and heritage education: A comparative analysis. Teaching and Teacher Education, 24(8), 2095-2107. 
Gimeno Sacristán, J., \& Gómez, P. (2002). Comprender y transformar la enseñanza. Madrid: Colección pedagogía manuales.

Gómez, I. y Cuenca-López, J.M. (2017). Trabajar las emociones desde la educación patrimonial para atender a la diversidad del aula. En Martínez R., García-Morís, R. y García, C.R. (Eds.). Didáctica de las ciencias sociales. Retos preguntas y líneas de investigación, (págs. 649-657).

Gómez-Carrasco, C. J., Cózar, R. y Miralles, P. (2014). La enseñanza de la historia y el análisis de libros de texto. Construcción de identidades y desarrollo de competencias. ENSAYOS. Revista de la Facultad de Educación de Albacete, 29(1), 1-25.

Gómez-Carrasco, C. J., Martínez, P. M. y Puche, S. M. (2015). Presentación, Evaluación, competencias históricas y educación ciudadana. Revista de estudios sociales, (52), 9-14.

Gómez-Carrasco, C., \& Miralles, P.M. (2016). Historical Skills in Compulsory Education: Assessment, Inquiry Based Strategies and Students' Argumentation. Journal of New Approaches in Educational Research (NAER Journal), 5(2), 130-136.

Gómez-Carrasco, C., López-Facal, R. y Castro-Fernández, B. (2019). Educación histórica y competencias educativas. Educar em Revista, 35(74).

Gómez-Redondo, C. (2011). El arte contemporáneo: Escenario para nuevas identidades. En Actas del II Congreso Internacional de arte, educación y cultura: Aportaciones desde la periferia. Jaén: Colegio Oficial Bellas Artes Sevilla.

Gómez-Redondo, C. (2012). Identización: La construcción discursiva del individuo. Arte, Individuo y Sociedad, 24(1), 21-37.

Gómez-Redondo, C. (2013). Procesos de patrimonialización en el arte contemporáneo: Diseño de un artefacto educativo para la identización. [Tesis doctoral]. Universidad de Valladolid. Valladolid, España.

Gómez-Redondo, C., Calaf, R. C. y Fontal, O. (2016). Colección Roser Calaf de recursos didácticos textuales para museos y sitios de patrimonio: Análisis y valoración desde la perspectiva de la educación patrimonial. Revista de Humanidades, (28), 85-114. 
Gómez-Redondo, C. y Fontal, O. (2017). Procesos de identización en el arte contemporáneo: Construir una identidad colectiva a través de una cartografía identitaria en la red. Cuadernos de Música, Artes Visuales y Artes Escénicas, 12(2).

González-Varas, S. (2000). La coherencia entre los Fondos estructurales y las Ayudas regionales. Noticias de la UE, (181).

Good, C. V., Barr, A. S., \& Scates, D. E. (1936). The methodology of educational research. Oxford, England: Appleton-Century.

Goodman, Y.M. y Goodman, K.S. (1990). Vigotsky in a whole language perspective. En L.C. Moll (ed.), Vigotsky and education. New York, Cambridge University Press. USA.

Guba, E.G. \& Lincoln, Y. S. (1982). Establishing dependability and confirmability in naturalistic inquiry through an audit. $66^{\text {th }}$ American Educational Research Association Annual Meeting, 1-22. New York.

Guba, E. G., \& Lincoln, Y. S. (1985). Fourth generation evaluation. Newbury Park, CA: Sage.

Guba, E.G. \& Lincoln, Y. S. (1989). Ethics: The failure of positivist science. The Review of Higher Education, 12(3), 221-240.

Guba, E.G. \& Lincoln, Y.S. (2002). Paradigmas en competencias en la investigación cualitativa. En C. Deman y J.A. Haro (Eds.), Por los rincones. Antología de métodos cualitativos en la investigación social (pp.113-145). El Colegio de Sonora: Hermosillo Sonora.

Guevara, J.M. y Colomer, J.C. (2017). Minecraft y Eduloc, en historia y geografía. Íber, $86,16-23$.

Guillate, I. (2014). Programas de Educación Patrimonial en contextos informales: análisis y valoración de su influencia en el alumnado de ESO de la zona mineroindustrial de Bizkaia. [Tesis doctoral]. Universidad del País Vasco- Euskal Herriko Unibertsitatea. País Vasco, España.

Graham, B. (2002). Heritage as knowledge: Capital or Culture? Urban studies. University of Glasgow, 39 (5-6), 1003-1017.

Graham, B. J., \& Howard, P. (2008). The Ashgate research companion to heritage and identity. Ashgate Publishing, Ltd. 
Greer, D. F. (1984). Industrial organization and public policy. New York: Macmillan Publishing Company.

Gretsova, I. (2013). El patrimonio urbano al alcance de la mano: Arquitectura, urbanismo y apps. Hemus, (2), 36-43.

Gronlund, N.E. (1985). Measurement and evaluation in teaching. Nueva York: Macmillan Publishing Company.

Harlen, W., Gipps, C., Broadfoot, P., \& Nuttall, D. (1992). Assessment and the improvement of education. The curriculum journal, 3(3), 215-230.

Hernández-Cardona, F.X. y Santacana, J. (1984). Museología crítica. Ediciones Trea, S.L.

Hernández-Cardona, F.X. (2001). Barcelona, història d'una ciutat: aproximació didáctica. Barcelona: Llibres del'Índex.

Hernández-Cardona, F. X. (2001). Los juegos de simulación y la didáctica de la historia. Iber: Didáctica de las ciencias sociales, geografía e historia, (30), 2336.

Hernàndez-Cardona, F. X. (2002). Didáctica de las ciencias sociales, geografía e historia. Barcelona: Graó.

Hernández-Ramírez, M. y Ruiz-Ballesteros, E. (2008). El patrimonio como proceso social. Intervención, desarrollo y consumo del patrimonio minero en Andalucía. In Arrieta, I. (coord..). Participación ciudadana, patrimonio cultural y museos: Entre la teoría y la praxis. Universidad del País Vasco-Euskal Herriko Unibertsitatea, Servicio de Publicaciones, 129-148.

Hernández Rojas, G. y Guzmán. J. (1991). Evaluación curricular. En Módulo Bases Psicopedagógicas, Maestría en Tecnología Educativa, Unidad 5, Diseño Curricular I, Tema IV. ILCE OEA, México, (pp.59-88). Disponible en http://es.scribd.com/doc/6571177/Historia-de-La-Evaluacion-Curricular

Hertz, E. (2015). Bottoms, Genuine and Spurious. In Adell, N., Regina F. Bendix, Chiara Bortolotto and Markus Tauschek (coord.). Between Imagined Communities and Communities of Practice: Participation, Territory and the Making of Heritage. Göttingen: Universitätsverlag Göttingen, 25- 57.

Horta, M. D. L. P., Grunberg, E. y Monteiro, A. Q. (1999). Guía básico de educação patrimonial. Brasília: Iphan.

House, E.R. (1994). Evaluación, ética y poder. Madrid: Morata 
Ibáñez Etxeberría, A. (2003). Entre Menosca e Ipuscoa. Arqueología y territorio en el Yacimiento de Santa María la Real de Zarautz (Gipuzkoa). Zarauz (Guipuzcoa) : Ayuntamiento de Zarauz.

Ibáñez-Etxeberria, A. (2006). Educación y patrimonio: El caso de los campos de trabajo en la comunidad autónoma del País Vasco. [Tesis doctoral]. Universidad del País Vasco- Euskal Herriko Unibertsitatea. País Vasco, España.

Ibáñez-Etxeberria, A., Vicent Otaño, N. y Asensio, M. (2012). Aprendizaje informal, patrimonio y dispositivos móviles: Evaluación de una experiencia en educación secundaria. Didáctica de las ciencias experimentales y sociales, (26).

Ibáñez-Etxeberria, A., Kortabitarte, A., Molero, M. B. y Luna, U. (2017).

Aprendizaje de Prehistoria y Arqueología en una neocueva: Relación entre competencia, percepción de aprendizaje y satisfacción. Estudios pedagógicos (Valdivia), 43(4), 137-146.

Ibáñez-Etxeberria, A., Fontal, O. y Rivero, M. P. (2018). Educación patrimonial y TIC en España: Marco normativo, variables estructurantes y programas referentes. Arbor: Ciencia, pensamiento y cultura, 194(788), 9.

Jiménez de Madariaga, C. (2002). La comercialización del patrimonio cultural. En Actas de las VI Jornadas Andaluzas de Difusión de Patrimonio Histórico. Andalucía, Consejería de Cultura, 129-148.

Jiménez, L., Aguirre, I., y Pimentel, L. G. (2009). Educación artística, cultura y ciudadanía. Organização dos Estados Ibero-americanos para a Educação, a Ciência e Cultura. Organización de Estados Iberoamericanos para la Educación, la Ciencia y la Cultura. Madrid: Fundación Santillana.

Jorrín-Abellán, I. M. (2006). Perfil formativo generado en los entornos cscl: un estudio de caso [Tesis Doctoral], Universidad de Valladolid. Valladolid, España.

Jorrín-Abellán, I. M. y Rubia Avi, B. (2012). Presentación: Procesamiento e interpretación de los datos en investigación: Almacenamiento y reducción de datos; Disposición, tratamiento y transformación de datos. Material docente del Máster de Investigación Aplicada a la Educación. Valladolid: Universidad de Valladolid.

Jorrín-Abellán, I.M. (2014). Hopscotch Building: A Model for the Generation of Qualitative Research Designs. Georgia Educational Researcher: Vol. 13: Iss. 1, Article 4. DOI: 10.20429/ger.2016.130104. 
Kincheloe, J. L. y Steinberg, S. R. (1997). Changing multiculturalism. Open University. Kirschner, r. A., Martens, R. L., \& Strijbos, J. W. (2004). CSCL in higher education? A framework for designing multiple collaborative environments. In P. Dillenbourg (Series Ed.) \& J. W. Strijbos, P. A. K1rschner \& R. L. Martens (Vol. Eds.), Computer-suported collaborative learning Vol. 3 What we know about CSCL_ And implementing it in higher education (pp. 3-30). Boston, MA: Kluwer Academic Publishers.

Kortabitarte, A., Ibáñez-Etxeberria, A., Luna, U., Vicent, N., Gillate, I., Molero, B. y Kintana, J. (2017). Dimensiones para la evaluación de aprendizajes en APPs sobre patrimonio. Pulso. Revista de educación, 40, 17-33.

Kratochwill, T. R., \& Levin, J. R. (1978). What time-series designs may have to offer educational researchers. Contemporary Educational Psychology, 3(4), 273-329.

Kuhn, T. (1962). La estructura de las revoluciones científicas. México: FCE.

Kuhn, D. (1972). Mechanisms of change in the development of cognitive structures. Child Development, 43(3), 833-844.

Kuhn, T. (1982). Objetividad, juicios de valor y elección de teoría. La tensión esencial, 2, 344-364.

Kushner, S. (2002). Personalizar la evaluación. Madrid: Morata.

Lasnier, F. (2000). Habilidades de entrenamiento exitoso. Montreal: Guerin.

Lave, J. y Wenger, E. (1991). Situated learning: Legitimate peripheral participation. Cambridge university press. Cambridge, UK.

Lavin-Berdonces, A. C., Vega, A. Y. y García, M. L. (1996). Arqueología y medios de comunicación. PH: Boletín del Instituto Andaluz del Patrimonio Histórico, 4(14), 98-103.

Le Boterf, G. (2000). Ingeniería de las competencias. Barcelona: EPISE.

Le Donné, N., Fraser, P. y Bousquet, G. (2016). Teaching Strategies for Instructional Quality: Insights from the TALIS-PISA Link Data. OECD Education Working Papers, No. 148, Paris: OECD. Publishing. http://dx.doi.org/10.1787/5jln1hlsr0lr-en

Legrand, J. (1970). Guía del trabajo cotidiano en el aula. Buenos Aires: Kapelusz. Buenos Aires, Argentina. 
Lemus Alvarado, M. (2012). La evaluación educativa tiene historia. Departamento de Pedagogía. Evaluación del Aprendizaje I. USAC Tricentenaria: Universidad de San Carlos de Guatemala. Recuperado de http://es.scribd.com/doc/80501271/La-evaluacion-educativa-tiene-historia

Levy-Leboyer, C. (1994). Gestión de las competencias: Cómo analizarlas, cómo evaluarlas, cómo desarrollarlas. Barcelona: Gestión 2000.

Lipovetsky, G. (1990). El imperio de lo efímero. La moda y su destino en las sociedades humanas. Madrid: Anagrama.

Llull, J. (2005). Evolución del concepto y de la significación social del patrimonio cultural. Arte, individuo y sociedad, 17, 177-206.

López-Cruz, I., Cuenca-López, J. M. (2014). Dificultades en torno a la educación patrimonial en la enseñanza y aprendizaje de las ciencias sociales. En Una mirada al pasado y un proyecto de futuro: investigación e innovación en didáctica de las ciencias sociales (pp. 95-102). Universidad de Barcelona: Servei de Publicacions.

López, L.I. (2013). La construcción, la apropiación y a transmisión de la noción de Patrimonio en los jóvenes, una propuesta metodológica: los Foros Juveniles del Patrimonio Mundial celebrados en España (2009-2012). [Tesis doctoral]. Universidad de la Sorbona, París. París, Francia.

López-Morales, E., Shin, H. B. \& Lees, L. (2016). Introduction: Locating gentrification in the global east. Urban Studies, 53(3), 455-470.

Lucas, L. y Estepa, J. (2016). Identidad, valores cívicos y participación ciudadana en la didáctica del patrimonio. Aprendizaje y enseñanza. En Molina Puche, S., Escribano-Miralles, A. y Díaz-Serrano, J. (eds). Patrimonio, identidad y ciudadanía en la enseñanza de las Ciencias Sociales. Murcia. Universidad de Murcia, 89-100.

Lucas, L. y de-Alba-Fernández, N. (2017). Educación patrimonial para formar ciudadanos críticos. Iber: Didáctica de las ciencias sociales, geografía e historia, (89), 26-31.

Macdonald, B. (1976). Evaluation and the control of education. En D. Tawney (Ed.), Curriculum evaluation today: Trends and implications (pp. 125-136). Londres: McMillan. 
Macdonald, S. (1997). A People's Story. Heritage, identity and authenticity. In Chris Rojek y John Urry (Eds). Touring Cultures. Transformations of Travel and Theory. London: Routledge.

Machin, S., \& McNally, S. (2008). The literacy hour. Journal of Public Economics, 92(5-6), 1441-1462.

Maldonado, M.S. (2015). Pablo de Castro Martín (Olaia Fontal Merillas y Álex Ibáñez Etxeberría, dirs.) Cartografía autoetnográfica de una genealogía de programas de educación patrimonial desde la perspectiva del aprendizaje basado en proyectos y la investigación-acción. Her\&Mus. Heritage \& Museography, (16), 171-172.

Maldonado, M.S. (2016). Educación patrimonial y redes sociales. Análisis y evaluación de acciones

en los medios de comunicación social para la definición de una cartografía educativa. [Tesis doctoral]. Universidad de Valladolid. Valladolid, España.

Mandler, G. (2003). Emotion. Handbook of psychology, 157-175.

Marín-Cepeda, S. (2014). Educación patrimonial y diversidad: Evaluación de programas y definición de un modelo basado en los procesos de patrimonialización. [Tesis doctoral]. Universidad de Valladolid. Valladolid, España.

Marín-Viadel, R. (1987). ¿Medir los resultados o comprender los procesos? Icónica: Revista de las artes visuales, didáctica e investigación, (9), 41-62.

Marín-Viadel, R. (Ed.) (2005). Investigación en Educación Artística: Temas, métodos y técnicas de indagación sobre el aprendizaje y la enseñanza de las artes y culturas visuales. Granada: Universidad de Granada y Universidad de Sevilla.

Marín-Viadel, R. (2011). Las Metodologías Artísticas de Investigación y la Investigación Educativa Basada en las Artes Visuales (sobre el paisaje de la Depresión Cuadrada de Bruce Nauman). En Roldán, J. y Marín, R. (eds.), Metodologías artísticas de investigación en educación, (14-39). Ediciones Aljibe. Málaga.

Marín, V., Negre, F., y Pérez, A. (2014). Entornos y redes personales de aprendizaje (PLE-PLN) para el aprendizaje colaborativo. Comunicar, 21, (42).

Mateos-Rusillo, M., (2009). Comunicación del patrimonio cultural. Barcelona: Universitat Oberta de Catalunya. 
Maxwell. J.A. (2008). Designing a qualitative study. En L. Bickman \& D. J. Rog (Eds.), Handbook of applied social science research methods, 2, 214-253. Thousand Oaks, California: Sage Publications.

Mayordomo, C., \& Vicente, L. G. (2013). Agrosystems protection as heritage elements: Cultural Landscapes. In Fourth International Scientific Symposium Agrosym 2013, Jahorina, Bosnia and Herzegovina, 3-6 October, 2013. Book of Proceedings (pp. 737-742). Faculty of Agriculture, University of East Sarajevo.

McClelland, D.C. (1973). Testing for competence rather than Intelligence. American Psichologist, 28 (1), 1-14.

McLane, J.B. (1990). Writing as a social process. In L.C. Moll (Ed.). Vigotsky and education. New York, Cambridge University Press. USA.

McLean, F. (2006). Introduction: Heritage and identity. International Journal of Heritage Studies. London, 12 (1), 3-7.

McMeekin, A. (2006). Negotiation in a Japanese study abroad setting. Language learners in study abroad contexts, 15, 177-202.

MECD. (2014). Informe español Talis 2013: Estudio internacional de la enseñanza y el aprendizaje. Madrid: INEE.

Méndez, I. (2015). Prácticas Docentes y Rendimiento Estudiantil: Evidencia a partir de PISA 2012 y TALIS 2013. Madrid: Instituto Nacional de Evaluación Educativa y Fundación Santillana.

Merriam, S. B. (1998). Qualitative research and case study applications in education. Revised and expanded from "Case Study Research in Education". San Francisco, California: Jossey-Bass Publishers.

Mesa-Bains, A. (2004). The real multiculturalism: A struggle for authority and power. Reinventing the museum: Historical and contemporary perspectives on the paradigm shift, 99-109.

Miralles, P. y Belmonte, P. (2004). Historiografía, historia de las mujeres y enseñanza de la historia. Formación de la Ciudadanía: Las TIC y los nuevos problemas. Alicante: Asociación Universitaria del Profesorado de Didáctica de las Ciencias Sociales, 619-629. 
Mishra, P. y Koehler, M. J. (2006). Technological pedagogical con- tent knowledge: A framework for teacher knowledge. Teachers College Record, 108, (6), 10171054.

Monereo, C. (2003). La evaluación del conocimiento estratégico a través de las tareas auténticas. Revista Pensamiento educativo, 32, 71-89.

Moreno, I. (2015). Interactividad, interacción y accesibilidad en el museo transmedia. Zer-Revista de Estudios de Comunicación, 20, (38), 87-107.

Morgan, K. (2007). The learning region: Institutions, innovation and regional renewal. Regional Studies, 41(S1), S147-S159.

Morin, E. (1999). Los siete saberes necesarios para la educación del futuro. Francia: Unesco.

Muñoz, S. R., \& Bangdiwala, S. I. (1997). Interpretation of Kappa and B statistics measures of agreement. Journal of Applied Statistics, 24(1), 105-112.

Muñoz, J. M. E. (2006). La formación del profesorado y la garantía del derecho a una buena educación para todos. En Alberto Luis Gómez y Juan Manuel Escudero (codos.), La formación del profesorado y la mejora de la educación: políticas y prácticas (pp. 21-54). Octaedro.

Muriel, D. (2015). La mediación experta en la construcción del patrimonio cultural como producción contemporánea de «lo nuestro». AIBR, Revista de Antropología Iberoamericana. Madrid, 10 (2), 259-288.

Murphy, R. (2010). Evaluating new priorities in assessment in Higher Education. In C. Bryan, \& K. Clegg (Eds.), Innovative assessment in higher education (37-46). London: Routledge.

Nevo, D., \& Shohamy, E. (1986). Evaluation Standards for the Assessment of Alternative Testing Methods: An Application. Studies in educational evaluation, 12(2), 149-58.

Noyes, J. (2012). The Common Heritage of Mankind: Past, Present, and Future. Denv. J. Int'l L. \& Pol'y. California Werster, (40), 447-471.

Nitko, A. J., \& Brookhart, S. M. (1996). Educational assessment of students. Englewood Cliffs, NJ: Merrill.

Nitko, A. J. (2001). Educational assessment of students (3rd ed.). Upper Saddle River, NJ: Merrill. 
Nunziati, G. (1990). Pour construiré un dispositif d'evaluation formatrice. Cahiers pédagogiques, 280, 47-64.

OCDE (2009). PISA 2009: Programa para la evaluación internacional de los alumnos. Madrid: Ministerio de Educación Cultura y Deporte. Instituto de Evaluación.

Oliva-Gimeno, M., Torres-Mendoza, M. (2017). La comunicación transmedia en las ciudades: Disfrutar y educar. Comhumanitas: Revista Científica de Comunicación, 8, (2), 33-49.

Ortega, C., Estepa, J. y Monteagudo, J. (1999). La provincia de Huelva y sus regiones naturales: Estudio preliminar y anotaciones al texto facsímil. Diputación Provincial de Huelva. Huelva, España.

Parlett, M. y Hamilton, D. (1976). Evaluation as illumination: A new approach to the study of innovative programmes. En D. Hamilton et al. (Eds.), Beyond the numbers game (pp. 85-99). Londres: MacMillan.

Patton, M. Q. (1990). Qualitative evaluation and research methods. California: Sage Publications.

Pérez, R. J., López, J. M. C., \& Listán, D. M. F. (2010). Heritage education: Exploring the conceptions of teachers and administrators from the perspective of experimental and social science teaching. Teaching and teacher education, 26(6), 1319-1331.

Perrenoud, C. (1999). Construir competencias desde la escuela. Santiago de Xile: Dolmen.

Perrenoud, Ph. (2009). Enfoque por competencias, ¿una respuesta al fracaso escolar? Revista Interuniversitaria de Pedagogía Social, 16, 45-64.

Prats, Ll. (1997). La selección de contenidos históricos para la educación secundaria. Coherencia y autonomía respecto a los avances de la ciencia histórica. IBER Didáctica de las Ciencias Sociales, Geografía e Historia. Barcelona, (12), 1827.

Piaget, J. (1968). Los estadios del desarrollo intelectual del niño y del adolescente. Editorial Revolucionaria. La Habana.

Piaget, J. (1973). La formación del símbolo en el niño. México: Editorial Fondo de Cultura económica.

Piaget, L., Lorenz, K. y Erikson, E. (1992). Juego y desarrollo. Méjico: Grijalbo. 
Pinto, H. (2012). Educación histórica y patrimonial: Concepciones de alumnos y profesores sobre el pasado en espacios del presente. [Tesis doctoral]. Universidad do Minho. Do Minho, Portugal.

Pinto, H., \& Puche, S. M. (2015). La educación patrimonial en los currículos de ciencias sociales en España y Portugal. Educatio siglo XXI, 33(1), 103-128.

Popham, W.J. (1980). Problemas y técnicas de la evaluación educativa. Madrid: Anaya.

Popham, W.J. (1983). Evaluación basada en criterios. Madrid: Magisterio Español, S. A.

Poria, Y., \& Ashworth, G. (2009). Heritage tourism-Current resource for conflict. Annals of Tourism Research, 36(3), 522-525.

Provus, M. N. (1971). Discrepancy evaluation. Berkeley, CA: McCutcheon.

Puche, S. M. (2016). Concepciones y uso del patrimonio por parte del profesorado de Geografía e Historia: una investigación en curso. Andamio| Revista de la didáctica de la historia, 2(3), 67-80.

Reyes Herrera, L. (2001). Evaluación de los aprendizajes en la educación superior. Tecné, episteme y didaxis: revista de la facultad de Ciencia y Tecnología, 9, 6879

Ribeiro, É. (1998). Cultura, patrimonio, preservación. Alteridades, Universidad Autónoma Metropolitana. México, 8 (16), 131-136.

Rivero, P. y Trepat, C. A. (2010). Didáctica de la historia y multimedia expositiva. Barcelona.

Rivero, P., \& Hernández, F. X. (2015). Aprender con y a través del paisaje cultural. Íber. Didáctica de las Ciencias Sociales, Geografía e Historia, 81, 6-8.

Robinson, K., (1999). Culture, Creativity and the Young: Developing Public Policy. Cultural Policies Research and Development Unit Policy Note $N^{\circ} 2$. Estrasburgo: Consejo de Europa.

Rodríguez-Sánchez, A. (2003). El conocimiento escolar. La experiencia educativa del conocimiento en un aula a través de un proceso de investigación en la acción. [Tesis doctoral no publicada]. Universidad de Málaga, España.

Roe, R. A. (2002). What makes a competent psychologist? European Psychologist, 7(3),192-202.

Rué, J. (2007). Enseñar en la universidad. El EEES como reto para la educación superior. Barcelona: Narcea. 
Salles, N, (2013). Las Apps y el aprendizaje del patrimonio basado en la indagación. Hemus, 2, 92-98.

Sánchez, M. (2012). El patrimonio urbano como recurso para desmontar estereotipos históricos. El modelo del Real Sitio de San Lorenzo. Íber, Barcelona, 70, 79-86.

Salgado-García, E. (2012). Enseñanza para la comprensión en la educación superior: La experiencia de una universidad costarricense. Revista iberoamericana de educación superior, 3(8), 34-50.

Sánchez-Carretero, C. y Jiménez-Esquinas, G. (2016). Relaciones entre actores patrimoniales: Gobernanza patrimonial, modelos neoliberales y procesos participativos. Revista PH90 perspectivas: Instituto Andaluz del Patrimonio Histórico, 90, (190-197).

Sánchez-Castillo, S. (2005). El proceso sociocultural y educativo de la televisión en la difusión del arte y el patrimonio. Ars Longa. Cuadernos de arte, (14-15).

Sánchez-Ferri, A. (2014). Memoria, identidad y comunidad: Evaluación de programas de educación patrimonial en la Comunidad de Madrid. [Tesis doctoral]. Universidad de Valladolid. Valladolid, España.

Sánchez-Macías, I. C. (2015). La evaluación por competencias en Educación Plástica en Primaria: Un estudio de caso. [Trabajo Fin de Máster]. Valladolid. Facultad de Educación y Trabajo Social. Universidad de Valladolid. Valladolid, España.

Santacana-Mestre, J., Martínez, T., Llonch, N. y López-Benito, V. (2016). ¿Qué opinan los adolescentes sobre los museos y la didáctica? Didáctica de las ciencias experimentales y sociales, 2, (31), 23-38.

Schachter, S. (1964). The interaction of cognitive and physiological determinants of emotional state. In Advances in experimental social psychology (1), 49-80. Academic Press.

Schaffert, S., y Hilzensauer, W. (2008). On the way towards Personal Learning Environments: Seven crucial aspects. Elearning papers, 9, 1-11.

Schickedanz, J.A. (1999). More than the ABC's: The early stages of reading and writing. NAEYC, Washington D.C.

Scriven, M. (1967). The methodology of evaluation. En M. Scriven (Ed.), Perspectives of Curriculum Evaluation, (pp. 39-83). Chicago: Rand McNally and Company. 
Scriven, M. (1993). Hard-won lessons in program evaluation. New Directions for Program Evaluation, 58.

Sharp, C. y Le Métais, J. (2000). The Arts, Creativity and Cultural Education: An International Perspective. International Review of Curriculum and Assessment Frameworks, National Foundation for Educational Research in England and Wales (NFER) on behalf of the Qualifications and Curriculum Authority (QCA) in England. (1-52).

Spendlove, M. (2003). Heritage in Britain: Lifelong learning, archaeology and partnerships. [Tesis doctoral]. University of Warwick, England.

Stake, R.E. (1975). Evaluating the arts in education: A responsive approach. Columbus, OH: Merril.

Stake, R.E. (1976). A theoretical stament of responsive evaluation. Studies in Educational Evaluation, 2, 19-22.

Stake, R. E. (1995). The Art of Case Study Research. Thousand Oaks: Sage Publications.

Stake, R.E. (2006). Evaluación comprensiva y evaluación basada en estándares. Barcelona: Graó.

Stake, R. y Munson, A. (2008). Qualitative assessment of arts education. Arts \& Education Policy Review, 109(6),13-22.

Stenhouse, L. (1984). Investigación y desarrollo del curriculum. Madrid: Morata

Sternberg, R.J. \& Grigorenko, E.L. (2003). Evaluación dinámica. Naturaleza y medición del potencial de aprendizaje. Barcelona: Paidós.

Stobart, G. (2010). Tiempos de pruebas: Los usos y abusos de la evaluación. Madrid: Morata.

Stronge, J. (2013). Effective teachers= student achievement: What the research says. London: Routledge.

Stufflebeam, D. L., \& Shinkfield, A. J. (1985). Systematic evaluation. Boston: KluwerNijhoff.

Stufflebeam, D.L. y Shinkfield, A.J. (2005). Evaluación sistemática. Guía teórica y práctica. Barcelona: Paidós/MEC.

Suárez, M. Á., Gutiérrez, S., Calaf, R. y San Fabián, J. L. (2013). La evaluación de la acción educativa museal: Una herramienta para el análisis cualitativo. Clío: History and History Teaching, 39, 1-45. 
Suárez, M. Á., Calaf, R., y San Fabián, J. L. (2014). Aprender historia a través del patrimonio. Los casos del Museo del Ferrocarril de Asturias y del Museo de la Inmigración de Cataluña. Ministerio de Educación.

Tashakkori, A., \& Teddlie, C. (Eds.). (2003). Sage handbook of mixed methods in social \& behavioral research. California: Sage Publications.

Tashakkori, A., \& Teddlie, C. (Eds.). (2010). Sage handbook of mixed methods in social \& behavioral research. USA: Sage.

Thorndike, E. L., and Hagen, E. (1977), Measurement and Evaluation in Psychology and Education (second edition), New York: Wiley.

Tikunoff, W. J. y Griffin, G. A. (1979). Interactive research and development on teaching study: Final report. The Laboratory. Far West Laboratory for Educational Research and Development. Chicago, USA.

Tobón, S., Pimienta, J. y García, J. (2010). Secuencias didácticas: Aprendizajes y evaluación de competências. México: Pearson Educación. México.

Torres, J., Cuaresma, M. J. E., \& Mejías, M. (2000). Aplicación de los sistemas de tratamiento de bibliotecas digitales al Sistema de Información del Patrimonio Histórico Andaluz. PH: Boletín del Instituto Andaluz del Patrimonio Histórico, 8(32), 205-209.

Torregrosa, A. (2011). En los intersticios de la educación. Climatosofía de la experiencia artística desde la relación profesor alumno. [Tesis doctoral]. Universidad de Barcelona. Barcelona, España.

Tunbridge, J.E. y Ashworth, G.J. (1996). Dissonant heritage: The management of the past as a resource in conflict. United States: John Wiley \& Sons Ltd.

Tyler, R. W. (1942). General statement on evaluation. Journal of Educational Research, 35, 492-501.

Tyler, R. W. (Ed.). (1969). Educational evaluation: New roles, new means. Chicago: University of Chicago Press.

UNESCO. (1952). Convención sobre la Protección de los Derechos de Autor y Derechos Conexos. Aprobada en Ginebra el 6 de septiembre de 1952.

UNESCO. (1954). Convención de la Haya para la Protección de Bienes Culturales en caso de Conflicto Armado. Aprobada en La Haya en 1954. 
UNESCO. (1970). Convención sobre las medidas que deben adoptarse para prohibir e impedir la importación, exportación y la transferencia de propiedad ilícitas de bienes culturales. Aprobada en París el 14 de noviembre de 1970.

UNESCO. (1971). Convención sobre la Protección de los Derechos de Autor y

Derechos Conexos. Aprobada en Ginebra el 29 de octubre de 1971.

UNESCO. (1972). Convención para la Protección del Patrimonio Mundial, Cultural y Material. Aprobada en París el 21 de noviembre de 1972.

UNESCO. (1972). Convención para la Protección del Patrimonio Mundial Cultural y Natural. Aprobada en París el 21 de noviembre de 1972.

UNESCO. (2001). Declaración Universal sobre la Diversidad Cultural. Aprobada en París el 2 de noviembre de 2001.

UNESCO. (2001). Convención sobre la Protección del Patrimonio Cultural Subacuático. Aprobada en París el 2 de noviembre de 2001.

UNESCO. (2003). Convención para la Salvaguardia del Patrimonio Cultural Inmaterial. Aprobada en París el 17 de octubre de 2003.

UNESCO. (2005). Convención sobre la Protección y la Promoción de la Diversidad de las Expresiones Culturales. Aprobada en París el 20 de octubre de 2005.

Velasco, M. (2009). Gestión turística del patrimonio cultural: enfoques para un desarrollo sostenible del turismo cultural. Cuadernos de turismo, (23), 237-254.

Vélez, C. (2007). El cambio de paradigma en evaluación de políticas públicas: El caso de la cooperación al desarrollo. Nuevas Políticas Públicas: anuario multidisciplinar para la modernización de las Administraciones Públicas, 3, 145-170.

Ventosa, V. J. (1993). Fuentes de la animación sociocultural en Europa. España: Editorial Popular.

Vicent, N. (2013). Evaluación de un programa de educación patrimonial basado en tecnología móvil. [Tesis doctoral]. Universidad Autónoma de Madrid. Madrid, España.

Vicent, N., y Torruella, M. F. (2015). Arqueología y tecnologías digitales en Educación Patrimonial. Educatio Siglo XXI, 33(1), 83-102. 
Vicent, N., Ibáñez-Etxeberria, A., \& Asensio, M. (2015). Evaluation of heritage education technology-based programs. Virtual Archaeology Review, 6(13), 2027.

Vigotsky, L. S. (1978). Mind in society. Cambridge, MA: Harvard University Press. UK.

Vigotsky, L. S. (1985). Historia del desarrollo de las funciones psíquicas superiores. La Habana: Ed. Científico Técnica.

Vygotsky, L. S. (1988). Aprendizagem e desenvolvimento intelectual na idade escolar. _et al. Linguagem, desenvolvimento e aprendizagem. São Paulo: Ícone: EDUSP.

Villamizar, L. (2018). Estado del arte sobre la utilización de transmedia para el desarrollo de recursos educativos. [Trabajo Fin de Grado]. Universidad Nacional Abierta y a Distancia. Bogotá: UNAD. Bogotá, Colombia.

Waters, T., Marzano, R. J., \& McNulty, B. (2003). Balanced Leadership: What 30 Years of Research Tells Us about the Effect of Leadership on Student Achievement. Aurora, CO: Mid-Continent Research for Education and Learning.

Weber, E. (1990). Student assessment that works; a practical approach. Boston: Allyn \& Bacon.

Weber, M. (1993). The sociology of religion. Beacon Press.

Weinert, F.E. (2004). Concepto de competencia: Una aclaración conceptual. En D.S Richen y Salganik (Eds.) Las competencias clave para el bienestar personal, social y económico (pp.49-71). Málaga: Aljibe.

Weinstein, C.E. \& Meyer, D.K. (1998). Implicaciones de la Psicología cognitiva en la aplicación de las pruebas: Contribuciones a partir del trabajo realizado en estrategias de aprendizaje. En Wittrock, M.C. \& Baker, E.L. (Eds.). Test y cognición. Investigación cognitiva y mejora de las pruebas psicológicas. Buenos Aires: Paidós, 65-92.

Wiggins, G. (1990). Teaching to the (authentic) test. Educational Laedership, 46(7), 4147.

Wrigley, T. (2013). Repensando el cambio escolar y el papel de la evaluación: La experiencia de dos países anglófonos. Revista Iberoamericana de Evaluación Educativa, 6(2), 73-90 
Yazan, B. (2015). Three approaches to case study methods in education: Yin, Merriam, and Stake. The Qualitative Report, 20(2), 134-152.

Yin, R. K. (2002). Estudio de caso. Porto Alegre: Bookman.

Yus, R. (2011). Educación por competencias: entre la retórica y la realidad. Una propuesta de solución curricular. PUBLICACIONES, 41.

Zamora, E. (2011). Sobre patrimonio y desarrollo. Aproximación al concepto de patrimonio cultural y su utilización en procesos de desarrollo territorial. Pasos, 9, 101-113.

\section{WEBGRAFÍA:}

-Consejo de Lisboa:

http://www.europarl.europa.eu/summits/lis1_es.htm

-Parlamento europeo, recomendaciones:

http://eurlex.europa.eu/LexUriServ/site/es/oj/2006/1_394/1_39420061230es00100018.pf -Proyecto Tunning:

http://acreditacion.unillanos.edu.co/contenidos/cpacitacion_docente_2semestre_2007/co mpetencias_proyectotuning.pdf

-UNESCO:

https://es.unesco.org

-IPCE:

https://ipce.culturaydeporte.gob.es

-DeSeCo:

https://www.oecd.org/education/skills-beyond-

school/definitionandselectionofcompetenciesdeseco.htm 
